P01-626 Puberty

Pharmacokinetics of prednisone and prednisolone at puberty and prepuberty

Roberto Rusconi ${ }^{1}$; Federica De Pari'; Silvia Bergamaschi²;

Marco Gervasoni ; Silvio R Bareggi ${ }^{3}$

${ }^{1}$ Irccs Fondazione Policlinico, Pediatrics, Milano, Italy;

${ }^{2}$ Irccs Fondazione Policlinico, Endocrine Sciences, Milano, Italy;

${ }^{3}$ School of Medicine University of Milan, Pharmacology, Milano, Italy

Background: Endocrine modifications at puberty, in particular the rise of Growth Hormone (GH) and Insulin Growth Factor 1(IGF-1), influence the pharmacokinetics of corticosteroids. This changes induce a decrease of the activity of 11 beta-HSD1, the enzyme which catalyzes the interconversion of cortisone to cortisol and that of prednisone to prednisolone. Objective: To determine the possible influence of these changes at puberty on exogenous corticosteroids.

Methods: We studied the pharmacokinetics of prednisone (PO) and prednisolone $(\mathrm{POH})$ in two groups of children after a single prednisone administration $(0.5 \mathrm{mg} / \mathrm{kg} /$ weight p.o); a group of six prepubertal (age 4.4-6.6 yrs) and pubertal children (10.5-12 yrs) without immunological pathologies (controls), and a group of ten prepubertal children(4.4-6.6 yrs) and six pubertal children (11.5-14.3 yrs) with autoimmune pathologies. A third group of seven children (three prepubertal and four pubertal) where on chronic treatment. All underwent blood sampling over eight hours period after their morning dose. PO, POH and cortisol levels were determinated by HPLC analysis.

Results: Control pubertal children had higher Cmax and AUC of PO as well as higher $\mathrm{PO} / \mathrm{POH}$ ratio compared to prepubertal children indicating a reduced activity of 11 beta-HSD1. This is confirmed by the significant positive correlation of IGF-1 levels and the AUC ratio $(\mathrm{p}<0.03)$. In children with autoimmune pathologies prepubertal patients had higher $\mathrm{PO} / \mathrm{POH}$ ratio compared to controls and not significantly different from pubertal patients either after single or chronic dosing.

Conclusions: These data indicate that the pharmacokinetics of glucocorticoids undergoing hydroxylation such as prednisone is markedly influenced by hormonal canges at puberty and children can not be regarded as an unique population.

\section{P01-627 Puberty}

\section{An extraction step is needed prior to immunoassay for determination of low serum $17 \beta$-oestradiol concentrations in children} Carina Ankarberg-Lindgren; Ensio Norjavaara

The Sahlgrenska Academy at Göteborg University, Department of Pediatrics, Gothenburg, Sweden

Background: Specific and sensitive assays for $17 \beta$-oestradiol measurements are needed in clinical practice for evaluation of pubertal disorders in children, low postmenopausal levels in women, monitor aromatase inhibitor therapy and monitor sex replacement hormone therapy in both adults and children. However, many 17 $\beta$-oestradiol immunoassays have limited functional sensitivity and do not give clinical useful results.

Objective: The aim of this study was to show the importance of using an extraction step for determination of low $17 \beta$-oestradiol concentrations in children.

Methods: The analytical and functional sensitivity of three oestradiol immunoassays was validated by use of 51 pooled sera and 508 sera from prepubertal and pubertal children. The three immunoassays consisted of one modified RIA (Spectria Estradiol RIA, Orion Diagnostica; Espoo, Finland) and one modified automated Time-resolved fluoroimmunoassay (AutoDELFIA Estradiol, Wallac oy, Turku Finland), both with increased serum volume and extended incubation time. In the third method, serum was purified and concentrated using diethyl ether extraction prior to measurement by the modified RIA.

Results: The analytical sensitivity and functional sensitivity were $9 \mathrm{pmol} / \mathrm{L}$ and $30 \mathrm{pmol} / \mathrm{L}$ for the direct RIA, $11 \mathrm{pmol} / \mathrm{L}$ and $50 \mathrm{pmol} / \mathrm{L}$ for the AutoDelfia, and $4 \mathrm{pmol} / \mathrm{L}$ and $6 \mathrm{pmol} / \mathrm{L}$ for serum determined by RIA including a diethyl ether extraction step.

Conclusion: To achieve high functional sensitivity and reliable quantification of low $17 \beta$-oestradiol concentrations in serum from children, it is important to purify serum by extraction before immunoassay. An extraction immunoassay overcomes the problems with interfering substances and gives clinical useful results.

\section{P01-628 Puberty \\ Serum estradiol levels and growth velocity in healthy girls \\ Anna-Karin Albin ${ }^{1}$; Carina Ankarberg-Lindgren²; Aimon Niklasson²; Ulf Westgren'; Kerstin Albertsson-Wikland²; Ensio Norjavaara² \\ ${ }^{1}$ Hospital of Helsingborg, Department of Pediatrics, Helsingborg, \\ Sweden; ${ }^{2}$ The Sahlgrenska Academy of Göteborg University, \\ Department of Pediatrics, Gothenburg, Sweden}

The role of estrogens for human growth is well known. However for paediatric clinical use we lack information about the relation between levels of estradiol and the phases of growth spurt ending in epiphyseal closure. We have retrospectively analysed $24 \mathrm{~h}$ profiles of serum estradiol in girls admitted for short or tall stature or participating as health subjects at Queen Silvia Children's Hospital in relation to their growth.

Inclusion criteria to the study were birth weight and length above -2SDS, gestational age 37-42 weeks, length and weight within \pm 3 SDS from birth to final height, normal $24 \mathrm{~h} \mathrm{GH}$ profile and no $\mathrm{GH}$ treatment. Assent was obtained from the girls and informed consent from parents for future analysis of the data. This resulted in 51 girls and 95 profiles of $24 \mathrm{~h}$ serum estradiol. Serum 17 $\beta$-estradiol was determined with pre-extraction of the sera and a modified assay (Spectria Estradiol RIA, Orion Diagnostica, Finland) Analytical detection limit $4 \mathrm{pM}$ and functional sensitivity $6 \mathrm{pM}$. A 6th grade function was fitted to the growth data and growth velocity and age of peak height velocity (PHV) was calculated. As the increase in morning estradiol is a mark of puberty this was used for correlation to growth velocity at the investigation.

In 30 profiles the investigation was performed at prepuberty, during early puberty and up to 6 months after PHV. A positive correlation between morning $17 \beta$-estradiol and increase in growth velocity was found $(\mathrm{R}=0.57)$. In a simple Effect-max model the $50 \%$ of increase in growth velocity from prepubertal growth to PHV was observed at a morning $17 \beta$-estradiol level of $18 \mathrm{pM} \pm 4$ (S.D). The morning $17 \beta$-estradiol median of the 6 girls who were investigated at $\mathrm{PHV} \pm 3$ months was $99 \mathrm{pM}(41-264)$

Conclusions:

1) Morning $17 \beta$-estradiol serum levels of $14-21 \mathrm{pM}$ is associated with $50 \%$ increased growth velocity from prepubertal growth to PHV in healthy girls 2) Morning 17 $\beta$-estradiol serum levels of 41-264 pM are seen around PHV with a median $99 \mathrm{pM}$

\section{P03-629 Rare Syndromes and Hormones}

Central precocious puberty (CPP) and growth hormone deficiency (GHD) in a boy with PraderWilli syndrome (PWS)

Girolamo Di Giorgio ${ }^{7}$; Riccardo Shiaffini²; Sabrina Spera';

Alessandra Fierabracci ${ }^{3}$; Andrea Maggioni'; Guido Castelli Gattinara';

Antonino Crinò ${ }^{1}$

${ }^{1}$ Bambino Gesù Children's Hospital - Research Instit, Paediatric and Autoimmune Endocrine Diseases Unit, Palidoro, Rome, Italy; Bambino Gesù Children's Hospital - Research Instit, Endocrinology Unit, Rome, Italy; ${ }^{3}$ Bambino Gesù Children's Hospital - Research Instit, Autoimmunity Laboratory, Rome, Italy

In PWS hypothalamic dysfunction is the cause of some clinical findings like growth hormone deficiency (GHD), hypogonadism, delayed or incomplete puberty. However, few cases of CPP have been reported in PWS children.

We reported a $8.8 \mathrm{y} / \mathrm{o}$ boy, with microdeletion of chromosome $15 \mathrm{q}$ and history of bilateral orchodopexy at the age of $4.5 \mathrm{yrs}$, who developed CPP. On admission: height was $131.1 \mathrm{~cm}(+0,17 \mathrm{SD})$, weight $45 \mathrm{~kg}$, BMI $26.2 \mathrm{~kg} / \mathrm{m}^{2}$, $\mathrm{P} 2$, testis $4.5 \mathrm{ml}$. Increased growth velocity $(\mathrm{GV}=7 \mathrm{~cm} / \mathrm{y})$, high testosterone (201.2 ng/dl), pubertal response to $\mathrm{GnRH}$ test $(\mathrm{LH}$ peak $=15.3 \mathrm{mU} / \mathrm{ml})$, advanced bone age (11 years) and normal IGF-1 $(139 \mathrm{ng} / \mathrm{ml})$ were found. The evaluation of growth hormone $(\mathrm{GH})$ secretion revealed a deficiency $(\mathrm{GH}$ peak $4 \mathrm{ng} / \mathrm{ml}$ and $11 \mathrm{ng} / \mathrm{ml}$ after insulin tolerance test and $\mathrm{GHRH}+$ Pyridostigmine test respectively). Pituitary MRI was normal. At the age of 8.9 yrs therapy with LHRH analogue (Leuproreline $3.75 \mathrm{mg} / 28$ days i.m.) was started. Five months later, GV $(2.8 \mathrm{~cm} / \mathrm{y})$, testosterone $(17.61 \mathrm{ng} / \mathrm{dl}), \mathrm{LH}$ peak $(0.8$ $\mathrm{mU} / \mathrm{ml})$, IGF-1 $(64 \mathrm{ng} / \mathrm{ml})$ strongly decreased with no progress in pubertal signs. GH $(0.24 \mathrm{mg} / \mathrm{kg} / \mathrm{w})$ therapy was started. At $11.2 \mathrm{y} / \mathrm{o}$ he had a bone age of $13 \mathrm{y} / \mathrm{o}, \mathrm{P} 3$, testis $3 \mathrm{ml}$, LH peak $0.9 \mathrm{mU} / \mathrm{ml}$, testosterone $46.4 \mathrm{ng} / \mathrm{dl}$, GV 5 $\mathrm{cm} / \mathrm{y}, \mathrm{IGF}-1613 \mathrm{ng} / \mathrm{ml}$, therefore LHRH therapy was discontinued. 
Ten months later, he presented spontaneous pubertal progression with augmented gonadotropins (LH peak $10.4 \mathrm{mU} / \mathrm{ml}$ ), testicular enlargement 4.5 $\mathrm{ml}$, testosterone $50.8 \mathrm{ng} / \mathrm{dl}, \mathrm{GV} 7 \mathrm{~cm} / \mathrm{y}, \mathrm{IGF}-1871 \mathrm{ng} / \mathrm{ml}$. At last observation (15.3 y/o) he had: height $170 \mathrm{~cm}\left(-0,01\right.$ SDS), weight $92.5 \mathrm{~kg}$, BMI $32 \mathrm{~kg} / \mathrm{m}^{2}$, $\mathrm{P} 4$, testis $10 \mathrm{ml}$, LH peak 32.97, testosterone $117.8 \mathrm{ng} / \mathrm{dl}$ and bone age of 17 $\mathrm{y} / \mathrm{o}$. GH therapy was stopped.

To our knowledge this is the forth case of CPP in genetically confirmed PWS and the first reported case with CPP and GHD with a good clinical and hormonal response to LHRH analogue and GH therapy and documented spontaneous pubertal progression after LHRH analogue interruption. Further studies will be necessary to clarify the physiopathology of CPP in these patients.

P03-630 Rare Syndromes and Hormones

\section{Short-term effect of rhGH treatment of} children with Prader-Labhart-Willi syndrome on respiratory function: a polysomnographic and ENT endoscopic study

Alessandro Salvatoni'; Elisabetta Veronelli'; Luana Nosetti'; Samantha de Simone'; Lorenzo lughetti ${ }^{2}$; Laura Bosio ${ }^{3}$; Giuseppe Chiumello ${ }^{3}$; Giovanni Delü4; Paolo Castelnuovo ${ }^{4}$; Giuliana Trifirò'5; Luigi Nespoli ${ }^{1}$

'Università degli Studi dell'Insubria, Pediatric Department, Varese, Italy; ${ }^{2}$ Università di Modena, Pediatric Clinic, Modena, Italy; ${ }^{3}$ Università "Vita e Salute"-Ospedale San Raffaele, Pediatric Clinic, Milano, Italy; “Università degli Studi dell'Insubria, Othorinolaringoiatric Clinic, Varese, Italy; ${ }^{5}$ Ospedale San Giuseppe, Pediatric Department, Milan, Italy

Background: Although significant improvement of respiratory function has been reported during rhGH treatment of Prader-Labhart-Willi Syndrome (PLWS), in the last five years several cases of sudden death during the first 6 months of GH therapy were reported in literature. Objectives and hypotheses: to establish if a short-term GH treatment causes obstructive apnea in PWLS patients with normal upper airways patency.

Population and methods: 12 patients (6 boys, aged 3.9 \pm 1.9 years) were studied by one night polysomnography (PSG) monitoring (Grass 4.2) and ENT video endoscopy before and after six weeks of rhGH treatment $(0.03 \mathrm{mg} /$ $\mathrm{kg}$ b.w./day). All patients underwent auxologic assessment including height, weight, BIA and plicometry, fasting blood glucose, insulin and IGF1 evaluation. The main PSG parameter considered was total apnea hypopnea index (AHI), resulting from the sum of two components: central apnea hypopnea index (CI) and obstructive apnea hypopnea index (OI). All patients were normal weight and free of severe or moderate upper airways obstruction (such as adenoid/tonsil hypertrophy, nasal obstruction with or without respiratory tract infection) when started GH treatment.

Results: Statistically unsignificant changes of PSG indexes were observed after six weeks of GH therapy (see Table). We didn't find any statistically significant correlation between body fat, IGF1 and insulin and PSG changing during GH treatment. ENT video endoscopic evaluation didn't show any significant increase of tonsil and adenoid size after GH treatment.

Precise conclusions: Our data confirm previous studies (Miller et al., JCEM, 2006; Festen et al. JCEM 2006) showing that GH treatment doesn't cause obstructive apnea in PWLS patients with normal upper airways patency.

\begin{tabular}{llll} 
& $\begin{array}{l}\text { Before GH } \\
\text { treatment }\end{array}$ & $\begin{array}{l}\text { After GH } \\
\text { treatment }\end{array}$ & $\mathrm{p}$ \\
\hline $\mathrm{AHI}$ & $3.91 \pm 3.48$ & $3.53 \pm 2.13$ & $\mathrm{~ns}$ \\
$\mathrm{Cl}$ & $3.18 \pm 3.29$ & $2.70 \pm 1.70$ & $\mathrm{~ns}$ \\
$\mathrm{OI}$ & $0.73 \pm 0.79$ & $0.83 \pm 1.03$ & $\mathrm{~ns}$ \\
\hline
\end{tabular}

P03-631 Rare Syndromes and Hormones

Hyperghrelinemia correlates with carotid intima-media thickness in children with PraderWilli syndrome

Joong-Bum Cho'; Sang Gu Lee'; Hye-Soo Yoo'; Su-Jin Kim';

Min Jung Kwak'; Kyung-Hoon Paik'; Dong-Kyu Jin'; Kwon Eun-Kyung'; Dong-lk Kim²; Yoo-jung Oh'; Kyung-Min Pyun ${ }^{3}$; Gae-Young Kim; Heon-Seok Han ${ }^{4}$

'Samsung Medical Center, Department of Pediatrics, Seoul, Republic of Korea; 'Samsung Medical Center, Department of Vascular Surgery, Seoul, Republic of Korea; ${ }^{3}$ Samsung Medical Research Center, Department of Pediatrics, Seoul, Republic of Korea; ${ }^{4}$ Chungbuk National University Hospital, Department of Pediatrics, Seoul,

Republic of Korea

Prader-Willi syndrome (PWS) is a contiguous gene syndrome resulting from deletion of the parental copies of the imprinted $S N R P N$ gene and is characterized by uncontrollable hyperphagia causing major somatic as well as psychologic problems. Eventually most PWS children become obese, which leads to cardiovascular disability within the first 3 decades of life and early death. It has been reported that the levels of acylated ghrelin and total ghrelin, which comprises acylated ghrelin and desacylated ghrelin, are elevated in PWS children.

To identify risk factors for future disabilities, carotid artery intima media thickness (IMT) was measured and correlated with risk factors in 27 children with PWS and 24 age, sex, BMI adjusted controls. The risk factors related to IMT included LDL cholesterol, blood pressure, Creactive protein and plasma ghrelin. IMTs in children with PWS were not different with those in control [median IMT $0.4 \mathrm{~mm}$ (interquartile range, $0.4-0.5)$ vs. $0.5(0.4-0.5), \mathrm{P}=0.172]$. However, total ghrelin was higher in PWS compared with controls [2.91ng/ $\mathrm{ml}(2.31-4.62)$ vs. $1.96(1.10-2.70), \mathrm{P}=0.003]$ and total ghrelin ( $\mathrm{r}=0.489$, $\mathrm{P}=0.046)$ were positively correlated with IMT in PWS, while BMI SDS $(\mathrm{r}=0.697, \mathrm{P}=0.005)$ were positively related with IMT in control.

Our results suggest no evidence of atheroscleosis in PWS at the age of 10 years. However, considering the positive correlation of IMT with total ghrelin and high level of ghrelin in PWS children, a vigorous effort to lower the known risk factors for atherosclerosis is advocated for in PWS.

\section{P03-632 Rare Syndromes and Hormones \\ Prevalence of endocrine dysfunctions in children with Prader-Willi syndrome in the French database of PWS}

Gwenaëlle Diene'; Sophie Caula ${ }^{1}$; Catherine Molinas ${ }^{1}$; Laurent Cazals'; Mélanie Glattard'; Pascal Barat'2; Michel Colle'; Fabienne Dallavale'; Philippe Garnier"; Claire Jeande/ ${ }^{3}$; Monique Jésuran-Pérelroizen ${ }^{1}$; Stéphane Boulard ${ }^{2}$; Anne Lienhardt ${ }^{5}$; Jean-Christophe Mas ${ }^{6}$; Anne Moncla ${ }^{7}$; Marc Nicolino ${ }^{8}$; Olivier Puel${ }^{2}$; Gilbert Simonin ${ }^{7}$; Katy Wagner ${ }^{6}$; Maithé Tauber ${ }^{1}$

Children's Hospital, Endocrinology Unit, Toulouse, France; ${ }^{2}$ Children's Hospital, Endocrinology Unit, Bordeaux, France; ${ }^{3}$ Children's Hospital, Endocrinology Unit, Montpellier, France; ${ }^{4}$ Children's Hospital, Endocrinology Unit, Grenoble, France; ${ }^{5}$ Children's Hospital, Endocrinology Unit, Limoges, France; ${ }^{6}$ Children's Hospital, Endocrinology Unit, Nice, France; ${ }^{7}$ Children's Hospital, Endocrinology Unit, Marseille, France; ${ }^{8}$ Children's Hospital, Endocrinology Unit, Lyon, France

The reference centre for Prader-Willi, set-up by the health ministry in November 2004, involves 6 regions of the South of France with a coordination team in Toulouse and collaborates actively with other centres in France. One of the objectives of the centre is to set-up a database starting with children and adolescents containing medical and psychosocial data.

This database is partially supported by Pfizer Inc. One hundred and forty eight children (81 male, 67 female) were included in the database with a median chronological age at inclusion of 7.3 years [0.21-23.25]. The objective of the study was to evaluate the prevalence of endocrine dysfunctions in this population.

This database including all children with PWS followed in the centre allows us to have a right idea on the prevalence and endocrine disorders in this syndrome and precise their evolution. 


\begin{tabular}{|c|c|c|c|c|}
\hline $\begin{array}{l}\text { Endocrine } \\
\text { dysfunction }\end{array}$ & $\begin{array}{l}\text { Number } \\
\text { of patients } \\
\text { studied }\end{array}$ & Sex ratio & Dysfunction & Normal \\
\hline GH deficiency & $\mathrm{N}=114(77 \%)$ & $62 \mathrm{M} / 52 \mathrm{~F}$ & $\begin{array}{l}\mathrm{N}=93(83 \%) \\
\mathrm{GHD} 36 \% \\
\text { partial } 46 \% \\
\text { complete }\end{array}$ & $\mathrm{N}=21(17 \%)$ \\
\hline Hypogonadism & $\mathrm{N}=62(41.9 \%)$ & $36 \mathrm{M} / 26 \mathrm{~F}$ & $\begin{array}{l}\mathrm{N}=32(51.6 \%) \\
15 \text { treated }\end{array}$ & $\mathrm{N}=30(48.4 \%)$ \\
\hline $\begin{array}{l}\text { Cryptorchi- } \\
\text { dism }\end{array}$ & $\mathrm{N}=77(95 \%)$ & $77 \mathrm{M}$ & $\begin{array}{l}\mathrm{N}=68(88.3 \%) \\
\text { Bilateral } 84 \% \\
\text { Surgery } \mathrm{N}=54 \\
(83 \%) \text { at a } \\
\text { median age } \\
3.9 \text { years }(1.5- \\
17.3)\end{array}$ & $\mathrm{N}=9(11.7 \%)$ \\
\hline $\begin{array}{l}\text { Hypothyroi- } \\
\text { dism }\end{array}$ & $\begin{array}{l}N=130 \\
(87.8 \%)\end{array}$ & $70 \mathrm{M} / 60 \mathrm{~F}$ & $\begin{array}{l}\mathrm{N}=32(24.6 \%) \\
31 \text { treated }\end{array}$ & $\mathrm{N}=98(75.4 \%)$ \\
\hline $\begin{array}{l}\text { Impaired } \\
\text { glucose } \\
\text { tolerance } \\
\text { (OGTT) }\end{array}$ & $\mathrm{N}=78(52.7 \%)$ & $46 \mathrm{M} / 32 \mathrm{~F}$ & $\mathrm{~N}=6(7.7 \%)$ & $\mathrm{N}=72(92.3 \%)$ \\
\hline $\begin{array}{l}\text { Diabetes } \\
\text { mellitus }\end{array}$ & $\begin{array}{l}N=122 \\
(82.4 \%)\end{array}$ & $70 \mathrm{M} / 52 \mathrm{~F}$ & $\mathrm{~N}=0$ & $\mathrm{~N}=122(100 \%)$ \\
\hline Obesity & $\mathrm{N}=137(92.6 \%)$ & $75 \mathrm{M} / 62 \mathrm{~F}$ & $\begin{array}{l}\mathrm{N}=62(45.3 \%) \\
<2 \text { years } 0 \% \\
\text { between } 2 \text { and } \\
6 \text { years } 20.9 \% \\
\text { between } 6 \text { and } \\
10 \text { years } 52.9 \% \\
>10 \text { years } \\
68.6 \%\end{array}$ & $N=75(54.7 \%)$ \\
\hline
\end{tabular}

P03-633 Rare Syndromes and Hormones

Natural history of pituitary-testicular function from infancy to adulthood in McCune-Albright syndrome: clinical and endocrine experience from a fifteen-year follow-up

Malgorzata Wasniewska; Teresa Arrigo; Giuseppe Crisafulli;

Immacolata Rulli; Giuseppina Salzano; Filippo De Luca

University of Messina, Department of Pediatrics, Messina, Italy

The natural history of autonomous testicular function in McCune-Albright sindrome (MAS) has not been elucidated hitherto. Our aim is to report for the first time the longterm natural history of pituitary-testicular axis function in MAS through the fifteen year clinical and endocrinological follow-up of a boy, who presented for the first time at the age of 2.9 years with a clinical picture of peripheral precocious puberty (PPP) and monolateral testicular enlargement (right testis $20 \mathrm{ml}$ vs $3 \mathrm{ml}$ the other one) and has been longitudinally followed from then until 18 years. Gonadotropin serum levels were in the prepubertal range and did not increase after LHRH stimulation throughout the overall follow-up period. In the same interval testosterone levels remained always in the pubertal range. At the age of 18 he exhibited complete pubertal development with persisting testicular asymmetry, bilateral testicular microlithiasis and final height of $155 \mathrm{~cm}$ (162 target height), polyostotic fibrous dysplasia and hypophosphatemic rickets. Total sperm count was severely subnormal (6.000.000) and also fertility index was impaired. A mutation at codon 201 resulting in $\mathrm{Arg} \rightarrow \mathrm{His}$ substitution (R201H), classically responsible for MAS, was identified in all the analysed DNA samples from both testes' biopsy and from leucocytes. This is the first study documenting the persistence of tetsicular dysfunction in a MAS boy from infancy to adolescence and adulthood, as demonstrated by the persistently elevated sex steroids with low or undetectable gonaotropin levels during the entire follow-up, from PPP onset onwards. Moreover this is the first report demonstrating that MAS adults may develop a picture of pathologically reduced spermatogenetic maturation with consequent oligospermia. Finally, another inference of this case history is that MAS in boys may present with a monolateral testicular enlargemenet as early clinical manifestation and that asymmetry between testes may persist until adulthood.
P03-634 Rare Syndromes and Hormones

Hypogonadotropic hypogonadism in Kabuki syndrome: the story of two adolescents Maria Cristina Maggio ${ }^{1}$; Silvano Bertelloni ${ }^{2}$; Andrea Liotta ${ }^{1}$; Giovanni Corsello ${ }^{1}$

'University of Palermo, Dumi, Palermo, Italy; ${ }^{2}$ University of Pisa,

Department of Reproductive Medicine and Pediatrics, Pisa, Italy

Kabuki syndrome (KS) is a rare genetic disease with typical face, reminiscent of the make-up of actors of a Japanese theatre form, mild mental retardation, organs malformations, bones deformities, scoliosis, recurrent otytis, possible short stature, hypogonadism, seldom linked to $\mathrm{GH}$ and/or gonadotropins deficiency.

We describe 2 cases of adolescents with KS and no puberty signs. C.F., born SGA (length $46 \mathrm{~cm}$; weight $2.330 \mathrm{~g}$ ) presented interatrial shunt. Height growth velocity $<-2 \mathrm{DS}$ is coupled with a KS phenotype (long palpebral fissures, arched eyebrow sparse in the lateral third, large prominent earlobes; brachydactyly $\mathrm{V}$, fingerpads), otitis media, posterior urethral valves with vescico-ureteral reflux, kidney recurrent lithiasis. At 15years height is 4DS, bone age 11years, stage PH1G1, testicular volume $2 \mathrm{ml}$; basal and after LHRHa LH: 1.2-2.4mUI/ml; basal and after LHRHa FSH: $1.1-1.2 \mathrm{mUI} / \mathrm{ml}$; basal and after LHRHa testosterone: $0.36-0.67 \mathrm{ng} / \mathrm{ml}$. GH secretion tested by clonidin and insulin is normal. CNS NMR shows adenohypophyseal volume at -2 SDS for age.

S.A., precociously presents psycho-motor retardation and low growth velocity with weight -2 DS and height $<-2$ DS.

KS phenotype (long palpebral fissures, eversion of the lateral third of the lower eyelids, depressed nasal tip, high-arched palate, bilateral cryptorchidism, microphallus) is suggestive. Treatment with hCG resolved cryptorchidism. At 13 years height is -2DS, bone age 11.3years, stage PH1G1, testicular volume $0.5 \mathrm{ml}$; basal and after LHRHa LH: $<0.1 \mathrm{mUI} / \mathrm{ml}$; basal and after LHRHa FSH: $0.3-0.4 \mathrm{mUI} / \mathrm{ml}$; basal and after LHRHa testosterone: $<0.02 \mathrm{ng} / \mathrm{ml}$. CNS NMR is normal. Both the patients are now treated with hCG.

Short stature in KS can be associated to hypogonadism with growth delay. Frequently the condition remains idiopatic and NMR evidences no hypotalamo-hypophyseal malformations. The treatment with hCG induces puberty and sometimes can be discontinued.

We stress the relieve of an accurate diagnosis and of an endocrine and auxological follow-up of patients with KS.

\section{P03-635 Rare Syndromes and Hormones}

\section{Noonan syndrome and PTPN11 mutations: clinical findings and growth follow-up with long-term GH therapy}

Laura Mazzanti' ; Emanuela Scarano²; Rosalba Bergamaschi²;

Cesare Rossi ${ }^{3}$; Chiara Matteucci2; Federica Tamburrino2;

Piero Pirazzoli ${ }^{2}$; Francesca Mencarelli ${ }^{2}$; Alessandro Cicognani ${ }^{2}$

'Department of Pediatrics, S.Orsola-Malpighi, University of Bologna, Bologna, Italy; '2Department of Pediatrics, S.Orsola-Malpighi Hospital, University of Bologna, Bologna, Italy; ${ }^{3}$ Medical Genetics Unit,

S.Orsola-Malpighi Hospital, University of Bologna, Bologna, Italy

Noonan syndrome (NS) is characterised by typical dysmorphic features, short stature and heart defects. PTPN11 mutations were identified in about half the patients (pts) with clinical diagnosis of NS. The aim of the study was to evaluate whether in NS pts PTPN11 mutations influence clinical findings, growth factors and growth after long-term GH therapy. Thirty-four pts who fulfilled strict diagnostic criteria were studied for auxo-anthropometric parameters, dysmorphic signs, renal and cardiac US. PTPN11 analysis was performed. In 16 pts with height $(\mathrm{H})<=-2$ SD GH levels were evaluated with arginine and L-Dopa tests and IGF-I before and during GH therapy. Fifteen pts received GH-therapy; no patient with hypertrophic cardiomyopathy (HCM) was included. PTPN11 mutations were found in 16 of 34 pts $(47 \%)$ : 19 males and 15 females; equal distribution of PTPN11 mutation and sex. No difference was found in birth-height and weight by PTPN11. At 1st observation mean CA was $5.3 \pm 3.6$ yrs. At log regression analysis PTPN11+ pts had a higher prevalence of prominent eyes $(\mathrm{p}=0.02)$ and malocclusion $(\mathrm{p}=0.03)$. No difference was found in congenital heart defects (CHD) prevalence: HCM had a different distribution by PTPN11, but not significantly. GH-secretion, GH-deficiency prevalence and IGF-I levels were comparable in PTPN11+ and PTPN11- pts. Baseline and after 1 and 5 yrs of GH-therapy H-SDS was comparable in the 2 groups; H-SDS gain vs baseline was higher in PTPN11- 
pts than in PTPN11+, only after 10 yrs of GH-therapy $(+1.7 \pm 0.9$ and +0.1 \pm 0.2 respectively; $p=0.05$ ) without any difference in body proportions. In conclusion subjects with NS phentype and prominent eyes and malocclusion have a 2.5 time higher relative risk for PTPN11 mutations. At diagnosis PTPN11+ group was not shorter than PTPN11-. However, GH-therapy improved height gain more in pts without mutation than in pts PTPN11+. Our data contribute to confirm the hypothesis of a mild GH resistance caused by PTPN11 mutations.

\section{P03-636 Rare Syndromes and Hormones \\ Interstitial 6q deletion: a new patient with empty sella and GH deficiency \\ Emanuela Scarano'; Laura Mazzanti'; Marco Seri; Rosalba Bergamaschi'; Chiara Matteucci'; Pamela Magini2; Manuela de Gregori ${ }^{3}$; Roberto Ciccone ${ }^{3}$; Orsetta Zuffardi ${ }^{3}$; Alessandro Cicognani ${ }^{1}$ \\ ${ }^{1}$ Department of Pediatrics, S. Orsola-Malpighi Hospital, University of Bologna, Bologna, Italy; ${ }^{2}$ Medical Genetics Unit, S.Orsola-Malpighi Hospital, University of Bologna, Bologna, Italy; ${ }^{3}$ Genetica Medica, University of Pavia, Pavia, Italy}

We present a male with a $6 \mathrm{q}$ interstitial deletion of about $7 \mathrm{Mb}$ [del(6)(q25.1q25.3)] detected by array-CGH, involving the region between 151,51 and $158,18 \mathrm{Mb}$.

The patient was prematurely born ( $32 \mathrm{wks}$, BW $1300 \mathrm{~g}$, BL $36 \mathrm{~cm}$ ). At 6 yrs of age he had orchidopexy and at 8 yrs he was brought to our attention for growth and psychomotor development delay; he showed severe GH deficiency and was submitted to GH therapy. GH is administered also now in the adult age. His adult height is $164.9 \mathrm{~cm}$. Cerebral MRI showed an empty sella, mild ventriculomegaly, dilatation of cisterna magna and hypoplastic cerebellar verme. He has mild MR. Physical examination showed macro-brachicephaly, coarse face, bushy eyebrows, short palpebral fissures, "prominent" nose, everted lower lip, broad and protruding chin, narrow palate, dysplasia of teeth enamel, retroverted ears, short, broad neck with reduntant skin, posterior low hair-line, scoliosis, cervical kyphosis, cubitus valgus, terminal broadening fingers, thick, but very sensitive palmar and sole skin. Skeleton X-ray: dysmorfic vertebrae, dysmorfic femoral and tibial condyle. Severe myopia. In conclusion this is the first report of an interstitial deletion of $6 \mathrm{q}$ associated with empty sella and severe GH-deficiency. GH-deficiency associated to cryptic chromosome deletion at $15 \mathrm{q} 24$ was previously reported highlighting the importance of array-CGH in syndromic GH-deficiency.

\section{P03-637 Rare Syndromes and Hormones \\ Aldosterone synthase deficiency: five years experience of a rare but important cause of hyponatraemia \\ John Porter ; Chetana Kallappa ${ }^{2}$; Nicholas Lipscomb ${ }^{3}$; Jeremy Kirk'; Sarah Ehtisham ${ }^{4}$; Deepthi Jyothi'; Timothy Barrett ${ }^{4}$ \\ 'Birmingham Children's Hospital, Diabetes Home Care, Birmingham, United Kingdom; 'Birmingham Children's Hospital, General \\ Paediatrics, Birmingham, United Kingdom; 'Birmingham Children's Hospital, Endocrinology and Diabetes, Birmingham, United Kingdom; ${ }^{4}$ Birmingham Children's Hospital, Endocrinology and Diabetes, Birmingham, United Kingdom}

Defects in the gene CypB2 (aldosterone synthase) have been shown to cause aldosterone deficiency. We present 5 year's experience with three families ( 5 children) with this condition. Infants presented at a median age 35 days (range 23-63 days) to the general paediatric department with failure to thrive, and taking small feed voumes. Vomiting was not a presenting feature, and no child appeared dehydrated, suggesting a mild feeding problem. In several cases measurement of electrolytes was delayed for hours or days.

Measurement revealed hyponatraemia (median $\mathrm{Na} 119.5 \mathrm{mmol} / 1$ range 115 129) and hyperkalaemia (median $\mathrm{K} 5.7 \mathrm{mmol} / 1$ range $4-6.5$ ). Infants were not virilized. Urine steroid profile revealed characteristically low corticosterone derivatives. Aldosterone levels were in the normal range (median 352pmol/1 range 69-656), but were inappropriate for the level of hyponatraemia. Renin levels were raised. Hyponatraemia was resistant to intravenous or oral replacement until introduction of fludrocortisone. Patients were stabilized on 50ìg Fludrocortisone and a median supplement of $30 \mathrm{mmol} /$ day $\mathrm{NaCl}$ (range 18-32). With normalisation of sodium infants showed catch up growth, but older children have shown some long-term problems with growth. $2 / 3$ families were Yemeni but unrelated, and no families were consanguineous. 2 families have had genetic analysis and share the same DNA variant which is predicted to alter a splice site for aldosterone synthase. Although Aldosterone synthase deficiency is rare, it is an important treatable cause of salt losing failure to thrive, which can be confused initially with congenital adrenal failure and renal tubular problems. Infants with failure to thrive should have electrolytes measured at an early stage, and aldosterone levels must be interpreted with reference to sodium levels not the normal reference range.

\section{P03-638 Rare Syndromes and Hormones Crouzon syndrome with acanthosis nigricans and $\mathbf{G H}$ deficiency} Dimitrios Papadimitriou'; Margarita Markouri'; : Grigoris Fytanidis'; Polyxeni Nicolaidou ${ }^{4}$; Anastasios Papadimitriou ${ }^{3}$ ${ }^{1}$ Athens Medical Center, Attikon University Hospital, Pediatric Endocrinology, Athens, Greece; ${ }^{2}$ Athens Medical Center, Pediatrics, Athens, Greece; ${ }^{3}$ Attikon University Hospital, Pediatric Endocrinology, Athens, Greece; ${ }^{4}$ Attikon University Hospital, Pediatrics, Athens, Greece

Crouzon syndrome with acanthosis nigricans is a rare syndrome due to a FGFR3 Ala391Glu substitution in the transmembrane domain, situated close to the recurrent achondroplasia mutation. About 30 cases have been reported so far. We report a prepubertal girl aged $11.6 \mathrm{yr}$ with typical signs of Crouzon syndrome (cranial synostosis, hypertelorism, parrot-beaked nose, short upper lip, hypoplastic maxilla) and diffuse excessive acanthosis nigricans, distributed not only in the axillae and neck, but also the chest, abdomen, breasts, perioral and periorbital areas, and nasolabial folds. Skeletal survey showed no evidence of the skeletal manifestations of achondroplasia, thanatophoric dysplasia, or hypochondroplasia, although she had an operation for hydrocephalus, possibly caused by stenosis of the jugular foramen, and interpediculate narrowing.

Multiple neurosurgical operations since early infancy achieved normal head circumference $(51.5 \mathrm{~cm},-1.05 \mathrm{SD})$ and neurological development. She was growing normally on -0.4 SD until the age of 3.3 yrs, her target height being $+0.65 \mathrm{SD}$. Then, growth velocity gradually fell from $7.5 \mathrm{~cm} / \mathrm{yr}(-0.08 \mathrm{SD})$ the $3 \mathrm{rd}$ yr to $2.8 \mathrm{~cm} / \mathrm{yr}(-4.84 \mathrm{SD})$ the 10th yr of age, her height being $132.3 \mathrm{~cm}(-$ $2.22 \mathrm{SD}$ ) at the age of $11.62 \mathrm{yr}$. Bone age was delayed by $1.5 \mathrm{yr}$. She received L-thyroxine for the last 6 months because of subclinical hupothyroidism due to autoimmune thyroiditis (before treatment: TSH $7.6 \mathrm{mIU} / \mathrm{ml}$, FT4 $1.25 \mathrm{ng} /$ $\mathrm{dl}$; under L-thyroxine: TSH 1.25, FT4 1.36). that resulted in no improvement in growth velocity. Endocrinological investigations revealed low IGF-1 90 $\mathrm{ng} / \mathrm{ml}$ and partial GH deficiency after provocation with glucagon (peak GH $5.6 \mathrm{ng} / \mathrm{ml}$ ) and levo-dopa (peak GH $7.0 \mathrm{ng} / \mathrm{ml}$ ). The corticotropic axis was intact and prolactin was normal. MRI of the hypothalamic-pituitary area showed anatomic integrity of the pituitary gland, although the pituitary fossa was narrowed and the optic chiasma had a peculiar vertical -instead of horizontal- orientation. This is the first case of Crouzon syndrome with acanthosis nigricans and GH deficiency reported.

\section{P03-639 Rare Syndromes and Hormones Is mutation analysis important in patients with achalasia? \\ Nihal Hatipoglu'; ; Duran Arslan²; Selim Kurtoglu4; Mustafa Kendirci'; Angela Huebner ${ }^{3}$ \\ ${ }^{1}$ Erciyes University Faculty of Medicine, Department of Pediatric Endocrinology, Kayseri, Turkey; ${ }^{2}$ Erciyes University Faculty of Medicine, Department of Pediatric Gastroenterology, Kayseri, Turkey; ${ }^{3}$ Technical University Dresden, Pediatric and Molecular Endocrinology, Dresden, Germany; ${ }^{4}$ Erciyes University, School of Medicine, Department of Pediatric Endocrinology, Kayseri, Turkey}

Introduction: Allgrove or AAA (triple-A) syndrome is an autosomal recessive condition associated with adrenal insufficiency, alacrima, achalasia and a variety of neurological and dermatological features. Mutations leading to disease have been found on the AAAS gene proteins and their function is 
not clear. We know that there is no strong phenotype-genotype correlation. Case: We presented a 16 year-old boy with dysphagia. He was born to nonconsanguineous parents. Upper GI endoscopy was suggestive of achalasia. On questioning her mother confirmed that boy has never had tears in his eyes. Ophthalmological Schirmer test suggested alacrima. Neurological symptoms and findings of adrenal insufficency were absent in patient. ACTH stimulation test performed on produced normal serum cortisol values and adrenal insufficiency was excluded. The diagnosis of Allgrove syndrome was confirmed in this patient by studying the gene mutation in the family. The parents and brother were heterozygous and asymptomatic. Mutation analysis has been identified AAAS gene G14fs homozygous splice mutation in exon 1 on $12 q 13$ in this patients and his brother.

Conclusion: Triple A syndrome should be considered in any young patient with achalasia and these patients must have an ophthalmologic examination for alacrima as was in this patient. Adrenal insufficiency in patients with this disorder may develop as late as the third decade of life. Subsequent endocrine investigations confirmed primary adrenal insufficiency and aldosterone deficiency. We suggest that achalasia may occur with alacrima, adrenal insufficiency and neurological and dermatological features. These conditions are called as ,double A', , triple A' or the ,4 A' syndromes. Mutation analysis should be done for certain diagnosis.

\section{P03-640 Rare Syndromes and Hormones \\ Wolcott-Rallison syndrome due to the same mutation (W521X) in the EIF2AK3 gene in two unrelated families}

M. Nuri Ozbek'; Sehnaz Aydemir'; Valerie Senee ${ }^{2}$;

Neslihan O. Mungan'; Bilgin Yuksel'; Cecile Julier'2; A. Kemal Topaloglu'

${ }^{1}$ Cukurova University, Faculty of Medicine, Pediatric Endocrinology and Metabolism, Adana, Turkey; ${ }^{2}$ INSERM E102, Institut Pasteur,

Genetique des Maladies Infectieuses et Autoimmune, Paris, France

Background: Wolcott-Rallison syndrome is a rare autosomal recessive disorder characterized by an early-infancy-onset diabetes mellitus associated with a variety of multisystemic clinical manifestations. Here, we present two patients with WRS from two unrelated families in Turkey due to the same mutation.

Patient one: A three-month-old girl was referred with the preliminary diagnosis of diabetes mellitus. She was the only living child of a consangious family. Two previous siblings died at the same age of very similar symptoms and clinical findings. She had had diarrhoea from birth on breast milk feeding. Her laboratory findings included very high ALT and AST, BUN, and creatinine levels, absolute neutropenia $\left(200 / \mathrm{mm}^{3}\right)$, and low FT4 and normal TSH levels. An X-ray survey revealed metaphyseal flaring and osteopenia, and small irregular osteopenic epiphyseas.

Patient two: A four-month-old girl presented with diabetic ketoacidosis and fever. She is the only living child of a consangious family. Her sister died at two months of age from DKA, neutropenia and sepsis, and hepatic and renal failure. Her laboratory results included normal ALT, AST, and creatinine levels, a low neutrophil count $\left(450 / \mathrm{mm}^{3}\right)$, a positive urine culture for E.coli, and normal thyroid function tests. A mutation screening was performed on genomic DNA on the coding regions of the EIF2AK3 gene. A G-to-T transition at nucleotide 1634 causing a STOP codon at residue 521 in the regulatory domain of the protein (W521X) was identified in homozygous state in both patients.

Conclusion: We present these patients to contribute to the phenotype-genotype correlation in this rare syndrome. Apparently, this mutation is associated with a severe form of the disease. Although, these two families deny any relationship, this same mutation in both families may be due to a founder effect. Alternatively, the site of the mutation is prone to mutagenesis.

\section{P03-641 Rare Syndromes and Hormones \\ A case of achondroplasia associated with Klinefelter syndrome}

Jessica Arditi'; Christina Kanaka-Gantenbein ${ }^{1}$; Helen Fryssira ${ }^{2}$; Alexandra-Maria Magiakou'; ${ }^{1}$ George Chrousos ${ }^{1}$

'University of Athens, First Dept of Pediatrics, Division of

Endocrinology, Diabetes and Metabolism, Athens, Greece;

${ }^{2}$ University of Athens, Department of Medical Genetics, Athens,

Greece

Achondroplasia (ACH), a sporadic autosomal dominant skeletal dysplasia, occurs in approximately 1:20,000 births. 47,XXY aneuploidy (Klinefelter Syndrome, KS) is the most common sex chromosome disorder with a prevalence of one case in 500 males, presenting with tall stature and hypergonadotropic hypogonadism. To the best of our knowledge, only three cases have been reported with the association of $\mathrm{ACH}$ and $\mathrm{KS}$, diagnosed in late puberty or young adulthood, when no androgen therapy was initiated.

These cases had a karyotypic confirmation of KS, but the molecular analysis of the FGFR3 gene was not available at the time to corroborate the diagnosis of $\mathrm{ACH}$. We report here the clinical and molecular characterization of a new patient with de novo $\mathrm{ACH}$ and $\mathrm{KS}$, diagnosed during early infancy because of the typical phenotype of $\mathrm{ACH}$, which was confirmed by molecular analysis (heterozygous 1138 G-to-A mutation). A karyotype revealed also the presence of KS. On his last visit at the age of $7 \mathrm{y} 11 / 12 \mathrm{mo}$, he presented severe rhizomelic dwarfism, height $97,4 \mathrm{~cm}(-5,4 \mathrm{SDS})$, weight $19,3 \mathrm{Kg}(-2,7 \mathrm{SDS})$ and head circumference $58,1 \mathrm{~cm}(+3,3 \mathrm{SDS})$. His testicular volume was $2 \mathrm{ml}$, and his penile length was normal. His motor and speech acquisitions were normal, but he had difficulty to concentrate. He had normal FSH and LH, normal thyroid function and normal glucose, phosphorus and calcium metabolism. In conclusion, although $\mathrm{KS}$ is most commonly associated with tall stature, our patient had a prominent ACH phenotype with severe rhizomelic dwarfism. Due to the early diagnosis, this patient profited from an early and regular multidisciplinary management with regular follow-up.

Furthermore, androgen replacement will be started during the therapeutic window of puberty in order to promote the development of normal secondary sex characteristics, improve behaviour and work performance and provide long-term benefit on bone density and breast cancer risk.

\section{P02-642 Testes and Androgens \\ A combined treatment with ketoconazole and cyproterone acetate may slow down the progression of male precocious puberty in McCune-Albright syndrome}

Maria Francesca Messina; Malgorzata Wasniewska; Immacolata Rulli;

Giuseppina Zirilli; Teresa Arrigo; Filippo De Luca

University of Messina, Department of Pediatrics, Messina, Italy

McCune-Albright syndrome (MAS) is characterized by the classical triad of polyostotic fibrous bone dysplasia, cafè-au-lait skin pigmentation and precocious puberty. It is caused by a post-zygotic mutation at codon 201 within exon 8 of the GNAS-1 gene that results in increased activity of Gsalpha protein. Precocious puberty is common in girls with MAS but has been reported in only $15 \%$ of affected boys. To date, therapy of precocious puberty associated with MAS has been rather disappointing, and effective treatment has remained elusive.

We report the case of a 7.3 years old boy with MAS who presented at the age of 4.6 years with monolateral testis enlargement. At physical examination he showed: height $119.2 \mathrm{~cm}(+3.0$ SDS), weight $19.200 \mathrm{~kg}$, bone age 5.6 yrs (GP), target height $179.8 \mathrm{~cm}(+0.8 \mathrm{SDS})$, no pubic or axillary hair and a striking asymmetry of testes (10 $\mathrm{ml}$ on the right and $3 \mathrm{ml}$ on the left side). MAS diagnosis was confirmed by genetic analysis (Horm Res 2006;65:114). Over the three year-clinical follow-up we noticed a progressive increase of height velocity $(13 \mathrm{~cm} /$ years $)$, pubic hair appearance and a significant increase of testosterone levels (91-169 ng/dl). After excluding other causes of overgrowth we decided to treat precocious puberty with a combined therapy of ketoconazolo (400 mg/day) and cyproterone acetate $(50 \mathrm{mg} /$ day $)$. Six months later we observed a significant reduction of testosterone $(155-21 \mathrm{ng} /$ dl) and free-testosterone (6-2.6 pg/ml) levels and a mild reduction of growth velocity $(3 \mathrm{~cm} / 6$ months). During this short follow-up no side effects have been reported and liver function is, up to date, completely normal. We believe that our clinical observation is worthy of mentioning and is promising for the 
treatment of male precocious puberty in MAS. If our results will be confirmed on long term follow-up, we can conclude that the association ketoconazolo/ cyproterone acetate is an effective and well tolerated therapeutical regimen of male precocious puberty in MAS.

\section{P02-643 Testes and Androgens \\ Sertoli cell tumor causing prepubertal gynecomastia in a boy with Peutz-Jeghers syndrome: the outcome of three-year treatment with aromatase inhibitors}

Cengiz Kara; Alev Oguz Kutlu; Semra Cetinkaya

Dr. Sami Ulus Children's Hospital, Pediatric Endocrinology, Ankara, Turkey

Introduction: Peutz-Jeghers syndrome (PJS) is a rare disorder characterized by benign intestinal hamartomatous polyps and mucocutaneous pigmentation, and with an increased risk for intestinal and extra-intestinal neoplasms. Sertoli cell tumors in boys with PJS have been increasingly recognized as a cause of prepubertal gynecomastia. However, an association between nephrocalcinosis and PJS has not been reported before. We report a boy with PJS, bilateral gynecomastia, Sertoli cell tumor and nephrocalcinosis, and we present the outcome of three-year treatment with aromatase inhibitors.

Case report: A 7.25 year-old boy presented with bilateral breast enlargement and mucocutaneous pigmentation. His bone age was 7 years. The testes were large in size ( $5 \mathrm{ml}$ each) without discrete masses. Testicular ultrasound revealed mild bilateral enlargement of the gonads, and parenchymal multiple microcalcifications. Histopathological examination was consistent with Sertoli cell tumors. It was also detected nephrocalcinosis due to idiopathic renal hypercalciuria. At the age of 7.5 , testolactone was begun in an attempt to prevent acceleration in the skeletal maturation. One-year treatment with testolactone reduced the breast base diameter from $7 \mathrm{~cm}$ to $3 \mathrm{~cm}$; and his bone age advanced 1.2 years during this period. However, the testes slightly enlarged to $6 \mathrm{ml}$ bilaterally. After that, we switched the drug therapy from testolactone to anastrozole, more potent aromatase inhibitor. Two-year therapy with anastrozole provided further reduction in the size of the breasts and testicles. At this time, the patient is 10.5 -year old age; the bone age is 10 years; both testicle volumes are 4 milliliters; and breast base diameters are 1-2 centimeters.

Conclusions: Our case demonstrates that waiting for the effect of aromatase inhibitors on gynecomastia and testicular tumor before decisions of mastectomy and orchiectomy may be a reasonable option. We also consider that the association between PJS and nephrocalcinosis may be a coincidence.

P02-644 Testes and Androgens

\section{Possible Sertoli cell dysfunction but high} normal testosterone levels in infants with nonmosaic Klinefelter syndrome

Lise Aksglaede ${ }^{1}$; Jørgen Holm Petersen ${ }^{2}$; Katharina M Main ${ }^{1}$;

Niels E Skakkebæk'; Anders Juul'

${ }^{1}$ Rigshospitalet, University Department of Growth and Reproduction, Copenhagen, Denmark; 'Univeristy of Copenhagen, Department of Biostatistics, Copenhagen, Denmark

Klinefelter syndrome (KS) is associated with hypergonadotropic hypogonadism in adulthood. However, limited information exists about the age at which hypogonadism occurs. The hypothalamic-pituitary-gonadal (HPG) axis is transiently activated during the first months of life, offering the opportunity to study testicular function by spontaneous, basal hormone levels. The aim of the study was to evaluate the HPG axis in KS infants.

Ten infants with KS aged 3.1 months (range 1.8-3.8) and 613 healthy boys aged 3.0 months (range 2.0-4.5) participated. Serum levels of total and free testosterone $(\mathrm{T})$, luteinizing hormone $(\mathrm{LH})$, follicle stimulating hormone (FSH), inhibin B and sex hormone binding globulin (SHBG) were determined by immunoassays.

$\mathrm{LH} / \mathrm{T}, \mathrm{LH} /$ free $\mathrm{T}$ and $\mathrm{FSH} /$ inhibin $\mathrm{B}$ bivariate charts and ratios were evaluated.

KS infants had significantly higher concentrations of total T [5.0 (2.2-11.2) vs. $3.4(0.7-8.3) \mathrm{nmol} / \mathrm{l}, \mathrm{p}=0.02]$, free T [31.6 (18.2-61.8) vs. $22.1(4.3-48.4)$ pmol/l, p=0.01], LH [3.3 (1.3-4.6) vs. $1.7(0.6-4.3) \mathrm{IU} / 1, \mathrm{p}=0.005]$ and $\mathrm{FSH}$ [1.7 (1.1-4.1) vs. $1.2(0.4-3.0) \mathrm{IU} / 1, \mathrm{p}=0.007]$ than controls. SHBG [138 (83$188)$ vs. $138(66-269) \mathrm{nmol} / \mathrm{l}]$ and inhibin B [330 (245-444) vs. $387(234-634)$ $\mathrm{pg} / \mathrm{ml}]$ did not differ from controls. LH/T [0.55 (0.17-2.1) vs. $0.54(0.17-2.3)]$ and $\mathrm{LH} /$ free $\mathrm{T}[83.3$ (30.7-206.5) vs. 82.3 (26.5-319.6)] ratios were normal, whereas the FSH/inhibin B ratio was elevated [6.5 (2.7-16.9) vs. $3.0(0.78$ 11.4), $\mathrm{p}=0.005$ ] compared to controls. The majority of KS infants turned out to have normal bivariate hormonal evaluations.

We found increased FSH/inhibin B ratio as a possible sign of Sertoli cell dysfunction. However, serum levels of $\mathrm{T}$ and $\mathrm{LH}$ were high normal suggesting an altered pituitary-gonadal set point. Our findings are in contrast with two recent studies on $\mathrm{KS}$ infants in which decreased serum $\mathrm{T}$ levels were reported.

P02-645 Testes and Androgens

Inhibin B measurement to differentiate hypogonadotropic hypogonadism from pubertal delay in male adolescents

Estelle Biette'; Najiba Lahlou' ${ }^{2}$; Natacha Bouhours-Nouet ${ }^{1}$;

Frédérique Gatelais ${ }^{1}$; Régis Coutant ${ }^{1}$

1 University Hospital, Pediatric Endocrinology, Angers, France;

2Saint Vincent de Paul Hospital, Pediatric Hormonology, Paris, France

Background: In the male, inhibin B is produced chiefly by the Sertoli cells of the testes. In adults, serum levels of inhibin B seem to be a good marker of Sertoli cell function.

Objective and Hypotheses: The aim of the present study was to evaluate whether serum inhibin B measurement may distinguish patients with constitutional delay of puberty from patients with congenital hypogonadotopic hypogonadism.

Population and Methods: 33 boys with delayed puberty (no development of secondary sexual characteristics $>14$ y) were studied: 23 had constitutional delay of puberty (CDP) (ascertained by the completion of puberty at a later age) and 10 had hypogonadotropic hypogonadism $(\mathrm{HH})$ (4 with multiple pituitary hormone deficiencies, 1 with Kallmann syndrome, and 5 with no development of secondary sexual characteristics, bone age $>14$ years, testosterone $<0.3$ $\mu \mathrm{g} / \mathrm{l}$, and low basal FSH and LH levels). Inhibin B (INHB) was measured by an enzyme immunometric assay using Oxford Bio-Innovation reagents (Argene Biosoft, Varilhes, France)

Results: Mean age was $15.2 \pm 2.3$ years and mean INHB level was $112 \pm 73$ $\mathrm{pg} / \mathrm{mL}$. INHB levels were $126 \pm 64 \mathrm{pg} / \mathrm{mL}$ in the 23 boys with CDP and $63 \pm$ $79 \mathrm{pg} / \mathrm{mL}$ in the 10 subjects with HH. At a threshold of $50 \mathrm{pg} / \mathrm{mL}$, specificity and sensitivity of INHB measurement for the diagnosis of $\mathrm{HH}$ was $78 \%$ and $70 \%$, respectively.

Conclusions: INHB measurement may be a useful tool to differentiate constitutional delay of puberty from hypogonadotropic hypogonadism.

\section{P02-646 Testes and Androgens \\ Serum inhibin B levels in CAH affected newborns and healthy infants with high 170HP at CAH screening}

Silvia Perlini; Paolo Cavarzere; Marta Camilot; Francesca Teofoli; Luciano Tatò

University of Verona, Mother and Child,Biology-Genetics,Div.

Pediatrics, Verona, Italy

The hypothalamic-pituitary-gonadal axis is transiently activated during the first months of life with a rise in gonadotropins, inhibin B and testosterone levels in males. The childhood production by Sertoli cells of inhibin B is clearly regulated by gonadotropins, becoming germ-cells' dependent during puberty. As the matter of fact, in adults inhibin B is considered a marker of fertility. For this reason, serum inhibin B in newborns affected by congenital adrenal hyperplasia $(\mathrm{CAH})$ is particularly valuable in view of recent reports evidencing a high rate of infertility in classical $\mathrm{CAH}$.

The aim of the study is to investigate the serum levels of inhibin B, in the first six months of life, in male newborns affected by the classic form of CAH, and to compare them to the levels of inhibin B of healthy infants with a hyper17-OHP-nemia at neonatal screening. 12 full term newborns with a hyper-17- 
OHP-nemia and $1 \mathrm{CAH}$ affected newborn (born at 40 week of gestational age, birth weight: $2900 \mathrm{~g}$ ) were recruited and serum determinations (means \pm SD) at 1,3 and 6 months of life are reported in the following table. Control values are taken from literature either as mean $\pm \mathrm{SD}$ or as min-max range. 17-OH-progesterone, FSH, LH and testosterone were measured by Immunolite 2000 analyzer. Serum inhibin B was measured by a specific ELISA test (DSL, Texas,USA).

\begin{tabular}{|c|c|c|c|c|c|c|}
\hline & $\begin{array}{l}\text { Months } \\
\text { of life }\end{array}$ & $\begin{array}{l}\text { 17OHP } \\
(\mathrm{nmol} / \mathrm{L})\end{array}$ & $\begin{array}{l}\text { Inhibin B } \\
\text { (ng/L) }\end{array}$ & $\begin{array}{l}\text { Testo- } \\
\text { sterone } \\
\text { (ng/mL) }\end{array}$ & $\begin{array}{l}\text { FSH } \\
(\mathrm{U} / \mathrm{L})\end{array}$ & $\begin{array}{l}\mathrm{LH} \\
(\mathrm{U} / \mathrm{L})\end{array}$ \\
\hline $\begin{array}{l}\text { Iper- } \\
17 O H P \\
\text { non } \\
\text { CAH } \\
(n=12)\end{array}$ & 1 & $\begin{array}{l}40.36 \\
\pm 28.1(6.1 \\
\pm 2.4)\end{array}$ & $\begin{array}{l}124.90 \\
\pm 47.1 \\
(361 \\
\pm 93)\end{array}$ & $\begin{array}{l}2.39 \\
\pm 0.9 \\
(2.10 \\
\pm 1.30)\end{array}$ & $\begin{array}{l}1.44 \\
\pm 0.9 \\
(1.48 \\
\pm 0.55)\end{array}$ & $\begin{array}{l}4.15 \\
\pm 2.1 \\
(2.95 \\
\pm 1.28)\end{array}$ \\
\hline $\begin{array}{l}\text { Iper- } \\
17 O H P \\
\text { non } \\
\text { CAH } \\
(n=12)\end{array}$ & 3 & $\begin{array}{l}12.25 \\
\pm 6.9(6.1 \\
\pm 2.4)\end{array}$ & $\begin{array}{l}223.10 \\
\pm 65.3 \\
(254-513)\end{array}$ & $\begin{array}{l}1.30 \\
\pm 0.3 \\
(1.83- \\
6.54)\end{array}$ & $\begin{array}{l}1.55 \\
\pm 0.8 \\
(0.90 \\
-2.93)\end{array}$ & $\begin{array}{l}2.40 \\
\pm 1.3 \\
(0.90 \\
-2.64)\end{array}$ \\
\hline $\begin{array}{l}\text { Iper- } \\
17 \mathrm{OHP} \\
\text { non } \\
\text { CAH } \\
(\mathrm{n}=12)\end{array}$ & 6 & $\begin{array}{l}3.69 \\
\pm 1.3 \\
(1.6 \pm 1) \\
\text { (outlier:54) }\end{array}$ & $\begin{array}{l}238.50 \\
\pm 7.8 \\
(204-427)\end{array}$ & $\begin{array}{l}0.16 \\
\pm 0.2 \\
(<0.23)\end{array}$ & $\begin{array}{l}0.84 \\
\pm 0.5 \\
(0.29 \\
-1.78)\end{array}$ & $\begin{array}{l}0.70 \\
\pm 0.3 \\
(0.16 \\
-1.07)\end{array}$ \\
\hline $\begin{array}{l}\mathrm{CAH} \\
(n=1)\end{array}$ & 1 & $\begin{array}{l}696(6.1 \\
\pm 2.4)\end{array}$ & $\begin{array}{l}144.6 \\
(361 \pm 93)\end{array}$ & $\begin{array}{l}18.09 \\
(2.10 \\
\pm 1.30)\end{array}$ & $\begin{array}{l}<0.1 \\
(1.48 \\
\pm 0.55)\end{array}$ & $\begin{array}{l}<0.1 \\
(2.95 \\
\pm 1.28)\end{array}$ \\
\hline $\begin{array}{l}\mathrm{CAH} \\
(n=1)\end{array}$ & 3 & $\begin{array}{l}8.1 \\
(6.1 \\
\pm 2.4)\end{array}$ & $\begin{array}{l}258.9 \\
(254-513)\end{array}$ & $\begin{array}{l}0.1 \\
(1.83- \\
6.54)\end{array}$ & $\begin{array}{l}1.7 \\
(0.90 \\
-2.93)\end{array}$ & $\begin{array}{l}0.6 \\
(0.90 \\
-2.64)\end{array}$ \\
\hline $\begin{array}{l}\mathrm{CAH} \\
(n=1)\end{array}$ & 6 & $\begin{array}{l}2.55 \\
(1.6 \\
\pm 1)\end{array}$ & $\begin{array}{l}120.3 \\
(204-427)\end{array}$ & $\begin{array}{l}0.1 \\
(<0.23)\end{array}$ & $\begin{array}{l}0.4 \\
(0.29 \\
-1.78)\end{array}$ & $\begin{array}{l}0.1 \\
(0.16 \\
-1.07)\end{array}$ \\
\hline
\end{tabular}

Serum inhibin B levels of subjects with high 17-OHP concentrations, either healthy or $\mathrm{CAH}$ affected, are lower than control ranges of literature particularly at the first month of life.

As far as comparison between the $\mathrm{CAH}$ positive subject and false positives at the screening for $\mathrm{CAH}$ : at 3 months of life $\mathrm{CAH}$ patient still exhibits higher testosterone level $(\mathrm{p}=0.008)$, whereas at 6 months of age inhibin $\mathrm{B}$ concentrations of false positives statistically exceed the serum level of the CAH positive subject $(\mathrm{p}<0.001)$.

\section{P02-647 Testes and Androgens \\ Apolipoprotein D (ApoD) is an androgen- regulated gene in normal male scrotal fibroblasts \\ Mahesh Appari'; Brigitte Karvelis'; Gila Hohmann ${ }^{1}$; Gunnar Cario'; Ralf Werner'; ${ }^{2}$ Olaf Hiort'; Felix Riepe'; Paul-Martin Holterhus ${ }^{1}$ 1 University Hospital Schleswig-Holstein, Kiel, Department of Pediatrics, Kiel, Germany; ${ }^{2}$ University Hospital Schleswig-Holstein, Lübeck, Department of Pediatrics, Lübeck, Germany}

Characterization of individual androgen receptor (AR) function has not yet been solved in androgen insensitivity syndrome (AIS). We have observed that male foreskin fibroblasts are transcriptionally inactive in vitro in response to androgen despite AR-expression. We hypothesized that (1) promoters of AR target genes might have been methylated during morphogenesis inhibiting activation by AR and / or (2) androgen resistance of normal male cells might be restricted to foreskin fibroblasts and not necessarily be present in cells from other genital locations. We aimed at analyzing androgen mediated gene transcription in normal scrotal fibroblasts in the presence and absence of the demethylating agent 5'-azadeoxycytidine (AZA) by genome-wide gene expression analysis. Two normal male scrotum-derived fibroblast strains (S4, S15) and one CAIS-labia majora strain (Arg855Cys, no androgen binding) were cultured. Cells were treated with $10 \mathrm{nM}$ dihydrotestosterone (DHT) or with DHT $+2 \mu \mathrm{g} / \mathrm{ml}$ AZA for $14 \mathrm{~d}$ while reaching confluency. Total RNA of treated and untreated samples was labeled using different fluorescent dyes and competitively hybridized to microarrays with 32,000 human genes.
Results were confirmed by hybridizations against a common reference RNA. Expectedly, overall response of scrotal cells was weak and variable. However, ApoD was consistently upregulated in the two scrotum strains in the presence of DHT (S4:4.4 fold+-2.4; S15:4.0-fold+-0.4) or DHT + AZA (S4:5.1-fold+0.3; S15:5.2-fold+-0.8). AZA treatment alone did neither induce nor repress ApoD. Neither treatment lead to changes of ApoD in the CAIS-experiments. We conclude that ApoD - a documented androgen regulated gene in prostate cancer - is androgen regulated in scrotum fibroblasts. Absence of androgen responsiveness of ApoD transcription in the CAIS strain supports ARspecificity. Therefore, ApoD may be a future marker reflecting individual functional competence of AR in patients with presumed or proven AIS.

\section{P02-648 Testes and Androgens \\ INSL3 levels in cord blood and 3-months serum samples from normal and cryptorchid boys} Katrine Bay'; Helena E Virtanen ${ }^{2}$; Katharina M Main ${ }^{1}$;

Niels E Skakkebaek'; Jorma Toppari'; Anna-Maria Andersson ${ }^{1}$

'University Hospital of Copenhagen, Department of Growth and Reproduction, Copenhagen, Denmark; ${ }^{2}$ University of Turku,

Departments of Physiology and Paediatrics, Turku, Finland

The Leydig cell hormone insulin-like factor 3 (INSL3) is a sensitive marker for Leydig cell function and is according to animal studies involved in testicular descent and germ cell protection. INSL3 serum levels were analysed in infant boys included in a prospective cohort study of abnormalities in male reproductive organs in Finnish boys. Blood samples were taken at 3-months age and, for some, also at birth (cord blood).

INSL3 levels were correlated to testicular position at both time points INSL3 levels are presented in the table. In cord blood, healthy boys (controls) had significantly higher INSL3 levels as compared to those cryptorchid at birth but with spontaneous testicular descent before 3-months age (recovered) $(\mathrm{P}=0.032)$ and as compared to boys cryptorchid both at birth and at 3 months (cryptorchid) ( $\mathrm{P}=0.001)$ (Mann-Whitney). Individual INSL3 levels did not change between birth and 3 months in controls, whereas a significant increase was observed with time in recovered $(\mathrm{P}=0.02)$ and cryptorchid $(\mathrm{P}=0.01)$ boys (Wilcoxon). At 3 months, there was no statistically significant difference in INSL3 levels between the groups. However, a positive correlation between INSL3 and LH was detected in control boys, whereas the INSL3/LH ratio was significantly reduced in cryptorchid versus control boys $(\mathrm{P}=0.005)$ (Mann Whitney).

\begin{tabular}{llll}
$\begin{array}{l}\text { INSL3 }(\mathrm{ng} / \mathrm{ml}) \\
\text { serum levels }\end{array}$ & & & \\
\hline median (range) & controls & recovered & cryptorchid \\
\hline Cord blood & $\mathrm{N}=20$ & $\mathrm{~N}=21$ & $\mathrm{~N}=20$ \\
& 0.13 & 0.09 & 0.08 \\
& $(<0.05-0.34)$ & $(<0.05-0.23)$ & $(<0.05-0.31)$ \\
\hline 3 months age & $\mathrm{N}=100$ & $\mathrm{~N}=28$ & $\mathrm{~N}=51$ \\
& 0.13 & 0.13 & 0.11 \\
& $(<0.05-0.60)$ & $(<0.05-0.37)$ & $(<0.05-0.30)$
\end{tabular}

At birth, INSL3 levels are reduced in undescended testes, pointing to a slightly impaired Leydig cell function in affected testes. The postnatal transient gonadotropin surge is, however, capable of driving INSL3 production from the affected Leydig cells, as suggested by the INSL 3 increase towards normal levels in recovered and cryptorchid boys between birth and 3 months, though with a reduced INSL3/LH ratio in 3-month-old cryptorchid boys. 
P02-649 Testes and Androgens

IGFBP-3 is an autocrine/paracrine regulator of Leydig cell survival and steroidogenesis in the rat testis

Eugenia Colón; Christine Carlsson-Skwirut; Konstantin Svechnikov; Olle Söder

Karolinska Institutet, Department of Woman and Child Health,

Stockholm, Sweden

Leydig cell function is regulated by the pituitary gonadotropin luteinizing hormone and paracrine factors in the testis. Also other hormones affect Leydig cells, among which members of the growth hormone - insulin-like factor-I axis are of particular interest both as endocrine and paracrine mediators at the onset of puberty and under certain metabolic conditions. We investigated the role of IGF binding proteins (IGFBPs) and particularly IGFBP-3 for Leydig cell function in the rat testis during postnatal development. Immunohistochemical and ligand blot analyses revealed that IGFBP-2,-3,-4 are expressed by testicular cells, including Leydig cells, from postnatal day 20 in rats and show increased levels in adult animals. When added to primary cultures of 40-day-old (pubertal) rat Leydig cells IGFBP-3 was found to induce apoptosis and reduce DNA synthesis under basal conditions in vitro. Further, IGFBP-3 was also found to inhibit IGF-I stimulated steroidogenesis and to counteract the anti-apoptotic action of IGF-I on Leydig cells in culture. IGF-I alone stimulated secretion of IGFBP2,-3,-4 into the culture medium of Leydig cells in vitro and similar effects were observed by tumor necrosis factor-á (TNFá ) alone. However, when added together, IGF-I reduced the TNFá induced increased secretion of IGFBPs, indicating that IGF-I can protect Leydig cells from TNFá mediated apoptosis. These data provide evidence that an autocrine/paracrine IGF/IGFBP circuit is operative in the testis fine-tuning Leydig cell function. This circuit may also be involved in the protection of testicular function(s) from cytokine-mediated inflammation damage.

\section{P02-650 Testes and Androgens \\ Failure and success? Two ways of management of a patient with LH-independent sexual precocity; a case report}

Maria Kalina'; Annette Richter-Unruh'; ; Barbara Kalina-Faska';

Aleksandra Januszek-Trzciakowska'; Ewa Malecka-Tendera ${ }^{1}$

${ }^{1}$ Medical University of Silesia, Pediatrics, Pediatric Endocrinology

and Diabetes, Katowice, Poland; ${ }^{2}$ Endokrinologikum, Pediatric

Endocrinology, Bochum, Germany

Male LH-independent sexual precocity caused by Leydig cell tumours and Leydig cell hyperplasia is due to a somatic activating mutation of the luteinizing hormone receptor (LHR).

In a 6 -year old boy with precocious puberty (P2A1G2), bone age accelerated by 2 years, asymmetry in testicular volume (right $4 \mathrm{ml}$, left $2 \mathrm{ml}$ ), penis length of $6 \mathrm{~cm}$ and height $+0,64 \mathrm{SD}$, (deviation from the mid-parental height +3.64 SD) an ultrasound (Acuson $128 \mathrm{XP}$, linear probe $7.5 \mathrm{MHz}$, colour Doppler) showed an oval, hyperechogenic area $(8.1 \times 8.7 \mathrm{~mm})$ in the right testis. Hormonal evaluation revealed elevated testosterone in serum, mildly increased urine excretion of androgen metabolites with low serum LH level. Biopsy sample was taken from the most suspicious area and histopathological examination revealed Leydig cell hyperplasia. The surgeons decided to perform right orchidectomy. Genomic DNA was extracted from a Leydig cell nodule but sequencing of the LHR gene showed no somatic activating mutation. In addition, Leydig cells from a nodule were picked by micro dissection, pooled, DNA extracted and exon 11 of the LHR gene sequenced. No mutation could be found. Two years later, there was progression of puberty and ultrasound visualised an analogous lesion in the left testis. This time it was decided just to monitor the patient strictly as hormonal levels were within the normal range. Once the boy entered physiological puberty, the lesion "dissolved" and gradually gained homogenous ultrasound echo of the testicular tissue. The patient is now 10 years old (P3G3, left testis $8 \mathrm{ml})$, with normal growth rate and sustained 2-year acceleration of the bone age. We conclude that in contrast to isolated Leydig cell tumours which should be surgically removed, management in Leydig cell hyperplasia is a matter of discussion. Invasive and potentially unnecessary procedures could be avoided due to strict monitoring of the affected boys.

P03-651 Sex Differentiation

A rare association: agonadism and atypical form of Rokitansky syndrome with a normal female karyotype

Filiz Mine Cizmecioglü ; Elif Aydiner ${ }^{1}$; Gurler Akpinar²; Sukru Hatun ${ }^{1}$ ${ }^{1}$ Kocaeli University of Medical School, Pediatric Endocrinology and Diabetes, Kocaeli, Turkey; ${ }^{2}$ Kocaeli University of Medical School,

Molecular genetics, Kocaeli, Turkey

Ovarian function and structure are usually normal in Mayer-RokitanskyKüster-Hauser (MRKH) syndrome. Reports of agonadism are usually associated with a 46,XY karyotype. We report an exceptional association between bilateral ovarian agenesis 46,XX and MRKH syndrome. An endocrine study including pituitary, ovarian, adrenal and thyroid evaluation was performed. Genetic study was done by karyotype and polymerase chain reaction $(\mathrm{PCR})$ to detect the presence of $\mathrm{Y}$ chromosome material. Pelvic ultrasound and magnetic resonance imaging (MRI) were made to evaluate the internal genitourinary system.

Patient: A 14,5 years old girl who presented with primary amenorrhea. She reported a complete lack of breast development, although she had observed pubic and axillary hair in the past 9 months. There was no consanguinity of parents and other family members with primary amenorrhea. Anthropometric parameters and psychomotor development were normal. There were no physical features except slightly webbed neck and increased number of nevus. The secondary sexual characteristics assessment showed axillary hair stage 3 , pubic hair stage 4 and breast stage 1 (Tanner). Prepubertal external genitalia and normal vagina ending in a blind pouch were found at the gynaecological exam. The endocrinological evaluation revealed a hypergonadotropic hypogonadism (FSH 99.1mIU/ml, LH $18.2 \mathrm{mIU} / \mathrm{ml}$ ). A pelvic sonography and MRI confirmed absence of internal genitalia and gonads. Cytogenetic studies on peripheral blood lymphocytes showed a 46,XX karyotype in the analysis of 100 metaphases. PCR was negative for SRY gene. She was diagnosed as MRKH with bilateral ovarian agenesis and oral conjugated estrogen was begun.

Gonadal disgenesis with a 46,XX chromosome complement is an extremely rare event. The association of MRKH with agonadism suggests the presence of a primitive undifferentiated gonad that secretes antimüllerian hormone in early stages of embriyogenesis, but this hypothesis is difficult to accept with no genosome $\mathrm{Y}$ in the chromosome.

\section{P03-652 Sex Differentiation \\ Altered transcription profiles of key-enzymes of androgen biosynthesis in genital skin fibroblasts from patients with hypospadias Ute Hoppe ${ }^{1}$; Lutz Wünsch'; Paul-Martin Holterhus ${ }^{3}$; Dieter Jocham; Annette Richter-Unruh ${ }^{5}$; Olaf Hiort ${ }^{1}$ \\ 'University of Luebeck, Department of Pediatric and Adolescent Medicine, Luebeck, Germany; 2University of Luebeck, Department of Pediatric Surgery, Luebeck, Germany; ${ }^{3}$ University of Kiel, Department of Pediatrics, Kiel, Germany; ${ }^{4}$ University of Luebeck, Department of Urology, Luebeck, Germany; ${ }^{5}$ Endokrinologikum Ruhr, Pädiatrische Endokrinologie, Wattenscheid, Germany}

Normal synthesis and action of androgens is essential for normal male sex differentiation. 17ß-hydroxysteroid dehydrogenases and 5alpha-reductase isoenzymes play essential roles in normal androgen biosynthesis. We hypothesized that differences in expression of these enzymes in genital skin could contribute to the pathogenesis of hypospadias. We investigated the mRNA - transcription patterns of 17ß-hydroxysteroid dehydrogenasesisoenzymes type $1,2,3,4,5,7$, and 10,5alpha-reductase type 1 , and 2 and the androgen receptor in genital skin fibroblasts from foreskin and scrotal skin obtained from healthy males and patients with hypospadias. Fibroblasts were cultured from biopsies obtained at surgery. The mRNA expression was semiquantified by Real-time polymerase chain reaction employing the LightCycler system. Although no systematic differences of gene expression of any enzyme between normal controls and hypospadias patients could be detected, our results showed noticeable differences in the transcription profiles of some of the patients' samples. Especially for the 17ß-hydroxysteroid dehydrogenase type 5 we found altered transcription profiles in nearly half of all investigated patients' samples. In scrotal skin samples of hypospadias patients a significantly higher transcription of the androgen receptor was detected. Our 
data indicate the existence of an age specific shift in the transcription pattern of the 17ß-hydroxysteroid dehydrogenase type 5 between hypospadias and control samples. A role for an altered expression pattern of different enzymes of steroidogenesis in the etiology of genital malformations in some patients may be postulated.

\section{P03-653 Sex Differentiation \\ Heterozygous SF1 mutation with a male- oriented phenotype in a $46 X Y$ patient}

Sonia Dahan ${ }^{1}$; Iva Gueorguieva' ${ }^{1}$; Jacques Weill'; Yves Morel2;

Maryse Cartigny-Maciejewski ${ }^{1}$

'Lille University Hospital, Paediatric Endocrine Unit, Lille, France;

${ }^{2}$ Debrousse Lyon University Hospital, Laboratory of Biochemistry and

Genetics of Steroid, Lyon, France

$\mathrm{SF} 1$ is an orphan nuclear receptor that regulates the transcription of an array of genes involved in many stages of reproduction: male differentiation, steroidogenesis and gonadotrope differentiation. First case reported of SF1 mutation (1999) presented with a perfectly female phenotype.

Since then, several mutations of SF1 gene have been discovered within patients with XY karyotype presenting gonadal dysgenesis with a predominantly female phenotype. Primary adrenal failure constitutes another feature,either isolatedly or in association with gonadal dysgenesis.

Here we report a case of a phenotypically clearly, but uncompletely, masculinized patient with hemizygous SF1 mutation. Although the prenatal ultrasound exam indicated a female genital apparence, he presented at birth with hypospadias, micropenis $(25 \mathrm{~mm}$ length), scrotal transposition but with testes located in the scrotum .No mullerian structure was found at the postnatal ultrasound exam. According to his phenotype he was male- oriented and surgeons performed a phalloplasty. Endocrinologically, undetectable basal testosterone level at 10 weeks of age attested gonadal dysfunction and an undetectable LH peak under Gn RH stimulation indicated the participation of a gonadotropic failure. However, a long-term hCG stimulation test (7X1500 U) with a poor testosterone response $(0.68 \mathrm{ng} / \mathrm{ml})$ and low plasma Sertolian markers (Antimullerian hormone:16 $\mathrm{ng} / \mathrm{ml}$ and Inhibin B:53 pg/ml) demonstrated the coexistence of a gonadal dysgenesis .ACTH levels and Cortrosyn test did not evidence primary adrenal insufficiency Genetic studies showed a normal $46 \mathrm{XY}$ karyotype and a monoallelic SF1 gene mutation : IVS3 $+1 \mathrm{G}>\mathrm{T}$ in intron 3 .

In conclusion, this patient presents the more virilized described case of SF1 mutation, at our knowledge.In addition to gonadal dysgenesis, he suffers from gonadotrope failure. The absence of adrenal failure is attributable to hemizygoty of the mutation.

\section{P03-654 Sex Differentiation \\ Identification of a G146A substitution within the SF1 gene in two patients with congenital bilateral anorchia: gene polymorphism or mutation?}

Pascal Philibert ${ }^{1}$; Felicien Mbou ${ }^{2}$; Françoise Audran ${ }^{3}$; Françoise Paris ${ }^{4}$; Charles Sultan ${ }^{4}$

${ }^{1} \mathrm{CHU}$ and INSERM Montpellier, Hormonologie, Montpellier, France; ${ }^{2} \mathrm{CHG}$ Lamentin, Martinique, Pediatry and Neonatalogy, Lamentin, France; ${ }^{3} \mathrm{CHU}$ Montpellier, Hormonologie, Montpellier, France; ${ }^{4} \mathrm{CHU}$ and INSERM Montpellier, Hormonologie et Endocrinologie Pédiatrique, Montpellier, France

Bilateral anorchia, the absence of testicular tissue in $46, \mathrm{XY}$ children, is associated with a male phenotype. It may result from mechanical problems leading to vanishing testes in late foetal life or the neonatal period.

Mutational analysis of SRY, a key factor involved in testes determination, has been negative. No mutation in the genes involved in testicular migration (INSL3 and its receptor, LGR8) has been identified so far. SF1 is considered to be a master regulator of the reproductive system because it regulates the expression of a large array of genes required for endocrine gland development and hormone synthesis. SF1 is involved in most of the enzymatic steps leading to testosterone synthesis and in the regulation of AMH and INSL3 gene expression.
The G146A SF1 gene polymorphism has been associated with cryptorchidism and micropenis in a Japanese population.

We had the opportunity to analyse DNAs from two 46, XY children with bilateral anorchia and micropenis. Plasma testosterone after HCG stimulation test was below $0.3 \mathrm{nmol} / \mathrm{l}$. SRY and WT1 gene sequences were normal. The reported decreases in in vitro transcriptions of the CYP11A and CYP19 genes suggest that this amino-acid substitution is responsible for the observed phenotype. It should, however, be noted that this substitution was found in some of the control individuals.

The association of this G146A abnormality in two patients with bilateral anorchia and micropenis is in favour of a mutation rather than a gene polymorphism.

\section{P03-655 Sex Differentiation \\ Progressive postpubertal loss of gonadal function in an Indian male pseudohermaphrodite with 5 alpha reductase 2 gene mutation}

A.C. Ammini'; M Eunice'; Bindu Kulshreshtha ${ }^{1}$; Francoise Audran ${ }^{2}$; Pascal Philibert ${ }^{2}$; ML Khurana'; E.P Praveen ${ }^{1}$; Charles Sultan ${ }^{2}$

${ }^{1}$ All India Institue of Medical Sciences, Endocrinology and Metabolism, Delhi, India; ${ }^{2}$ Hopital Lapeyronie, Montpellier, Hormonologie,

Montpellier, France

Reproductive ageing in men is a poorly understood phenomenon. A progressive decline in both testosterone and DHT has been associated with andropause. The gonadal function in men with 5 alpha reductase deficiency is known to be subnormal. However, little is known of the long-term effects of this disorder on the reproductive endocrine axis. Here, we present a male pseudohermaphrodite with 5 alpha reductase deficiency, who had a progressive reduction of sperm counts from puberty till age 25 years This case reared as a female presented at age 11 years with a discordant male gender identity. Examination revealed perineoscrotal hypospadias. Male specific pubertal changes occured around age 16-17 years. Hormonal details are given in TABLE 1.

\begin{tabular}{|c|c|c|c|c|c|c|c|c|}
\hline $\begin{array}{l}\text { Age } \\
\text { (yrs) }\end{array}$ & $\begin{array}{l}\text { Basal } \\
\mathrm{T}(\mathrm{ng} / \\
\text { dl) }\end{array}$ & $\begin{array}{l}\text { Basal } \\
\text { DHT } \\
\text { (ng/dl) }\end{array}$ & $\begin{array}{l}\text { Basal } \\
\text { T: DHT }\end{array}$ & $\begin{array}{l}\text { Post } \\
\text { hCG } \\
\text { T(ng/ } \\
\text { dl) }\end{array}$ & $\begin{array}{l}\text { Post } \\
\text { hCG } \\
\text { DHT } \\
\text { (ng/dl) }\end{array}$ & $\begin{array}{l}\text { Post } \\
\text { hCG T: } \\
\text { DHT }\end{array}$ & $\begin{array}{l}\mathrm{LH} \\
\text { (U/L) }\end{array}$ & $\begin{array}{l}\text { FSH } \\
\text { (U/L) }\end{array}$ \\
\hline 18 & 660 & 17 & 37.5 & 800 & 22 & 36.4 & 7.3 & 9.0 \\
\hline
\end{tabular}

Genetic analysis revealed a R246Q mutation in the fifth exon of the 5 alpha reductase gene. Surgery was performed at age 18 years to correct the hypospadias. Semen analysis at this age revealed a sperm count of 60 million $/ \mathrm{ml}$. There was a further reduction in sperm counts to 12 million / $\mathrm{ml}$ at age 21 years.

\begin{tabular}{lllll} 
Age $(\mathrm{yrs})$ & $\begin{array}{l}\text { Semen } \\
\text { Volume }(\mathrm{ml})\end{array}$ & Sperm count & motility & $\begin{array}{l}\text { morphology } \\
\text { (\%abnormal) }\end{array}$ \\
\hline 18 & 1 & $60 \mathrm{million} / \mathrm{ml}$ & $35 \%$ active & $5 \%$ abnormal \\
21 & 0.5 & $12 \mathrm{million} / \mathrm{ml}$ & $10 \%$ active & $41 \%$ abnormal \\
25 & \multicolumn{5}{c}{ azoospermia } & \\
\hline
\end{tabular}

He married at age 22 years and presented with infertility at age 25 years. The semen analysis done at this age revealed azoospermia, LH and FSH levels had risen to 28.6 and $36.9 \mathrm{U} / \mathrm{L}$ respectively. It is possible that the programming of reproductive ageing in men has origins as early as the antenatal years. A sequentially organized pattern of hormonal contribution during the antenatal period (by testosterone, DHT, estrogens and steroid precursors) may govern not only the genital differentiation and pubertal sexual spurts but also andropause. When this orchestration is disrupted as in patients with 5 alpha reductase deficiency, an early andropause may ensue. In conclusion, this was a rare case of a 5 alpha reductase 2 deficiency who had a progressive loss of gonadal function with advancing age. This case possibly points to a role of DHT in reproductive endocrine aging and highlights the need for the establishment of sperm banks at an early age in patients with 5 alpha reductase deficiency. 
P03-656 Sex Differentiation

Peripubertal male transsexualism in a patient with complete androgen insensitivity syndrome M Eunice $^{1}$; Bindu Kulshreshtha ${ }^{1}$; Pascal Philibert2; Francoise Audran ${ }^{2}$; ML Khurana'; E.P Praveen ${ }^{1}$; M Mehta ${ }^{1}$; R Sagar ${ }^{1}$; AC Ammini ${ }^{1}$; Charles Sultan ${ }^{2}$

${ }^{1}$ All India Institute of Medical Sciences, Endocrinology and Metabolism, Delhi, India; ${ }^{2}$ Hopital Lapeyronie, du Developpement et de la Reproduction, Montpellier, France

The sex of rearing in an intersex individual is usually governed by the external phenotype and future prognosis for pubertal development, reproduction and gender identity. Social and cultural factors peculiar to a region may sometimes defy these scientific logics. We report here a case of CAIS who presented at peripuberty with a gender identity discordant with the female phenotype. This 11 year old child was the youngest sister of five siblings - eldest brother followed by three younger sisters. One year back, laparatomy was done for bilateral inguinal swellings. Bilateral testicular tissue and found on exploration and the patient was referred to this hospital. The child was accompanied by her father and brother at the first visit. They expressed their desire to rear the child as a male, the patient herself appeared uncommunicative. They insisted that they had always observed a male pattern of behaviour since her early childhood which was quite distinct from her elder sisters. Examination revealed a complete female phenotype with no development of secondary sexual characters ( A1B1 P1). Investigations revealed a pubertal LHRH response and basal testosterone levels of $2.97 \mathrm{ng} / \mathrm{ml}$. A homozygous mutation $\mathrm{M} 749 \mathrm{~V}$ in the LBD of Androgen receptor gene was found on genetic analysis. On careful questioning, mother revealed that during the birth of this child both parents had nursed a strong desire for a male child after three female siblings were born. She had always preferred a male pattern of dressing for the child and took pleasure in seeing a male appropriate behaviour in her. Psychiatric evaluation of the patient revealed a strong motivation to live as a male. The recent disclosure of surgical details had caused them all to strongly voice their opinion.

The divergent attitude of parents and community towards the two sexes in a male dominated society and the clear advantage of being a male may have motivated the child for a male sex. Societal norms and beliefs sometimes dictate the sex of rearing in intersex individuals.

\section{P03-657 Sex Differentiation \\ Mutations in the ligand binding domain of the human androgen receptor and their role for N/C- and coactivator interaction \\ Ralf Werner ${ }^{1}$; Julia Gesing ${ }^{1}$; Jianying Zhan ${ }^{1}$; Dagmar Struve'; Paul-Martin Holterhus'; Olaf Hiort ${ }^{1}$ \\ ${ }^{1}$ UK-SH Campus Luebeck, Dept. Paediatrics and Adolescent Medicine, Luebeck, Germany; '2UK-SH Campus Kiel, Dept. Paediatrics, Kiel, Germany}

We selected mutations within the ligand binding domain (LBD) of the human androgen receptor (AR) leading to partial androgen insensitivity syndrome (PAIS), or complete AIS (CAIS) but having substantial ligand binding. Selected mutations in the hAR-LBD were recreated by site-directed mutagenesis and analysed for their impact on the binding of AR coactivators or on the human AR-N/C-terminal interaction by one- and two-hybrid assays. Some mutations like L712F leading to PAIS showed a complete loss of $\mathrm{N} / \mathrm{C}$-interaction and BAG-1L/ LBD interaction while Q798E, which also leads to variable forms of PAIS exhibits normal N/C and BAG-1L interaction. Nevertheless, in transactivation-assays with full length receptor $\mathrm{L} 712 \mathrm{~F}$ showed an androgenresponsive but reduced transactivation. On the other hand, H917R a mutation leading to CAIS showed a relevant androgen dependent N/C-interaction of $70 \%$ of the wild type AR. A disrupted or substantial N/C interaction could not always be correlated with the CAIS or PAIS phenotype of AR-LBD mutations.

We propose that the development of PAIS or CAIS might also depend on the binding of other developmentally regulated coactivators, which are not bound by activation function 2 (AF2) and are not depending on functional $\mathrm{N} / \mathrm{C}$ interaction, but are influenced by mutations in the LBD.
P03-658 Sex Differentiation

A new case of familial mutation in the SRY gene implicated in the pure gonadal dysgenesis in two sisters and in their unaffected father

Piero Pirazzoli'; Annalisa Nicoletti2; Monia Gennari ${ }^{1}$; Lilia Baldazzi²; Antonio Balsamo ${ }^{1}$; Francesca Mencarellir ; Alessandro Cicognani ${ }^{1}$ ${ }^{1}$ S.Orsola-Malpighi Hospital, University of Bologna, Pediatrics,

Bologna, Italy; ${ }^{2}$ S.Orsola-Malpighi Hospital, Pediatrics, Bologna, Italy

Mutations in the SRY gene have been found to account for approximately $15 \%$ of cases with male to female sex reversal. The majority of the SRY variants are de novo mutations. However, a small subset of these reports describes familial mutations. Paternal mosaicism explain the inheritance but in other cases that couldn't be demonstred. To our knowledge only few familial mutations are localized outside the HMG-box: four at the N-terminal domain and only one at the C-terminal.

We presented a frameshift mutation (Q158fsX180) downstream the HMGbox, (Baldazzi et al., 2003) in a 46XY sex reversal proband presented at $17 \mathrm{yrs}$, referred to us seven years ago because of primary amenorrhoea and virilization signs, such as hirsutism and clitoris enlargement. Disgerminoma/ seminoma in gonadoblastoma were found in her streak gonads, with poorly defined seminiferous tubules. The father did not consent to analysis of his DNA. In 2006 the younger sister (15 yrs old) was referred for primary amenorrhoea.

A 46XY kariotype was discovered. She underwent gonadectomy and a disgerminoma/seminoma in gonadoblastoma was found in her streak gonads. The SRY analysis of the younger sister and their father, who finally accepted to be studied, showed the same mutation carried by the oldest one. The father presented normal male genitalia and normal testes at ultrasonography. The frameshift mutation (Q158fsX180) is resulting in an altered protein at the Cterminus lacking last 24 residues. The major hypothesis of the altered proteinthe rapid degradation of the truncated protein- could not be verified in vivo and the presence of a stable mutant protein missing its $\mathrm{C}$-terminal region could not be excluded. The other mutation described in this region (L163X) produce a 3 ' truncated protein and was identified as familial mutation: two 46XY sisters with complete gonadal dysgenesis were affected. Both mutations strengthen the case for functional region 3' to the HMG-box in familial form.

\section{P03-659 Sex Differentiation \\ Complete XY gonadal dysgenesis caused by a novel SRY gene mutation}

Desiree Dunstheimer ${ }^{1}$; Olaf Hiort ${ }^{2}$; Ralf Werner2;

Peter Heinrich Heidemann

${ }^{1}$ Klinikum Augsburg, I. Klinik für Kinder und Jugendliche, Augsburg, Germany; ${ }^{2}$ Universitätsklinikum Schleswig-Holstein, Klinik für Kinderund Jugendmedizin, Lübeck, Germany

Normal development and function of Sertoli and Leydig cells are essential for hormone-mediated sex differentiation of the internal and external genitalia in the male. Failure of these specialized cells to develop gives rise to dysgenetic gonads and the clinical disorder XY gonadal dysgenesis (GD), also called Swyer syndrome. Mutations in the SRY gene, which encodes for testis determining factor, a testis specific transcription factor, account for only 10$15 \%$ of $46, \mathrm{XY}$ GD. The majority of SRY mutations are de novo mutations. We report a 16.2 year old phaenotypic female, who was referred with primary amenorrhea and hypergonadotropic hypogonadism. Gynaecological examination showed a normal vagina, a hypoplastic uterus $(4.8 \mathrm{ml})$ and small gonads $(1.6$ and $1.7 \mathrm{ml})$. Despite estrogen therapy for 3 months the patient showed no breast development and did not menstruate. At first presentation we saw a phaenotypic female with tall stature $(180.2 \mathrm{~cm})$ with retarded bone age (13.5 years). FSH and LH concentrations were elevated (82 and $28 \mathrm{mIU} / \mathrm{ml})$, estradiol low $(<20 \mathrm{pg} / \mathrm{ml})$ and testosterone $(0.4 \mathrm{ng} / \mathrm{ml})$ and DHEA-S normal $(127 \mu \mathrm{g} / \mathrm{dl})$. Chromosome analysis with fluorescence in situ hybridization revealed a 46, XY karyotype. Using DNA direct sequencing of the SRY coding region a single nucleotide transversion with subsequent amino acid substitution from proline to arginine at codon 83 was identified. To our knowledge this mutation was not described before, but other cases of complete GD with SRY gene mutations in codons (e.g. 78 or 86 ) close to codon 83 are known. Bilateral laparoscopic removal of the streak gonads was performed and histopathological examination showed a gonadoblastoma on the left side. 
SRY mutations may cause complete XY GD and lead to complete sex reversal and no ambiguity in sex development. There is a high risk of gonadal tumors such as gonadoblastoma. Since SRY mutations are rarely inherited by the father, genetic family investigations are highly recommended.

\section{P03-660 Sex Differentiation \\ Pubertal development of $46, X Y$ DSD patients with partial androgen insensitivity due to mutation of the androgen receptor assigned to male sex}

Silke Steltenkamp; Olaf Hiort

University of Luebeck, Department of Pediatric and Adolescent

Medicine, Luebeck, Germany

Sex assignment in patients with disorders of sex development (DSD) depends mainly on phenotypic appearance and the underlying diagnosis. In partial androgen insensitivity syndrome (AIS) due to mutation of the androgen receptor (AR), prediction of the virilization potential at puberty as well as gender development of the patients is difficult and little data exist. We have followed 15 patients (age range 12;6 to $43 ; 0$ yrs.) with $46, \mathrm{XY}$ DSD due to mutation of the AR with respect to biochemical data and pubertal development.

At the time of presentation, 6 patients had minimal AIS with no overt malformation of the urethra, corresponding to AIS grade 1 (according to Sinnecker). Eight patients were graded as AIS type 2 with hypospadias and bifid scrotum, one patient as AIS type 3 with ambiguous genitalia. Penile length was measured in 12 patients and was 3 to $7 \mathrm{~cm}$. Testicular volume was between $2 \mathrm{ml}$ to $27 \mathrm{ml}$ (in one patient with AIS grade 1). Except for one AIS type 1 patient, all patients had gynecomastia, ranging from B2 to B5. All patient carried point mutations altering the amino acid sequence of the AR. Hormone values were available only partly, with testosterone ranging from 2.08 to $18.35 \mathrm{ng} / \mathrm{ml}$ with $\mathrm{LH}$ from 4.9 to $25.3 \mathrm{mU} / \mathrm{ml}$ and FSH from 2.4 to $74.3 \mathrm{mU} / \mathrm{ml}$. The androgen sensitivity index (T x LH [ng x mU/ml]) could be determined in 11 patients and ranged from 19.55 to 264.24 (reference range $<50)$.

We conclude that outcome in patients with AIS and male sex assignment is highly variable. Clinically, the gynecomastia is most prominent. Penile length is mostly below the normal reference range. Biochemical analysis demonstrates androgen insensitivity, but in some patients secondary testicular atrophy is accounted for with highly elevated FSH and low testicular volume.

\section{P03-661 Sex Differentiation \\ 46,XY disorder of sex development (DSD): management, gender reassignment and initiation of therapy after delayed diagnosis in a feminized male due to 17 alpha- hydrox ylase/17,20-lyase deficiency}

Michael Steigert ${ }^{1}$; Stephanie Rosa ${ }^{2}$; Mariarosaria Lang-Muritano ${ }^{2}$;

Eugen J. Schoenle'; Anna Biason-Lauber ${ }^{2}$

${ }^{1}$ Kantonsspital Graubuenden, Pediatric Endocrinology and

Diabetology, Chur, Switzerland; 'University Children's Hospital Zurich,

Pediatric Endocrinology and Diabetology, Zurich, Switzerland

A 7 week-old infant assigned to female sex at birth was referred for gender evaluation one week before baptism. Physical examination revealed apparent female genitalia with enlarged clitoris, posterior labial fusion and bilateral labial mass. A Disorder of Sex Development (DSD) under-masculinized male was suspected. The parents were advised to delay baptism until gender assignment could be based on medical findings. First line testing revealed male karyotype, confirming diagnosis of 46,XY DSD. Steroid hormone measurements showed low 17OHP, DHEA, androstendione and testosterone concentrations, both basal and after hCG-stimulation, while progesterone and mineralocorticoid precursors were elevated, supporting hypothesis of an androgen synthesis defect and suggesting a 17a-hydoxylase/17,20-lyase deficiency. The diagnosis was genetically confirmed by identification of a CYP17A1 gene compound heterozygosity in exon 6 of the CYP17A1 gene leading to Ile332Thr and Ala355Pro exchanges in the P450c17 protein. The

46th Annual Meeting of the ESPE findings were discussed in a multidisciplinary team. Despite of controversial opinions concerning feasibility of penile construction due to small penis size and reluctance of some caregivers to reassign sex the team finally proceeded to recommend the parents to have their child re-assigned to the male sex, to which they agreed. Challenges in our case were late presentation, leaving a limited time span for potential micropenis therapy, thus requiring a particularly efficient diagnostic procedure; gender re-assignment when knowledge of the patient's former female sex was widespread in the small living community; and initial discordance of involved caregivers concerning gender re-assignment. Rapid diagnosis based on clinical skills and a competent laboratory service, a multidisciplinary team approach, a well established physician-parent relationship and continuous information of the parents leading to parental codetermination under medical guidance permitted rapid gender re-assignment, micropenis treatment and parental satisfaction in a challenging setting.

\section{P03-662 Sex Differentiation \\ Disorders of sex development and human rights: health advocacy \\ Isabel Maria Sampaio Lima'; 'Luciana M B Oliveira Oliveira²; \\ Renata Lago ${ }^{1}$; Kátia Virginia Dórea Almeida²; \\ Maria Betania Pereir Toralles ${ }^{2}$ \\ ${ }^{1}$ Catholic University of Salvador, Law School, Salvador, Brazil; \\ ${ }^{2}$ Federal University of Bahia, Genetics, Bahia, Brazil}

Disorders of sexual development (DSDs) present a great challenge, not only for health teams, but also for children and families, especially in underdeveloped countries. The civil registration of a newborn child means not only a civil right, but also the right of assignment to one gender. The civil society, families and the multidisciplinary team need to act according to human rights to help children with DSDs achieve their rights. The objective of the present study is to analyze the experience of a multidisciplinary team and health advocacy experience to ensure the rights of children with DSDs.

This is a case-study project that describes an experience of health advocacy by a multidisciplinary team in Salvador, Bahia, Brazil. Several procedures were used: participative observation, field reports, semi-structured interviews, focal groups, document analysis and review of literature. A non-governmental organization was created by families of forty-five affected children during 36 months' long work of a multidisciplinary team formed by law professionals, social workers, geneticist, endocrinologists, psychiatrist and psychologist.

Fifty-one families of children with DSDs followed at the Genetics Service of Federal University of Bahia Hospital were interviewed between 2004 and 2005. Sixteen multidisciplinary meetings were held. It was found that the birth of $3,92 \%$ of the patients had not been registered and $7,84 \%$ needed to reassign their gender and change their names in the Birth Certificate. This work shows that, only with integrated actions by different members of the multidisciplinary team and family participation, it was possible to make the necessary changes in the gender assignment of the Birth Certificate and corrections in their civil documents to fit human civil rights to dignity. The organization of a civil association to support these actions was fundamental.

\section{P03-663 Sex Differentiation}

\section{Agenesis of the scrotum in a boy with non-} lethal multiple pterygium syndrome: insight into normal male genital development

Andréa Maciel-Guerra'; Suzana Moraes²; Letícia Beraldo ${ }^{3}$.

Antônia Paula Marques-de-Faria'; Maria Tereza Baptista"; Gil Guerra-Júnior ${ }^{3}$

'State University of Campinas, Medical Genetics, Campinas, Brazil; ${ }^{2}$ Pontifícia Universidade Católica de São Paulo, Morphology and Pathology, Sorocaba, Brazil; ${ }^{3}$ State University of Campinas, Pediatrics, Campinas, Brazil; ${ }^{4}$ State University of Campinas, Internal Medicine, Campinas, Brazil

Agenesis of the scrotum is an extremely rare congenital anomaly with only six cases previously reported. In one of these cases, the child had popliteal pterygium syndrome, an autosomal dominant disorder (OMIM 119500). Nonlethal multiple pterygium syndrome (NMPS) or Escobar syndrome (OMIM 265000) is a rare autosomal recessive disorder characterized by 
webbing (pterygia) of the neck, elbows, and/or knees and joint contractures. Males may have hypospadias and cryptorchidism, while females may exhibit aplasia of the labia majora. We report on a 6-year-old boy with NMPS who had a 5-cm phallus with normal urethral opening and agenesis of the scrotum with a poorly defined midline raphe; the gonads were palpable in the inguinal region. He was the first child of consanguineous parents (first cousins), and there was no family history of similar cases. He had prepubertal FSH and LH levels, and testosterone levels increased after beta-hCG stimulation test, revealing normal Leydig cell function. Agenesis of the scrotum in this case is compatible with the finding of aplasia of the labia majora in some girls with NMPS, indicating that agenesis of the labioscrotal folds may be a feature of its clinical picture. Interestingly, in the case of popliteal pterygium syndrome there were evidences of both agenesis and abnormal migration of the scrotal skin; the link between pterigia (whichever the etiology) and abnormal labioscrotal folds would be an interesting matter for future research.

Moreover, the fact that scrotal agenesis is associated with fused midline raphe raises a question regarding normal male genital development: does dihydrotestosterone lead to fusion of embryonic structures (labioscrotal folds) in the midline to form the scrotum or simply to a fusion of the embryo midline on the genital region?

\section{P03-664 Sex Differentiation \\ Congenital perineal lipoma presenting as ambiguous genitalia in two girls with and without anorectal malformation}

Gil Guerra-Junior'; Adriana Aun ${ }^{1}$; Marcio Miranda'; Leticia Beraldo';

Suzana Moraes ${ }^{3}$; Maria Tereza Baptista;

Antonia Paula Marques-de-Faria ${ }^{5}$; Andrea Maciel-Guerra ${ }^{5}$

${ }^{1}$ State University of Campinas, Pediatrics, Campinas, Brazil; ${ }^{2}$ State

University of Campinas, Pediatric Surgery, Campinas, Brazil; ${ }^{3}$ Catholic

University of Sao Paulo, Morphology and Pathology, Sorocaba, Brazil;

${ }^{4}$ State University of Campinas, Internal Medicine, Campinas, Brazil;

${ }^{5}$ State University of Campinas, Medical Genetics, Campinas, Brazil

Congenital perineal lipoma is extremely rare and appears to be more common in males. The association of perineal lipoma and anorectal malformation was described in a few cases, all males. We report on 2 girls classified erroneously in other service as having ambiguous genitalia. Patient 1 (17-days-old) and patient 2 (2-months) had unremarkable gestational and perinatal history. Both had normal female external genitalia, but patient 1 had a polypoid, protruding $3.0 \times 2.0 \times 1.5 \mathrm{~cm}$ phallic-like mass arising at the inferior border of the left labium majora, and patient 2 a similar mass with $1.5 \times 1.5 \times 1.0 \mathrm{~cm}$ at the same site and imperforate anus. In both cases the mass was removed and found to be a lipoma. Perineal lipoma may be associated with accessory scrotum in rare but well documented cases. Accessory scrotum is always located posterior to the normal scrotum, and is the result of early division of the labioscrotal swelling with subsequent abnormal migration of the inferior portion. Because of its high association with perineal lipoma, it has been suggested that the accessory labioscrotal fold develops as a consequence of intervening mesenchymal tissue that disrupts the continuity of the caudal aspect of the developing labioscrotal swelling. The intervening tissue becomes the lipoma.

To our knowledge an accessory labial fold (homologous of accessory scrotum) leading to a perineal lipoma has been reported only in three cases, all without associated anorectal malformation. The lipomas in our patients are almost identical in size, location and appearance to that of the previously reported cases, and reinforce the explanation above. The association of perineal lipoma and imperforate anus in a girl is being described on the first time and its origin remains obscure.

\section{P03-665 Sex Differentiation \\ Comparison of basal anti-Müllerian hormone values and testosterone levels after hCG stimulation in prepubertal patients with disorders of sex development and cryptorchidism}

Maria Szarras-Czapnik'; Marzena Gajewska ${ }^{1}$;

Janusz Benedykt Ksiazyk'; Roman Janas²; Maria Ginalska-Malinowska'

The Childrens Memorial Health Institute, Department of

Endocrinology, Warsaw, Poland; ${ }^{2}$ The Childrens Memorial Health

Institute, Department of Radioimmunology, Warsaw, Poland

In prepubertal patients basal levels of testosterone are very low and testicular function should be assessed in hCG stimulation test. AS in males antiMüllerian hormone (AMH) is produced by testes from fetal life to puberty, measurements of basal serum AMH levels can be useful in diagnosis of patients with disorders of sex development (DSD).

The aim of the study was to compare the serum AMH levels with testosterone levels after hCG stimulation in patients with DSD and cryptorchidism. Basal serum AMH levels we assessed in 79 prepubertal patients with: gonadal dysgenesis $(n=23)$, partial androgen insensitivity $(n=4)$, scrotal hypospadias $(n=16)$, bilateral cryptorchidism $(n=20)$, anorchia $(n=10)$ and unilateral cryptorchidism $(n=6)$. HCG tests were performed (one dose of $2000 \mathrm{IU} / \mathrm{m} 2$ i.m.) and testosterone levels were determined.

AMH level was not impaired in patients with unilateral cryptorchidism and partial androgen insensitivity (median $350 \mathrm{pmol} / \mathrm{l}$ ). In these subjects normal testosterone values after $h C G$ were found. Significant differences were observed between AMH levels in boys with hypospadias (median $317 \mathrm{pmol} / \mathrm{l}$ ) and the patients with gonadal dysgenesis (median $174 \mathrm{pmol} / \mathrm{l} ; \mathrm{p}<0,001$ ). In bilateral cryptorchidism group AMH level was normal in $50 \%$ of boys. In boys with vanishing testes no testosterone response to $\mathrm{hCG}$ was observed. There was a significant difference between AMH levels in cryptorchid boys (median 249,5 $\mathrm{pmol} / \mathrm{l}$ ) and patients with anorchia (median $1,0 \mathrm{pmol} / \mathrm{l} ; \mathrm{p}<0,001$ ). The basal AMH levels were correlated with testosterone response to hCG, the Spearman rank correlation coefficient value was $0,53(p<0,001)$. There were no statistical differences between $\mathrm{AMH}$ values and testosterone levels after hCG stimulation. Basal AMH measurements correlate with testosterone response to hCG.

Therefore both methods can be equally useful in diagnostic process in children with DSD. In patients with non-palpable testes a single measurement of serum AMH level can distinguish between cryptorchidism and anorchia.

\section{P03-666 Sex Differentiation Karyotyping is important in childhood glomerulosclerosis}

Kurt Kristensen; Niels F Jørgensen; Henrik Hasle; Niels H Birkebæk

Aarhus University Hospital, Pediatric Department, Aarhus, Denmark

Background: Frasier Syndrome (FS) is characterized by $46, \mathrm{XY}$, gonadal dygenesis, streak gonads and renal failure. FS is mainly caused by a splice site mutation of intron 9 of the Wilms Tumor 1 gene (WT1). WT1 is a transcriptional activator or repressor, required for normal formation of the genitourinary system and mesothelial tissue.

Objective: To report on the importance of karyotyping in girls whith glomerulosclerosis aiming to reveal a gonadal dysgenesis.

Case report: A phenotypic girl underwent renal transplantation eight years old due to end-stage renal disease with focal segmental glomerulosclerosis. Posttransplantational treatment consisted of cyclosporine and mycophenolatmofetil. 14 years old she presented with an abdominal B lymphoblasic Non-Hodgkin Lymphoma (NHL). At the same time delayed puberty was diagnosed and normal female external genitalia was seen. Her height was $146 \mathrm{~cm}$ (target height $161+/-8 \mathrm{~cm}$ ), bone age was 8 years. Biochemically hypergonadotropic hypogonadism was found. Her karyotype was 46, XY. Laparoscopic examination demonstrated streak gonads. WT1 gene mutational analysis revealed a c228 $+5 \mathrm{G}>\mathrm{A}$ mutation in intron 9 .

Discussion: The girl fulfils the criteria for FS. The WT1 mutation is associated to FS. End-stage renal failure in FS is seen from early life to late adulthood depending on the mutation. However, if end-stage renal failure due to diffuse or segmental glomerulosclerosis is diagnosed in a young phenotypic girl, karyotyping is important to exclude gonadal dysgenesis. In this patient NHL was diagnosed and WT1 may play a role in the development of lymphomas as WT1 is a tumor suppressor. However, in the present case it is most likely 
that the NHL was due to several years of immunosuppressive treatment since NHL has not previously been reported in FS.

\section{P03-667 Sex Differentiation \\ Clinical, biological, radiological and molecular aspects of isolated hypogonadotrophic hypogonadism with or without anosmia: 23 paediatric cases}

Virginie Leplatre'; Christine Raybaud ${ }^{1}$; Michel David' ${ }^{1}$ Pierre Chatelain'; Nicolas de Roux ${ }^{2}$; Yves Morel'; Jean-Pierre Pracros ${ }^{1}$; Marc Nicolino 'University Hospital Debrousse, Division of Paediatric Endocrinology, Lyon, France; 'Bicetre Hospital, Laboratory of Hormonology and Molecular Biology, Kremlin Bicetre, France

The aim of this retrospective study is to describe the clinical, biological, radiological and new molecular features in isolated hypogonadotropic hypogonadisms with or without anosmia, in a paediatric cohort, investigated in Lyon in the last twenty years. We report 23 paediatric cases including 16 patients (15 males and 1 female) with Kallmann syndrome and 7 males with isolated hypogonadotropic hypogonadism without anosmia. Clinical aspects were analyzed, MRI of olfactive system was performed in 16 patients. LH and FSH response to LHRH stimulation test was studied to establish the diagnosis. The Testosterone level after an HCG stimulation test (6x1500U) was measured. Molecular study of Kal 1 and Kal 2 was first performed in the patients with anosmia. In those without anosmia, GnRH receptor and GPR 54 gene mutations were first studied. The results showed that the age of diagnosis is more precocious in Kallmann syndrome. Bilateral cryptorchidism associated with micropenis, synkinesia, midline craniofacial abnormalities and olfactory system hypoplasia on MRI scans were specific of Kallmann syndrome. We did not find any cryptorchidism in isolated hypogonadotropic hypogonadism without anosmia. Molecular study showed $4 \mathrm{Kal} 1$ and $3 \mathrm{Kal}$ 2 (FGFR 1) mutations among Kallmann syndrome patients. Only one GnRH receptor mutation was found among patients with isolated hypogonadotropic hypogonadism without anosmia. Molecular abnormalities were more frequent in familial cases. Genetic studies remain difficult in sporadic cases, as well as genetic counselling regarding intra-familial variable expressivity

\section{P03-668 Sex Differentiation \\ Inibin A generation after gonadotropin stimulation: a new method to detect ovarian tissue in patients with intersex conditions such as true hermaphroditism}

Leandra Steinmetz'; Carlos Alberto Longui ; Mylene Neves Rocha ${ }^{2}$; Nuvarte Setian'; Durval Damiani

'São Paulo University Medical School, Pediatric Endocrinology UnitInstituto da Criança, São Paulo, Brazil; ${ }^{2}$ Santa Casa S.P. Faculty of Medical Sciences, Pediatric Endocrinology Unit, São Paulo, Brazil

Background: True hermaphrodism (TH), characterized by the presence of ovarian and testicular tissue in the same patient, comprises $5 \%$ of the intersex cases. As there is a great phenotypical variation, ranging from women to men with normal genitalia, covering a wide range of intermediary presentations, it becomes very difficult to make the diagnosis of $\mathrm{TH}$ on clinical ground only. The evaluation of testicular tissue has been well established but there is no available test to demonstrate the presence of ovarian tissue.

Objectives: 1. To evaluate the effectiveness of the LH/FSH gonadal stimulation in demonstrating ovarian function 2 . To evaluate the presence of ovarian tissue in intersex patients upon gonadotropic stimulation. Patients and Methods: Ten patients with congenital adrenal hyperplasia (CAH), 10 with unilateral cryptorchidism, 13 intersex patients with no defined etiology, and seven TH patients have been included in the study. All the patients had a gonadotropic stimulation test with $150 \mathrm{IU}$ of LH and $150 \mathrm{IU}$ of FSH (menotropin), for three consecutive days. LH, FSH, estradiol, testosterone, and Inibin A were measured before ( 0 time), $24 \mathrm{~h}$ after the first gonadotropin dose, and $24 \mathrm{~h}$ after the third gonadotropin dose.

Results: LH did not show significant increase in the four groups. FSH increased in the four groups in a similar way. Estradiol increased in $\mathrm{CAH}$ patients $(\mathrm{p}=0.005)$ and in $\mathrm{TH}$ pacients $(\mathrm{p}=0,031)$, while testosterone increased in patients whit unilateral cryptorchidism $(\mathrm{p}=0.027)$ as well as in the intersex patients without defined etiology. Inhibin A levels increased in $\mathrm{CAH}$ patients $(\mathrm{p}=0.005)$ and in the TH patients $(\mathrm{p}=0.043)$.

Conclusions: The LH/FSH stimulation test demonstrated to be a useful method to diagnose the presence of ovarian tissue in CAH patients as well as in $\mathrm{TH}$ patients, becoming an important tool to diagnose $\mathrm{TH}$ even before the surgical procedure and histologic studies of the gonads.

\section{P03-669 Sex Differentiation}

\section{A molecular analysis of candidate genes for hypospadias in Italian subjects}

Annalisa Nicoletti'; Lilia Baldazzi'; Soara Menabò ${ }^{1}$;

Antonio Balsamo'; Monia Gennari'; Fabio Buzi'; Andrea Pasini'; Alessandro Cicognani ${ }^{1}$

'University of Bologna, Pediatric Department, Bologna, Italy;

${ }^{2}$ University of Brescia, Pediatric Department, Brescia, Italy

Hypospadias is a common disorder among male genital anomalies with different degrees of severity, in which the urethra has failed to completely form causing an incorrect opening at different levels along the ventral line of the penis. The etiology is generally considered multifactorial, familiarity is reported and other phenotypic signs may be present (Syndromic Hypospadias). Chromosomal abnormalities are associated, single genes are also involved, in particular those responsible for androgens production/action.

In this study thirty-six $46, \mathrm{XY}$ subjects aged 0,2 to 15 with different degrees of Hypospadias, were collected for the genetic analysis of AR, SRD5A2 and SRY genes, after testicular function tests and abdominopelvic ultrasound. The genomic DNA was isolated from peripheral blood and all coding sequences of candidate genes were submitted to direct sequencing. Seven different mutations in SRD5A2 gene were found in six patients; three mutations are new. Another new mutation was found in AR gene in one patient. The frequencies of known polymorphisms of SRD5A2 and AR genes were determined, and two very rare/new AR glycine-genotypes were found. All the relatives available for the genetic analysis were studied for carrier identification. No alterations were found in SRY gene. Further genes are under consideration for analysis in the negative patients, including HSD17B3 gene and the recently candidate CXorf6 gene.

In $17,5 \%$ of the patients the genetic basis was identified; among the mutations found, most are causative of 5áRD2 Deficiency, the four new mutations must be characterized. Polymorphism frequencies overlap normal control values. The two glycine-genotypes need further studies on structural-functional role of the AR repeats.

It is largely approved that all clinical and hormonal finding have to direct genetic analysis in DSD, but, as transient deficit of crucial factors during external genital formation is often hypothesized, genetic approach can be considered a valid early diagnostic step in the characterization of subjects with heterogeneous DSD as Hypospadias.

\section{P01-670 SGA \\ Gene-gene interactions between the IGF-I, IGF- IR and IGF-II gene region determine gestational age in short SGA children}

Wietske Ester ; Joyce van Meurs'; Nicolette Arends';

Andre Uitterlinden'; Anita Hokken-Koelega'

'ErasmusMC-Sophia Children's Hospital, Dep. Pediatrics, Subdiv. Endocrinology, Rotterdam, Netherlands; ${ }^{2}$ ErasmusMC, Dep. Internal

Medicine, Rotterdam, Netherlands; ${ }^{3}$ ErasmusMC, Dep. Internal

Medicine, Dep. Biostatistics, Rotterdam, Netherlands

The etiology of short SGA children involves both genetic and environmental factors. We hypothesized that the combined effects of genetic variations in growth regulating genes determine birth size of short SGA children.

In this study we investigated in total 20 genetic variations in the IGFI, IGF-IR and IGF-II gene region, that tag most common variation. These polymorphisms were investigated in 201 short SGA children for associations with gestational age, birth length, birth weight and gestational hypertension. All polymorphisms were in Hardy-Weinberg equilibrium and analyzed according to a dominant model. Gene-gene interactions were tested by linear regression entering interaction. We used Bonferroni adjustment to correct for 
multiple testing.

Three single genetic variations in the IGF-I, one in IGF-IR and three in the IGF-II gene region were associated with a 1 week shorter gestational age. Gene-gene interaction analyses showed that the combination of IGFIR rs11635251 [AA] and IGF-II rs3213221 [CC] genotypes, (Fig 1, P regr $=0.008$ ), and of IGF-I -G1245A [GA/AA] and the INS VNTR [I/I] (Fig $2, \mathrm{P}$ regr $=0.012)$, resulted in a $3.2(\mathrm{P}=0.001)$ and 2.7 weeks $(\mathrm{P}=0.001)$ shorter gestational age, respectively.

Further analyses of pregnancy pathology showed that gestational hypertension explained the association of gestational age with IGF-I -G1245A and the INS VNTR. Adjusting for gestational hypertension did not change the association of IGF-II rs3213221 and IGF-IR rs11635251 ( $\mathrm{P}=0.015$, $\mathrm{P}$ corr=0.09).

In conclusion, while some individual genetic variations show a one week shorter gestational age, we observed that interactions between the IGF-IR (rs11635251) and IGF-II (rs3213221) gene variants, and between IGF-I (G1245A) and INS (VNTR), both show a 3 weeks shorter gestational age. For IGF-I and INS, this association can be explained by gestational hypertension but not for IGF-II and IGF-IR.
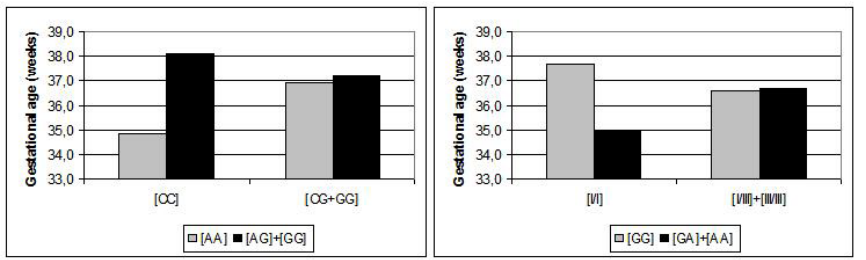

Figure 1: IGF-IR (AA vs. AG+GG) and IGF-II (CC vs. CG+GG).

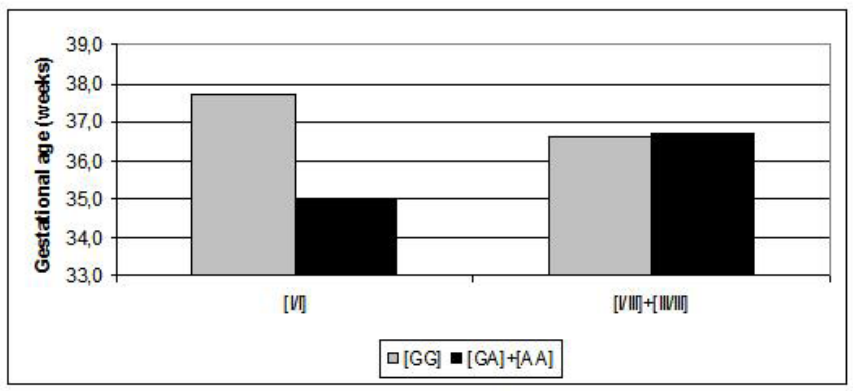

Figure 2: IGF-I (GG vs. GA+AA) and INS (I/I vs. I/III+III/III).

\section{P01-671 SGA \\ Two new short SGA children with IGF-IR haploinsufficiency illustrate the heterogeneous phenotype of IGF-IR mutations \\ Wietske Ester ${ }^{1}$; Caroline de Wit'; Jan Maarten Wit'; \\ Anita Hokken-Koelega' ${ }^{1}$; Monique Losekoot ${ }^{4}$ \\ ${ }^{1}$ ErasmusMC-Sophia Children's Hospital, Dep. Pediatrics, Subdiv. Endocrinology, Rotterdam, Netherlands; ${ }^{2}$ Leiden University Medical Center, Dep. of Pediatrics \& Human and Clinical Genetics, Leiden, Netherlands; 'Leiden University Medical Center, Dep. of Pediatrics, Leiden, Netherlands; ${ }^{4}$ Leiden University Medical Center, Dep. of Human and Clinical Genetics, Leiden, Netherlands}

So far 9 short cases born small-for-gestational age (SGA) have been described in the last 15 years with IGF-IR haploinsufficiency as part of a heterozygous terminalmicrodeletion of 15q. Mainphenotypic characteristics were:SGA, short stature, microcephaly and developmental delay. The objective of this study was to determine the frequency of IGF-IR haploinsufficiency in short SGA children and to specify their phenotype in comparison with previously reported cases. 100 short SGA children were investigated for IGF-IR deletions by multiplex ligation-dependent probe amplification (MLPA). In this population, 2 children had IGF-IR haploinsufficiency. Case 1 was a girl of age 7, born at term with a length of -2.2 SDS, weight of -1.3 SDS and head circumference (HC) of -1.1 SDS. She had bilateral hip dysplasia, clump feet and delayed motor development. At 4 years of age, she started GH therapy in a dose of $1 \mathrm{mg} / \mathrm{m}^{2} /$ day, with a height of -3.5 SDS, improving to -2.5 SDS after 1 year of treatment. Her IGF-I at start of GH therapy was -2.8 SDS. Dysmorphic features included hypertelorism, flat nasal bridge and proximally placed thumbs. Case 2 was a boy of 17 years of age, born at term, with a length of -2.2 SDS, weight of -1.9 SDS and HC of -1.1 SDS.

At age 7, he started GH therapy in a dose of $1 \mathrm{mg} / \mathrm{m}^{2} /$ day, with a height of -3.6 SDS, improving to -2.7 SDS after 1 year of treatment. His IGF-I at start of GH therapy was 1.3 SDS. Dysmorphic features were hypertelorism, bilateral extra nipple, clinodactyly and a proximally placed thumb.

Thus, IGF-IR haploinsufficiency was present in $2 \%$ of the short SGA children. When all reported short SGA cases with IGF-IR haploinsufficiency of the last 15 years were reviewed (Table 1), we conclude that birth length and postnatal height $<-2.0$ SDS are the strongest predictors. Growth hormone therapy leads to an acceptable catch-up growth. These 2 new cases illustrate that the absence of severe SGA, microcephaly or high IGF-I serum levels does not exclude IGF-IR haploinsufficiency.

Table 1.

\begin{tabular}{|c|c|c|}
\hline Feature & $\begin{array}{l}\text { Frequency in } 11 \text { cases } \\
\text { (\%) }\end{array}$ & Order \\
\hline $\begin{array}{l}\text { Postnatal height }<-2.0 \\
\text { SDS }\end{array}$ & $10 / 10(100)$ & 1 \\
\hline Birth length $<-2.0$ SDS & $6 / 8(80)$ & 2 \\
\hline $\begin{array}{l}\text { IGF-I serum level > +1.0 } \\
\text { SDS }\end{array}$ & $4 / 5(80)^{*}$ & 2 \\
\hline Birth weight $<-2.0$ SDS & $7 / 11(64)$ & 3 \\
\hline $\begin{array}{l}\text { Developmental } \\
\text { delay and/or mental } \\
\text { retardation }\end{array}$ & $6 / 10(60)$ & 4 \\
\hline Micrognathia & $6 / 11(55)$ & 5 \\
\hline $\begin{array}{l}\text { Birth } \mathrm{HC}<-2.0 \text { SDS } \\
\text { and/or microcephaly }\end{array}$ & $5 / 11(45)$ & 6 \\
\hline Proximal placed dig I & $3 / 11(27)$ & 7 \\
\hline Cardiac disorders & $3 / 11(27)$ & 7 \\
\hline
\end{tabular}

\section{P01-672 SGA \\ Height and insulin resistance in children born SGA after 1 year of GH treatment \\ Sara Bachmann ${ }^{1}$; Susanne Bechtold ${ }^{1}$; Walter Bonfig'; \\ Stephanie Putzker'; Oliver Fuchs ${ }^{1}$; Matthias Buckl'; \\ Hans Peter Schwarz ${ }^{1}$ \\ University Children's Hospital Munich, Pediatric Endocrinology and Diabetology, Munich, Germany; '2University Children's Hospital, Pediatric Endocrinology/Diabetology, Munich, Germany}

GH treatment is well accepted for children born small for gestational age (SGA) who fail catch-up growth. As GH reduces insulin sensitivity, and low birth weight is associated with an increased risk of diabetes type 2, the effect of GH on glucose metabolism is of special concern in this patient group.

We evaluated glucose tolerance and insulin sensitivity before and after 1 year of GH treatment in SGA children.

In 23 children born SGA treated with $\mathrm{GH}$ at a dose of $33 \mu \mathrm{g} / \mathrm{kg}$ per day an oral glucose tolerance test was performed at baseline (age $9.3 \pm 2.8 \mathrm{y}$ ) and after 1 year. Insulin sensitivity was calculated using the homeostasis model assessment (HOMA) and the insulin sensitivity index (ISI).

\begin{tabular}{lll} 
Patients $(n=23)$ & Baseline & 12 months \\
\hline Height SDS & $-3.2 \pm 0.8$ & $-2.6 \pm 0.9$ \\
\hline BMI SDS & $-1.5 \pm 1.4$ & $-1.4 \pm 1.5$ \\
\hline Fasting glucose $(\mathrm{mg} / \mathrm{dl})$ & $81.6 \pm 9.3$ & $83.3 \pm 8.9$ \\
\hline Glucose $120 \mathrm{~min}(\mathrm{mg} / \mathrm{dl})$ & $100.7 \pm 17$ & $103.6 \pm 20$ \\
\hline HbA1c $(\%)$ & $5.4 \pm 0.3$ & $5.5 \pm 0.3$ \\
\hline HOMA $(>2.5)$ & $1.6 \pm 1.9(4 / 23)$ & $2.6 \pm 2.9(5 / 23)$ \\
\hline ISI $(<5)$ & $11.6 \pm 10.1(5 / 23)$ & $5.4 \pm 3.5(14 / 23)$
\end{tabular}


No correlation was found between ISI or HOMA after 12 months and $\Delta$ height SDS or height velocity SDS. There was a trend to a lower ISI (4.7 vs 5.8$)$ and a higher HOMA (4.0 vs 1.7) in children $(n=9)$ with a height velocity $<2$ SDS, compared to those $(n=14)$ with a height velocity $>2$ SDS over 12 months. Even before GH treatment, insulin sensitivity was compromised in some children and markedly decreased after 1 year in most of the patients, while glucose levels and HbAlc remained normal. Careful monitoring of glucose metabolism by yearly glucose tolerance testing is crucial in these predisposed subjects. Risk and benefit of GH treatment should be assessed continuously in children born SGA.

\section{P01-673 SGA \\ Long-term growth and clinical assessment of children born small for gestational age}

Susan O'Connell'; Elaine O'Mullane'; Margaret Sheridan-Pereira²; Edna Roche ${ }^{1}$; Hilary Hoey ${ }^{1}$

'National Children's Hospital, Paediatrics, University of Dublin, Trinity

College, Dublin, Ireland; '2Coombe Women's Hospital, University of

Dublin, Trinity College, Dublin, Ireland

Children born small for gestational age (SGA) (Birth weight $\leq-$ 2SDS) have increased risk of health problems in later life including cardiovascular disease, hypertension and non-insulin dependent diabetes. Metabolic syndrome occurs more frequently among adults born with a low birth weight especially in those with rapid weight gain during infancy. Approximately $10 \%$ of children born SGA will remain short $\leq-2$ SDS) throughout childhood and into adult life. A study was performed on 14,726 consecutive live births born at the Coombe Womens Hospital in order to identify those born SGA. Height, weight and clinical development was assessed in children born SGA in order to identify those with failure of catch up growth and those who are overweight and at risk of the metabolic syndrome. Mothers of children born SGA ( $\mathrm{n}=306)$, gestation $\geq 28$ weeks, aged 4-6 years, were asked for clinical information and invited to participate in study. 18 patients were excluded due to a complicated medical history, including one sudden infant death. Auxological data were compared to those of the normal Irish population. Of the mothers contacted, 175 were Irish, 19 non-Irish EU, 29 non-EU origin and 80 of unknown nationality. Of the 67 who responded, all were Irish except 1 non-EU patient. Assessment was performed on 58 patients. Children born SGA were shorter (mean height $-0.8 \mathrm{SDS}$ ) and lighter (mean weight $-0.9 \mathrm{SDS}$ ) when compared to the general population. Severe short stature (SDS $<-2.5$ ) previously unidentified was detected in 2 children (both fulfill the Growth Hormone treatment criteria). Only one child was overweight $(\mathrm{BMI}=20.4)$. Children born SGA are shorter and considerably lighter compared to the overall general population. Close follow-up of children born SGA is recommended in order to identify those at risk of future health problems. Follow up of children of ethnic minority groups needs special attention.

\section{P01-674 SGA \\ Final height of short children born small for gestational age (SGA) treated with growth hormone (GH) in a single centre}

Roland Schweizer; David Martin; Martin Haase; Michael Ranke

Children's Hospital Tübingen, Pediatric Endocrinology, Tübingen, Germany

Growth hormone (GH) therapy was approved in 2003 for treating short children $>4$ yrs who were born SGA. Since few data are available on final height following GH treatment in this group, we collected and analyzed final height data in SGA patients treated at our hospital.

Patients and Methods: mean data given, SD scores based on references for height by Prader et al. and birth size by Niklasson et al.. We analysed 27 (5 female) short SGA patients with a gestational age of 37.7 weeks, birth weight and/or length $<-2$ SDS, mean age at GH start 8.9 years, target height -0.41 SDS, all with a peak GH level of $>8 \mu \mathrm{g} / \mathrm{l}$ in the stimulation test. All patients received GH for 5.5 years (mean) at a GH dosage of $51 \mu \mathrm{g} / \mathrm{kg} / \mathrm{d}$ (mean). Mean height at GH start was - 3.2 SDS (range -2 to -4.7 SDS).

Results: Height after 1 year of GH was -2.4 SDS (-1.0 to - 4.35), final height -2.0 SDS (range -0.59 to -4.92 ). Age at final height was $17.6 \mathrm{yrs}$. Total height gain (delta height from GH start to final height was +1.1 SDS, range -0.49 to +2.56 ). Delta height correlated positively with first year height gain (0.73 SDS, range -0.20 to 1.50$), R=0.46(p<0.01)$, and with treatment duration, $R=0.56(\mathrm{p}<0.01)$, but negatively with age at $\mathrm{GH}$ start, $\mathrm{R}$ $=-0.42(\mathrm{p}<0.01)$. Severe adverse events were not observed.

Conclusions: A supraphysiological dose of $\mathrm{GH}$ is suitable for achieving an increase in final height in short SGA children, given that GH treatment started early and a good response to GH in the first treatment year was observed. Since several patients did not profit from GH therapy, future investigations should identify the causes of poor response. The GH dose recommended in Europe $(35 \mu \mathrm{g} / \mathrm{kg} / \mathrm{d})$ seems evidently not sufficient for height normalisation in all SGA children.

\section{P01-675 SGA \\ Body composition and metabolic changes during high dose growth hormone therapy in SGA children: a longitudinal study}

Stefan Giseke'; Franziska Phan Hug'; Jessica Ezry'; Tiziana Testa'; François Gudinchet'2; Philippe Schneiter ${ }^{3}$; Luc Tappy;

Gerald Theintz ${ }^{1}$

'Endocrinology and Diabetology Unit, Dept. of Paediatrics, University Hospital, Lausanne, Switzerland; '²Dept. of Radiology, University Hospital, Lausanne, Switzerland; ${ }^{3}$ nstitute of Physiology, University of

Lausanne, Lausanne, Switzerland

Metabolic alterations are present early in children born SGA and possibly related to alterations of body composition, fat representing a higher percentage of total body weight in SGA than in normal children. High doses of growth hormone $(\mathrm{GH})$ induce a substantial catch-up growth in these children. The aim of our prospective study was to evaluate the alterations of body composition induced by such a therapy. Ten SGA subjects aged $10.6 \pm 0.6$ yrs $(\mathrm{M} \pm \mathrm{SEM})$ were followed prospectively before and during 2 years of treatment using $0.054 \pm 0.001 \mathrm{mg} / \mathrm{kg} \mathrm{BW} /$ day of human recombinant $\mathrm{GH}$ (a generous gift of Novo Nordisk). Standard auxological, metabolic and hormonal growth monitoring parameters were measured before and at respectively 2 weeks, 3,12 , and 24 months of therapy. Body composition was assessed by dual Xray absorptiometry (DEXA). Indirect calorimetry and ${ }^{13} \mathrm{CO}_{2}$ monitoring were also performed. Significant gains in stature, sitting-height and body weight were observed (respectively $+1.04,+1.08$ and +0.6 SDS, $p<0.01$ ) whereas BMI did not change significantly $(+0.27$ SDS, ns). When corrected for age, lean body mass also increased $(\mathrm{p}<0.01)$. Removing the effect of age, total fat mass did not change significantly over time. However, its distribution was markedly altered: the percentage of peripheral (head and limbs) body fat decreased contrasting with an increase in central (trunk) body fat ( $\mathrm{p}=$ 0.01 ). These changes were related to a significant increase in mean diastolic $\mathrm{BP}(+12.5 \mathrm{~mm} \mathrm{Hg}, \mathrm{p}<0.05)$ and to a near significant rise in HOMA-IR $(2.6$ \pm 0.43 vs $8.6 \pm 2.6, \mathrm{p}=0.08$ ). Therapy using high dose of $\mathrm{GH}$ appears to worsen some of the alterations of body composition already observed in SGA children before therapy. Contrasting with gains in height, weight and lean body mass, GH therapy markedly altered fat mass distribution, increasing central fat. This observation correlates with increased diastolic pressure and insulin resistance. The long term effects of altered body composition due to therapy remained to be evaluated.

\section{P01-676 SGA \\ Insulin sensitivity and early growth patterns in young adults born preterm \\ Joost Rotteveel; Mirjam Van Weissenbruch; \\ Henriette Delemarre-Van de Waal \\ VU University medical center, pediatrics, Amsterdam, Netherlands}

Background: During childhood, low birth weight is related with decreased insulin sensitivity, especially in children with catch up growth. Since growth hormone therapy is advocated for children with growth delay due to premature birth, it is important to study the relation between growth and insulin sensitivity.

Purpose: To investigate insulin sensitivity in relation to infant and childhood growth patterns in very preterm and very low birth weight infants as young adults.

Patients and methods: From the Dutch preterm cohort (POPS 1983) subjects 
at the age of 21 years were recruited: 30 subjects born appropriate (GA 28,9 weeks, BW $+1,1 \mathrm{sds}$ ), and 28 subjects born small for gestational age (GA 31,9 weeks, BW -2 sds). The hyperinsulinemic euglycaemic clamp technique was used to measure insulin sensitivity (glucose disposal mg/ $\mathrm{kg} / \mathrm{min} /$ (insulin levels pmol/1) x100). Follow up data for height and weight until the age of 21 were analysed.

Results: Increases in height sds within the first 5 years of life were significantly associated with lower insulin sensitivity. Increases in weight sds were also associated with lower insulin sensitivity (table). The lowest quartile for insulin sensitivity (Mi-value 0,93 ) was compared to the highest quartile (Mi-value 2,56). The growth pattern of the group in the lowest quartile for insulin sensitivity was characterized by a significantly higher height sds at age 1,2 and $5(\mathrm{p}=0,006, \mathrm{p}=0,02, \mathrm{p}=0,001)$ years as well as higher weight sds at age $2,5,10,19$ and 21 years $(\mathrm{p}=0,0046, \mathrm{p}=0,013, \mathrm{p}=0,012, \mathrm{p}=0,041$, $\mathrm{p}<0,0001)$. Differences at other ages were not significant.

\begin{tabular}{|c|c|c|c|c|c|c|}
\hline & $\begin{array}{l}\text { Height } \\
\text { sds }\end{array}$ & $\begin{array}{l}\text { Height } \\
\text { sds }\end{array}$ & $\begin{array}{l}\text { Weight } \\
\text { sds }\end{array}$ & $\begin{array}{l}\text { Weight } \\
\text { sds }\end{array}$ & BMI sds & BMI sds \\
\hline & $\mathrm{R}$ & $\mathrm{p}$ & $\mathrm{R}$ & $\mathrm{p}$ & $\mathrm{R}$ & $\mathrm{p}$ \\
\hline $\begin{array}{l}\text { Birth-3 } \\
\text { months }\end{array}$ & & ns & -0.35 & 0.013 & & ns \\
\hline $\begin{array}{l}\text { Birth-1 } \\
\text { year }\end{array}$ & $-0,43$ & 0.005 & -0.36 & 0.011 & & ns \\
\hline $\begin{array}{l}\text { Birth- } 2 \\
\text { years }\end{array}$ & $-0,39$ & 0.014 & -0.36 & 0.012 & & ns \\
\hline $\begin{array}{l}\text { Birth- } 5 \\
\text { years }\end{array}$ & $-0,40$ & 0.006 & -0.38 & 0.004 & & ns \\
\hline $\begin{array}{l}\text { Birth-21 } \\
\text { years }\end{array}$ & & ns & -0.37 & 0.001 & & \\
\hline $\begin{array}{l}3 \text { months- } \\
21 \text { years }\end{array}$ & & ns & -0.41 & 0.003 & -0.43 & 0.002 \\
\hline $\begin{array}{l}6 \text { months- } \\
21 \text { years }\end{array}$ & & ns & -0.45 & 0.001 & -0.47 & 0.001 \\
\hline $\begin{array}{l}1 \text { year-21 } \\
\text { years }\end{array}$ & & ns & -0.44 & 0.002 & $-0,53$ & $<0.0001$ \\
\hline $\begin{array}{l}2 \text { years- } \\
21 \text { years }\end{array}$ & & ns & -0.47 & 0.001 & -0.56 & $<0.0001$ \\
\hline $\begin{array}{l}5 \text { years- } \\
21 \text { years }\end{array}$ & & ns & & ns & -0.46 & $<0.0001$ \\
\hline
\end{tabular}

Conclusion: Catch up in height and weight during infancy and childhood is inversely associated with insulin sensitivity in young adults born prematurely.

\section{P01-677 SGA \\ Growth assessment at $\mathbf{6}$ years in children with extremely low birth weight $(<1000 \mathrm{~g})$ : comparison between those born small (SGA) or appropriate (AGA) for gestational age \\ Bettina Gohlke ${ }^{1}$; Sonja Stutte ${ }^{1}$; Peter Bartmann ${ }^{2}$; Joachim Woelfle ${ }^{1}$ ${ }^{1}$ University Hospital, Pediatrics, Bonn, Germany; ${ }^{2}$ University Hospital, Neonatology, Bonn, Germany}

With recent advancement in intensive care mortality for extremely premature infants has improved. It is well known that their postnatal growth is insufficient and their final height differs significantly from their genetically determined target height. In combination with being SGA this might be even aggravated. We studied postnatal growth of 46 otherwise healthy former premature infants with extremely low birth weight $(<1000 \mathrm{~g})$. They were evaluated with regard to being SGA or AGA. SGA was defined for birth length and/or weight $<-2$ SD according to German standards. Data were always corrected for gestational age.

$3 / 31(9.7 \%)$ in the AGA and 4/15 (26.7\%) in the SGA group were still too short (<-2 SDS) at the age of 6 years; $10(32.1 \%)$ in the AGA and $8(53 \%)$ in the SGA group did not show catch-up growth with height SDS difference more than 1SD from target height SDS.

Impaired continuous postnatal growth in early childhood is very common in children born with extremely low birth weight, irrespective of SGA or AGA.
SGA children did not catch-up to their AGA peers at any time.

\begin{tabular}{|c|c|c|c|}
\hline & AGA $(n=31)$ & $S G A(n=15)$ & $p$-value \\
\hline $\begin{array}{l}\text { Birth weight } \\
\text { (SDS, range) }\end{array}$ & $\begin{array}{l}-0.59(-1.84 \text { to } \\
0.89)\end{array}$ & $\begin{array}{l}-2.43(-2.51 \text { to } \\
-1.21)\end{array}$ & $p<0.0001$ \\
\hline $\begin{array}{l}\text { Birth length } \\
\text { (SDS, range) }\end{array}$ & $\begin{array}{l}-0.41(-1.86 \text { to } \\
0.57)\end{array}$ & $-2.1(-3.0$ to 0.08$)$ & $p<0.0001$ \\
\hline $\begin{array}{l}\text { Length, } 0.5 \text { yrs } \\
\text { (corrected) }\end{array}$ & $-3.24(-5.4$ to -0.9$)$ & $\begin{array}{l}-4.65(-7.4 \text { to } \\
-2.97)\end{array}$ & $p<0.0001$ \\
\hline $\begin{array}{l}\text { Length, } 1 \mathrm{yr} \\
\text { (corrected) }\end{array}$ & $-0.38(-2.4$ to 1.1$)$ & $\begin{array}{l}-1.69(-3.14 \text { to } \\
0.14)\end{array}$ & $p<0.0001$ \\
\hline $\begin{array}{l}\text { Height, } 2 \text { yrs } \\
\text { (corrected) }\end{array}$ & $\begin{array}{l}-0.41(-2.74 \text { to } \\
1,75)\end{array}$ & $\begin{array}{l}-1.05(-3.06 \text { to } \\
-0.17)\end{array}$ & $p<0.0001$ \\
\hline $\begin{array}{l}\text { Height, } 4 \text { yrs } \\
\text { (corrected) }\end{array}$ & $\begin{array}{l}-0.49(-1.78 \text { to } \\
0.77)\end{array}$ & $-1.1(-2.8$ to 0.24$)$ & $p<0.001$ \\
\hline $\begin{array}{l}\text { Height, } 6 \text { yrs } \\
\text { (corrected) }\end{array}$ & $\begin{array}{l}-0.45(-2,53 \text { to } \\
1.23)\end{array}$ & $\begin{array}{l}-1.17(-3.67 \text { to } \\
0.68)\end{array}$ & $p<0.0001$ \\
\hline $\begin{array}{l}\text { Target height } \\
\text { (SDS) }\end{array}$ & $\begin{array}{l}0.04(-1.14 \text { to } \\
1.58)\end{array}$ & $\begin{array}{l}-0,13(-1,95 \text { to } \\
1,5)\end{array}$ & NS \\
\hline
\end{tabular}

\section{P01-678 SGA \\ GH responsiveness in a large multinational cohort of SGA children with short stature (NESTEGG) is related to the exon 3 GHR polymorphism}

Maithé Tauber ${ }^{1}$; Wieske Ester ${ }^{2}$; Françoise Auriol'; Catherine Molinas ${ }^{1}$; Josette Fauve/ ${ }^{3}$; Janina Caliebe ${ }^{4}$; Tim Nugent ${ }^{5}$; Linda Fryklund ${ }^{6}$; Michael Ranke ${ }^{4}$; Martin Savage ${ }^{5}$; Adrian Clark ${ }^{5}$ Linda Johnston ${ }^{5}$; Anita Hokken-Koelega ${ }^{2}$

${ }^{1}$ Children's Hospital, Endocrinology Unit, Toulouse, France; 'Erasmus MC-Sophia Children's Hospital, Division of Endocrinology, Rotterdam, Netherlands; ${ }^{3}$ Hôpital Purpan, Laboratoire de Biochimie 3, Toulouse, France; 'University Children's Hospital, Pediatric Endocrinology Section, Tubingen, Germany; ${ }^{5}$ Barts and the London Queen Mary School of Medicine, Department of Endocrinology, London, United Kingdom; ${ }^{6}$ Pfizer health, Endocrinology, Sollentuna, Sweden

The polymorphic deletion of exon 3 of the GH receptor (d3-GHR) has recently been linked to the magnitude of growth response to recombinant human $\mathrm{GH}$ (rhGH) therapy in short children with or without GH deficiency. Our objective was to investigate if this association exists in a large multinational NESTEGG (Network of European Studies of Genes in Growth) cohort of short children born small for gestational age (SGA). The study included 240 white Caucasian short prepubertal SGA children (138 male, 102 female), aged $6.6 \pm 2.3$ years, treated with rhGH for 1 or 2 years with a height at $-3.0 \pm 0.7$ SDS at start of rhGH treatment. It also included 193 ethnically matched controls in early or mid-adulthood. The GHR polymorphism (fl/fl, $\mathrm{fl} / \mathrm{d} 3$ or $\mathrm{d} 3 / \mathrm{d} 3$ ) was genotyped by PCR multiplex assay. Growth velocity in $\mathrm{cm} / \mathrm{yr}(\mathrm{GV})$, increment in $\mathrm{GV}$ during the 1 st and the 2 nd year of rhGH treatment were evaluated. The increment in GV was significantly higher in SGA patients carrying one or two copies of the d3-GHR allele than in SGA patients carrying two copies of the fl-GHR allele, 3.7 vs. $4.2 \mathrm{~cm} / \mathrm{yr}$ for the 1 st year $(\mathrm{p}=0.038$ ) and $2.1 \mathrm{vs.} 2.6 \mathrm{~cm} /$ $\mathrm{yr}$ for the 2 nd year of GH treatment $(\mathrm{p}=0.041)$. The mean birth weight in SDS was significantly lower in the $\mathrm{d} 3 / \mathrm{d} 3$ group than in the two other groups: $-2.6 \pm$ 0.7 SDS vs. $-2.2 \pm 0.9$ SDS in the $\mathrm{fl} / \mathrm{d} 3$ group $(\mathrm{p}=0.016)$ and $-2.2 \pm 0.7$ SDS in the $\mathrm{fl} / \mathrm{fl}$ group $(\mathrm{p}=0.034)$. We confirmed an increased responsiveness to $\mathrm{rhGH}$ in association with the exon $3 \mathrm{GHR}$ polymorphism in a large multinational cohort of short SGA children. 


\section{P01-679 SGA}

The prevalence of metabolic syndrome in children and adolescents born small for gestational age

II Tae Hwang; Hae Ran Lee

College of Medicine, Hallym University, Pediatrics, Seoul, Republic of Korea

Objective:Type2 diabetes mellitus, dyslipidemia, hypertension, cardiovascular disease, called metabolic syndrome(MS), occur more frequently among individuals who were born small for gestational age(SGA).

SGA children with catch-up growth in height and high BMI are the most insulin resistant. We investigated the prevalence of MS and evaluated the risk factors affecting the development of MS in children and adolescents born SGA.

Methods: The study population $(\mathrm{n}=65)$ were born less than 10th percentile in body weight for their gestational age and the body weights of the contro group $(\mathrm{n}=34)$ were more than 10th percentile at birth. The SGA and control subjects divided into prepubertal and pubertal groups.

Results: Systolic blood pressure was significantly higher in the pubertal SGA group than in the control group $(113.2 \pm 10.3$ vs. $98.7 \pm 16.4, \mathrm{P}=0.001)$ The prevalence of high triglyceride and high fasting glucose levels were significantly increased in pubertal SGA group than prepubertal SGA group $(\mathrm{P}<0.05)$. The prevalence of those having more than one, more than two, more than three, more than four risk factors of MS were $42,4 \%, 7.7 \%$, $3.9 \%$, and $3,9 \%$, respectively, in prepubertal SGA group and $61.3 \%, 29.1 \%$, $9.7 \%$, and $0.0 \%$, respectively. in pubertal SGA group. Insulin resistance was correlated to systolic blood pressure, triglyceride levels, HDL-cholesterol levels, insulin levels 2 hours after oral glucose tolerance test and body fat mass in $\mathrm{SGA}$ group $(\mathrm{P}<0.05)$

Conclusion: We suggested that the monitoring of these risk factors including systolic blood pressure, triglyceride, HDL-cholesterol levels and body fat mass is important for the prevention of MS in children and adolescents born SGA.

\section{P01-680 SGA \\ High-density lipoprotein (HDL) cholesterol is reduced in children born SGA with catch-up growth in body mass index. Results from a case-control study}

Piera Torre; Christini Ladaki; Arianna Maiorana; Caterina Geremia

Giuseppe Scirè; Gian Luigi Spadoni; Stefano Cianfarani

Tor Vergata University, Department of Public Health and Cell Biology,

Roma, Italy

Low birth weight is a risk factor for coronary heart disease. It has been reported that persons who have coronary events as adults tend to have been small at birth and thin at two years of age, after which they tended to increase their BMI rapidly. This pattern of growth is also related to insulin resistance in later life. It is uncertain how postnatal growth affects disease risk. We asked whether catch-up growth in BMI is associated to alterations in insulin sensitivity and/or lipid profile in children born SGA. We carried out a casecontrol study in 78 children (mean age $7.8 \pm 2.5$ years): 26 SGA children (10 males and 16 females) with catch-up growth in BMI (CG-SGA, BMI: 10th to 75 th centile), 26 SGA with no catch-up growth (NCG-SGA, BMI $<10$ th centile), and 26 AGA children (BMI: 10th to 75th centile). For each CG-SGA child, we selected a NCG-SGA and an AGA child of the same gender, age (within 1 year), and pubertal status. Glucose was significantly lower in NCGSGA than AGA group ( $\mathrm{p}=0.002$ ). No significant differences in fasting insulin, fasting glucose/insulin ratio, HOMA, and QUICKI were found among the three groups. HDL-cholesterol was significantly lower, in CG-SGA than NCG-SGA and AGA groups (CG-SGA: $51.2 \pm 9.9 \mathrm{mg} / \mathrm{dL} v s$ NCG-SGA: $58.6 \pm 12.7 \mathrm{mg} / \mathrm{dL}, \mathrm{p}<0.01$ and $v s$ AGA: $58.3 \pm 11.3 \mathrm{mg} / \mathrm{dL}, \mathrm{p}<0.01)$. No significant differences in total cholesterol and LDL-cholesterol levels were found. These results confirm our previous reports showing reduced glucose blood levels in SGA children, indicating that this finding might be restricted to NCG-SGA. Although no differences in insulin sensitivity parameters were found, the finding of reduced HDL-cholesterol concentrations in CG-SGA children is consistent with the reported higher risk of cardiovascular disease in subjects with low birth weight and rapid BMI gain in childhood.

\section{P01-681 SGA \\ Changes in circulating adiponectin and leptin levels during the first year of life in neonates}

Elena Bozzola ${ }^{1}$; Cristina Meazza'; Paola Travaglino'; Sara Pagani';

Luisa Pavia Strocchio'; Irene Bonomelli'; Antonella Gasparoni²;

Mauro Bozzola

${ }^{1}$ University of Pavia, Pediatric Department, Pavia, Italy; ${ }^{2}$ Spedali Civili,

Division of Neonatal Intensive Care, Brescia, Italy

The control of the growth in the neonate is a complex mechanism, in which also hormones produced by the adipose tissue such as adiponectin and leptin are involved. Reduced size at birth has been associated to increased long-term risk of obesity, insulin resistance, hypertension and cardiovascular diseases in adulthood. The aim of the present study was to evaluate circulating levels of adiponectin and leptin in infants born appropriate for gestational age (AGA) and small for gestational age (SGA) during the first year of life.

Thirty-three full-term AGA (birth weight $>10$ th percentile) and 29 full-term SGA infants (birth weight $<10$ th percentile) participated this study. We have determined by an ELISA method serum levels of adiponectin and leptin at birth, at 1, 6 and 12 months of life.

AGA and SGA adiponectin and leptin levels showed statistically significant changes over time $(p<0.0005$ by Friedman Anova test). Adiponectin concentrations increased from birth to the first month of life and then decreased at 1 year of age and were comparable between AGA and SGA subjects all over the study. Leptin levels significantly increased from birth to the sixth month but at one year they tended to return to birth levels. At birth circulating concentrations of leptin were significantly higher in AGA than in SGA neonates (median $900.65 \mathrm{pg} / \mathrm{ml}$ and $535.85 \mathrm{pg} / \mathrm{ml}$, respectively). At 1 and 6 months of age they returned to be comparable between the two groups and at 1 year they are increased in SGA infants (median $1563.85 \mathrm{pg} / \mathrm{ml}$ ) compared to AGA ones (median $1103.3 \mathrm{pg} / \mathrm{ml}$ ). In conclusion, adiponectin levels do not differ between AGA and SGA subjects while leptin concentrations are different at birth and at one year of age and positively associated to the birthweight.

\section{P01-682 SGA \\ Adiponectin levels and insulin sensitivity in young adults born small for gestational age (SGA)}

Walter Bonfig: Stephanie Putzker; Susanne Bechtold Dalla Pozza; Sara Bachmann; Matthias Buckl; Karl Kugler; Hans Peter Schwarz University Children's Hospital LMU, Division of Pediatric

Endocrinology and Diabetes, Munich, Germany

Adiponectin is exclusively produced in the adipose tissue and is associated with insulin sensitizing effects. Decreased adiponectin levels and disturbed insulin sensitivity have been described in subjects born SGA.

Patients \& Methods: Adiponectin levels were measured in 76 (34f, $42 \mathrm{~m}$ ) young adult German patients born SGA. Oral glucose tolerance testing was performed and insulin sensitivity index (ISI) according to Matsuda et al (Diabetes Care, 1999;22(9):1462-70) was calculated.

Results: Patients were examined at a mean age of $19.2 \pm 0.5$ years. BMI-SDS was normal $(0.1 \pm 1.1$ in females and $-0.7 \pm 0.9$ in males $)$. None of the patients was obese and all patients had a normal body composition measured by bioimpedance analysis. Impaired glucose tolerance was found in one patient, none of the patients had developped type 2 diabetes. Final height $(\mathrm{FH})$ was below the third percentile in 7 patients $(9.2 \%)$. Mean serum adiponectin levels were $13.4 \pm 5.4 \mu \mathrm{g} / \mathrm{ml}$ in females and $9.7 \pm 4.2 \mu \mathrm{g} / \mathrm{ml}$ in males, $\mathrm{p}<0.05$. In all patients adiponectin levels were above $-2.0 \mathrm{SD}$ (mean adiponectin SD in females $-0.1 \pm 1.0$ and in males- $0.3 \pm 1.0, \mathrm{p}>0.05)$. ISI was reduced $(<5)$ in 18 patients $(23.7 \%)$. There was a positive correlation between adiponectin levels and ISI, $r=0.3, p<0.01$. No correlation was found between waist-hip ratio and ISI. Hyperandrogenemia was present in both females and males with elevated levels of androstenedione $(+4.8 \pm 2.6 \mathrm{SD})$, testosterone $(+2.5 \pm 3.1 \mathrm{SD}), 17$ hydroxy-progesterone $(0.1 \pm 2.1 \mathrm{SD})$ and DHAS $(-0.4 \pm 1.5 \mathrm{SD})$.

Conclusion: Adiponectin levels in young adults born SGA were within the normal range and correlated positively with insulin sensitivity $(\mathrm{r}=0.3, \mathrm{p}<0.01)$. Despite normal adiponectin levels reduced insulin sensitivity was present in almost one quarter of the patients. Hyperandrogenemia with excessive levels of androstenedione and testosterone was found in our cohort of SGA adults and may contribute to altered insulin sensitivity. 


\section{P01-683 SGA \\ Deterioration of glucose metabolism in adults born SGA: results from a 10-yr prospective study \\ Taly Meas ${ }^{1}$; Didier Chevenne'; Samia Deghmoun ${ }^{1}$; Dominique Collin ${ }^{3}$; Paul Czernichow'; ${ }^{1}$ Claire Lévy-Marchal ${ }^{1}$ \\ ${ }^{1}$ Robert Debré Hospital, INSERM Unit 690, Paris, France; ${ }^{2}$ Robert \\ Debré Hospital, Hormonology, Paris, France; ${ }^{3}$ Hôpital of Haguenau, \\ Gynecology and Obstetrics, Haguenau, France}

Insulin resistance (IR) observed in adults born SGA (small for gestational age) may result either from changes in body composition induced as early as during the catch-up period or from "programming" of peripheral tissues inducing IR, which would be more severe and more rapidly progressive in SGA-born subjects than in adults born AGA (adapted for gestational age).

These hypotheses were tested by prospectively observing over 10 years two groups of young adults selected on birth data from a population-based Maternity registry: 88 subjects $(43 \mathrm{~F}+45 \mathrm{M})$ born full-term SGA $(\mathrm{BW}<10$ th percentile) have been compared to $133(70 \mathrm{~F}+63 \mathrm{M})$ AGA controls $(25$ th $<$ AGA $<75$ th perc.) at 22 and 32 years of age. All subjects underwent OGTT and insulin sensitivity was assessed by QUICKI (derived from glucose and insulin fasting concentrations).

\begin{tabular}{llll}
\hline & SGA & AGA & $p$ \\
\hline $\begin{array}{l}\text { Age (yr) 1rst } \\
\text { observation }\end{array}$ & $21.9(2.1)$ & $21.2(2.0)$ & 0.05 \\
\hline $\begin{array}{l}\text { BMI (kg/m2)1rst } \\
\text { observ }\end{array}$ & $22.4(3.9)$ & $23.0(4.2)$ & 0.3 \\
\hline $\begin{array}{l}\text { Glucose 120min } \\
\text { (mmol/l) 1rst } \\
\text { observ }\end{array}$ & $5.3(1.1)$ & $5.2(1.0)$ & 0.3 \\
\hline $\begin{array}{l}\text { QUICKI 1rst } \\
\text { observ }\end{array}$ & $0.17(0.01)$ & $0.17(0.01)$ & 0.2 \\
\hline $\begin{array}{l}\text { Age 2nd observ } \\
\text { BMl 2nd observ }\end{array}$ & $31.9(1.2)$ & $32.4(1.3)$ & 0.4 \\
\hline $\begin{array}{l}\text { Glucose 120 min } \\
\text { 2nd observ }\end{array}$ & $5.9(1.6)$ & $24.7(5.0)$ & 0.8 \\
\hline $\begin{array}{l}\text { QUICKI 2nd } \\
\text { observ }\end{array}$ & $0.16(0.01)$ & $0.4(1.4)$ & 0.05 \\
\hline Diff BMI (2nd-1rst) & $2.6(3.2)$ & $1.7(3.2)$ & $0.06 \dagger$ \\
\hline $\begin{array}{l}\text { Diff QUICK (2nd- } \\
\text { 1rst) }\end{array}$ & $-0.007(0.002)$ & $-0.005(0.001)$ & $0.06 \dagger$ \\
\hline
\end{tabular}

$\dagger$ In a multivariate analysis, the progression of QUICKI over time was not significantly affected by gender and fat mass but was significantly associated with the change in BMI $(p=0.01)$ and marginally different between SGA- and AGA-groups $(p=0.06)$. In conclusion, over a 10 -yr period, adults born SGA show a more rapid deterioration of glucose tolerance and insulin sensitivity due in part but not only to accretion of more adiposity. This observation suggests that fetal programming affects both body composition and glucose metabolism independently.

\section{P01-684 SGA \\ Serum lipid concentrations in children and young adults born SGA; a longitudinal study Maria Salonen ${ }^{\text {; }}$ Sirpa Tenhola²; Jarmo Jääskeläinen"; \\ Raimo Voutilainen ${ }^{1}$ \\ ${ }^{1}$ Kuopio University Hospital, Department of Pediatrics, Kuopio, \\ Finland; 'Kymenlaakso Central Hospital, Department of Pediatrics, Kotka, Finland}

Low birth size has been associated with increased risk for cardiovascular diseases in adults, and some studies have shown a relationship between low birth weight and dyslipidemia. The aim of our study was to measure serum lipid concentrations and anthropometric characteristics in an SGA population at 20 years of age and relate the lipid values to those at 12 years of age and to catch-up growth in early childhood. Twenty-five SGA subjects (17 females) and their age- and sex-matched appropriate for gestational age (AGA) control subjects were studied at the age of 20 years. These SGA and AGA subjects had been studied at the age of 12 years. Anthropometric measures were available at birth, 5 years, and 20 years age. The BMI-adjusted serum total cholesterol (4.36 vs. $4.17 \mathrm{mmol} / \mathrm{l}, \mathrm{p}=0.499)$, LDL cholesterol (2.74 vs. 2.39 $\mathrm{mmol} / \mathrm{l}, \mathrm{p}=0.097$ ), and triglycerides ( 1.08 vs. $1.04 \mathrm{mmol} / \mathrm{l}, \mathrm{p}=0.585)$ did not differ between the SGA and AGA groups, but HDL cholesterol concentrations were lower in the SGA than AGA group (1.43 vs. $1.55, \mathrm{p}=0.029)$. Serum total, LDL and HDL cholesterol concentrations at 20 years correlated strongly with those measured at 12 years $(\mathrm{r}=0.587, \mathrm{p}=0.002 ; \mathrm{r}=0.592, \mathrm{p}=0.002 ; \mathrm{r}=0.589$, $\mathrm{p}=0.002$, respectively) in the SGA subjects. LDL cholesterol level at 20 years correlated inversely with catch-up growth in height between 0 and 5 years of age $(r=-0.446, p=0.025)$. In conclusion, BMI-adjusted serum HDL cholesterol concentration was lower in the 20-year-old SGA subjects than in their AGA controls, and poor early catch-up growth in height was associated with higher LDL cholesterol level. In addition, clear tracking of cholesterol concentrations was found between 12 and 20 years of age.

\section{P01-685 SGA \\ The relationships between adiponectin, leptin, IGF-I, insulin and account of mitochondrial DNA in cord blood and birth weight \\ Sae Min Lee $;$; Heon-Seok Han²; Choong Ho Shin ${ }^{3}$; Sei Won Yang ${ }^{3}$ \\ ${ }^{1}$ College of medicine, Hanyang University, Pediatrics, Seoul, Republic of Korea; 2University of medicine, Chungbuk Univesity, Pediatrics, Seoul, Republic of Korea; ${ }^{3}$ Seoul National University College of Medicine, Department of Pediatrics, Seoul, Republic of Korea}

Adipocytokine have been thought to have a role in fetal growth and intrauterine growth retardation(IUGR) is associated with development of non-insulin dependent diabetes mellitus(NIDDM) in adulthood and recently some investigators reported that the amount of mitochondrial DNA(mtDNA) in a given amount of genomic DNA were lower in adult NIDDM patients than in healthy controls. This study investigated whether the plasma leptin and adiponectin, IGF-1 and amount of mtDNA in cord blood are related to birth weight.

We studied 143 term babies(Gestational age $\geq 37$ weeks). These babies were classified into 3 groups; SGA(small for gestational age, birth weight $<2500 \mathrm{~g}$, $\mathrm{n}=21$ ), $\mathrm{AGA}$ (appropriate for gestational age, $2500 \mathrm{~g} \leq \mathrm{BW}<4000 \mathrm{~g}, \mathrm{n}=112$ ), LGA(large for gestational age, $\mathrm{BW} \geq 4000 \mathrm{~g}, \mathrm{n}=10$ ). We measured the plasma adiponectin, IGF-1 leptin and insulin level in cord blood by RIA(leptin, adiponectin) and IRMA(IGF-1insulin). Amount of mtDNA of just 47 samples were measured by quantitive method in use of real time PCR.

There was significant positive correlation between birth weight and cord blood leptin and IGF-1( $\mathrm{r}=0.473, \mathrm{P}=0.00 / \mathrm{r}=0.307, \mathrm{P}=0.00)$. In addition, plasma leptin level were positively correlated with plasma insulin and IGF-1( $\mathrm{r}=037$, $\mathrm{P}=0.00 / \mathrm{r}=0.2, \mathrm{P}=0.02$ ). SGA group showed adiponectin levels significantly lower than AGA group (84.3?33.6 ug/ml vs. 101.1?51.4 ug/ml) and higher than LGA group $(84.3 ? 33.6 \mathrm{ug} / \mathrm{ml}$ vs. $64.7 ? 35.3 \mathrm{ug} / \mathrm{ml} ; \mathrm{P}=0.041)$. LGA group showed significantly higher amount of mtDNA compared with SGA either AGA group(29.4?44.4 vs. 8.5?10.1, $\mathrm{P}=0.015 / 29.4$ ? 44.4 vs. 6.7?5.8, $\mathrm{P}=0.029)$. In Multiple regression analysis, independent factors that affects birth weight are cord blood leptin, IGF-1 level. Serum leptin and IGF-1 level of cord blood is positively correlated to fetal growth. Our results indicate that amount of mtDNA may not contribute to the development of NIDDM in adults who have born SGA 


\section{P01-686 SGA \\ Assessment of metabolic parameters in children born premature with extremely low birth weight $(<1000 \mathrm{~g})$ : comparison between those born small (SGA) or appropriate (AGA) for gestational age}

Sonja Stutte ${ }^{1}$; Joachim Woelfle ${ }^{1}$; Alexandra Kehl'; Peter Bartmann ${ }^{2}$; Bettina Gohlke

'University Hospital, Pedatrics, Bonn, Germany; ${ }^{2}$ University Hospital, Neonatology, Bonn, Germany

With recent advancement in intensive care mortality for extreme premature infants (birth weight $<1000 \mathrm{~g}$ ) has improved. Term newborns with birth weight classified as "small for gestational age" have an increased risk to develop certain metabolic abnormalities later in life. There is now evidence that prematurity as well conveys a risk of reduced insulin sensitivity similar to that observed in SGA children. We studied metabolic data in 46 otherwise healthy former premature infants with extremely low birth weight $(<1000 \mathrm{~g})$ with regard to SGA or AGA. Mean age at examination 6.1 years. We subdivided in those who had a sufficient catch-up growth (actual height SDS within +/- 1 SD from target height SDS) and those without sufficient catch-up growth. SGA was considered for birth length and/or weight $<-2$ SD according to German standards. Blood glucose levels, Insulin, HOMA, lipids, IGF1, IGFBP3, Cortisol, Androstendion, DHEAS and blood pressure were within normal ranges and not significantly different between groups.

\begin{tabular}{llll} 
& AGA $(n=31)$ & SGA $(n=15)$ & $p$-value \\
\hline HOMA (range) & $0.58(0.2-2.67)$ & $0.52(0.19-2,93)$ & 0.82 \\
\hline IGF-1 (SDS) & $-0.21(-1,98$ to 1,15$)$ & $-0,33(-3.64$ to 1.16$)$ & 0.69 \\
IGF-BP-3 (SDS) & $0.33(-1.73$ to 2.92$)$ & $-0.05(-3.12$ to 2.21$)$ & 0.35 \\
$\begin{array}{l}\text { Adiponectin } \\
\text { (ng/ml) }\end{array}$ & $14.7(3.9$ to 30.7$)$ & $14.3(7.5-21.0)$ & 0.93
\end{tabular}

There was no significant difference for all parameters between those infants who had a sufficient catch-up growth in comparison to those who did not. Although we did not find metabolic abnormalities or an altered secretion of energy homeostasis regulating hormones this might be due to the small size of our patient group. Furthermore metabolic disturbances might become manifest later in life. Therefore, further follow-up is mandatory.

\section{P01-687 SGA \\ Thyroid volume evaluation in children born small for gestational age (SGA)}

Maria Korpal-Szczyrska' ${ }^{1}$; Wojciech Kosiak²; Jozef Szczyrski²; Dorota Birkholz

${ }^{1}$ Medical University of Gdansk, Pediatric Endocrinology, Gdansk, Poland; ' 2 Medical University of Gdansk, Pediatric Nephrology, Gdansk, Poland

Alterations in thyroid function in SGA children have been reported but little is known about thyroid size in them. The aim of the study was to examine thyroid size in short SGA (SSGA) children and compare to those in short born appropriate for gestational age (SAGA) and children born appropriate for gestational age of normal height (NAGA).

Thyroid was evaluated by ultrasound in 48 SSGA ( 24 males) mean age 7,45 $\pm 1,15 \mathrm{yr}, 50 \mathrm{SAGA}$ (25 males) mean age 7,5 $\pm 1,32 \mathrm{yr}$ and 50 NAGA (25males) mean age 7,66 $\pm 1,17 \mathrm{yr}$. TSH, fT4,fT3 and anti-thyroid antibodies were determined in all of them. All children lived in iodine sufficient area.

Height SDS in SSGA $(-3,04 \pm 0,67)$ was not different $(\mathrm{p}>0,1)$ from SAGA ($2,97 \pm 0,68)$; in NAGA was $0,25 \pm 0,69$ SDS. Thyroid volume in SSGA $(2,99$ $\pm 1,24 \mathrm{ml})$ was not significantly different neither from SAGA $(2,76 \pm 0,98 \mathrm{ml})$ nor NAGA $(3,16 \pm 0,8 \mathrm{ml})$. But the body surface in SSGA $\left(0,71 \pm 1,15 \mathrm{~m}^{2}\right)$ was lower $(\mathrm{p}<0,025)$ than in SAGA $\left(0,76 \pm 0,09 \mathrm{~m}^{2}\right)$ as well as in NAGA $\left(0,98 \pm 0,1 \mathrm{~m}^{2}, \mathrm{p}<0,001\right)$. When thyroid volumes of the children were related to their body surface (Vol/BS) significant differences were found. Vol/BS in SSGA $\left(4,15 \pm 1,51 \mathrm{ml} / \mathrm{m}^{2}\right)$ was higher $(\mathrm{p}<0,05)$ than in SAGA $(3,61 \pm 1,11 \mathrm{ml} / \mathrm{m}$ $\left.{ }^{2}\right)$ as well as in NAGA $\left(3,22 \pm 0,7 \mathrm{ml} / \mathrm{m}^{2}, \mathrm{p}<0,001\right)$.TSH levels were higher in SSGA than in SAGA group $(3,22 \pm 1,21$ vs. $1,28 \pm 1,04 \mathrm{mU} / \mathrm{L}, \mathrm{p}<0,01)$. Antithyroid antibodies were negative in all children.

Conclusions: Although thyroid volume in SSGA children is similar to this in SAGA and NAGA when related to the body surface volume turns out to be higher. Therefore in evaluation of thyroid size in SGA children we should refer it to the body surface.

\section{P01-688 SGA \\ Plasma matrix metalloprotein-9 (MMP-9) levels and blood pressure in short children born small for gestational age (SGA) before and during growth hormone treatment}

Ruben Willemsen ${ }^{1}$; Marije van Dijk'; Albert van Toorenenbergen²; Anita Hokken-Koelega

${ }^{1}$ Erasmus MC Sophia, Pediatric Endocrinology, Rotterdam, Netherlands; 'Erasmus MC, Clinical Chemistry, Rotterdam, Netherlands

Background: Matrix metalloproteinases (MMPs) are zinc-dependent endoproteinases with the capability to remodel the extracellular matrix. Since atherosclerosis results from constant remodelling of the arterial wall, MMPs are thought to play a prominent role in the development of atherosclerosis and cardiovascular disease. Increased levels were found in hypertensive patients and high levels predicted cardiovascular mortality. Short SGA children have an increased systolic blood pressure (SBP), which decreases during long-term $\mathrm{GH}$ treatment. The underlying mechanism is still unknown.

Objectives: (i) to compare plasma MMP-9 levels and BP in short SGA children before and during $\mathrm{GH}$ treatment with untreated SGA controls and (ii) to investigate if MMP-9 is associated with BP

Methods: 38 prepubertal short SGA children were randomized to receive either 1 (group A) or 2 (group B) $\mathrm{mg} \mathrm{GH} / \mathrm{kg} \cdot$ day for $1 / 2$ year followed by $1 \mathrm{mg}$ thereafter. At baseline, after $1 / 2$ and 1 year, MMP- 9 levels were measured. For comparison, 17 untreated age- and sex-matched SGA controls were measured at baseline and after 1 year. Resistin levels were measured in the GH-groups only at baseline and after $1 / 2$ year. BP was measured in all groups at baseline, after $1 / 2,1$ and 3 years.

Results:

\begin{tabular}{|c|c|c|c|c|c|c|c|c|}
\hline & Groups & Baseline & $1 / 2$ year & $\begin{array}{l}\text { P-value } \\
\text { change } \\
0 \rightarrow 1 / 2 \\
\text { year }\end{array}$ & 1 year & $\begin{array}{l}\text { P-value } \\
\text { change } \\
0 \rightarrow 1 \\
\text { year }\end{array}$ & 3 year & $\begin{array}{l}\text { P-value } \\
\text { change } \\
0 \rightarrow 3 \\
\text { year }\end{array}$ \\
\hline \multirow[t]{3}{*}{ Age } & A & $6.4(1.0)$ & $6.9(1.0)$ & & $7.4(1.1)$ & & $9.4(1.0)$ & \\
\hline & $\begin{array}{c}\text { B } \\
\text { Untreated }\end{array}$ & $\begin{array}{l}6.5(1.1) \\
6.2(0.9)\end{array}$ & $\begin{array}{l}7.0(1.1) \\
6.5(1.2)\end{array}$ & & $\begin{array}{l}7.5(1.2) \\
7.2(1.0)\end{array}$ & & $\begin{array}{l}9.5(1.2) \\
9.2(1.1)\end{array}$ & \\
\hline & SGA & & & & & & & \\
\hline \multirow[t]{3}{*}{ MMP-9 } & A & $125(74-341)$ & $117(79-145)$ & 0.09 & $95(62-132)$ & 0.04 & - & - \\
\hline & & $106(60-218)$ & $92(69-114)$ & 0.22 & $79(62-144)$ & 0.63 & - & - \\
\hline & $\begin{array}{l}\text { Untreated } \\
\mathrm{SGA}\end{array}$ & $88(73-118)$ & - & - & $93(69-169)$ & 0.52 & - & - \\
\hline \multirow[t]{3}{*}{ SBP SDS } & A & $1.3(0.6)$ & $1.6(1.2)^{*}$ & 0.45 & $1.4(0.7)$ & 0.81 & $0.7(0.7)$ & 0.015 \\
\hline & & $1.1(1.1)$ & $1.6(1.1)^{*}$ & 0.052 & $1.0(0.9)$ & 0.60 & $0.2(1.2)$ & 0.026 \\
\hline & $\begin{array}{l}\text { Untreated } \\
\text { SGA }\end{array}$ & $0.6(1.1)$ & $0.6(0.7)$ & 0.74 & $0.8(1.0)$ & 0.68 & $0.5(1.0)$ & 0.56 \\
\hline \multirow[t]{3}{*}{ DBP SDS } & A & $0.7(1.1)$ & $0.6(1.2)$ & 0.45 & $-0.1(1.0)$ & 0.016 & $0.0(0.7)$ & 0.004 \\
\hline & & $0.1(1.2)$ & $0.4(0.7)$ & 0.39 & $0.3(0.9)$ & 0.75 & $0.0(0.7)$ & 0.64 \\
\hline & $\begin{array}{c}\text { Untreated } \\
\text { SGA }\end{array}$ & $0.4(0.9)$ & $0.2(0.9)$ & 0.17 & $0.2(1,1)$ & 0.66 & $-0.4(0.8)$ & \\
\hline \multirow{3}{*}{ Resistin } & & $10.4(2.9)$ & $12.5(4.3)$ & & - & - & . & - \\
\hline & & $7.9(2.7)$ & $11.4(6.8)$ & $<0.05$ & - & . & - & - \\
\hline & Untreated & & & & - & - & - & - \\
\hline 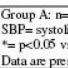 & $\begin{array}{l}\text { Gerkg kg } \\
\text { pressure } \\
\text { ed SGA }\end{array}$ & $\mathrm{B}: \mathrm{n}=20$. & $\begin{array}{l}\text { /kg.day, Unt } \\
\text { c: SDS= stan }\end{array}$ & $\begin{array}{l}\text { GA: : }= \\
\text { viation }\end{array}$ & & 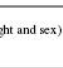 & & \\
\hline
\end{tabular}

MMP-9 levels and DBP SDS decreased during GH treatment in group A only, but were not correlated with each other. SBP SDS tended to increase in the GH-treated groups after $1 / 2$ year, but after 3 years it was significantly lower than baseline. At baseline and after $1 / 2$ year, MMP-9 levels correlated with resistin levels and changes in these levels during GH treatment were also correlated.

Conclusions: MMP-9 levels and DBP SDS decreased modestly during GH treatment in the low GH-dose group only, but were not correlated with each other. MMP-9 correlated with resistin and did not correlate with SBP SDS SBP SDS in GH-treated children decreased significantly on the longer term, whereas in untreated SGA children it remained similar, indicating that these changes are not due to increased anxiety at baseline. 


\section{P01-689 SGA}

Thyroid function in short SGA children and the effect of grow th hormone (GH) treatment

Sandra De Kort; Ruben Willemsen; Marije Van Dijk;

Danielle Van der Kaay; Anita Hokken-Koelega

Erasmus MC Sophia, Department of Pediatrics, Div. of Endocrinology, Rotterdam, Netherlands

SGA has been associated with altered thyroid function, particularly in preterm born SGA infants. One study in short non-GH-deficient children concluded that $\mathrm{GH}$ treatment did not change thyroid function. However, in GH-deficient patients treated with GH, fT4 and TSH levels decreased. No reports exist about the effect of GH treatment on thyroid function in short SGA children. The aim of this study was to explore the hypothesis that thyroid function is altered in short SGA children and influenced by GH treatment. Height, TSHandfT4levelsweremeasured in 227 pre-pubertalshortSGAchildren (mean age $7.4 \mathrm{yr}$ ) without GH deficiency, at start of GH treatment and after 6, 12 and 24 months. A reference group was used to calculate age-matched SDscores for fT4 and TSH levels. All patients were treated with GH $1 \mathrm{mg} / \mathrm{m} 2 \cdot$ day except for 15 patients who received $2 \mathrm{mg} / \mathrm{m} 2$-day during the first 6 months. At baseline, fT4 SDS was not significantly different from 0, but TSH was $>$ 0 SDS. FT4 SDS decreased during the first 6 months of GH treatment and remained at the same level until 24 months, within the normal range.

TSH SDS did not change during treatment. Changes in fT4 SDS did not correlate with changes in TSH SDS. There was at baseline no significant correlation between fT4 SDS or TSH SDS and gestational age, birth weight SDS or birth length SDS. There was after 6 months no significant difference in the decrease of fT4 between children treated with 1 or $2 \mathrm{mg} \mathrm{GH}$.

Short SGA children have slightly elevated TSH levels within the normal range. $\mathrm{GH}$ treatment coincides with a significant decrease of fT4 after 6 months of treatment but mean levels stay in the normal range.

\begin{tabular}{|c|c|c|c|c|}
\hline & $T=0$ & $T=6 m o$ & $\mathrm{~T}=12 \mathrm{mo}$ & $\mathrm{T}=24 \mathrm{mo}$ \\
\hline$N$ & 227 & 141 & 161 & 135 \\
\hline fT 4 & $19.37(3.7)$ & $17.75(2.9)^{\circ}$ & $17.75(3.2)^{\circ}$ & $18.04(2.8)^{\circ}$ \\
\hline fT 4 SDS & $0.10(1.0)$ & $-0.35(0.8)^{\mathrm{a}, \mathrm{c}}$ & $-0.35(0.9)^{\mathrm{a}, \mathrm{c}}$ & $-0.27(0.8)^{\mathrm{a}, \mathrm{c}}$ \\
\hline fT $4<p 5$ & - & - & $2(1 \%)$ & - \\
\hline fT $4>p 95$ & $11(5 \%)$ & $2(1 \%)$ & $4(2 \%)$ & $3(2 \%)$ \\
\hline TSH & $2.59(1.3)$ & $2.69(1.3)$ & $2.43(1.2)$ & $2.55(1.3)$ \\
\hline TSH SDS & $0.15(1.0)^{\mathrm{b}}$ & $0.23(0.9)^{b}$ & $0.08(0.8)$ & $0.15(0.9)^{b}$ \\
\hline $\mathrm{TSH} \leq p 5$ & $1(0.4 \%)$ & $2(1 \%)$ & - & - \\
\hline $\mathrm{TSH}=p 95$ & $26(11 \%)$ & $13(9 \%)$ & $14(8 \%)$ & $11(8 \%)$ \\
\hline Height SDS & $-3.00(0.6)$ & $-2.42(0.6)$ & $-2.20(0.6)$ & $-1.74(0.7)$ \\
\hline
\end{tabular}

\section{P01-690 SGA \\ Hyperandrogenism in young adults born small for gestational age}

Stephanie Putzker ${ }^{1}$; Walter Bonfig ${ }^{1}$; Susanne Bechtold ${ }^{1}$; Karl Kugler2; Hans Peter Schwarz'

${ }^{1}$ Dr. von Haunersches Kinderspital, Pediatric Endocrinology and Diabetology, Munich, Germany; ${ }^{2}$ Dr. von Haunersches Kinderspital, Pediatric Neurology, Munich, Germany

Being born small for gestational age (SGA) has often been demonstrated to have an impact on the cardiovascular and metabolic system but also affects hormone levels and pubertal development. Asymptomatic hyperandrogenism and polycystic ovary syndrome have also been found in SGA patients.

Objective was to examine whether patients with SGA within the well documented cohort of the Bavarian Longitudinal Study (BLS II) showed abnormalities in androgen levels or signs of hyperandrogenism.

Venous blood samples of $76(34 \mathrm{f} / 42 \mathrm{~m})$ young adults $(19.2 \pm 0.5 \mathrm{yr})$ born SGA were drawn during a $2 \mathrm{~h}$ oral glucose tolerance test for measurement of dehydroepiandrosterone sulphate (DHEAS), testosterone, androstenedione, 17-hydroxyprogesterone (17-OHP), LH, FSH and estradiol. Age at pubarche and menarche was asked during examination. Hirsutism in girls was assessed by using Ferriman-Gallwey's score. Insulin sensitivity was measured by using Matsuda's index (ISI), indicating insulin resistance with values $<5$.

Elevated levels were found for androstenedione (4.8 $\pm 2.6 \mathrm{SD})$ and testosterone $(2.5 \pm 3.1 \mathrm{SD})$ for the whole group. Hormone levels based on gender are given in the table.

\begin{tabular}{|c|c|c|c|c|c|c|c|c|}
\hline & \multicolumn{4}{|c|}{$\begin{array}{l}\text { Females } \\
(n=34)\end{array}$} & \multicolumn{4}{|c|}{$\begin{array}{l}\text { Males } \\
(n=42)\end{array}$} \\
\hline & Min & $\operatorname{Max}$ & Mean & SD & Min & $\operatorname{Max}$ & Mean & SD \\
\hline DHEAS SDS & -2.0 & 4.0 & 0.4 & 1.4 & -3.3 & 1.3 & -1.1 & 1.2 \\
\hline $\begin{array}{l}\text { Androstene- } \\
\text { dione SDS }\end{array}$ & 0.0 & 7.9 & 3.7 & 2.0 & 0.6 & 12.1 & 5.8 & 2.6 \\
\hline 17-OHP SDS & -2.4 & 5.1 & -0.4 & 2.2 & -2.8 & 5.1 & 0.5 & 1.8 \\
\hline $\begin{array}{l}\text { Testosterone } \\
\text { SDS }\end{array}$ & -2.5 & 15.1 & 3.6 & 3.9 & -3.4 & 5.4 & 1.5 & 1.8 \\
\hline $\begin{array}{l}\text { Estradiol } \\
{[\mathrm{pg} / \mathrm{ml}]}\end{array}$ & 2.2 & 236.0 & 51.0 & 62.4 & 15.8 & 46.4 & 28.1 & 8.0 \\
\hline $\mathrm{LH}[\mathrm{mU} / \mathrm{ml}]$ & 0.1 & 14.9 & 5.2 & 4.7 & 2.1 & 18.3 & 5.7 & 3.2 \\
\hline $\mathrm{FSH}[\mathrm{mU} / \mathrm{ml}]$ & 0.1 & 10.1 & 4.0 & 2.6 & 0.9 & 43.0 & 5.8 & 7.0 \\
\hline
\end{tabular}

Acne was present in 7 (20.6\%) females and 9 (21.4\%) males; hirsutism score according to Ferriman-Gallwey was $>5$ in only $2(6 \%)$ girls. $18(53 \%)$ female patients were taking oral contraceptives. Age at pubarche and menarche in girls was $11.4 \pm 1.1 \mathrm{yr}(\mathrm{n}=28)$ and $13.0 \pm 1.2 \mathrm{yr}(\mathrm{n}=34)$. Pubarche in boys took place at a mean age of $12.5 \pm 1.1 \mathrm{yr}(\mathrm{n}=12)$. The $2 \mathrm{~h}$ oral glucose tolerance test showed reduced insulin sensitivity (ISI $<5$ ) in $23.7 \%$ of the patients.

In our cohort markedly increased serum levels of androstenedione and testosterone could be found. Interestingly, only a few patients showed clinical signs. Hyperandrogenism seems to play a part in the endocrinemetabolic setting of SGA patients leading to insulin resistance and increasing hyperinsulinemia.

\section{P01-691 SGA \\ Abnormal aromatase and 5o-reductase activity in adult males born SGA \\ Kerstin Allvin; Hans Fors; Carina Ankarberg-Lindgren; \\ Jovanna Dahlgren \\ Institute of Clinical Sciences, Department of Pediatrics, Gothenburg \\ University, Gothenburg, Sweden}

In females, fetal growth restriction correlates with hyperandrogenism and ovarian hyporesponsiveness to FSH. In adult males, born SGA, we have previously found increased $17 \beta$-estradiol (E2) levels but normal testosterone (T) levels (Hormone Research 2004; 62(suppl 2):1-215). Therefore we proceeded to study other sex hormones, as we hypothesized that several steroid enzymes are affected in individuals born SGA. 25 adult males of normal stature, born SGA (birth weight and/or length <-2 SDS), were studied. Their mean (SD) birth weight was $-2.21(0.82)$ and birth length $-2.38(0.75)$ SDS.

Age at investigation was 22.3 (2.5) years and final height was $-0.39(0.79)$ SDS. Sex hormones and gonadotropin levels were measured and compared with samples drawn from 44 male controls. Their age was $20.6(0.74)$ years and final height 0.34 (0.89) SDS. BMI did not differ between groups, 23.5 (3.3) and $22.9(2.3) \mathrm{kg} / \mathrm{m} 2$, respectively. The SGA group showed significantly higher levels of dihydrotestosterone (DHT) 1803 (559) pmol/L compared to controls 1489 (371) pmol/L $(\mathrm{p}<0.05)$. DHT correlated negatively to adult weight SDS $(\mathrm{r}=-0.36, \mathrm{p}<0.01)$, adult BMI $(\mathrm{r}=-0.26, \mathrm{p}<0.05)$, birth weight $\operatorname{SDS}(\mathrm{r}=-0.27, \mathrm{p}<0.05)$ and birth length SDS $(\mathrm{r}=-0.27, \mathrm{p}<0.05)$. Aromatase activity, calculated as E2/T ratio, was higher in males born SGA $0.45(0.14)$ $\%$ compared to controls $0.31(0.10) \%(\mathrm{p}<0.001)$. 5- $\alpha$ reductase activity, calculated as DHT/T ratio, was also higher in the SGA group 12.0 (2.7) \% than in controls $9.9(2.5) \%(\mathrm{p}<0.01)$. Gonadotropin levels did not differ between groups. Adult males of normal stature, born SGA, have increased $17 \beta$-estradiol/testosterone ratio and dihydrotestosterone/testosterone ratio, an indirect measurement of abnormal aromatase and $5 \alpha$-reductase activity. 
P01-692 SGA

Russell-Silver syndrome: attention deficit hyperactivity disorder (ADHD) incidence and the effect of age

Amy Barkham ${ }^{1}$; Jeremy Kirk²; Gill Harris ${ }^{3}$

University of Birmingham, Psychology, Birmingham, United Kingdom; Birmingham Children's Hospital, Endocrinology, Birmingham, United Kingdom; ' University of Birmingham, Psychology, Birmingham, United Kingdom

Attention Deficit Hyperactivity Disorder Combined, is a disorder characterised by developmentally inappropriate hyperactivity, impulsivity and inattention. The symptoms are known to decrease with age (DuPaul et al, 1998) The connection between low birth weight and ADHD is well established (Kelly, 2001). However, little research has looked at the incidence in children with Russell Silver Syndrome (RSS), a group of children with low birth weight as a consequence of growth restriction in utero, continued short stature and characteristic facial features. Bogdanov et al (1995) reported, in a published abstract, a higher incidence of ADHD in a group of 16 RSS children, than in controls. The objective of this research was to establish the incidence of ADHD in an RSS population and assess age effects. 23 children, 12 boys and 11 girls, aged, 5 - 16 years (mean age 9.47), with an RSS diagnosis, were recruited through the Child Growth Foundation. Parents completed the home version of ADHD rating scale-IV, scores were converted to percentiles, using age and gender norms (DuPaul et al 1998). 17 of the 23 children (10 males and 7 females) had scores placing them above the 70th percentile for their age and gender, indicating a higher incidence of ADHD in children with RSS. There was a significant positive correlation between age and percentile, $(\rho=0.441, p=0.035)$, as age increased, the percentile increased. Total raw score, unexpectedly showed a positive, though not significant, correlation with age, $(\rho=0.170, p=0.434)$ as age increased, the raw score increased. The data indicate that children with RSS score higher on the ADHD rating scale in all domains. They also show that these symptoms do not decrease with age, they appear to increase. The reason for this unexpected finding requires further investigation.

\section{P02-693 Thyroid 1 \\ Urinary iodine status of postpartum mothers and their term newborns and the relationships to neonatal thyroid functions}

Narumon Patarakijvanich ${ }^{1}$; Prasit Ruengrairatanaroj'; Arrinda Maaree ${ }^{3}$; Ratana Limamornrat

${ }^{1}$ Prince of Songkla University, Pediatrics, Songkla, Thailand; 'Prince of Songkla University, Pathology, Songkla, Thailand; ${ }^{3}$ Prince of Songkla University, Epidemiology, Songkla, Thailand; ${ }^{4}$ Prince of Songkla

University, Postpartum Ward, Songkla, Thailand

Songkla is a seashore province in Southern Thailand and is believed to be iodine sufficient. However, according to WHO criteria, the percentage of newborn with $\mathrm{TSH}>5 \mathrm{mIU} / \mathrm{L}$ from congenital hypothyroid newborn screening program in Songkla was $>40 \%$ indicating that Songkla is severely deficient in iodine.

To study the urinary iodine levels of postpartum mothers and their term newborns, their relationships, and the relationships to neonatal thyroid functions 175 pairs of postpartum mothers and their newborns delivered at our university hospital from February 2005 to September 2005 were studied. The mothers were without thyroid diseases and the newborns were healthy and term of 37-43 week gestation. The urine specimens of mothers and newborns were collected at 2-6 days postpartum. The venous blood samplings from the newborns for free thyroxine, total thyroxine, thyroglobulin and TSH were done mostly on the same day.

The median urinary iodine concentrations (UI) of newborns and postpartum mothers were $160.5 \mathrm{microg} / \mathrm{L}$ (range $37.3-4519)$ and $112.6 \mathrm{microg} / \mathrm{L}$ (range 0 -2398) respectively. The percentage of cases with UI below 100 microg/L in newborns and mother were $20.4 \%$ and $39.3 \%$ respectively. There was no correlation between maternal and neonatal UI ( $p$-value $=0.84)$. As regards the relationships of neonatal thyroid functions to UI and UI to creatinine ratio, there was statistically significant positive correlation between neonatal TSH and maternal UI ( $p$-value $=0.023)$.

This study revealed that although the median value of maternal and neonatal UI were higher than 100 microg/L, there were still $20.4 \%$ of the newborns and
$39.3 \%$ of the mothers who had a low iodine concentration in the urine, therefore the issue needs further intervention. The finding of positive correlation between neonatal TSH and maternal UI needs further study to evaluate the appropriateness of neonatal TSH as indicator of iodine deficiency.

\section{P02-694 Thyroid 1 \\ CTLA-4 gene polymorphism at position 49 in exon 1 and the expression of CTLA-4 on peripheral $\mathbf{T}$ cells in children with Hashimoto's thyroiditis}

Anna Kucharska ${ }^{1}$; Alicja Wisniewska'; Elzbieta Gorska², Katarzyna Popko'; Maria Wasik²; Barbara Rymkiewicz-Kluczynska 'Medical University Warsaw, Paediatrics and Endocrinology, Warsaw, Poland; 'Medical University Warsaw, Laboratory Diagnostics and Clinical Immunology, Warsaw, Poland

CTLA-4 gene polymorphism is one of the strongest candidates of autoimmune thyroid diseases susceptibility locus except the HLA.

Some studies show that CTLA-4 exon 1 polymorphism affects the function of the CTLA-4 gene products. The aim of the study was to investigate the surface expression of CTLA-4 on peripheral T cells in homozygotes A/A and G/G at position 49 of exon 1 of CTLA-4 gene among children with Hashimoto's thyroiditis (HT) and in healthy controls.

Material: blood samples were obtained from 43 children with Hashimoto's thyroiditis and 45 children without any autoimmune disease or thyroid disease. HT was diagnosed on the basis of presence of thyroglobulin and thyroid peroxidase antibodies and typical picture of thyroid ultrasound.

Methods: CTLA-4 exon 1 polymorphism was defined by SSCP analysis and confirmed with FRLP using BbvI enzyme. The T cells subsets were analysed with three colour flow cytometry by Coulter EPICS XL cytometer. Statistical analysis was performed using Student's t test.

Results: Among children with HT there were more individuals with $\mathrm{G} / \mathrm{G}$ alleles than in control group (30\% and $12 \%$ respectively). The comparison of CTLA-4 expression between homozygotes $\mathrm{G} / \mathrm{G}$ and individuals with $\mathrm{A} / \mathrm{A}$ alleles in HT group showed no statistically significant difference. The same results were found in a control group. Nevertheless statistically significant lower CTLA-4 expression was found in HT children than in controls, both in $\mathrm{G} / \mathrm{G}$ homozygotes and in $\mathrm{A} / \mathrm{A}$ homozygotes $(\mathrm{p}<0,05)$.

Conclusions: our data suggest that the low surface expression of CTLA-4 on T cells in children with Hashimoto's thyroiditis is not dependent on genotype at position 49 in exon 1 of CTLA-4 gene.

\section{P02-695 Thyroid 1}

\section{A new mutation in the PAX8 gene in three members of the same family: from congenital hypothyroidism associated with thyroid hypoplasia to mild subclinical hypothyroidism Monica Vincenzi; Francesca Teofoli; Rossella Gaudino; \\ Marta Camilot; Francesca Federici; Luciano Tatò \\ University of Verona, D. Mother and Child, Biology-Genetics, Div. Pediatrics, Verona, Italy}

Several genetic causes of congenital hypothyroidism due to thyroid disgenesis are known, including mutations in genes encoding TSH receptor and transcription factors PAX8, FOXE1 and TTF1.

After genomic DNA extraction from circulating leucocytes, we amplified the exonic fragments of the PAX8 gene of a congenital hypothyroid male subject (23 yrs old), treated from birth with L-thyroxine. He exhibited at diagnosis blood spot TSH and T4 of $281 \mathrm{mIU} / \mathrm{L}$ (n.v. $<9 \mathrm{mIU} / \mathrm{L}$ ) and 1.8 $\mu \mathrm{g} / \mathrm{dL}$ (n.v. $>4.0 \mu \mathrm{g} / \mathrm{dL}$ ), respectively, associated with a hypoplastic thyroid by ultrasonography.

Upon DNA sequencing of DHPLC positive fragments, we identified a new mutation in PAX8 causing the heterozygous substitution of a conserved arginine with a triptophane in the pair box domain (c.397C/T, R133W). Analysis of his family revealed that his father and his sister (60 and $30 \mathrm{yrs}$ old, respectively) carried the same mutation at the heterozygous state too. Serum determinations evidenced high serum TSH for both the subjects (father: serum TSH $20.5 \mathrm{mIU} / \mathrm{L}$ and fT4 $7.3 \mathrm{ng} / \mathrm{L}$; daughter: serum TSH 6.85 
mIU/L and fT4 13.2 ng/L; n.v. TSH 0.4 - 4.0 mIU/L, fT4 8 - 19 ng/L). They were never detected and treated because at the time of their birth congenital hypothyroidism newborn screening still had to be instituted. The ultrasound examination revealed normally located thyroid glands with hypoplastic left lobes and nodules in the right lobes for both father and daughter. Functional studies of the new mutation are presently under evaluation.

As already reported in literature, PAX8 gene mutations display variable expressivity and even the same mutation gives rise to different clinical and biochemical phenotype in the same family.

\section{P02-696 Thyroid 1 \\ Incidence and aetiology of congenital hypothyroidism in Leeds, UK \\ Runa Majumdar'; Richard Feltbower'; Leonie Shapiro3; Paul Arundel'; Evangelia Charmandari'; Gary Butler'; Sabah Alvi' \\ ${ }^{1}$ Leeds Teaching Hospitals NHS trust, Dept of Paediatric and \\ Adolescent Endocrinology, Leeds, United Kingdom; ${ }^{2}$ University of \\ Leeds, Dept of Epidemiology and Statistics, Leeds, United Kingdom; \\ ${ }^{3}$ Leeds Teaching Hospitals NHS trust, Dept of Clinical Biochemistry, \\ Leeds, United Kingdom; ' ${ }^{4}$ niversity of Reading, Dept of Child Health, \\ Reading, United Kingdom}

Congenital hypothyroidism $(\mathrm{CH})$ has an annual incidence in the UK of between 1 in 3500 to 4000 births. In the majority of cases it is due to agenesis/ dysgenesis of the thyroid gland, which is almost always sporadic in nature. The aim of this study was to determine the incidence and aetiology of $\mathrm{CH}$ in Leeds (a city with a population of around 700000 ), and to compare these with published national data. The diagnosis of $\mathrm{CH}$ was based on thyroid stimulating hormone concentrations $>30 \mathrm{miu} / \mathrm{L}$ on neonatal screening capillary blood samples, confirmed with subsequent venous sampling. We used data from the regional neonatal screening laboratory to identify all babies who were diagnosed with $\mathrm{CH}$ between 1993 and 2003. We obtained information on sex, ethnicity, clinical presentation and family history from the medical case notes. Biochemical and radiological investigations and treatment schedules were also documented. During these 11 years, 102194 babies were screened and 34 were diagnosed with $\mathrm{CH}$, giving an annual incidence rate for our city of 1 in 3005 births. Of the 34 patients, 9 (26.5\%) had dyshormonogenesis, 8 $(23.5 \%)$ had agenesis of the thyroid gland, $7(20.5 \%)$ had gland hypoplasia and $2(6 \%)$ had ectopic thyroid tissue. Four $(11.75 \%)$ proved to have transient hyperthyrotropinaemia. A further 4 patients $(11.75 \%)$ were lost to follow-up. The incidence of $\mathrm{CH}$ in our centre is higher than that for the country as a whole, and probably reflects the high prevalence of dyshormonogenesis in our cohort (twice the figures cited in other studies). This is likely to be due to the fact that $8(23.5 \%)$ of our patients were of South Asian origin. Five of these $(62.5 \%)$ had dyshormonogenesis and were of consanguineous parentage. This study highlights the importance of detailed evaluation of infants with $\mathrm{CH}$ in ensuring the correct approach to management.

\section{P02-697 Thyroid 1 \\ lodine intake during pregnancy: its relationship to maternal and neonatal thyroid function and to child neurodevelopment}

Cristina Azcona; Marta Suarez; Marta Martin; Patricia Bastero;

Valentin Alzina; Genoveva Miranda

University Hospital. University of Navarra, Paediatric Endocrinology

Unit, Pamplona, Spain

Combined maternal and foetal hypothyroidism is almost always due to iodine deficiency. Its consequences in the newborn and child neurodevelopment are well recognised. Iodine requirements increase during gestation and the daily reference intake during this period is $200 \mathrm{mcg}$ (OMS, 2001).

The aim of this study is to assess daily iodine intake during pregnancy and its relationship to thyroid function at 37 weeks' gestation and newborn thyroid stimulating hormone (TSH) level. We also assess the relationship between iodine intake during pregnancy and child neurodevelopment. We studied 147 pregnant women prior informed consent. We determined TSH, Free-T4 (fT4) and 24-hour iodine urinary concentration (Kolthoff-Sandell method) at 37 weeks' gestation. Iodine intake was assessed by a food frequency intake questionnaire. Child neurodevelopment was evaluated by McCarthy scales.
Seven women were excluded because they were diagnosed with primary hypothyroidism. Only $21 \%$ of pregnant women took more than $200 \mathrm{mcg} /$ day of iodine. Ninety percent of women had urinary iodine concentration under $200 \mathrm{mcg} / \mathrm{L}$. There was a positive correlation between 24-hour iodine urinary concentrations and iodine intake $(r=0,23, p<0,05)$. Mean $\mathrm{f}-\mathrm{T} 4$ was $9,45 \mathrm{pmol} / \mathrm{L}$. Sixtyfour percent of women had hypothyroxinemia and $79 \%$ had TSH levels under $2 \mathrm{mcU} / \mathrm{mL}$. 3,6\% of the newborns of these mothers had TSH levels above $5 \mathrm{mcU} / \mathrm{L}$ in the neonatal screening. Neurodevelopment was evaluated in 27 children (at 38-44 months). They were divided in two groups: children of mothers with $\mathrm{f}-\mathrm{T} 4$ above $10 \mathrm{pmol} / \mathrm{L}$ and children of mothers with f-T4 under $10 \mathrm{pmol} / \mathrm{L}$. Neurodevelopment was not statistically significant different between both groups of children. Iodine urinary concentration and iodine intake show that most of these pregnant women do not take the amount of iodine daily recommended. The maternal iodine intake that is below the daily recommended amount can justify the high percentage $(3,6 \%)$ of neonates with TSH level above $5 \mathrm{mcU} / \mathrm{L}$.

\section{P02-698 Thyroid 1 \\ Congenital hypothyroidism in two siblings caused by compound heterozygous mutations of thyroid peroxidase (TPO) gene} Diemud Simm ${ }^{1}$; N. Pfarr²; Joachim Pohlenz ${ }^{2}$; Helmuth-Günther Dörr

'Universitätsklinikum Erlangen, Kinderklinik und Kinderpoliklinik/ Endokrinologie, Erlangen, Germany; ${ }^{2}$ Universitätsklinikum Mainz,

Kinderklinik und Kinderpoliklinik/Endokrinologie, Mainz, Germany

Background: Congenital hypothyroidism $(\mathrm{CH})$ occurs with an incidence of 1: 3500 . In approximately $20 \%$ of these patients $\mathrm{CH}$ is a consequence of defects in the biochemical mechanisms responsible for thyroid hormone synthesis. Among these, defects in the thyroid peroxidase play an improtant role and mutations in the TPO gene are the most frequent cause of iodide organification defect.

Case report: We here report two siblings ( 2 and 5 years old) with congenital hypothyroidism due to compound heterozygous mutations of the TPO gene. Clinical and laboratory findings:Both patients were identified in newborn screening (child 1: fT4 < 0,5 ng/dl, TSH $220 \mathrm{mU} / 1$; child 2: fT4 0,1 ng/dl, TSH $>220 \mathrm{mU} / \mathrm{l}$ ) and adequately treated with L-thyroxine (L-T4). Both children were presented in our hospital for the first time at the ages of 1 and 4 years, respectively. Thyroglobin $(\mathrm{Tg})$ was elevated in child 1 with $61,5 \mathrm{ng} / \mathrm{ml}$ (under L-T4), as well as in child 2 with $981 \mathrm{ng} / \mathrm{ml}$ after birth. Ultrasound showed in both children a normally located thyroid gland of normal size and stucture. In child 1 , an elevated and rapid radioiodide ( $\left({ }^{23} \mathrm{I}-\right)$ uptake by the thyroid gland was found. There was no hearing loss in both children. Molecular analysis of TPO Gene revealed compound heterozygous mutations (Q446H and W527C) of which one $(\mathrm{Q} 446 \mathrm{H})$ has not been described before.

Conclusions: In cases of $\mathrm{CH}$ with evidence of a thyroid gland and high thyroglobin concentrations, mutations in the TPO gene should be taken into account and are likely to be identified by molecular analysis.

\section{P02-699 Thyroid 1}

Postnatal longitudinal growth, skeletal
maturation and start of puberty in children
with orthotopic thyroid gland and permanent
congenital hypothyroidism (CH) picked up by
neonatal thyroid screening (NTS) program
Iva Stoeva'; Reni Koleva ${ }^{2}$

University Paediatric Hospital, Screening and Functional Hormonal Diagnostic, Sofia, Bulgaria; ${ }^{2} 1$ st Medical Diagnostic Center Stara Zagora, Pediatrics, Stara Zagora, Bulgaria

Limited data are available concerning height after infancy and childhood in $\mathrm{CH}$ screening patients. Especially, the correlation of their long-term growth with the target heights is informative for the evaluation of the treatment results. Aim: to set up a follow up study on longitudinal growth, skeletal maturation and start of puberty in children with permanent $\mathrm{CH}$ and orthotopic thyroid gland - part of a systematic growth and development re-evaluation in all children with permanent forms of $\mathrm{CH}$. Participants: 55 (42 girls, 13boys) children with proven permanent $\mathrm{CH}$ and orthotopic thyroid (3 suspected for 
enzyme defects, 52 with proven hypoplasia), discovered by NTS (TSH Delfia, cut off $>15 \mathrm{mU} / \mathrm{l}$ ), confirmed, treated, followed and re-evaluated according the revised ESPE guidlines; mean age 8.4 years (SD 3.6, median 9.2 range 0.5 14.5). Length and standing height measured by stadiometer and expressed as standard deviation score (SDS) for chronological age (Prader\&Largo). Bone age assessment - annually (G\&P). Thyroid volume: measured by US (7.5 $\mathrm{MHz}, \mathrm{Fa}$ GE, Brunn formula). Statistics: Student's $\mathrm{t}$ test and linear regression analysis (significance: $\mathrm{p}<0.05$ ). L-Thyroxine therapy started at a mean age of 21.1 days (SD 2.5; median 14.5, range 6-240). At investigation (mean age 8.4 years), average TSH, fT4 and T4 concentrations were within the reference values, mean L-Thyroxine dosage $75.8 \mathrm{mcg} / \mathrm{d}$ or $2.9 \mathrm{mcg} / \mathrm{kg} / \mathrm{d}$. The attained height (SDSh) in the whole group was - 0.11 (SD 1.1), significantly higher $(\mathrm{p}<0.001)$ compared to the SDS-MPH of - 0.9 (SD 1.1). The correlation between SDSh and SDS-MPH was also significant $(r=0.63, p<0.001)$. Bone and chronological age showed the strongest correlation $(\mathrm{r}=0.93, \mathrm{p}<0.001)$. Puberty started in 24 of the patients at median age 9.7 ys in girls and 11 ys in boys. Early diagnosis and treatment with L-Thyroxine adjusted to the different age-specific requirements in patients with permanent $\mathrm{CH}$ provide not only normal longitudinal growth but guarantee the fulfilling of the genetic growth program, normal skeletal maturation and puberty.

\section{P02-700 Thyroid 1 \\ Hypothyroid coma in a newborn due to the placental transfer of TSH receptor blocking antibodies (TRAK) from the mother presenting an untreated Hashimoto thyroiditis \\ Claire-Lise Gay' ${ }^{1}$ Michel David ${ }^{1}$; Maguelone G. Forest ${ }^{1}$; \\ Frédérique Tixier'; Patricia Bretones ${ }^{1}$; Christine Raybaud ${ }^{1}$; \\ David Cheillan' ${ }^{2}$ Pierre Chatelain ${ }^{1}$; Marc Nicolino' \\ 'Hôpital Debrousse, Pediatric Endocrinology, Lyon, France; ${ }^{2 H o ̂ p i t a l ~}$ \\ Debrousse, Neonatal Screening (National), Lyon, France}

Chaima presented already at birth with severe symptoms of hypothyroidism: jaundice, puffy face, a large protruding tongue with blueish shadows around the mouth, inappropriately large fontanels, distended abdomen, collateral circulation, major axial hypotonia, no mobility, hoarse cry, no sucking reflex, no awakening. At day 3, TSH was $387 \mathrm{mIU} / \mathrm{L}$, total thyroxin $(\mathrm{T} 4)=9 \mathrm{nmol} / \mathrm{L}$ (normal: $80-100$ ). At day 8 , free $\mathrm{T} 3=2.2 \mathrm{pmol} / \mathrm{L}$, free $\mathrm{T} 4<2.9 \mathrm{pmol} / \mathrm{L}, \mathrm{TSH}$ $=750 \mathrm{mIU} / \mathrm{L}$; antithyroperoxydase antibodies $=892 \mathrm{IU} / \mathrm{L}$, TRAK $=1675$ IU/L. Echography showed a normal size thyroid gland in normal location. There was no iodine fixation at scintigraphy. Familial history revealed that the mother suffered from Hashimoto disease for several years. T4 treatment was stopped several months before her pregnancy for unknown reasons.

She had no medical control since. After delivery, maternal hormonal status was: free $\mathrm{T} 3<1.5 \mathrm{pmol} / \mathrm{L}$, free $\mathrm{T} 4<2.9 \mathrm{pmol} / \mathrm{L}, \mathrm{TSH}=425 \mathrm{mIU} / \mathrm{L}, \mathrm{TRAK}=$ $5,586 \mathrm{U} / \mathrm{L}$, antithyroperoxydase antibodies $=6,699 \mathrm{IU} / \mathrm{mL}$. Diagnosis in the neonate was hypothyroidism due to placental transfer of TRAK. Starting at day 8 , the baby was given $5 \mathrm{mg}$ of hydrocortisone for a month, and 7.5 then 10 $\mu \mathrm{g} / \mathrm{kg} / \mathrm{d}$ of L-T4 (drops). TSH was normalized at day 28. Forcible feeding was necessary for 42 days. Evolution was favorable. Cerebral MRI was normal. Evoked potentials were all normal. At 6 months, under $4.5 \mu \mathrm{g} / \mathrm{kg} / \mathrm{d}$ of L-T4, clinical examination was normal, in particular muscular tonicity.

In this clinical case, the usual maternal contribution of thyroid hormones was absent, thus would appear not to be required for fetal organogenesis of the brain and cerebral trunk. The lack of fetal thyroid hormones after the 20th week of pregnancy, because of the placenta transfer of thyroid antibodies, did no harm to this organogenesis. Only the long-term evolution will permit to conclude whether the neuronal proliferation and neuronal migration did occur normally in spite of everything.

\section{P02-701 Thyroid 1 \\ High versus low initial doses of L-thyroxine for congenital hypothyroidism normalise thyroid function more rapidly with no effect on somatic growth after 6 months}

Balazs Gellen ${ }^{1}$; Jeremy H Jones²; Stephen Beaton ${ }^{2}$;

Malcolm DC Donaldson ${ }^{2}$

'University of Szeged, Department of Paediatrics, Szeged, Hungary;

${ }^{2}$ Royal Hospital for Sick Children, Glasgow, Department of Child

Health, Glasgow, United Kingdom

The optimal dose of L-thyroxine (T4) in congenital hypothyroidism $(\mathrm{CH})$ during infancy is controversial. Advocates of high doses cite improvement in cognitive scores, whileopponentssuggest thatbehaviouraldifficultiesmayoccurlaterinlife. 274 children with $\mathrm{CH}$ were stratified according to initial daily dose of T4: Group1 (25 ig, $n=124)$, Group2 (30-40 ig, $n=67)$ and Group3 (50 ì , $n=83$ ). The groups were compared for thyroid function - free thyroxine (fT4) and thyroid stimulating hormone (TSH); and somatic growth - length, weight and head circumference (OFC), at diagnosis and at 3, 6, 12, 18, 24 and 36 months of age. Thyroid function was also compared immediately following referral and between 7 and 21 days after the start of treatment (7-21dT4).

No statistical difference was found between the groups at diagnosis for any parameter. At 7-21dT4, median (interquartile range) TSH values for Groups 1,2 and 3 were 56.2 (26.5-100.0), $21.7(10.0-49.7)$ and $8.1(1.87-33.2) \mathrm{mU} /$ $\mathrm{L}$ respectively. At 6 months TSH remained significantly lower in Group 3. Although median fT4 was $>9.0 \mathrm{pmol} / \mathrm{L}$ in all 3 groups at $7-21 \mathrm{dT} 4,11.7 \%$ of groupl had values $<9.0 \mathrm{pmol} / \mathrm{L}$ compared with $3.4 \%$ and $3.2 \%$ for Groups 2 and 3 respectively.

At 3 months Group 1 was below the mean for length $(-0.43 \mathrm{SD})$ and weight $(-0.32 \mathrm{SD})$ with normal OFC $(0.06 \mathrm{SD})$, while Group 3 was $0.5 \mathrm{SD}$ greater for each parameter, reaching statistical significance for weight $(\mathrm{p}=0.02)$. By 12 months the growth status of these two groups was similar.

An initial T4 dose of 50 ig daily normalises thyroid function several months earlier than lower dose regimes, with no evidence of sustained somatic overgrowth between 3 months and 3 years. We believe that a starting dose of 25 ig should no longer be used in severe or moderate $\mathrm{CH}$.

\section{P02-702 Thyroid 1 \\ Optimal screening frequency for hypothyroidism in children and adolescents with Down's syndrome using a capillary TSH method}

Jeremy H Jones ${ }^{1}$; Wendy Paterson'; Ian Hunter'; Patricia Charleton ${ }^{3}$; Kathleen Leyland ${ }^{4}$; Arlene Brown ${ }^{5}$; Joan Mackenzie ${ }^{6}$;

Malcolm DC Donaldson

${ }^{1}$ Royal Hospital for Sick Children, Department of Child Health, Glasgow, United Kingdom; 'Wishaw General Hospital, Department of Paediatrics, Wishaw, United Kingdom; ${ }^{3}$ Raeden Centre, Department of Paediatrics \& Child Health, Aberdeen, United Kingdom; ${ }^{4}$ Southbank Chid Centre, Department of Community Child Health, Glasgow, United Kingdom; ${ }^{5}$ National Screening Laboratory, Scotland, Department of Biochemical Genetics, Glasgow, United Kingdom; ${ }^{6}$ National Screening Laboratory, Scotland, Department of Biochemical Genetics, Glasgow, United Kingdom

The incidence of acquired hypothyroidism in Downs' syndrome is significantly higher than in the general population. Thus screening is justified, but screening frequency is a matter of debate. The management of asymptomatic patients with mild thyroid stimulating hormone (TSH) elevation $(6-10 \mathrm{mU} / \mathrm{L})$ is unclear.

78 patients referred (1997-2005) with TSH elevation on school-based capillary screening were investigated, with particular reference to those who had tested negative during the preceding year and patients who did not start thyroxine immediately following referral. Confirmed hypothyroidism was defined as moderate venous TSH elevation $(>6 \mathrm{mU} / \mathrm{L})$ with positive thyroid autoantibodies or significant TSH elevation ( $>15 \mathrm{mU} / \mathrm{L}$ ) irrespective of antibody status. The median (range) age at referral was $10.14(0.03-17.91)$ years. 10 of 78 were detected in the first year of screening, all of whom were antibody positive. Of the remainder, 37 (54.4\%) had screened negative while $28(41.2 \%)$ had not been tested during the preceding year, data unavailable in 3 patients. 29 patients of median (range) age $14.25(6.47-17.73)$ years at referral were 
investigated in terms of diagnostic thyroid function. Median (range) venous $\mathrm{TSH}$ and free T4 at diagnosis were 16.4 (7.3-132.0) $\mathrm{mU} / \mathrm{L}$ and 9.5 (4.2-15.9) $\mathrm{pmol} / \mathrm{L}$ respectively. $96.5 \%$ (28 of 29 ) had confirmed hypothyroidism and $93.1 \%$ (27 of 29 ) were thyroid autoantibody positive. $60.9 \%$ started thyroxine therapy immediately following post-referral assessment. Of those that did not, $44.4 \%$ went on to receive thyroxine as thyroid function later worsened, while one patient became hyperthyroid and thyroxine was withdrawn.

We conclude that the significant proportion of Down's children with confirmed hypothyroidism who had tested negative one year prior to detection indicates that annual screening is required. Nearly half the patients with modestly raised initial venous TSH will progress to thyroxine treatment. This group should be closely monitored for deteriorating thyroid function.

\section{P02-703 Thyroid 1 \\ Congenital hypothyroidism in Iceland; outcome of a 25 year nationwide screening (1979-2004) \\ Hanna Torp ${ }^{1}$; Ragnar Bjarnason ${ }^{1}$; Jon Johannes Jonsson ${ }^{2}$ Isleifur Olafsson ${ }^{3}$; Elizabeth Cook ${ }^{3}$; Arni V Thorsson \\ ${ }^{1}$ Landspitali University Hospital, Childrens Medical Center, Reykjavik, Iceland; 'Landspitali University Hospital, Dep of Genetics and Molecular Medicine, Reykjavik, Iceland; ${ }^{3}$ Landspitali University \\ Hospital, Dep of Clinical Biochemistry, Reykjavik, Iceland}

Introduction: A nationwide screening for Congenital Hypothyroidism $(\mathrm{CH})$ was introduced January 1. 1979 in Iceland, measuring TSH at the age of five days. Objective: To evaluate the results of the screening program for $\mathrm{CH}$ in the Icelandic population for 25 years 1979-2004.

Patients/Material and Methods: All children diagnosed through the screening program have been treated and followed at the same pediatric institution. The hospital records were examined, all patients were examined and their parents interviewed between March and May 2005. Blood samples were obtained for genetic analysis.

Results: During the study period TSH was measured from a total of 112177 neonates. Permanent $\mathrm{CH}$ was diagnosed in 36 infants ( 25 girls/11 boys) giving female/male ratio of 2.3:1 The incidence was $1 / 3116$ live births. The median age at diagnosis was 15 days $(95 \%$ confidence interval $14.5-31.4$ days). Dyshormonogenesis (goiter) was found in $25 \%$ of cases, dysgenesis in $75 \%$. Scintigraphy with TC99 showed ectopy of the thyroid gland in $40.7 \%$ of the cases. The mean initial dose of thyroxin was $11.2 \mu \mathrm{g} / \mathrm{kg} /$ day. Mean birth length was $1.02 \mathrm{SDS} \pm 1.39 \mathrm{SD}$. At the age of 4 years mean height was $0.08 \mathrm{SDS} \pm 1.14 \mathrm{SD}$ and at the last examination the mean height was $0.01 \mathrm{SDS} \pm 1.06 \mathrm{SD}$. Various other congenital anomalies were found in $22.2 \%$ of the children. We made an attemt to evaluate school performance and behavior. No or minimal assistance in school was needed for $83.4 \%$ of the children and they were considered well adjusted socially. The remaining $16.6 \%$ had a history of learning disability and/or behavior problems that needed special attention or treatment.

Conclusion: The incidence of $\mathrm{CH}$ in Iceland 1: 3116 is similar to reports from other Europian countries. In the majority of cases growth and psychomotor development has been normal. Genetic analysis of the cohort is in progress.

\section{P02-704 Thyroid 1 \\ Congenital hypothyroidism (CH); a significant number of false negative results when the cut- off point of $20 \mathrm{mU} / \mathrm{L}$ is applied}

Chryssanthi Mengreli'; Maria-Alexandra Magiakou';

Panagiotis Girginoudis ${ }^{1}$; Christina Kanaka-Gantenbein ${ }^{2}$; Catherine Dacou-Voutetakis ${ }^{2}$

IInstitute of Child health, Department of Biochemical Laboratories, Athens, Greece; ${ }^{2}$ Medical School, Athens University, First Department of Pediatrics, Athens, Greece

The screening program for $\mathrm{CH}$ was established in Greece in 1979. RIA-TSH on dried blood spots of $20 \mathrm{mU} / \mathrm{L}$ (whole blood) was initially applied as cutoff point. Since cases with CH, clinically diagnosed, had been classified as "normal" using this approach, we initiated a pilot study using as cut-off point the value of $10 \mathrm{mU} / \mathrm{L}$. In a 3 years period 311,390 newborns aged 3 to 5 days were examined .A reevaluation of $\mathrm{CH}$ patients was carried out following a 3 weeks withdrawal of therapy at the age of 1.5 to 4 years. Thyroid hormone determination, sonography and/or a thyroid scintiscan with I123, followed by a perchlorate discharge test were used. Two hundred cases of $\mathrm{CH}$ were diagnosed and $143(71.5 \%)$ were reevaluated. $127 / 143$ children proved to suffer permanent CH. 36/127 (28.3\%) had blood spot TSH values $<20 \mathrm{mU} /$ $\mathrm{L}(\mathrm{x}=12.5 \pm 2,8 \mathrm{mU} / \mathrm{L}) .15 / 36$ were prematures. The etiologic classification revealed that $25 / 36$ cases had an orthotopic normal in size thyroid gland, 5 had an orthotopic gland with functional defects, 4 showed a single thyroid lobe and 2 had ectopic thyroid tissue.10/25 cases with normal thyroid gland were familial cases. The biochemical findings of these 36 cases at initial diagnosis and upon reevaluation are shown in the Table.

\begin{tabular}{lllll} 
& $\begin{array}{l}\mathrm{T} 4(\mathrm{ig} / \mathrm{dL}) \\
\mathrm{x} \pm \mathrm{SD}\end{array}$ & $\begin{array}{l}\mathrm{FT} 4(\mathrm{pg} / \mathrm{mL}) \\
\mathrm{x} \pm \mathrm{SD}\end{array}$ & $\begin{array}{l}\mathrm{T} 3(\mathrm{ng} / \mathrm{dL}) \\
\mathrm{x} \pm \mathrm{SD}\end{array}$ & $\begin{array}{l}\mathrm{TSH}(\mathrm{mU} / \mathrm{L}) \\
\mathrm{x} \pm \mathrm{SD}\end{array}$ \\
\hline At Diagnosis & $8.3 \pm 3.4$ & $11.2 \pm 3.5$ & $174 \pm 70$ & $41 \pm 80$ \\
\hline $\begin{array}{l}\text { At } \\
\text { Reevaluation }\end{array}$ & $8.2 \pm 2.3$ & $11.4 \pm 2.4$ & $149 \pm 27$ & $26 \pm 44$ \\
\hline
\end{tabular}

Conclusions: A significant number of cases with $\mathrm{CH}$ are missed following the recommended cut-off point of $20 \mathrm{mU} / \mathrm{L}$. The consequences of thyroid dysfunction in this group of patients, until clinically recognized, might be significant. This approach, however, raised the recall rate from $0.12 \%$ to $1.2 \%$, a significant drawback.

\section{P02-705 Thyroid 1 \\ Thyroid hormones in pregnancy: intra- individual variability and correlation to fetal growth \\ Malene Boas'; Anders Juul'; Ulla Feldt-Rasmussen²; \\ Niels E. Skakkebæk'; Marla Chellakooty ${ }^{1}$; Torben Larsen ${ }^{3}$; Jørgen Falck-Larsen ${ }^{4}$; Katharina M. Main ${ }^{1}$ \\ 'Rigshospitalet, Department of Growth and Reproduction, Copenhagen, Denmark; ${ }^{2}$ Rigshospitalet, Department of Medical Endocrinology, Copenhagen, Denmark; ${ }^{3}$ Holbæk Sygehus, Department of Obstetrics and Gynecology, Holbæk, Denmark; ${ }^{4} \mathrm{Herlev}$ Hospital, Department of Obstetrics and Gynecology, Copenhagen, Denmark}

Thyroid hormones are crucial to fetal growth and development, and aberrations have been associated with adverse pregnancy outcomes. We aimed to investigate the intra-individual variability of thyroid hormones during pregnancy, and to estimate the influence of thyroid function on fetal growth. 133 pregnant women without known thyroid disease had 7 (1-12) blood samples and 3 (1-8) ultrasound examinations (for estimations of fetal weight) performed during gestation. Thyroid stimulating hormone (TSH); thyroxine (T4); free T4; triiodothyronine (T3); free T3; and antibodies against thyroglobulin (anti-TG) and thyroid peroxidase (anti-TPO) were determined by immunoassays. Z-scores for hormone levels were calculated for five weeks intervals throughout gestation. Fetal growth rate was calculated from measurements at mean gestational age 200 and 235 days.

The serum concentrations of thyroid hormones changed during gestation as expected (table 1). There was a large inter-individual variation of thyroid hormone levels (coefficients of variation (CV) are listed in table 1). However, individual z-scores showed little variability throughout gestation (mean CV for T4: $8 \%$; free T4: 10\%; T3: $10 \%$; free T3: $8 \%$ ).

Anti-TG was present in $41(31 \%)$, and anti-TPO in $28(21 \%)$ women. The thyroid variables showed largely similar results whether auto-antibodies were present or not. Mean free T3 and z-scores of free T3, but not the other thyroid parameters, were correlated with third trimester fetal growth rate $(r=0.235$, $\mathrm{p}<0.011 ; \mathrm{r}=0.253, \mathrm{p}<0.006$, respectively). There were no correlations between maternal thyroid parameters and fetal size or head circumference at birth.

In conclusion, individual thyroid hormone levels showed little variability during pregnancy compared to inter-individual variation, which is in line with findings in non-pregnant women. Maternal serum concentration of free T3 correlated positively with fetal growth rate in third trimester. Assessment of the individual change in thyroid function variables seems superior to gestation based reference intervals. 


\begin{tabular}{|c|c|c|c|c|c|c|c|c|c|}
\hline \multirow[t]{2}{*}{$\begin{array}{l}\text { Gesta- } \\
\text { tional } \\
\text { weeks }\end{array}$} & $\begin{array}{l}0-13(n \\
=85)\end{array}$ & & & $\begin{array}{l}14- \\
26(n \\
= \\
388)\end{array}$ & & & $\begin{array}{l}27- \\
43(n \\
= \\
474)\end{array}$ & & \\
\hline & $\begin{array}{l}\text { Mean } \\
\left({ }^{\star} \mathrm{me}-\right. \\
\text { dian })\end{array}$ & $\begin{array}{l}\text { SD (*2.5- } \\
97.5 \\
\text { percenti- } \\
\text { les) }\end{array}$ & $\begin{array}{l}\text { CV } \\
\text { (\%) }\end{array}$ & $\begin{array}{l}\text { Mean } \\
\left({ }^{\star} \mathrm{me}-\right. \\
\text { dian) }\end{array}$ & $\begin{array}{l}\text { SD (*2.5- } \\
97.5 \\
\text { percenti- } \\
\text { les) }\end{array}$ & $\begin{array}{l}\text { CV } \\
\text { (\%) }\end{array}$ & $\begin{array}{l}\text { Mean } \\
\text { ( }^{\star} \mathrm{me}- \\
\text { dian) }\end{array}$ & $\begin{array}{l}\text { SD }\left({ }^{*} 2.5-\right. \\
97.5 \\
\text { percenti- } \\
\text { les) }\end{array}$ & $\begin{array}{l}\mathrm{CV} \\
\text { (\%) }\end{array}$ \\
\hline $\begin{array}{l}\mathrm{TSH}^{*} \\
\text { (miu/l) }\end{array}$ & 1.35 & $0.19-4.23$ & & 1.51 & $0.39-4.16$ & & 1.63 & $0.46-4.42$ & \\
\hline $\begin{array}{l}\text { T4 } \\
\text { (nmol/ } \\
\text { I) }\end{array}$ & 140 & 26 & 18 & 155 & 23 & 15 & 150 & 25 & 16 \\
\hline $\begin{array}{l}\text { Free } \\
\text { T4 } \\
\text { (pmol/ }\end{array}$ & 16.8 & 2.4 & 14 & 14.3 & 1.8 & 13 & 13.4 & 1.8 & 13 \\
\hline $\begin{array}{l}\text { T3 } \\
\text { (nmol/ } \\
\text { l) }\end{array}$ & 2.7 & 0.5 & 20 & 3.1 & 0.5 & 17 & 3.1 & 0.5 & 17 \\
\hline $\begin{array}{l}\text { Free } \\
\text { T3 } \\
\text { (pmol/ } \\
\text { l) }\end{array}$ & 4.8 & 0.7 & 14 & 4.5 & 0.6 & 12 & 4.3 & 0.6 & 13 \\
\hline
\end{tabular}

\section{P02-706 Thyroid 1}

\section{Final diagnosis in children with subclinical} hypothyroidism, preliminary results Doga Turkkahraman'; Funda Aydýn²; Akýn Yýldýzz; Banu Guze/3.

Gulay Karaguzel'; Sema Akcurin'; Iffet Bircan

${ }^{1}$ Akdeniz University Hospital, Pediatric Endocrinology, Antalya, Turkey; ${ }^{2}$ Akdeniz University Hospital, Nuclear Medicine, Antalya, Turkey; ${ }^{3}$ Akdeniz University Hospital, Pediatrics, Antalya, Turkey; ${ }^{4}$ Karadeniz

University Hospital, Pediatric Endocrinology, Trabzon, Turkey

Objective: To determine final diagnosis and underlying causes of subclinical hypothyroidism $(\mathrm{SCH})$ in eligible children through the use of an algorithm. Method: Patients records were scanned retrospectively, and infants with SCH (defined as mildly elevated serum TSH with normal ST4 concentrations, and with exaggerated TSH response to TRH stimulation test) were included into study. Thyroid sonography and, or scintigraphy was performed to all infants. Subjects with thyroid agenesis, hemiagenesis or ectopic thyroid were excluded. Children ? 2 years of age without an identified permanent cause, and still on thyroxine treatment underwent a diagnostic algorithm. After thyroxine was discontinued for 4 weeks, thyroid function tests (TFT) and a thyroid ultrasound were obtained. A perchlorate washout test (PWT) was performed in subjects with a normal ultrasound but abnormal TFT. Children with normal results were followed for at least 6 months.

Results: In preliminary results, 29 subjects $(17$ males and 12 females) completed the trial. Among these children, $10(34.5 \%)$ had transient SCH, and $19(65.5 \%)$ had permanent SCH. Among subjects with permanent $\mathrm{SCH}$, 13 had thyroid hypoplasia, 2 had organification defect with positive PWT, and 4 had other dyshormonogenesis with negative PWT. Mean stimulated peak TSH was $46,5 \pm 15,6 \mu \mathrm{IU} / \mathrm{ml}$ in transient cases versus $52,6 \pm 15,3$ in permanent ones $(p>0,05)$. Average thyroxine dose before the medication ceased was $1,2 \pm 0,53 \mu \mathrm{g} / \mathrm{kg} /$ day in transient cases, while $1,7 \pm 0,41$ in permanents $(\mathrm{p}<0,05)$. Additionally, thyroid peroxidase gene mutations will be screened in subjects with positive PWT.

Conclusion: We demonstrated that patients with $\mathrm{SCH}$ diagnosed in neonatal period by TRH stimulation test have mostly permanent $\mathrm{SCH}$ with definite pathology in thyroid gland. Peak TSH response in TRH stimulation test does not seem helpful in differentiation of whether $\mathrm{SCH}$ is permanent or not Therefore, it is clear that in neonatal period infants with $\mathrm{SCH}$ with exaggerated response to TRH stimulation test should be treated with thyroxine.

\section{P02-707 Thyroid 1 \\ Ef fect of early thyroid scanning on levothyroxine dosage and neuropsychological development in congenital hypothyroidism}

Silvia Perlini; Roberto Franceschi; Mara Vanzati; Elena Monti;

Rossella Gaudino; Francesca Teofoli; Marta Camilot;

Franco Antoniazzi; Silvana Lauriola; Luciano Tato

Pediatrics Unit, University of Verona, Dept. Mother and Child, BiologyGenetics, Verona, Italy

Despite receiving early therapy, several studies show subtle neuropsychological disturbances in some children with $\mathrm{CH}$. The etiology of $\mathrm{CH}$ may play an important role on determining both the disease severity at diagnosis as well as its outcome. The purpose of this study was to evaluate whether the etiology of CH may exhibit an independent effect on both levothyroxine (LT4) dose administered during follow up and neuropsychological development. We studied 55 children affected by $\mathrm{CH}$, identified by neonatal screening program, who performed $99 \mathrm{mTc}$-pertechnetate thyroid scan at the time of diagnosis and were longitudinally followed up to 8 years of life. They started T4 substitutive therapy at a mean age of $18.63 \pm 6.37$ days, with L-T4 dose of $8-10 \mu \mathrm{g} / \mathrm{Kg} / \mathrm{die}$. At 3 years of age, the patients underwent the Brunet-Lezine test to evaluate the DQ (development quotient). Later on, the Terman-Merril test was administered to calculate IQ score. At the time of testing, most of patients were in euthyroidism. The parental socioeconomic status was taken into account as well. By ANOVA, we found in athyreosis at diagnosis higher TSH levels $(p<0.01)$ associated with lower serum T4 and FT4 concentrations $(\mathrm{p}<0.05)$. In all the patients, reference range values of serum FT4 and TSH were reached in one and two months, respectively, but a higher quantity of L$\mathrm{T} 4$ both at 1 and 8 years of life had to be administered in athyreosis compared to other types of dysgenesis or dyshormonogenesis $(p<0.05)$. Despite higher L-T4 dose and early therapy, patients with agenesis exhibit worse QS at 1 year $(\mathrm{p}<0.05)$, whereas IQ normal values were reached at 3 and 8 years of life.

The results obtained for athyreosis could be suggestive of a prenatal hormone deficit, only partially compensated by substitutive therapy in the extra-uterine life.

\section{P02-708 Thyroid 1 \\ Neonatal hyperthyrotropinemia (HT): population characteristics, diagnosis, management and outcome after cessation of therapy}

Amnon Zung'; Shiri Barkan'; Yardena Tenenbaum-Rakover'; Aaron Hanukoglu3; Eli Hershkovitz; ; Tzvy Bistrizer

Orit Pinhas-Hamie/ ${ }^{6}$; Zvi Zadik

${ }^{1}$ Kaplan Medical Center, Pediatric Endocrinology Unit, Rehovot, Israel; 2Ha'Emek Medical Center, Pediatric Endocrinology Unit, Afula, Israel; ${ }^{3} \mathrm{E}$. Wolfson Medical Center, Division of Pediatric Endocrinology, Holon, Israel; ${ }^{4}$ Soroka Medical University Center, Pediatric

Endocrinology Unit, Beer-Sheva, Israel; ${ }^{5}$ Assaf-Harofe Medical Center, Pediatric Endocrinology Unit, Tzrifin, Israel; 'Safra Children's Hospital, Sheba Medical Center, Pediatric Endocrinology Unit, Tel-Hashomer, Israel

HT is defined by normal plasma levels of T4 in association with high plasma $\mathrm{TSH}$. In a newborn screening that measures total T4, the ability to diagnose HT is limited. On cessation of therapy, some of the patients with HT remain euthyroid (transient HT; t-HT), while others show the typical pattern of HT (persistent HT; p-HT). This study was conducted to determine the proportion of t-HT vs. p-HT. We also aimed to evaluate the diagnosis pattern, perinatal characteristics and principles of treatment that characterize both types of HT, in comparison with patients with congenital hypothyroidism $(\mathrm{CH})$.

We conducted a retrospective, multi-center study in six pediatric endocrine units. All neonates who were diagnosed with either HT or CH from 1995 to 2006 were included. Infants born to mothers with thyroid disease were excluded. The study included 26 patients with $\mathrm{HT}$ and 67 patients with $\mathrm{CH}$ By comparison with $\mathrm{CH}$, more HT patients were diagnosed based on clinical signs of hypothyroidism ( $54 \%$ vs. $28 \%, \mathrm{p}=0.04)$, were born prematurely, ( $38 \%$ vs. $10 \%, \mathrm{p}=0.004)$, and had normal thyroid gland imaging $(73 \%$ vs. $27 \%, \mathrm{p}=0.002$ ). Elthroxin dosage was lower in HT patients compared with $\mathrm{CH}$ patients only after 1.5 years of age. On cessation of therapy, $12 \mathrm{CH}$ patients $(46 \%)$ became euthyroid. Within HT group, t-HT patients had higher 
prevalence of normal thyroid gland imaging than patients with p-HT $(100 \%$ vs. $43 \%, \mathrm{p}=0.04$ ), and most of them maintained normal TSH levels throughout treatment period ( $92 \%$ vs. $29 \%$ of $\mathrm{p}-\mathrm{HT}$ patients, $\mathrm{p}=0.004)$. Among HT neonates, the proportion of $\mathrm{t}-\mathrm{HT}$ is higher than previously reported.

Prematurity, lower requirements of elthroxin and normal thyroid imaging are more common in HT than in $\mathrm{CH}$. Normal thyroid imaging and normal TSH levels during treatment suggest a transient nature of HT.

\section{P02-709 Thyroid 1 \\ Pitfalls in the diagnosis of thyroid dysgenesis by thyroid ultrasonography (USG) alone}

Avdiner Elif'; Serap Turan ${ }^{1}$; Ihsan Akpinar ${ }^{2}$; Pinar Isguven ${ }^{3}$; Erdal Adal';

Fuat Dede ; Teoman Akcay'; Tulay Guran'; Turgut Turoglu ${ }^{5}$;

Abdullah Bereket ${ }^{1}$

${ }^{1}$ Marmara University, Pediatric endocrinology, Istanbul, Turkey;

${ }^{2}$ Marmara University, Radiology, Istanbul, Turkey; ${ }^{3}$ Goztepe Education

Hospital, Pediatric Endocrinology, Istanbul, Turkey; ${ }^{4}$ Bakirkoy

Education Hospital, Pediatric Endocrinology, Istanbul, Turkey;

${ }^{5}$ Marmara University, Nuclear Medicine, Istanbul, Turkey

Diagnostic evaluation of a patient with congenital primary hypothyroidism $(\mathrm{CPH})$ involves thyroid ultrasound (USG) and/or thyroid scan. However, thyroid USG alone is increasingly recommended in recent textbooks or guidelines because of being radiation-free. We aimed to determine validity of this approach by evaluating our patients with thyroid dysgenesis (TD) whose diagnosis based on USG or thyroid scan. $83(30 \mathrm{M}, 53 \mathrm{~F})$ patients with TD were included in the study. Thyroid USG in 46 subjects and scan in 60 subjects had been performed at the time of diagnosis. The patients were reevaluated at the age of $8.1 \pm 5.6 \mathrm{yrs}(1-24 \mathrm{yrs})$ with USG (n:83) and, thyroid scan in those scan was not done at the time of diagnosis. (after 3 weeks of off treatment, n:23). Final diagnoses based on thyroid scan were ectopia in $35(42 \%)$, athyreosis in $35(42 \%)$, hypoplasia in $10(12 \%)$, and hemiagenesis in $3(4 \%)$.

A rudimentary euthopic thyroid tissue on USG was detected in 42 cases. Scintigraphic diagnosis was hypoplasia in only 9 of these cases. Remaining patients had ectopia (n:17), athyreosis (n:15) and, hemiagenesis (n:1) on scan. Thus, $76 \%(n=32)$ of patients with rudimentary thyroid tissue detected by USG actually had ectopia or athyreosis on the scan. USG was able to detect thyroid tissue in ectopic location in only $2 / 35$ ectopia cases.

We conclude that in nearly half of the patients with athyreosis and thyroid ectopia, USG shows a euthopic rudimentary thyroid tissue giving the impression of hypoplasia, but these tissues are usually nonfunctional in thyroid scan. If these patients were evaluated only by USG, they were falsely classified as hypoplasia rather than ectopia or athyreosis. Since each method provides different information, we should continue to use both thyroid USG and thyroid scan in the diagnostic evaluation of $\mathrm{CPH}$.

\begin{tabular}{|llll|}
\hline & \multicolumn{3}{c}{ Thyroid USG } \\
\hline Thyroid Scan & $\begin{array}{l}\text { Euthopic small } \\
\text { Tissue }(\mathrm{n}: 42)\end{array}$ & $\begin{array}{l}\text { No tissue } \\
(\mathrm{n}: 39)\end{array}$ & Ectopic (n:2) \\
\hline $\begin{array}{l}\text { Athyrosis } \\
(\mathrm{n}: 35)\end{array}$ & 15 & 16 & 2 \\
$\begin{array}{l}\text { Hypoplasia } \\
(\mathrm{n}: 10)\end{array}$ & 9 & 20 & 0 \\
\hline $\begin{array}{l}\text { Hemiagenesis } \\
(\mathrm{n}: 3)\end{array}$ & 1 & 1 & 0 \\
\hline
\end{tabular}

\section{P02-710 Thyroid 1 \\ 13 year follow-up of severe congenital nonautoimmune hyperthyroidism due to an activating neomutation of the TSH receptor gene: thyrotoxic relapse after thyroidectomy leading to radioiodine therapy}

Georges Gelwane'; Nicolas de Roux²; Thierry Van Den Abbeele;

Eric Baudin ${ }^{4}$; Michel Polak' ${ }^{5}$ Michel Peuchmaur ${ }^{6}$; Yves Aigrain ${ }^{7}$;

Paul Czernichow' ${ }^{\top}$ Juliane Léger ${ }^{1}$

${ }^{1}$ Robert Debré Hospital, Pediatric Endocrinology Department, Paris, France; ${ }^{2}$ Robert Debré Hospital, INSERM U690, Paris, France; ${ }^{3}$ Robert Debré Hospital, Pediatric Otorhinolaryngology Department, Paris, France; ${ }^{4}$ Gustave Roussy Institute, Nuclear Medicine Department, Villejuif, France; ${ }^{5}$ Necker Hospital, Pediatric Endocrinology Department, Paris, France; ${ }^{6}$ Robert Debré Hospital, Pathology Department EA 3102, Paris, France; ${ }^{7}$ Robert Debré Hospital, Pediatric Surgery Department, Paris, France

Nonautoimmune hyperthyroidism due to activating mutation of the TSH receptor is a rare disease with its long term course currently not well documented. We describe a 13 y follow-up period of a boy with sporadic congenital nonautoimmune hyperthyroidism due to a Met453 Thr heterozygous substitution in the TSH receptor gene leading to constitutive activation.

The neonatal history of this small for date premature boy with severe hyperthyroidism (FT4 $>100 \mathrm{pmol} / 1$, FT3 $>35 \mathrm{pmol} / \mathrm{l})$, goiter and exophtalmus, and with both parents not having any history of thyroid disease, has been previously reported (JCEM 1996). Carbimazole treatment (1 mg/kg/d) started at 11 days of life, was successful in controlling hyperthyroidism. High doses of carbimazole $(0.6 \mathrm{mg} / \mathrm{kg} / \mathrm{d})$ complemented with L-Thyroxine $(25 \mu \mathrm{g} / \mathrm{d})$ were necessary to maintain euthyroidism during the follow-up period. Height, head circumference and psychomotor development were quite normal. The goiter progressively increased and became multinodular (thyroid volume of $48 \mathrm{ml}$; normal for age $<7 \mathrm{ml}$ ). A subtotal thyroidectomy was performed at the age of 10.5 years. Because of this unusual large goiter, surgery was particularly difficult and provided side effects, such as a persistent hypoparathyroidism, a transient bilateral recurrential paralysis that required a tracheotomy during several weeks before a partial recovery of vocal fold mobility. The histology showed follicular adenomas without any lymphocytic infiltration. Thyrotoxic relapse occurred within 2 weeks and carbimazole was resumed. After one year, thyroid tissue regrowth in the small thyroid remnant and radioiodine therapy $(30 \mathrm{mCi})$ was administered. Thyroid hormones were low one month later and L-Thyroxine therapy was instituted.

In conclusion, the clinical course of congenital nonautoimmune thyrotoxicosis has to be carefully managed. Even with high doses of antithyroid drug for controlling severe congenital thyrotoxicosis, thyroid nodules and goiter enlargement develop early in life and require subtotal thyroidectomy followed by radioiodine therapy.

\section{P02-711 Thyroid 1 \\ The evolution of neonatal TSH screening strategies modifies the characteristics of congenital hypothyroidism}

Maria Cristina Vigone ${ }^{1}$; Paola Viganò ${ }^{2}$; Francesca Cortinovis ${ }^{1}$ Arianna Passoni'; Marta Odoni'; Davide Calebiro ${ }^{3}$; Luca Persani3; Giovanna Weber ${ }^{1}$; Carlo Corbetta ${ }^{2}$

'Vita-Salute San Raffaele University, Department of Pediatrics, Milan, Italy; ${ }^{2}$ sstituti Clinici di Perfezionamento, Lab. Riferimento Regionale Screening Neonatale, Milan, Italy; ${ }^{3}$ University of Milan, Department of Medical Sciences, Milan, Italy

Neonatal screening programs enable early detection and treatment of Congenital Hypothyroidism $(\mathrm{CH})$, thus preventing irreversible brain damages. Nowadays nearly all $\mathrm{CH}$ screening programs report an incidence of 1:3000/4000. The reduction of TSH cut-off values seems to determine an increased recall index, but also a sensitive decrease of negative forgeries. We described a retrospective study of the Lombardy (Italy) screening data of a 7-year period (1999-2005), to verify whether the use of a lower TSH cut-off might improve the $\mathrm{CH}$ screening efficiency. The Lombardy $\mathrm{CH}$ screening program adopts a primary b-TSH method (fluoroimmunometric assay) with a b-TSH cut-off of $12 \mathrm{mU} / \mathrm{L}$ between 1999-2002 and $10 \mathrm{mU} / \mathrm{L}$ 
between 2003-05. A positive child is referred for serum dosage (TSH,FT4) and to endocrinologist pediatrician for the prompt introduction of the L-T4 therapy. The etiology of $\mathrm{CH}$ is studied with thyroid ultrasonography and/or scintigraphy. $\mathrm{CH}$ children with thyroid in situ are later revaluated. In the period 1999-2005, 629.042 (89.864/y) newborns were screened and $418 \mathrm{CH}$ patients were identified and treated with L-T4: 143 thyroid dysgenesis and 275 glands in situ ( $6.1 \%$ severe preterm infants). The screening recalling rate increased from $0.7 \%(1999-2002)$ to $1.07 \%(2003-05)$ for the lst b-TSH.

This fact determines a higher prevalence of $\mathrm{CH}$ from 1:1915 (1999-2002) to $1: 1189$ (2003-05) with an unvaried rate of dysgenesis and a double incidence of glands in situ. At 3 years of age $41 / 274 \mathrm{CH}$ children with gland in situ were revaluated and were observed a $71 \%$ of permanent $\mathrm{CH}$. Among these $\mathrm{CH}$ children $41 \%$ had TSH levels $>40 \mathrm{mU} / \mathrm{L}$ at diagnosis, $14 \%$ had $\mathrm{TSH}$ $20-39 \mathrm{mU} / \mathrm{L}$ and $45 \%$ had TSH $10-19 \mathrm{mU} / \mathrm{L}$. The incidence of congenital thyroid dysfunction appears to be the double than previously thought; excess or defect in iodine intake in perinatal period and mild/transient forms of $\mathrm{CH}$ of genetic origin (TSH receptor - DUOX2) may have contributed to the number of positive b-TSH results. So, these data suggest the need of a revision of the screening strategies and the following diagnostic steps.

\section{P02-712 Thyroid 1 \\ T4 plus T3 treatment in patients with congenital hypothyroidism who have persistently high TSH on T4 treatment despite euthyroidism}

Teoman Akcay'; Abdullah Bereket'; Serap Turan'; Tulay Guran'; Goksenin Unluguze/2; Goncagul Haklar ${ }^{2}$

${ }^{1}$ Marmara University, Pediatric Endocrinology, Istanbul, Turkey;

${ }^{2}$ Marmara University, Biochemistry, Istanbul, Turkey

Inappropriately elevated TSH levels have been reported in $20-50 \%$ of T4 treated cases with congenital hypothyroidism $(\mathrm{CH})$, despite clinical euthyroidism and normal thyroid hormone concentrations. Reasons and treatment of this relative hyperthyrotropinemia (hTSH) are controversial. hTSH might reflect the relative hypothyroidism of hypothalamo-pituitary axis and relating brain tissue, and has risks of nodul formation in case of dyshormonogenesis.

\begin{tabular}{|c|c|c|c|c|}
\hline & $\begin{array}{l}\text { L-T4 treatment } \\
\text { (Initial) }\end{array}$ & $\begin{array}{l}\text { Combination } \\
\text { treatment*}\end{array}$ & $\mathrm{P}$ & Reference \\
\hline $\begin{array}{l}\text { Dosage (mcg/ } \\
\mathrm{kg} / \text { day) }\end{array}$ & $3.4 \pm 0.9$ (L-T4) & $\begin{array}{l}2.1 \pm 0.4 \text { (L-T4) } \\
0.5 \pm 0.1 \text { (T3) }\end{array}$ & & \\
\hline TSH (ulU/mL) & $\begin{array}{l}24.0 \pm 14.9(10.2- \\
49.9)\end{array}$ & $2.9 \pm 1.6(0.9-5.6)$ & 0.001 & $0.7-6.4$ \\
\hline T4 (mcg/dL) & $\begin{array}{l}11.2 \pm 1.2(9.8- \\
13.9)\end{array}$ & $\begin{array}{l}7.5 \pm 1.3(6.0- \\
10.7)\end{array}$ & $<0.001$ & $5.1-14.1$ \\
\hline f-T4 (ng/dL) & $\begin{array}{l}1.47 \pm 0.17(1.2- \\
1.7)\end{array}$ & $\begin{array}{l}0.99 \pm 0.15(0.81- \\
1.3)\end{array}$ & $<0.001$ & $0.93-1.7$ \\
\hline T3 (ng/dL) & $133 \pm 20(91-156)$ & $\begin{array}{l}160 \pm 8.7(129- \\
222)\end{array}$ & 0.009 & $80-200$ \\
\hline $\mathrm{f}-\mathrm{T3}(\mathrm{pg} / \mathrm{mL})$ & $3.7 \pm 0.4(3.0-4.2)$ & $4.0 \pm 0.659(2.9-5)$ & 0.12 & $2.6-4.4$ \\
\hline $\begin{array}{l}\text { Alkaline } \\
\text { Phosphatase } \\
\text { (U/L) }\end{array}$ & $494 \pm 81$ & $534 \pm 80$ & 0.036 & \\
\hline $\begin{array}{l}\text { Prolactin (ng/ } \\
\mathrm{mL} \text { ) }\end{array}$ & $12.4 \pm 4.7$ & $9.2 \pm 2.2$ & 0.039 & \\
\hline $\begin{array}{l}\text { Cholesterol } \\
\text { (mg/dL) }\end{array}$ & $189 \pm 52$ & $161 \pm 24$ & 0.02 & \\
\hline $\begin{array}{l}\text { LDL Cholesterol } \\
\text { (mg/dl) }\end{array}$ & $117 \pm 54$ & $88 \pm 29$ & 0.03 & \\
\hline $\begin{array}{l}\text { HDL Cholesterol } \\
(\mathrm{mg} / \mathrm{dl})\end{array}$ & $55.1 \pm 11.0$ & $58.0 \pm 8.7$ & 0.23 & \\
\hline $\begin{array}{l}\text { Triglycerides } \\
\text { (mg/dL) }\end{array}$ & $87.4 \pm 51.8$ & $93.0 \pm 72.3$ & 0.645 & \\
\hline $\begin{array}{l}\text { Osteocalcin } \\
\text { (ng/mL) }\end{array}$ & $38.3 \pm 19.8$ & $51.2 \pm 19.4$ & 0.06 & \\
\hline SHBG (nmol/L) & $72.3 \pm 26.2$ & $81.3 \pm 29.7$ & 0.188 & \\
\hline Ferritin $(\mathrm{ng} / \mathrm{mL})$ & $47.5 \pm 38.8$ & $31.9 \pm 23.3$ & 0.171 & \\
\hline
\end{tabular}

* At the time of euthyrotropinemia

We aimed to search the effect of T3+T4 treatment in patients with persistently hTSH levels despite high normal serum T4 levels on T4 treatment. Ten cases
(6M, 4F) with $\mathrm{CH}$ (8 dysgenesis, 2 dyshormonogenesis) whose TSH levels were persistently high despite euthyroidism and can only be normalized with hyperthyroidism were included in the study. Patients who were older than 5 years (mean $7.1 \pm 2$ yrs) were selected to exclude cases with transient hTSH. $\mathrm{T} 4$ treatment of the patients was switched to T3+T4 combination (Bitiron ${ }^{\circledR}$ tablet $50 \mathrm{mcg}$ L-T4 $+12.5 \mathrm{mcg}$ T3). Usual L-T4 dose of the patient was decreased by $50 \%$ and $1 / 4$ of the remaining $50 \%$ was replaced by $\mathrm{T} 3$ as a starting dose.

The dose of Bitiron ${ }^{\circledR}$ was then titrated to achieve normal TSH levels. Serum thyroid hormones and biochemical markers were followed periodically for 1 year. Euthyrotropinemia achieved at a mean of 7 th month (2-12 months) after combination treatment. Serum T4 and f-T4 were lower and T3 was higher during combination compared to T4 treatment. Serum T3 and f-T3 did not exceed upper limits except one patient at the euthyrotropinemia. Total and LDL-cholesterol significantly decreased and ALP significantly increased in euthyrotropinemic state. There was no significant difference in pulse rates and blood pressures between hTSH and euthyrotropinemia.

In conclusion, $\mathrm{T} 3+\mathrm{T} 4$ treatment provide euthyrotropinemia in $\mathrm{CH}$ cases with persistent hTSH without causing hyperthyroidism. This suggests decreased negative feed back due to lower T3 levels at CNS is a main reason for persistent hTSH.

\section{P02-713 Thyroid 1 \\ Preliminary molecular approach to congenital hypothyroid goiter with deficient thyroglobulin (Tg) synthesis}

Laura Gruñeiro Papendieck'; Ana Chiesa'; Karina Rivolta²; M Caputo'; Hector Targovnik

${ }^{1}$ Hospital de Niños R Gutierrez, Endocrinology Division, Buenos Aires, Argentina; ${ }^{2}$ Catedra de Genetica y Biologia molecular, Universidad de Buenos Aires, Buenos Aires, Argentina

Congenital hypothyroidism $(\mathrm{CH})$ may be due to defects in thyroid development $(75 \%)$ or dishormonogenesis $(25 \%)$. Among the latter, defects of TPO, DUOX2 and pendrin originate iodine organification defects and mutations of TG gene originate defective TG. We report the evaluation of patients with $\mathrm{CH}$, goitre and TG synthesis defect.

We studied 11/50 CH with goitre detected mostly by newborn screening, selected if they had at diagnosis or reevaluation high TSH levels, low T4 and TG values. 8 underwent a perchlorate discharge test that was always negative $(<10 \%) .22$ of 48 exons of the TG gene were studied by DNA sequencing.

We found mutations in 7/11 patients. 1) Two hypothyroid siblings from non consanguineous parents were compound heterozygous for a $886 \mathrm{C}>\mathrm{T}$ in exon 7 and a $4588 \mathrm{C}>\mathrm{T}$ in exon 22 , substitutions that resulted in a premature stop codon at aminoacids 277 (R277X) and 1511 (R1511X) respectively. 2) One patient was homozygous R277X mutation in exon 7.3) Three patients were heterozygous R277X in exon 7. 4) One patient had an heterozygous insertion in exon 7. Low TG levels in a goitrous hypothyroid patient suggest a TG synthesis defect. 7/11 patients with these features showed mutations in exon 7,2 as compound heterozygous, 1 homozygous and 4 heterozygous with only 1 mutation found. Coinciding with previous reports the R277X mutation was the most frequently found and could be considered as a hot spot. Consequently, it would be helpful to consider its investigation in patients with goitre and low $\mathrm{Tg}$ levels 
P02-714 Thyroid 1

Novel mutations, novel phenotypes: TSH- or T3receptor mutations may present in childhood with delayed speech, stuttering and dysphagia Inge Francois ${ }^{1}$; Maria van Helvoirt ${ }^{1}$; VKK Chatterjee ${ }^{2}$; Guy Vassart ${ }^{3}$; Francis de Zegher ${ }^{1}$

'University of Leuven, Pediatric Endocrinology, Leuven, Belgium;

2University of Cambridge, Medicine, Cambridge, United Kingdom;

${ }^{3}$ University of Brussels, Clinical Biology, Brussels, Belgium

The spectrum of early-pediatric phenotypes evoked by newly recognized disorders within the thyroid axis remains to be fully delineated. Here we summarize the subtle phenotypes of two children with a TSH- or T3-receptor mutation.

A boy aged $6.8 \mathrm{yr}$ was seen because of borderline-high serum levels of free T4 $(1.72 \mathrm{ng} / \mathrm{dl})$ and low TSH $(<0.01 \mathrm{mIU} / \mathrm{L})$ detected serendipitously within a broad screening for headache. TSH-receptor antibodies were undetectable. He had delayed speech and major stuttering, logopedic support being initiated at age 3 . He had a macroglossia, was hyperactive, and needed little sleep. His height was at $+1.5 \mathrm{SD}$ (target $-0.6 \mathrm{SD}$ ), bone age $6.8 \mathrm{yr}$, accelerated dental maturation, pulse $86 \mathrm{bpm}$, BP $118 / 62 \mathrm{~mm} \mathrm{Hg}$. Absence of a goiter was confirmed by ultrasound. A novel S641L mutation in the gene encoding the TSH-receptor was identified in one allele, causing constitutive activation of the TSH-receptor.

A girl aged $5.5 \mathrm{yr}$ was referred to the pediatric gastroenterology unit because of dysphagia. She was found to have high serum levels of free T4 $(6.3 \mathrm{ng} / \mathrm{dl}$; normal $0.7-1.9)$ and total T3 (257 ng/dl; normal 80-190), but TSH was still detectable $(2.3 \mathrm{mIU} / \mathrm{L})$. The prime complaints were dysphagia and delayed speech development. Height was at $0 \mathrm{SD}$, bone age $4.8 \mathrm{yr}$, dental maturation accelerated, pulse $156 \mathrm{bpm}$, BP 140/88 mm Hg. There was no goiter. The girl proved in 1995 to be heterogeneous for a novel in-frame deletion of three nucleotides (ACA) in the thyroid hormone receptor beta gene leading to an Isoleucine deletion (

In conclusion, delayed speech, stuttering and dysphagia may in children be among the presenting symptoms of TSH- or T3-receptor mutations. Early diagnosis allows for an early and targeted intervention, and thus possibly for long-term benefits.

\section{P02-715 Thyroid 1 \\ Pseudodominant inheritance of congenital thyroid dyshormonogenesis in a non- consanguineous family \\ Johnny Deladoëy ${ }^{1}$; Nicole Pfarr'; Jean-Marc Vuissoz ${ }^{3}$; Jasmine Parma ${ }^{4}$; Gilbert Vassart ${ }^{4}$; Joachim Pohlenz'; Guy Van Vliet ${ }^{5}$ \\ ${ }^{1}$ Ste-Justine Hospital/University of Montreal, Dpt of Pediatrics,

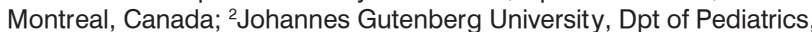 Mainz, Germany; ${ }^{3}$ University of Bern, Dpt of Pediatrics, Bern, \\ Switzerland; ${ }^{4}$ Free University of Brussels/Erasme Hospital, IRIBHM and Genetics Service, Brussels, Belgium; ${ }^{5}$ University of Montreal/Ste- Justine Hospital, Dpt of Pediatrics, Montreal, Canada}

Congenital thyroid dyshormonogenesis (CTDH), which follows a recessive mode of inheritance, is most often due to mutations in the thyroid peroxidase gene (TPO). We report the genetic mechanism underlying the apparently dominant inheritance of CTDH in a non-consanguineous family of French Canadian origin. Two brothers identified by newborn TSH screening had severe hypothyroidism and a large thyroid gland with increased technetium uptake. The mother was clinically and biochemically euthyroid, but the father had also been diagnosed with CTHD as a newborn (see pedigree). Because of the dominant transmission of hypothyroidism with a gland in situ, we first sequenced the coding exons of the PAX8 gene directly from genomic DNA, but only polymorphisms were found. We next hypothesized that the euthyroid mother could be a carrier of a TPO mutation. Indeed, sequencing analysis of the TPO gene revealed that both probands had inherited a deletion from their mother (nt 1496 del C). From their father, one brother had inherited a missense mutation (nt 1978 CAG $>$ GAG transversion, resulting in the replacement of a glutamine by a glutamic acid at position 660 -Q660E-) and the other an insertion (nt 1955 ins T). In conclusion, we report the first pedigree presenting with pseudodominant CTDH due to compound heterozygous TPO mutations.

Although CTDH generally follows a recessive mode of inheritance, the high frequency of carriers of TPO mutations in the general population may lead to pseudodominant inheritance. Wild-type and Q660E TPO are being modelized in silico.

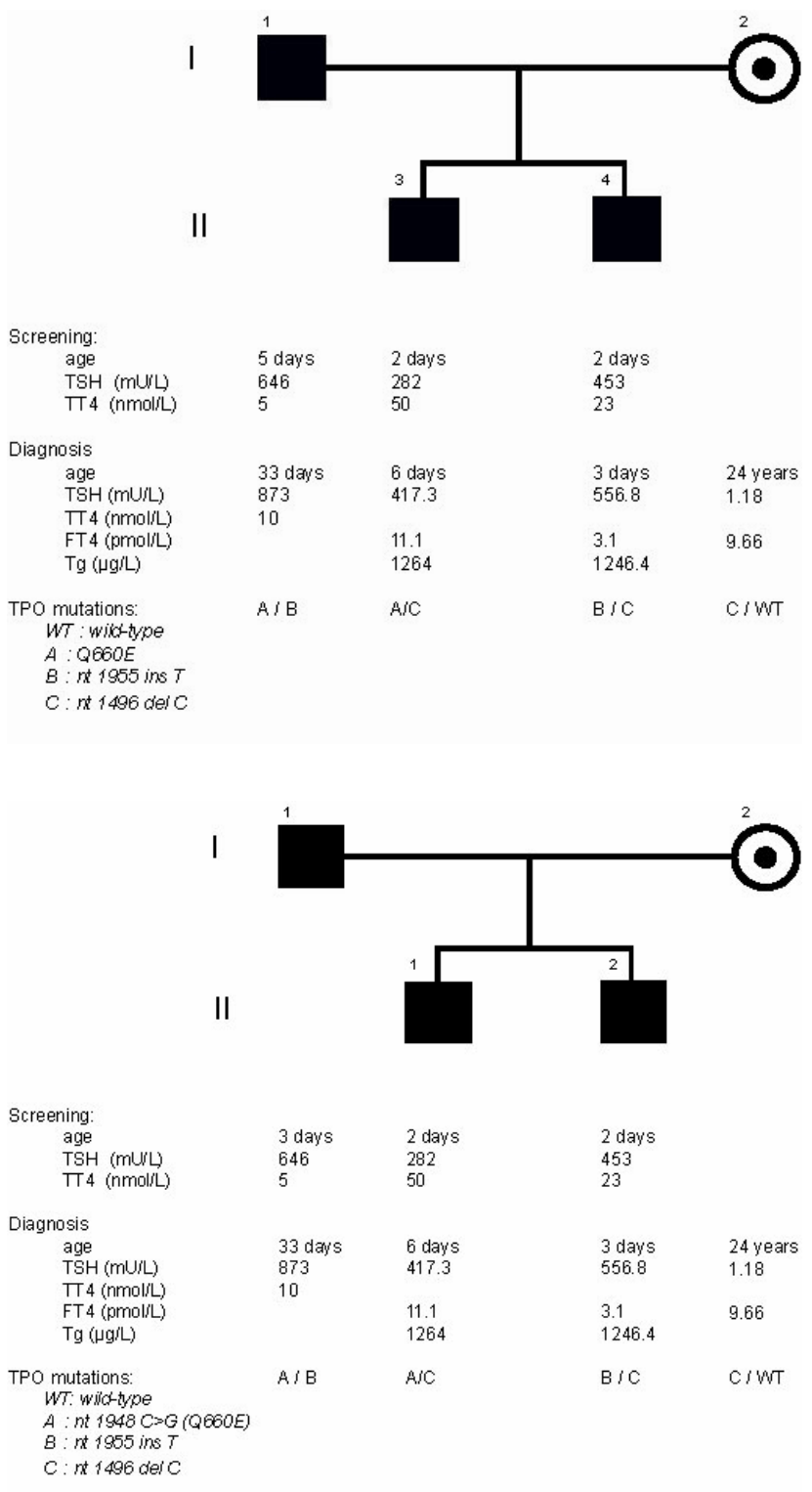

\footnotetext{
P02-716 Thyroid 1
}

\section{Children born after assisted reproduction} (classic IVF) have hyperthyrotropinemia: are they more prone to subclinical hypothyroidism? Sophia Sakka'; Christina Kanaka-Gantenbein ${ }^{\dagger}$

Ariadne Malamitsi-Puchner ${ }^{2}$; Dimitrios Loutradis ${ }^{3}$; George Chrousos ${ }^{1}$ 'University of Athens, First Department of Pediatrics, Athens, Greece; ' 2 University of Athens, Second Department of Obstetrics and Gynaecology, Athens, Greece; ${ }^{3}$ University of Athens, First Department of Obstetrics and Gynaecology, Athens, Greece

Assisted reproduction techniques are commonly used. Although classic in vitro fertilization (IVF) started almost 30 years ago, long-term systematic prospective studies of children conceived after IVF are rare. In these children, a slight increase in the frequency of congenital malformations, but no differences in growth patterns or the psychomotor and intellectual development compared to naturally conceived ones have been reported. However, there has not been any data on other endocrine axes in these 
children. The aim of this study was to investigate thyroid function in children conceived after IVF vs. naturally conceived controls. Subjects and methods: We studied 106 children born after classic IVF and 68 naturally conceived controls, aged 4-14 years. All children were thoroughly examined and serum Triiodothyronine (T3), Thyroxin (T4), Thyroid-Stimulating Hormone (TSH), Antithyroid peroxidase (anti-TPO) and Antithyroglobulin (anti-TG) antibodies were measured. Those with a TSH value of $>5 \mathrm{iIU} / \mathrm{ml}$ were retested with a second blood test and a thyroid ultrasound, and were considered to have persistent hyperthyrotropinemia and subclinical primary hypothyroidism, if TSH elevation was confirmed. Results: 7IVF children but none of the controls had subclinical hypothyroidism $(\mathrm{p}=0,044)$. TSH was significantly higher in the IVF group compared to controls $(p=0,046)$, although T3 and T4 concentrations were not statistically different between groups. None of the children had detectable circulating anti-thyroid antibodies in either group. In conclusion, significant increase of subclinical hypothyroidism in children born after IVF compared to controls was observed. This cannot be due to the presence of autoantibodies. We suggest that the persistently elevated TSH and/or mild primary hypothyroidism observed in IVF children might represent a slight epigenetic developmental abnormality related to the early treatment of the embryo prior to implantation. Further studies need to be performed to confirm these findings and to better determine their aetiopathogenesis and clinical significance.

\section{P02-717 Thyroid 1 \\ Cardiac effects of subclinical hypothyroidism observed in patients with congenital hypothyroidism (CH) during treatment Helen Tsoka-Gennata'; Thaleia Papazoglou'; Evangelos Karanasios²; Vasiliki Plakoula'; Aspasia Fotinou ${ }^{3}$ \\ 1"Aghia Sophia" Children's Hospital, Pediatrics, Athens, Greece; \\ 2"Aghia Sophia" Children's Hospital, Cardiology, Athens, Greece; \\ 3"P \& A. Kyriakou" Children's Hopsital, Biochemistry, Athens, Greece}

During long-term thyroxine treatment, patients with C.H. may develop subclinical hypothyroidism, i.e. TSH concentrations above normal levels, with consequences, which are not completely known. The aim of this study was to determine the impact of subclinical hypothyroidism on cardiac function in a group of 53 patients with $\mathrm{CH}$, diagnosed by neonatal screening aged $15.62 \pm 3.4$ years. All were clinically euthyroid. The mean daily thyroxin dose was $2.18 \mu \mathrm{g} / \mathrm{kg}$. Left ventricular dimensions and function were investigated by means of Echocardiography. Cardiac parameters were correlated to the TSH, T4 and T3 levels on the same day as the echocardiography, as well as to their TSH, T4 and T3 mean concentrations of the last 3-year period. TSH levels on the examination day and of the last 3 years were $3.74 \pm 2.6$ and $3.29 \pm 2.1 \mu \mathrm{IU} / \mathrm{ml}$ respectively, T4 levels were $8.28 \pm 2.5$ and $8.05 \pm 2.08 \mu \mathrm{g} /$ $\mathrm{dl}$, and $\mathrm{T} 3$ levels $1.24 \pm 0.2$ and $1.17 \pm 0.4 \mathrm{ng} / \mathrm{ml}$. Twelve patients had elevated TSH concentrations on examination and 11during the last 3 years. Cardiac parameters were within the normal range. However, cardiac parameters [left ventricular end diastolic and end systolic diameter, left ventricular posterior wall diastolic diameter, isovolumetric relaxation time and early diastolic mitral flow velocity/late diastolic mitral flow velocity (E/A ratio)] of the patients with elevated TSH differed significantly to those of patients with normal TSH. Furthermore, a statistically significant positive correlation was noted between TSH values (at examination as well as of the last 3 years) and left ventricular end diastolic $(\mathrm{r}=+0.593, \mathrm{p}<0.01)$ and end systolic diameter $(\mathrm{r}=+$ $0.587, \mathrm{p}<0.01)$, left ventricular posterior wall diastolic diameter $(\mathrm{r}=+0.671, \mathrm{p}<$ $0.001)$ and isovolumetric relaxation time $(r=+0.692, \mathrm{p}<0.001)$ and a significant negative correlation between TSH and $\mathrm{E} / \mathrm{A}$ ratio $(\mathrm{r}=-0.689, \mathrm{p}<0.001)$. T3 and $\mathrm{T} 4$ values had a significant inverse correlation with the above parameters. In conclusion, subclinical hypothyroidism may affect cardiac function in patients with C.H. while on a subnormal thyroxin dose.

\section{P03-718 Thyroid 2 \\ Association of autoimmune thyroiditis with HLA-DQB1 gene polymorphisms}

Thaleia Papazoglou'; Evangelos Bozas²; Dimitris Tsonopoulos²; Vasiliki Plakoula'; Ioannis Androulakis ${ }^{2}$; Helen Tsoka-Gennata ${ }^{1}$ 'Children's Hospital 'Aghia Sophia', Athens, Endocrinology Clinic, A' Department Of Pediatrics, Greece; 'Pediatric Research Laboratory, Faculty Of Nursing, University Of Athens, Greece

Autoimmune thyroiditis is an organ-specific T-cell-mediated disease resulting in dysfunction of the thyroid gland. It appears to develop as a result of an interaction between predisposing genes and environmental factors. The histocompatibility leucocyte antigen DQB1 (HLA-DQB1) polymorphisms may modulate the susceptibility to the disease. The aim of our study was to assess possible associations between autoimmune thyroidits and the HLADQB1 polymorphisms. To this purpose, molecular typing of six HLA-DQB1 alleles $\left({ }^{*} 0201, * 0301, * 0302,{ }^{*} 0602, * 0603,{ }^{*} 0604\right)$ was carried out, using the group-specific polymerase chain reaction amplification technique, to 21 patients with autoimmune thyroiditis, aged $14.5 \pm 2.4$ years, as well as to 1784 controls from the general population. Autoimmune thyroiditis was diagnosed at an age of $9.6 \pm 1.2$ years, through positive antithyroid antibody testing and ultrasound findings suggestive of the disease(heterogenity and hypertrophy of the gland). The TSH levels at diagnosis were $15.7 \pm 6.5 \mathrm{iIU} / \mathrm{ml}$ and the thyroxine dose requirements at last examination were $1.6 \mathrm{ig} / \mathrm{kg} / \mathrm{day}$. The HLA-DQB $1 * 0201,0302$ and the DQB1* 0302,x genotypes were associated with predisposition to autoimmune thyroiditis( $\mathrm{p}=0.017, \mathrm{OR}: 5.1$ and $\mathrm{p}=0.032$, OR:1.83 respectively), while the $\mathrm{DQB} 1^{*} 0301, \mathrm{x}$ genotype was associated with protection $(\mathrm{p}=0.029$, OR:0.30). Additionally, a positive association was found with the HLA-DQB $1 * 0302$ allele $(\mathrm{p}=0.042$, OR:1.94) and a negative one with the DQB1*0301 allele $(\mathrm{p}<0.001$, OR:0.16). Statistically significant associations of autoimmune thyroiditis were found neither with the HLA-DQB $1 * 0201, \mathrm{x}$, the DQB $1 * 0602, \mathrm{x}$, the DQB $1 * 0301,0302$ and the DQB1*0602,0201 genotypes nor with the DQB1*0201 and DQB1*0602*0603-*0604 alleles. In conclusion, our preliminary data indicate that there might be an association of autoimmune thyroiditis with the HLA-DQB1 gene polymorphisms in the establishment of either a predisposing or protective response. However, the number of patients studied will be increased and the importance of each allele and genotype will be further investigated.

\section{P03-719 Thyroid 2 \\ Precocious puberty in a girl with Hashimoto's thyroiditis}

Vichit Supornsilchai; Thaninee Petwijit; Nattakarn Wongjitrat; Suphab Aroonparkmongkol; Suttipong Wacharasindhu

King Chulalongkorn Memorial Hospital, Endocrinology unit,

Department of Pediatric, Bangkok, Thailand

Background: Some children with juvenile hypothyroidism can develop isosexual precocity with retarded bone age. Congenital hypothyroidism became less common cause due to newborn screening program.

Methods/Results: We describe a 9 year-old girl with vaginal bleeding due to untreated Hashimoto's thyroiditis. Markedly decreased in FT4 level and elevated TSH level with high titer of anti-thyroglobulin and anti-thyroid peroxidase antibodies. Technaetium 99 thyroid scan showed normal shape and size of thyroid glands. Suppressed gonadotropin levels, but estradiol was in pubertal range. Together with pelvic ultrasound showed pubertal size of ovaries and uterus. Moreover, hypothyroidism was long enough to inhibit negative feedback of hypothalamic-pituitary-thyroidal axis resulting in pituitary hyperplasia. However, all consequences are reversible upon thyroxin replacement therapy.

Conclusion: Untreated Hashimoto's thyroiditis during childhood period caused precocious puberty with vaginal bleeding which the underlying pathogenesis still unclear. 
P03-720 Thyroid 2

Prevalence of diabetes-related autoantibodies in young patients with autoimmune thyroid

\section{disease}

Daniela Larizza; Valeria Calcaterra; Cristina Torre; Claudia Caramagna; Valeria Ghiglione; Gaia Lanati; Mara De Amici

Fond. IRCCS Pol. S. Matteo and University of Pavia, Department of

Pediatric Sciences, Pavia, Italy

Background: Patients with autoimmune thyroid disease (ATD) are predisposed to develop other autoimmune disorders such as type 1 diabetes. We determined the prevalence of diabetes-related autoantibodies in young patients with ATD.

Patients and methods: we determined by IRMA anti-glutamic acid decarboxilase (GAD65) and anti-tyrosine phosphatase (IA2) antibodies in sera from 160 non-diabetic patients with ATD (mean age $17.77 \pm 5.55 \mathrm{yr}, 130$ females, 30 males), including 133 with Hashimoto thyroiditis (HT) and 27 with Graves disease (GD). Seventeen patients (16 HT and 1 GD) were also affected by celiac disease (CD). As controls, we evaluated 52 healthy agematched subjects.

Results: The prevalence of diabetes-related autoantibodies (particularly GAD65) resulted higher in patients with ATD than in healthy controls, even if the difference was not statistically significant (table).

\begin{tabular}{|c|c|c|c|c|}
\hline & $\begin{array}{l}\text { GAD65 and/or } \\
\text { IA2 }\end{array}$ & GAD65 & $\mathrm{IA} 2$ & $p$ vs controls \\
\hline ATD $(n=160)$ & 17 (10.62\%) & 10 (6.25\%) & 12 (7.50\%) & ns \\
\hline $\mathrm{HT}(n=133)$ & $13(9.77 \%)$ & $8(6.01 \%)$ & $10(7.69)$ & ns \\
\hline $\mathrm{GD}(\mathrm{n}=27)$ & 4 (11.81\%) & 2 (7.40\%) & 2 (7.40\%) & ns \\
\hline $\begin{array}{l}\text { Controls } \\
(n=52)\end{array}$ & $4(7.69 \%)$ & 1 (1.92\%) & $3(5.76 \%)$ & \\
\hline
\end{tabular}

Presence of CD in ATD subjects was associated with higher prevalence of GAD65 and/or IA2 antibodies respect to ATD subjects without CD (GAD65 $14.67 \%$ vs $4.89 \%$; IA2 $11.76 \%$ vs $6.99 \%$ ), but without statistically significant difference. No statistical difference in the prevalence of GAD65 and/or IA2 was found between males and females and HT and GD patients. All GAD65 antibody and IA2-positive patients with ATD had normal blood glucose levels and glycosylated haemoglobin.

Conclusions: in our ATD patients mainly GAD65 antibodies prevalence resulted higher than in controls. Whether the presence of diabetes-related autoantibodies predicts the future development of type 1 diabetes remains to be determined in follow-up studies.

\section{P03-721 Thyroid 2 \\ Autoimmune thyroiditis and thyroid hormone resistance (THR) \\ Ana Chiesa' ${ }^{1}$; Alicia Martinez ${ }^{2}$; Ana Vieites²; Karina Rivolta ${ }^{3}$; \\ Hector Targovnik ${ }^{3}$ : Laura Gruñeiro Papendieck ${ }^{1}$ \\ ${ }^{1}$ Hospital R Gutierrez, Endocrinology Division, Buenos Aires, \\ Argentina; ${ }^{2}$ Hospital de Niños R Gutierrez, Endocrinology Division, \\ Buenos Aires, Argentina; ${ }^{3}$ Catedra de Genetica y Biologia molecular, \\ Universidad de Buenos Aires, Buenos Aires, Argentina}

THR is a dominantly inherited syndrome of reduced tissue responsiveness to thyroid hormone usually due to mutations in the T3 receptor beta gene. We describe a 17 year old boy that was referred to our department at 4.7 years for short stature. He had a mild subvalvular aortic stenosis without cardiac insufficiency and celiac disease. He grew along the the 3 rd percentile up to age 11 coping well with his gluten free diet. At 14 years of age he started puberty. At 14.5 years he grew poorly, (height -2.5 SDS) and a diffuse goitre was noted. Thyroid function was assessed and TSH levels were $26.7 \mathrm{mU} / \mathrm{L}$ T4 $11 \mathrm{ug} / \mathrm{dl}$ with positive anti thyroid antibodies. With diagnosis of autoinmune thyroiditis was treated with 1-T4 100ug/day. Growth improved but TSH levels failed to inhibit in spite of high T4 levels (TSH $14 \mathrm{mU} / \mathrm{L}, \mathrm{T} 413.5 \mathrm{ug} / \mathrm{dl}$, FT4 $3.11 \mathrm{ng} / \mathrm{dl}$ ) (Normal values: TSH 0.5- $5 \mathrm{mu} / \mathrm{L}$ T4:4.5-12.5ug/dl FT4: 0.8$2.2 \mathrm{ng} / \mathrm{dl})$. At the age of 17 with height at $-1.96 \mathrm{SDS}$ and complete sexual development, treatment was withdrawn and pituitary and peripheral tissue responses to graded doses of triiothyronine (LT3) were studied. 50,100 and $200 \mathrm{ug} / \mathrm{m} 2$ /day of LT3 inhibited basal TSH to 3, 2 and $0.70 \mathrm{mU} / \mathrm{L}$ respectively.
TSH response after TRH-test was still present under the higher dose of LT3 and SHBG showed a paradoxical decrease. The patient became clinically hypothyroid. Molecular studies found a missense mutation in exon 9 of the TRb gene (pN331D). Treatment with 1-thyroxine was reinitiated with clinical improvement but TSH remained high. TRIAC was added to treatment. THR has to be considered in patients with high TSH and thyroid hormones levels even in the occurrence of autoimmune disorders.

\section{P03-722 Thyroid 2 \\ Long-term follow-up outcome in children and adolescents with Hashimoto's thyroiditis} Jung Hyun Lee; Jung Min Ko; Han-Wook Yoo

Asan Med. Ctr. Univ. of Ulsan College of Med., Pediatrics, Seoul, Republic of Korea

Hashimoto's thyroiditis is the most cause of acquired hypothyroidism in children and adolescents. The purpose of this study is to investigate the clinical course and outcome of Hashimoto's thyroiditis with long-term follow up. A total of 112 patients with Hashimoto's thyroiditis were included. The mean age at diagnosis was $10.41 \pm 2.58$ years old. Goiter was found in more than $95 \%$ of patients, whereas 5 patients presented with profound short stature without goiter. Positive family history of thyroid disease was documented in 36 out of 112 patients $(32.1 \%)$. At diagnosis, 40 of 112 patients $(35.7 \%)$ studied were in euthyroidal status, $64(57.1 \%)$ in overt or compensated hypothyroidism, and $8(7.1 \%)$ in hyperthyroidism. Among the 35 patients that were followed up for more than five years, 10 patients were in euthyroidal status, 24 in overt or compensated hypothyroid, and 1 in hyperthyroidism at initial presentation. Five patients initially diagnosed with euthyroidism remained in euthyroidal status while 14 patients with hypothyroidism were shifted to euthyroidism. Overall, 20 out of 35 patients were in remission status at the last follow-up. Initial TSH level was significantly higher in non-remission group $(\mathrm{p}<0.05)$. Euthyroidism at initial diagnosis is more likely to develop hypothyroidism during follow up when the TSH level at diagnosis is higher $(\mathrm{p}<0.05)$. Initial thyroid auto-antibody titers were not correlated with remission rate. The clinical course of patients with Hashimoto's thyroiditis was varying. Initial TSH level can be a prognostic factor of Hashimoto's thyroiditis.

\section{P03-723 Thyroid 2 \\ Low prevalence of autoimmune thyroiditis in acute Iymphoblastic leukemia survivors \\ Maurizio Delvecchio; Valerio Cecinati; Letizia Pomponia Brescia; Nicola Santoro; Sonia Peruzzi; Maria Felicia Faienza; \\ Domenico De Mattia; Luciano Cavallo \\ University of Bari, Department of Biomedicine of Developing Age, Bari, Italy}

Survival of childhood acute lymphoblastic leukemia (ALL) increased over the last decades and follow-up studies regarding late events of its treatment are increasingly important. An impairment of the pituitary-thyroid axis was sporadically described in cohorts of patients treated with both chemotherapy (CT) and prophylactic craniospinal irradiation. Scanty data in patients who underwent only CT are available, thus we studied thyroid function in these subjects. TSH, fT4, anti thyroglobulin and thyroperoxidase antibodies were assayed in 60 patients $(20 \mathrm{~F})$, off-CT for at least 3 months and without any relapse. Mean age (yrs): at diagnosis $5.6 \pm 3.1$, at off-therapy $7.5 \pm 3.1$, at study recruitment $11.8 \pm 4.1$; mean off-therapy period $4.2 \pm 3.1$ yrs. Nobody had goiter or any clinical symptom of thyroid disease. Mean TSH $2.8 \pm 1.7$ (normal values $0.35-5.5) \mu \mathrm{U} / \mathrm{ml}$, mean fT4 $1.2 \pm 0.1(0.8-1.8) \mathrm{ng} / \mathrm{dl}$. TSH was above the normal range up to $8 \pm \mathrm{U} / \mathrm{ml}$ for 6 patients $(10 \%)$ and within for 54 . FT4 was normal in everybody. Nobody had autoimmune thyroiditis (AT). No correlations were detected between hormonal values and age at diagnosis, or at stop therapy, or at recruitment. Despite some studies show negative effects of CT on thyroid function, others state that permanent thyroid axis damage is not ascribable to CT. In our study, $10 \%$ of patients had sub-clinical hypothyroidism, comparable to $12 \%$ reported by a multicenter study run on pediatric controls in our Country, but nobody had AT, whereas a prevalence of $10 \%(\mathrm{p}<0.025)$ was reported in normal pediatric population by the same study. As the AT prevalence in Europe is reported heterogeneous, from 1 to $10 \%$, the fact that nobody of our patients shows AT could suggest that not only 
CT does not increase the risk of AT, but also it could be partially protective. Studies concerning the prevalence of other autoimmune diseases and T-cell function in a larger cohort of ALL children are in progress to confirm this hypothesis.

\section{P03-724 Thyroid 2 \\ A novel ultrasound sign of Hashimoto's thyroiditis (HT) in children}

Wojciech Kosiak'; Dominik Swieton ${ }^{1}$; Maciej Piskunowicz²; Maria Korpal-Szczyrska ${ }^{3}$; Dorota Birkholz ${ }^{3}$; Mariusz Kujawa

${ }^{1}$ Medical University of Gdansk, Pediatric Nephrology Department,

Gdansk, Poland; ${ }^{2}$ Medical University of Gdansk, Nuclear Medicine

Department, Gdansk, Poland; ${ }^{3}$ Medical University of Gdansk, Pediatric Endocrinology Department, Gdansk, Poland

The typical sonographic features of Hashimoto's Thyroiditis as: increase in size, fibrotic septa, micronodulation with a reduction in thyroid echogenicity and marked intraparenchymal hypervascularity in power Doppler modality, are commonly known.

We present an additional novel ultrasound sign of HT in children. A total of 98 children 14 boys (14\%) / 84 girls (86\%) - mean age 12,7 years were examined. All of them went through diagnostic requirements for HT. The diagnosis of HT was based on: clinical data, laboratory tests and fineneedle aspiration biopsy. Due to comparison, two control groups were enrolled. Group A- N= 102 healthy volunteers: 45 boys $(44 \%) / 57$ girls $(56 \%)$ - mean age 10,6 years and group $\mathrm{B}-\mathrm{N}=56$ from the register of the oncology outpatient department - children with limphadenopathy: 26 boys $(46 \%)$ and 30 girls (54\%) - mean age 12,5 years. All thyroid ultrasound evaluations were carried out by the two operators using a real-time instrument (GE LOGQ 500). In each patient grey-scale and power Doppler ultrasound was performed using standardized parameters. Special attention was paid at the presence and size of the thyroid gland adjacent lymph nodes. The size of lymph nodes were graded as small $(<5 \mathrm{~mm})$ medium $(5-10 \mathrm{~mm})$ and large $(>10 \mathrm{~mm})$.

In all children with the diagnostic requirements for HT thyroid echogenicity and power Doppler suggested HT and in all patients nodes adjacent to the lower part of thyroid gland lobes were found. Small lymph nodes were found in $4 \%$, medium in $70 \%$ of cases and large in $26 \%$ cases. In group A and B lymph nodes adjacent to the lower part of thyroid gland lobes were not found.

Conclusions: The presence of the lymph nodes adjacent to the lower part of thyroid gland lobes seems to be an additional novel ultrasound sign of Hashimoto's lymphocytic thyroiditis.

\section{P03-725 Thyroid 2}

\section{Natural history of Hashimoto's thyroiditis in children and results of treatment with thyroxin Vasiliki Skarpa; Asteroula Papathanasiou; Athanasia Tertipi; Afroditi Kitsopoulou; Petros Papachilleos; Panagiotis Nikolopoulos; Vasilios Petrou; Marina Vakaki; Charalambos G. Hadjiathanasiou P. \& A. Kyriakou, Endocrinology, Athens, Greece}

Hashimoto's thyroiditis (HT) is the commonest cause of goiter in children with sufficient iodine intake. Whether thyroxin (T4) administration is necessary and/or effective in euthyroid children with HT and in those with subclinical hypothyroidism remains a matter of debate. The aim of the study was to compare the evolution of HT in children and adolescents, with or without administration of T4, over a period of 2 years. We studied prospectively 89 children with HT (77 girls, 12 boys), with a mean chronological age $10.2 \pm 2.6$ yr (range $3.3-14.6$ yr). 59 were euthyroid, 27 presented subclinical hypothyroidism and 3 had overt hypothyroidism. All children with subclinical and overt hypothyroidism were treated with T4 $(2.4 \pm 0.7 \mathrm{ig} / \mathrm{kg} / \mathrm{day}) . \mathrm{T} 4$ treatment was also prescribed in 23 children who had thyroid gland volume (TV) $\mathrm{SDS}>1.5$, while those with TVSDS $<1.5(\mathrm{n}=36)$ received no treatment. Non treated euthyroid children had a significant increase in TV SDS from $0.2 \pm 0.6$ to $0.8 \pm 1.2(\mathrm{p}=0.007)$ after 2 years, without significant alteration in TSH and FT4. In contrast, euthyroid children treated with T4 experienced a significant decrease in TVSDS, from $2.4 \pm 0.8$ to $1.6 \pm 1.3$ ( $\mathrm{p}=0.002$ ).

Subclinically hypothyroid children with TVSDS $>1.5$, after 2 years of treatment, experienced also a significant decrease of TVSDS (1.5 $1.3 \mathrm{vs}$
$2.8 \pm 1.1, \mathrm{p}=0.003)$, and of TSH levels $(2.2 \pm 0.8 \mathrm{vs} 7.3 \pm 1.7 \mathrm{i} \mathrm{U} / \mathrm{ml})$. In children with overt hypothyroidism TVSDS decreased from 3.8 to 0.7 and FT4 and TSH returned to normal levels. Antithyroid antibodies showed no change in any of the study group. HT is an evolutive disease in children and even in the euthyroid state the TV can be increased. T4 administration in children with subclinical hypothyroidism and in euthyroid children with TVSDS > 1.5 decreases thyroid gland volume. Treatment does not affect the antithyroid antibodies levels.

\section{P03-726 Thyroid 2 \\ Dynamics of TSH receptor antibodies as a predictor of Graves' disease relapse after long- term course of anti-thyroid drug therapy Galina Smirnova'; Sergey Prokofyev'2; Olga Bezlepkina'; Valentina Peterkova ${ }^{1}$ \\ 'Endocrinology Research Center, Institute of Pediatric Endocrinology, Moscow, Russian Federation; ${ }^{2} E$ ndocrinology Research Center, \\ Laboratory of immunology, Moscow, Russian Federation}

Graves' disease (GD) develops as a result of TSH receptor antibodies action on thyrocytes. Long-term therapy with anti-thyroid drugs (ATD) is the first line method of GD treatment in children. Decision to stop therapy is based on analysis of different factors characterizing thyroid status; but relapse is always difficult for prognosis.

The aim of our study was to determine the levels and dynamics of thyroidbinding inhibiting immunnoglobulins (TBII) (second generation assay) as relapse predictor during 1 year after discontinuation of long-term ATD therapy in children with GD.

We examined 54 children with GD onset at $10.5 \pm 3.5$ yrs (girls to boys ratio 4:1). All children received methimazole $(0.7-1.0 \mathrm{mg} / \mathrm{kg} / \mathrm{day})$ at least for 1.5 yrs. TBII was measured at GD onset, at the end of ATD, and within 1 year after discontinuation

At GD onset all children presented with positive TBII $(12.1 ; 1.42-38.9(\mathrm{Me}$; min-max) IU/L). We evaluated only 18 patients from GD onset till ATD discontinuation ( $25 \pm 5.3$ months). GD relapsed in $7 / 18$ patients in $7.0 \pm 1.6$ months. TBII levels were compared between patients with (group 1) and without relapse (group 2). TBII at GD onset did not differ between groups $(ð=0.9)$. At the end of ATD TBII was elevated $(ð=0.03)$ in group $1(3.9$; 0.64-68.9) compared to group $2(0.64 ; 0.12-6.4)$; after ATD discontinuation TBII was also increased in group $1(34 ; 1.8-57)$ more than in group $2(1.26$; $0.01-6.2)(\delta=0.03)$. According to Fisher criterion patients with elevated TBII levels while on ATD had the most risk of relapse $(\delta=0.05)$; patients whose TBII was more than $10 \mathrm{IU} / \mathrm{L}$ also relapsed.

The study demonstrated, that evaluation of TBII levels in children with GD at the end of ATD therapy can be used as a predictor of early relapse.

\section{P03-727 Thyroid 2 \\ Pseudotumor cerebri in two patients with Hashimoto's thyroiditis}

Asteroula Papathanasiou'; Petros Papachilleos ${ }^{1}$; Vasiliki Skarpa ${ }^{1}$; Helen Georgouli'; Anastasia Garoufi'; George Koliofotis²;

Vasilios Petrou'; Charalambos Hadjiathanasiou

'P\&A Kyriakou Children's Hospital, Pediatric Endocrinology, Athens, Greece; '2P\&A Kyriakou Children's Hospital, University Pediatric Clinic, Athens, Greece

Background:Pseudotumor cerebri(PC) is characterized by increased intracranial pressure in the absence of a space-occupying lesion, normal ventricular size and CSF composition.Some cases are associated with end ocrinopathy(hypothyroidism,obesity, $\mathrm{GH}$ therapy)and most reported cases in pediatric patients occurred after the initiation of thyroxine replacement therapy.

Objective:To present two unusual cases of PC occurring in children who did not receive treatment for Hashimoto's thyroiditis (before developing subclinica hypothyroidism and seven months after subclinical hyperthyroidism, respectively).Case report:1)A12-year old girl was admitted to the hospital with headaches and blurred vision of recent onset without focal neurological signs.Pappilledema was noted on fundoscopy.Lab:TSH:3,28iU/ml $(0,4$ 5),fT4:1,6ng/dl(0,8-2), anti-TPO:445(<16), anti TG:neg.U/Sscan:borderline 
enlarged thyroid of normal echogenity.The patient's symptoms resolved after treatment with acetazolamide and she was followed up regularly.Three months later she developed subclinical hypothyroidism(TSH:6,2 iU/ml, antiTPO: 878) and was started on thyroxine replacement therapy.No recurrence of ICP was noted and she remained euthyroid on follow-up. 2)A10- year old girl was referred for assessment of growth. She was euthyroid with a small palpable firm goiter.Lab:TSH:0,005 iU/ml (0,4-5), fT4:1,63 ng/dl $(0,8-$ 2),T3:200 ng/dl(80-215), anti-TPO:14(<16), anti-TG:230(<100). She was not treated because of the absence of clinical symptoms, remained euthyroid and gained $3 \mathrm{kgr}$ over the next 5 months.TSH and antithyroid antibodies increased slightly(TSH:0,02 and anti-TPO:180). Seven months after the initial evaluation she developed sudden headaches, nausea and diplopia.CSF pressure:500 $\mathrm{mHG}(<100)$,MRI:normal. TSH:0,58 iU/ml(0,4-5), fT4:1,36 $\mathrm{ng} / \mathrm{dl}(0,8-2)$, T3:3,9ng/dl(2,5-5). Symptoms subsided after treatment with acetazolamide and she remained euthyroid on follow-up.

Conclusion:PC should be suspected when relevant symptoms occur even in euthyroid or untreated patients with Hashimoto's thyroiditis.

\section{P03-728 Thyroid 2 \\ Association of CTLA4 and TSHR gene polymorphisms with Graves' disease in Russian children}

Galina Smirnova'; Alexey Shestakov²; Kirill Sevostyanov²; Valery Nosikov'; ; Valentina Peterkova ${ }^{1}$

${ }^{1}$ Endocrinology Research Center, Institute of Pediatric Endocrinology, Moscow, Russian Federation; ${ }^{2}$ National Research Centre "GosNII

genetika", LMDGD, Moscow, Russian Federation

Graves' disease (GD) is a complex autoimmune thyroid disease with a strong genetic component. Autoantibodies against thyroid-stimulating hormone receptor (TSHR) molecules are the main autoimmune marker of the pathology. Two genes were reported to be associated with GD: cytotoxic T-lymphocyteassociated antigen-4 (CTLA-4) gene and TSH receptor gene (TSHR).

The aim of our study was to investigate an association with GD of two polymorphisms: Ala17Thr, located in codon 17 of CTLA4 gene, and Glu727Asp, located in codon 727 of TSHR gene, in Russian children with GD.

We examined 86 children with GD, mean age $11.5 \pm 3.9$ years, disease duration $0-6$ years, and 153 healthy controls, using polymerase chain reaction-restriction fragment length polymorphism (PCR-RFLP) analysis.

In case of Ala17Thr polymorphous marker of CTLA4 gene we have not found significant difference $(\delta>0.05)$ of allele frequencies between children with GD and controls; but in GD children group we have found significantly increased frequency of Ala/Ala genotype $(\mathrm{OR}=1.9, \mathrm{p}<0.05)$ in contrast to decreased frequency of heterozygous genotype $\mathrm{Ala} / \mathrm{Thr}(\mathrm{OR}=0.58, \mathrm{p}<0.05)$. In case of Glu727Asp polymorphous marker of TSHR gene we have found that carriers of Glu allele and Glu/Asp genotype had higher risk $(\mathrm{OR}=2.12$ and 2.34, correspondingly; $p<0.05$ ) whereas the carriers of Asp allele and Asp/Asp genotype had lower risk of GD development $(\mathrm{OR}=0.47$ and 0.43 , correspondingly; $\mathrm{p}<0.05$ ).

The significant differences of allele and genotype frequencies of Ala17Thr (CTLA4 gene) and Asp727Glu (TSHR gene) polymorphisms in groups of children with GD and without this disease support the hypothesis about a significant role of CTLA4 and TSHR genes in the formation of genetic predisposition to GD in Russian children.

\section{P03-729 Thyroid 2 \\ Ultrasound image of thyroid gland in obese children - is there similarity with Hashimoto's thyroiditis?}

Jozef Szczyrski'; Wojciech Kosiak'; Maria Korpal-Szczyrska²; Maciej Piskunowicz'; Dominik Swieton ${ }^{1}$; Anna Bernad ${ }^{1}$; Lukasz Grodecki'; Joanna Bautenbach-Minkowska ${ }^{2}$

'Medical University of Gdansk, Pediatric Nephrology, Gdansk, Poland; ${ }^{2}$ Medical University of Gdansk, Pediatric Endocrinology, Gdansk, Poland; ${ }^{3}$ Medical University of Gdansk, Nuclear Medicine, Gdansk, Poland

It is suggested that obese children may show similar ultrasound (US) image of thyroid gland to those with Hashimoto's thyroiditis due to the morphological changes caused by obesity. The aim of the study was to evaluate US features of thyroid in obese children. Two groups underwent US examination: 58 obese children (30 girls), mean age 12,76 $\pm 3,28 \mathrm{yr}$, height SDS $0,66 \pm 1,35$, BMI SDS 7,35 $\pm 3,14$ and 62 non-obese children (54 girls) of the same age $(12,71 \pm 2,94)$ with Hashimoto's thyroiditis as a control group. TSH, fT4, fT3 and anti-thyroid antibodies were performed in all children. US examination of the obese group (OG) revealed: reduction in thyroid echogenicity in 27 children $(46,6 \%)$, isthmus enlargement in 39 children $(67,2 \%)$, mildly increased intraparenchymal blood flow in 3 cases $(5,2 \%)$ and the presence of the thyroid adjacent lymph nodes in $6(10,3 \%)$. Simultaneous occurrence of all above elements was noted in 3 patients $(5,2 \%)$ of the OG and in 59 children $(95,16 \%)$ of the Hashimoto's thyroiditis group (HG). In the OG mean thyroid volume was $10,37 \mathrm{ml} \pm 8,2$, no differences were found between patients with and without ultrasound changes $(8,8 \mathrm{ml} \pm 4,11 \mathrm{vs} .12,17 \mathrm{ml} \pm 11$, $\mathrm{p}>0,1)$. Thyroid volume in $\mathrm{HG}$ was higher $(20,35 \mathrm{ml} \pm 14,65)$ than in the OG $(\mathrm{p}<0,001)$. The isthmus width $(3,74 \mathrm{~mm} \pm 1,4)$ was above norm but lower than in $\mathrm{HG}(6,92 \mathrm{~mm} \pm 2,21, \mathrm{p}<0,001)$. Positive antibodies were found in all $\mathrm{HG}$ and in 3 children $(5,2 \%)$ of OG patients. Two of those 3 patients in OG were suspected to have Hashimoto's thyroiditis after the US examination, with thyroid volumes of 52,5 and 31,8 $\mathrm{ml}$ and with TSH above norm respectively. We conclude: isthmus enlargement and reduction of thyroid echogenicity in ultrasound examination are typical changes to obese children and should not be evaluated as signs of Hashimoto's thyroiditis, especially when thyroid is not enlarged.

\section{P03-730 Thyroid 2 \\ Thyroid hormones in obese children and adolescents}

Feneli Karachaliou'; Elpis Vlachopapadopoulou'; Dimitris Thomas ${ }^{1}$. Aspasia Fotinou'2 ${ }^{2}$ Erini Paraskaki²; Stefanos Michalacos ${ }^{1}$

'P \& A Kyriakou Children's Hospital, Growth and Development, Athens, Greece; '2P \& A Kyriakou Children's Hospital, Microbiology, Athens, Greece

The aim of this study was to examine thyroid function and assess the frequency of thyroid dysfunction in obese children and adolescents. Triiodothyronine (T3), thyroxine (T4), thyroid stimulating hormone (TSH) and antithyroid antibodies were determined in 380 obese children and adolescents ( 154 boys) aged 3-15.5 years. Thyroid function was also assessed in 120 healthy children of normal weight. Median values of TSH, T3 and T4 in obese children were normal but significantly higher compared to those of normal weight. Also a correlation was observed between thyroid hormone concentrations and BMI Z-scores of obese children. Elevated TSH ( $>5 \mathrm{IU} / 1)$ with normal thyroxine levels and negative antithyroid antibodies was detected in $5.5 \%$ of obese children but only in $0.7 \%$ of the controls. Positive antithyroid antibodies were detected in $6.8 \%$, but only in $3.5 \%$ of the control population. In a group of 38 obese children, significant weight reduction resulted in a decrease in $\mathrm{T} 3$ and T4 levels (Wilcoxon-test, $\mathrm{p}<0.01$ ).

In conclusion, thyroid hormones are increased in obese children and weight reduction seems to result in a decrease of their levels. A high prevalence of autoimmune thyroiditis is observed among obese children 
P03-731 Thyroid 2

\section{Suppurative thyroiditis in a 15 year old boy}

Asteroula Papathanasiou'; Helen Kostakioti'; Petros Papachilleos ${ }^{1}$; Vasilios Petrou'; Panagiotis Nikolopoulos ${ }^{1}$; Helen Pantazi ${ }^{2}$; Charalambos Hadjiathanasiou ${ }^{1}$

'P\& A Kyriakou Children's Hospital, Pediatric Endocrinology, Athens,

Greece; ${ }^{2}$ Alexandra General Hospital, Endocrinology, Athens, Greece

Background:Bacterial infections of the thyroid are rare both in children and adults. The thyroid is remarkably resistant to infections because of the high blood supply; however embryologic remnants (thyroglossal duct or pyriform sinus) as well as immune system suppression can be associated with suppurative thyroiditis.

Objective: To present the case of an adolescent with suppurative thyroiditis and a pyriform sinus tract without any previous neck infections.

Case Report: A 15 year old boy presented with painful swelling of the thyroid, fever $\left(39^{\circ} \mathrm{C}\right)$, malaise and sense of local pressure after a respiratory tract infection 3 weeks ago. On examination: thyroid diffusely enlarged, predominantly left, extremely painful without palpable lymph nodes. Lab. eval: ESR: $120 \mathrm{~mm} / \mathrm{h}, \mathrm{WBC}: 17.000, \mathrm{TSH}: 0,5 \mu \mathrm{U} / \mathrm{ml} \quad(0,5-4,5), \mathrm{T} 4: 147 \mathrm{nml} /$ 1 (58-161),T3:1,9 nml/1(1,3-2,6).U/S scan : normal right lobe, diffuse hypoechogenic enlarged left lobe $(6 \times 2,7 \times 2,4 \mathrm{~cm})$.Tc99scan:left lobe: decreased inhomogeneous uptake. The patient was initially treated with prednisolone because of presumed subacute thyroiditis and was reevaluated after 3 days. Fever and pain subsided but a large, painful mass (abscess) was palpated on the left lobe. FNA aspiration produced suppurative fluid with culture of streptococcus p. and haemophilus p. Intravenous therapy (ceftriaxone, amikacin, clindamycin) and surgical abscess drainage controlled the infection. Three months later clinical and laboratory examination of the thyroid were normal. A barium follow through revealed a left pyriform sinus tract which was treated surgically.

Conclusion: Infectious thyroiditis in children is rare and can lead to abscess formation. Early differentiation from subacute thyroiditis (also rare in children) may be difficult, but signs of hyperthyroidism are uncommon. The diagnosis should always prompt to discover an underlying embryologic defect. Surgical removal is indicated to avoid recurrent infections.

\section{P03-732 Thyroid 2 \\ Zinc deficiency in goitrous school children of Semirom, Iran \\ Mohammad Hassan Moaddab ${ }^{1}$; Mahin Hashemipour'; \\ Hasan Rezvanian²; Mohammad Mohammady²; Ashraf Aminorroaya²; Masoud Amini'; Ali Kachuei²; Mansour Siavash Dastjerdi \\ IIsfahan University of Medical Sciences, Pediatrics, Islamic Republic of Iran; ${ }^{2}$ Isfahan University of Medical Sciences, Internal Medicine, Islamic Republic of Iran; ${ }^{3}$ sfahan University of Medical Sciences, Internal Medicine, Isfahan, Islamic Republic of Iran}

Background: Iodine deficiency produces the spectrum of iodine deficiency disorders (IDDs): endemic goiter, hypothyroidism, cretinism, and congenital anomalies. Other factors, including goitrogens and micronutrient deficiencies may influence the prevalence and severity of IDDs and response to iodine supplementation. An association between zinc and goiter has previously been reported.

Methods: A cross sectional, descriptive study investigating an association between thyroid status and serum zinc was performed in 2003 in elementary school children of Semirom, a mountainous region of Iran. Out of a total of 1869 children selected by a multistage cluster sampling procedure, serum zinc levels were available in 210. Grade 2 goitrous children were compared with equal number of non goitrous children for serum zinc, total thyroxine (T4), thyroid stimulating hormone (TSH) and urinary iodine concentration (UIC).Goiter was detected by two pediatric endocrinologist by palpation and inspection.

Results: 210 children (105 goiter grade 0 and 105 goiter grade 2$)$ entered this sub-study. Serum zinc $(82.81 \pm 17.98$ vs $83.37 \pm 16.25 \mu \mathrm{g} / \mathrm{dl})$, T4 ( $8.65 \pm 1.59$ vs $9.14 \pm 1.47 \mu \mathrm{g} / \mathrm{dl}$ ), and TSH (3.08 2.95 vs $2.45 \pm 1.17 \mathrm{mIU} / \mathrm{L}$ ) were in normal range. There was no significant difference in serum zinc $(\mathrm{p}=0.66)$ and T4 ( $\mathrm{p}=0.16$ ) in two groups, but serum TSH was significantly higher in group 2 in comparison with control group $(\mathrm{p}=0.006)$.

Conclusion: Contrary to previous reports, our data does not show an association between serum zinc and the presence of a goiter.

\section{P03-733 Thyroid 2 \\ The role of vitamin $A$ in the prevalence of goiter in an endemic area}

Mahin Hashemipour'; Mohammad Hassan Moaddab'; Masoud Amini2; Ashraf Aminorroaya ${ }^{2}$; Ali Kachouei ${ }^{2}$; Hasan Rezvanian ${ }^{2}$; Roya Kelishadi'; Mansour Siavash Dastjerdi'; Silva Hovsepian ${ }^{1}$; Jale Amini'

${ }^{1}$ Isfahan University of Medical Sciences, Pediatrics, Isfahan, Islamic Republic of Iran; ${ }^{2}$ Isfahan University of Medical Sciences, Internal

Medicine, Isfahan, Islamic Republic of Iran

Background: Although Iodine supply in Iran has improved from many years ago, the prevalence of goiter is still high in some areas in spite of high iodine intake and normal urinary iodine, which indicate the possible role of micronutrients on the pathogenesis of goiter in such regions. Objective: To evaluate the role of vitamin A on the prevalence of goiter in Semirom, an endemic area for goiter in Isfahan province, Iran.

Methods: This cross-sectional study was conducted in 2003 in Semirom, a mountainous region in the central area of Iran that is reported as a hyperendemic .By multistage random cluster sampling method, 30 clusters (primary schools) were selected from rural and urban areas of this region. A total of 1,948 students aged 8-10 years were examined by endocrinologists and were evaluated for the presence of goiter. Two groups of students with $(\mathrm{n}=106)$ and without goiter $(\mathrm{n}=106)$ were selected randomly from among the subjects studied for measurement of serum Vitamin A. Serum T4, TSH and Retinol were measured with RIA, IRMA and HPLC methods respectively. Urine iodine was measured using digestive method. Serum Retinol $<26 \mu \mathrm{g} / \mathrm{dl}$ was considered as vitamin A deficiency (VAD).

Results: The prevalence of goiter was $36.9 \%$, the median urinary iodine excretion level of the subjects was $19.3 \pm 9.1 \mathrm{ug} / \mathrm{dl}$ that was within normal limits. Of 212 students studied for vitamin A, 10.4\% had VAD. VAD was more prevalent in students with than those without goiter $(14 \%$ vs.6\%, respectively $=0.07$ ). There was no significant relationship between sex, mean serum T4 and TSH,as well as urine iodine among students with and without VAD.

Conclusion: VAD was more prevalent among goiterous subjects.Though it was not significant statistically but had a trend to be significant .In order to make an accurate conclusion in this field, larger studies should be conducted in the field of protein-energy malnutrition and the role of other micronutrients and autoantibodies.

\section{P03-734 Thyroid 2 \\ Congenital nephrotic syndrome and persistent hypothyroidism}

Martina Kacer'; Thomas A. Wilson'; Dilys A Whyte'; Ivy I Boydstun ${ }^{2}$

State University of New York at Stony Brook, Pediatric Endocrinology, Stony Brook, NY, United States; ${ }^{2}$ State University of New York at Stony Brook, Pediatric Nephrology, Stony Brook, NY, United States

Congenital nephrotic syndrome is commonly associated with hypothyroidism. Thyroid hormone supplementation is recommended as standard of care.

The hypothyroidism is postulated to occur secondary to chronic massive proteinuria with loss of thyroid binding globulin, thyroid hormone and iodine. Previous reports have indicated that thyroxine may be discontinued following bilateral nephrectomies. We report our experience with one child with congenital nephrotic syndrome, Finnish type, and hypothyroidism who had a high requirement for thyroxine $(100-150 \mathrm{mcg} / \mathrm{d})$ from infancy to $4 \mathrm{yr}$. of age.

Hypothyroidism persisted despite bilateral nephrectomy and later following renal transplantation. However, his thyroxine requirement is now subtantially lower $(62.5 \mathrm{mcg} / \mathrm{d})$ at age 14 yr. No goiter was detected clinically and antithyroid antibodies were negative. Thyroid ultrasound and ${ }^{123} \mathrm{I}$ scan revealed a thyroid gland in the anatomically normal location. ${ }^{123} \mathrm{I}$ uptake was elevated, 18 $\%$ at 6 hours and $51 \%$ at 24 hours (normal values: $3-16 \%$ at 6 hours and $8-25$ $\%$ at 24 hours). Perchlorate was unavailable for a perchlorate washout study. We speculate that this patient may have an intrinsic problem with thyroid hormone synthesis. It is unclear whether this is related or coincidental to the Finnish nephrotic syndrome. We recommend following thyroid functions closely if thyroxine is discontinued following bilateral nephrectomies in Finnish type congenital nephrotic syndrome. 
P03-735 Thyroid 2

Linear growth, bone age, grow th-hormone (GH) secretion and IGF-I generation in children with neglected hypothyroidism before and after thyroxine replacement

Soliman Ashraf'; Omar Magdi2; Hazem Gouda²; Ahmad ElAwwa2; Elsaid Bedair ${ }^{3}$

${ }^{1}$ Hamad Medical Center, Pediatric Endocrinology, Doha, Qatar; ${ }^{2}$ Alexandria University Children's Hospital, Pediatrics, Alexandria, Egypt; ${ }^{3}$ Alexandria University, Radiology, Alexandria, Egypt

We performed standard Clonidine stimulation test for GH release and IGFI generation test and surveyed the skeleton of 15 children $(7 \mathrm{M}, 8 \mathrm{~F})$, with neglected primary hypothyroidism (age $=6.4+/-7$ years and measured their auxologic parameters for 1-2 years after starting thyroxine replacement.

Ten age-matched normal children served as controls. The Mean $( \pm \mathrm{SD})$ free T4 (fT4) increased from $2.0 \pm 1.5 \mathrm{mcg} / \mathrm{dl}$ at baseline to $13.7 \pm 3.7 \mathrm{mcg} / \mathrm{dl}$ following T4 therapy. One year after treatment, The height SDS (HtSDS) increased from $-4.3+/-2.5$ to $-2.7+/-2.3$. The peak $\mathrm{GH}$ response to clonidine increased significantly from $3.2+/-1.2 \mathrm{ng} / \mathrm{ml}$ to $7.62+/-1.38 \mathrm{ng} / \mathrm{ml}$ after treatments. Basal IGF-I concentration increased from $34.67+/-17.9 \mathrm{IU} / \mathrm{ml}$ to $58.4 \mathrm{H} / \mathrm{-}-38.3 \mathrm{IU} / \mathrm{ml}$ after treatment but was significantly lower vs those for age-matched controls $234.0+/-61.5 \mathrm{IU} / \mathrm{ml}$. Peak IGF-I response to GH increased from $58+/-38 \mathrm{IU} / \mathrm{ml}$ to $207+/-117 \mathrm{IU} / \mathrm{ml}$ after treatment but was still significantly lower compared to controls $386+/-109 \mathrm{IU} / \mathrm{ml}$. The increments in T4 level was correlated significantly with increments in HSDS ( $r=0.56 \& \mathrm{p}<$ 0.05 ). Radiological imaging revealed epiphyseal dysgenesis in $87 \%$, wormian bones in the skull in $67 \%$, large sella turcica in $20 \%$, vertebral changes in $33.3 \%$ and lines of arrested growth in $27 \%$ of patients before treatment. The bone age increased from $-4.5+/-2$ years before to $-3.3+/-2.2$ years after a year of treatment. HtSDS increments were correlated significantly with basal free T4 concentrations $(\mathrm{r}=0.62, \mathrm{P}<0.01)$, and GVSDS was correlated significantly with increments in IGF-I concentrations with treatment $(\mathrm{r}=$ $0.365, \mathrm{P}<0.01$ ). In summary, T4 replacement improves GH secretion and increases both basal and GH stimulated IGF-I levels in patients with primary hypothyroidism. However, both were still significantly lower than those for normal controls. Only partial correction of radiological manifestations has been noted. It appears that variable but irreversible damage to the GH-IGF-I -chondrocyte axis occurs due to prolonged hypothyroidism.

\section{P03-736 Thyroid 2}

\section{Type 2 amiodarone-induced hyperthyroidism:} a case report

Hasan Onal'; Gulcan Seymen ${ }^{2}$; Gurkan Altun 2 ; Oya Ercan ${ }^{1}$

${ }^{1}$ Istanbul University Cerrahpasa Medical Faculty, Pediatric

Endocrinology, Istanbul, Turkey; ${ }^{2}$ Istanbul University Cerrahpasa

Medical Faculty, Pediatrics, Istanbul, Turkey

Amiodarone which contains an appreciable amount of iodine is widely used in treatment of tachyarrhythmia.Two types of amiodarone induced hyperthyroidism ( $\mathrm{AIH}$ ) are recognized. Absence of preexisting and latent thyroid disorders and presence of goiter and/or autoantibodies supports type 1 AIH. Type 2 occurs with previously normal thyroid. There is no reported experience about the treatment of AIH in childhood.We report successful treatment of AIH in a 15 -yr-old.

Case: A 15-yr-old female patient had been followed up with diagnosis of cardiac rhabdomyoma since 9 months of age. At 3 years of age, ventricular tachyarrhythmia was realized and amiodarone treatment ( $75 / \mathrm{mg} /$ day) was given. During 12 years follow up, she had been asymptomatic, but laboratory results revealed elevated free T3/T4 levels and suppressed thyrotropin level at 15 years of age. There was no goiter. Laboratory test results were as follows: TSH: $0.011 \mathrm{mIU} / \mathrm{L}$, fT $4: 7.41 \mathrm{ng} / \mathrm{dl}$, fT3 : $2.99 \mathrm{ng} / \mathrm{ml}$, anti TG $: 0.01 \mathrm{U} / \mathrm{ml}$, anti TPO : $0.49 \mathrm{U} / \mathrm{ml}$ and urine iodine level $203 \mathrm{mg} /$ creatinine. The patient was diagnosed as type $2 \mathrm{AIH}$ and methylprednisolone ( $32 \mathrm{mg} /$ day ) was given to the patient for 3 weeks. At the end of third week of treatment, serum free T4/ T3 and thyrotropin levels were normal. Methylprednisolone was tapered in one week and amiodarone was stopped. Follow up for tachyarrythmia without treatment was planned.

Discussion: Amiodarone induced hyperthyroidism may appear few weeks or long years after amiodarone use. In our patient it appeared after 12 years of treatment. In AIH, discontinuation of amiodarone might not be possible in the presence of life threatening arrythmia. Furthermore, cessation of the drug might cause " heart thyrotoxicosis."In our case methylprednisolone was started and amiodarone was continued until thyroid function became normal which was at the end of the third week of treatment.

\section{P03-737 Thyroid 2 \\ The responsiveness to antithyroid drug therapy depending on clinical characteristics of Graves' disease in children}

Anna Kucharska; Izabela Rogozinska; Krystyna Grela;

Barbara Rymkiewicz-Kluczynska

Medical University Warsaw, Paediatrics and Endocrinology, Warsaw, Poland

Antithyroid drug therapy (ATD) is still the first choice therapy of Graves' disease in children in many countries. Long term remission rate after ATD is not above $25 \%$. If it were possible to find the patients who are unresponsive to ATD therapy it could save them from long ineffective therapy, and it would allow to make earlier decisions about the radical treatment.

The aim of the study was to analyse the clinical factors which could predict the effectiveness of ATD therapy in children with Graves' disease

Material and methods: 39 children with Graves' disease were retrospectively analysed: 32 girls and 7 boys, mean age 11,7y. Criteria required for inclusion: ATD therapy for minimum 18 months, known recurrence time, or minimum 3-year observation after ADT withdrawing in children who remained in remission. According to literature data we chose the factors which could be significant as predictors of responsiveness to ATD: male sex, younger age, family history of Graves' disease, coexisting of other diseases with immune system impairment, ophtalmopathy, large goitre, decrease of goitre size during ATD treatment, TSH-receptor antibodies level, time of TSH normalisation of TSH during ATD therapy.

Results: TSH normalisation at the beginning of ATD treatment correlated positively with the length of remission. None of the other factors alone has statistically significant influence on remission after ending the ATD therapy. Each patient who had more than 3 risk factors had relapse in short time after withdrawal of ATD.

Conclusion: The TSH normalisation during the first 6 weeks of ATD therapy is a good prognostic of remission. In children with Graves' disease who have more than 3 risk factors the radical treatment could be recommended as a first choice therapy.

\section{P03-738 Thyroid 2 \\ Prognostic and diagnostic value of carcinoembryonic antigen (CEA) in patients with familial medullary thyroid carcinoma} Nargiza Pulatova

Institute of Biochemistry of Academy of Science, Oncology, Tashkent, Uzbekistan

Background: Today Calcitonin (CT) and carcinoembryonic antigen (CEA) are widely used as markers of medullary thyroid carcinoma (MTC). Postoperative CT and CEA normalization are favorable prognostic factors. This work was initiated to assess the prognostic and diagnostic value of CEA before and after surgery in patients with familial MTC (FMTC).

Methods: Blood serum from 11 patients with FMTC (mean age $24,4 \pm 3,2$ years) undergoing total thyroidectomy and lymph node dissection in the central and lateral neck areas was investigated by means of commercially available kits (Immunotech, Czech Republic). Basal CT $\geq 300 \mathrm{pg} / \mathrm{ml}$ and CEA $>10 \mathrm{ng} / \mathrm{ml}$ were considered to be typical of MTC.

Results: Preoperative CEA levels were elevated in 8 patients $(73 \%)$, the level in patients with regional metastases being higher than in those with no metastases: $243,4 \pm 9,6 \mathrm{ng} / \mathrm{ml}$ versus $34,7 \pm 2,0 \mathrm{ng} / \mathrm{ml}$. Basal CT levels were elevated in 7 patients $(63,6 \%)$ with mean values of $185,4 \pm 11,2 \mathrm{pg} / \mathrm{ml}$ and correlated with the tumor stage. Stimulated CT levels were elevated in all patients $(100 \%$ with a mean peak of $1485,4 \pm 11,2 \mathrm{pg} / \mathrm{ml})$. With progression of the disease the increase in the CEA concentration rate was found to be dependent on time, while basal CT levels were varying. Following surgery, the elevated CEA levels to stably decrease to the normal range within 10 days 
in all patients: $8,7 \pm 2,1 \mathrm{ng} / \mathrm{ml}$. The normalization of CT lacked the stability of the above, requiring a more prolonged follow-up of from 2 to 18 month. Neither regional nor remote metastases were detected within the follow-up period.

Conclusions: In comparison with basal CT, CEA is the more sensitive prognostic marker for following the effects of surgery but even so it cannot replace the stimulated $\mathrm{CT}$ value which is sensitive diagnostic marker in MTC.

\section{P03-739 Thyroid 2 \\ The aging increase in the thyroid volume is mainly due to the augmentation of the longitudinal diameter of the gland}

Graziano Cesaretti; Ambra Bartoli; Luti Daniele; Giuseppe Saggese University of Pisa, Department of Pediatrics, Pisa, Italy

It is well known that the thyroid gland volume increases with the age. The ultrasonographic evaluation has allowed to evaluate exactly the changes in the dimensions of the gland. In this abstract we report about the modification of the thyroid volume by the evaluation of the ultrasonographic diameters of the gland.

Patients and Methods: We choose five groups of normal subjects at the following ages: $3,6,9,12$ and 15 years. In all the subjects the ultrasonographic examination of the thyroid was performed by a $7.5 \mathrm{MHz}$ linear transducer, the morphology was investigated and the gland volume was calculated according to the formula of the ellipsoid model for each lobe. The ultrasonographic images were normal in all the subjects.

Results: In the table we report the values of the volume of the thyroid, the three diameters of the lobes of the gland (as the mean of the values of the each of two lobes) and the ratios among the three diameters.

\begin{tabular}{|c|c|c|c|c|c|c|c|c|}
\hline Age & Number & Volume & & $\begin{array}{l}\text { Diameters } \\
(\mathrm{mm})\end{array}$ & & & Ratios & \\
\hline Years & & $\mathrm{ml}$ & Depth & Width & Length & $\begin{array}{l}\text { Length/ } \\
\text { Depth }\end{array}$ & $\begin{array}{l}\text { Length/ } \\
\text { Width }\end{array}$ & $\begin{array}{l}\text { Depth/ } \\
\text { Width }\end{array}$ \\
\hline 3 & 42 & $\begin{array}{l}1.74 \\
\pm 0.47\end{array}$ & $\begin{array}{l}9.2 \\
\pm 2.1\end{array}$ & $\begin{array}{l}8.6 \\
\pm 2.0\end{array}$ & $\begin{array}{l}21.1 \\
\pm 5.3\end{array}$ & $\begin{array}{l}2.29 \\
\pm 0.55\end{array}$ & $\begin{array}{l}2.45 \\
\pm 0.59\end{array}$ & $\begin{array}{l}1.08 \\
\pm 0.20\end{array}$ \\
\hline 6 & 45 & $\begin{array}{l}2.14 \\
\pm 0.43\end{array}$ & $\begin{array}{l}9.4 \\
\pm 2.2\end{array}$ & $\begin{array}{l}8.9 \\
\pm 2.0\end{array}$ & $\begin{array}{l}24.6 \\
\pm 6.2\end{array}$ & $\begin{array}{l}2.61 \\
\pm 0.61\end{array}$ & $\begin{array}{l}2.76 \\
\pm 0.62\end{array}$ & $\begin{array}{l}1.06 \\
\pm 0.21\end{array}$ \\
\hline 9 & 43 & $\begin{array}{l}2.52 \\
\pm 0.52\end{array}$ & $\begin{array}{l}9.9 \\
\pm 2.4\end{array}$ & $\begin{array}{l}9.3 \\
\pm 2.1\end{array}$ & $\begin{array}{l}26.3 \\
\pm 6.0\end{array}$ & $\begin{array}{l}2.66 \\
\pm 0.67\end{array}$ & $\begin{array}{l}2.83 \\
\pm 0.62\end{array}$ & $\begin{array}{l}1.06 \\
\pm 0.23\end{array}$ \\
\hline 12 & 51 & $\begin{array}{l}2.94 \\
\pm 0.54\end{array}$ & $\begin{array}{l}10.3 \\
\pm 2.4\end{array}$ & $\begin{array}{l}9.6 \\
\pm 2.2\end{array}$ & $\begin{array}{l}28.6 \\
\pm 7.4\end{array}$ & $\begin{array}{l}2.78 \\
\pm 0.62\end{array}$ & $\begin{array}{l}2.98 \\
\pm 0.69\end{array}$ & $\begin{array}{l}1.07 \\
\pm 0.20\end{array}$ \\
\hline 15 & 53 & $\begin{array}{l}6.81 \\
\pm 1.13\end{array}$ & $\begin{array}{l}13.1 \\
\pm 3.0\end{array}$ & $\begin{array}{l}11.5 \\
\pm 2.3\end{array}$ & $\begin{array}{l}43.4 \\
\pm 11.4\end{array}$ & $\begin{array}{l}3.31 \\
\pm 0.82\end{array}$ & $\begin{array}{l}3.77 \\
\pm 0.84\end{array}$ & $\begin{array}{l}1.14 \\
\pm 0.22\end{array}$ \\
\hline
\end{tabular}

Statistical analysis: Ratios Length/Depth and Length/Width at 15 years significantly higher $(\mathrm{p}<0.01)$ that those at 3,6 and 9 years.

Conclusion: Our data demonstrate that in normal paediatric subjects all the thyroid diameters, evaluated by an ultrasonographic method, show an augmentation with the age, but that the length significantly increases more than the depth and the width. Therefore the aging enlargement in thyroid gland volumes is mainly linked to the increase in longitudinal diameters.

\section{P03-740 Thyroid 2 \\ Penicillamine induced dyshormonogenesis and hypothyroidism in healthy infants born to a mother with Wilson disease, and in Wilson disease patients}

Aaron Hanukoglu'; Batya Curiel2; Drora Berkowitz ${ }^{3}$; Arieh Levine ${ }^{4}$; Mordehai Lorberboym ${ }^{5}$

${ }^{1} \mathrm{E}$. Wolfson Medical Center, Tel-Aviv University, Division of Pediatric Endocrinology, Holon, Israel; ${ }^{2} \mathrm{E}$. Wolfson Medical Center, Division of Pediatric Endocrinology, Holon, Israel; ${ }^{3}$ Rambam Medical Center, Division of Pediatric Gastroenterology, Haifa, Israel; ${ }^{4} \mathrm{E}$. Wolfson Medical Center, Division of Pediatric Gastroenterology, Holon, Israel; ${ }^{5} \mathrm{E}$. Wolfson Medical Center, Institute of Nuclear Medicine, Holon, Israel

Background: Thyroid dysfunction has not been previously reported in Wilson disease (WD) patients. An infant born to a mother with WD, who was on penicillamine, had transient goitrous hypothyroidism, raising the question of whether penicillamine inhibits thyroid hormonogenesis in-utero. Penicillamine was previously shown to inhibit myeloperoxidase activity. Thyroid peroxidase that catalyzes the iodination and coupling of tyrosine, shares amino acid sequence homology with myeloperoxidase. We hypothesize that penicillamine may inhibit thyroperoxidase activity in-utero and in WD patients

Patients and methods: Two siblings born to a WD mother who received penicillamine during pregnancy, and 5 patients (the mother of two sibs, two brothers and two unrelated children aged 10-13 y) who were on penicillamine for 3-5 yrs. Thyroid function tests, thyroid antibodies and thyroid radionuclide imaging (Tc- $99 \mathrm{~m})$ were performed in all subjects.

Results: Two siblings born to a mother with WD had goitrous hypothyroidism diagnosed at 15 and 36 days of age (FT4=undetectable, TSH $>100 \mathrm{mU} / \mathrm{L}$ ) with negative thyroid stimulating and blocking abs. Sib.1: On L-T4, the thyroid function tests normalized within few weeks and the goiter disappeared. L-T4 was stopped at 4 y. of age. Sib. 2: radionuclide imaging (enlarged thyroid gland with increased uptake) was consistent with goitrous hypothyroidism. LT4 therapy was stopped at $2.5 \mathrm{mo}$. Four additional WD patients had subclinical hypothyroidism on penicillamine (mean $\pm \mathrm{SD}, \mathrm{TSH}=4.3 \pm 03$, normal $=0.25-4$ $\mathrm{mU} / \mathrm{L})$. On zinc therapy, TSH decreased significantly in all $(\mathrm{TSH}=2.2 \pm 0.29$ $\mathrm{mU} / \mathrm{L}, \mathrm{P}<0.0001)$. FT4 levels were normal.

Conclusions: Penicillamine inhibits thyroperoxidase activity (iodination and coupling) in-utero and in WD patients, resulting in transient goitrous hypothyroidism in healthy infants and sub-clinical hypothyroidism in patients. In pregnant WD mothers, zinc therapy may prevent goitrous hypothyroidism in newborns

\section{P03-741 Thyroid 2 \\ A randomized controlled trial of early L. thyroxine treatment in young patients with autoimmune thyroiditis and type 1 diabetes Beate Karges ${ }^{1}$; Rainer Muche ${ }^{2}$; Ina Knerr ${ }^{3}$; Waldemar Ertelt4; Thomas Wiesel ${ }^{5}$; Regine Hub ${ }^{6}$; Andreas Neu ${ }^{6}$; Albrecht Klinghammer Julia Aufschild ${ }^{1}$; Andrea Rapp ${ }^{1}$; Andreas Schirbel${ }^{8}$; Bernhard Boehm ${ }^{9}$; Klaus-Michael Debatin ${ }^{1}$; Eberhard Heinze ${ }^{1}$; Wolfram Karges ${ }^{10}$ ${ }_{1}^{1}$ Pediatric Endocrinology and Diabetes, University of UIm, UIm, Germany; 'Institute of Biometrics, University of UIm, UIm, Germany; ${ }^{3}$ University Hospital for Children and Adolescents, University of Erlangen, Erlangen, Germany; ${ }^{4}$ Children's Hospital Heidenheim, University of Ulm, Heidenheim, Germany; ${ }^{5}$ Children's Hospital Datteln, University of Witten-Herdecke, Datteln, Germany; ${ }^{6}$ University Hospital for Children and Adolescents, University of Tübingen, Tübingen, Germany; ${ }^{7}$ Children's Hospital Chemnitz, Pediatrics, Chemnitz, Germany; ${ }^{8} \mathrm{Clinic}$ of Nuclear Medicine, University of Würzburg, Würzburg, Germany; ${ }^{9}$ Division of Endocrinology, Clinic for Internal Medicine I, University of Ulm, UIm, Germany; ${ }^{10}$ Division of Endocrinology and Diabetes, RWTH Aachen University, Aachen, Germany}

The risk to develop autoimmune thyroiditis (AIT) is increased in patients with type 1 diabetes (T1D). We conducted a prospective, randomized, open, controlled clinical trial to assess whether L-thyroxine (L-T4) treatment may prevent the clinical manifestation of AIT in euthyroid subjects with T1D. 
611 children and adolescents with T1D from six tertiary care centers were screened for eligibility, and 89 individuals ( 14.5 percent) were identified with positive thyroid peroxidase antibodies (TPOAb), thyreoglobulin antibodies $(\mathrm{TgAb})$, or both. 30 patients (age $13.3 \pm 2.1$ years) meeting the inclusion criteria were randomized to receive L-T4 ( $\mathrm{n}=16$ patients) or no active treatment ( $\mathrm{n}=14$ patients). L-T4 $(1.3 \mu \mathrm{g} / \mathrm{kg}$ daily) was given for 24 months in the treatment group, followed by an additional observation period of 6 months in both groups. Thyroid gland volume (as determined by ultrasound), serum levels of thyrotropin, thyroid hormones, TPOAb, and TgAb were assessed bianually for 30 months. Mean thyroid volume decreased in the treatment group after 24 months (-0.60 standard deviation score, SDS) and increased in the observation group $(+1.11 \mathrm{SDS}, \mathrm{p}=0.0218)$. Serum thyrotropin, fT4, TPOAb, and $\operatorname{TgAb}$ levels were not significantly different in both groups during the entire study period. Hypothyroidism developed in three individuals treated with L-T4 and in four control patients (conversion rate, 9.3\% per year). In conclusion, treatment with L-thyroxine reduced thyroid volume but had no effect on thyroid function and serum autoantibody levels in euthyroid patients with AIT and T1D. adrenal hyperplasia and tumours, data of 14 patients were collected. The objective was to get a better definition of this clinical entity in childhood and adolescence, to collect epidemiological data in a paediatric population and to look for a possible correlation between anti-Müllerian hormone (AMH) levels and ovarian volume and cysts. The mean age of the patients at presentation was $13.7 \pm 1.6$ years (range 10.6-16.2). The principal symptom was hirsutism or acne in 5/14, dysfuntional bleeding in 6/14 and/or obesity in $3 / 14$ patients. According to the laboratory results the diagnosis was ovarian hyperandrogenism, or metabolic syndrome and ovarian hyperandrogenism, with or without obesity, with or without increased ovarian volume and/or cysts. 11/14 patients were obese (mean BMI $32.7 \mathrm{~kg} / \mathrm{m} 2$ ), 3/14 were overweight, $12 / 14$ had high testosterone levels $(3.1 \pm 1 \mathrm{nmol} / 1$, normal up to 0.8$), 6 / 12 \mathrm{had}$ high dehydroandrosteron levels $(35.6 \pm 26.3 \mathrm{nmol} / 1$, normal up to 21$), 4 / 14$ had elevated HOMA-Index, 2 impaired glucose tolerance and dyslipidemia, 3 showed ovarian size more than $10 \mathrm{ml}$ in ultrasonography. AMH was elevated to $9.4 \pm 4.0 \mathrm{ng} / \mathrm{ml}$ (normal 3.1, $\max 8.6$ ). Eleven patients had elevated AMH. Four of them with increased ovarian volume and/or multiple cysts had up to $4 \mathrm{x}$ higher AMH levels than normal controls. These data, although preliminary and based on a limited number of patients may help to define a pattern of clinical and biochemical criteria that could be useful to identify beginning $\mathrm{PCO}$ in younger girls.

\section{P03-742 Thyroid 2}

\section{Detailed age-dependent reference intervals for TSH, thyroid hormones, and thyroid antibodies are required for assessing thyroid function in paediatrics \\ Juergen Kratzsch ${ }^{1}$; Georg Schubert ${ }^{1}$; Ferdinand Pulzer ${ }^{2}$; \\ Roland Pfaeffle ${ }^{2}$; Antje Koerner ${ }^{2}$; Joachim Thiery'; Wieland Kiess ${ }^{2}$ \\ ${ }^{1}$ University Hospital Leipzig, Institute of Laboratory Medicine, Leipzig, \\ Germany; ${ }^{2}$ University Hospital Leipzig, Department of Paediatrics, \\ Leipzig, Germany}

The diagnostic specificity and sensitivity of thyroid tests is affected by the validity of reference intervals. The purpose of our study was to establish reference intervals for thyroid tests in children and adolescents using a statistically sufficient number of subjects for each included age-dependent subgroup and to identify factors that may modulate the limits of these intervals. TSH, FT3, FT4, T3, T4, t-uptake, thyroid peroxidase antibodies (TPO-Ab), thyroglobulin antibodies (Tg-Ab) and thyroglobulin levels were determined in serum or EDTA plasma by the Elecsys system (Roche). Samples of 1004 children and adolescents were measured within the study. The age ranged from the newborn period (cord blood) up to 20 years. Patients with known endocrine disorders or severe non-endocrine diseases that may have influenced the thyroid function were excluded. A distinct overall age-dependent decrease of analyte levels was found for all parameters investigated. However, the course of both TPO- and Tg-antibody levels demonstrated two peaks, one within the first year of life and one during puberty. Moreover, puberty leads to a timely increase of FT3 levels. Results of T4, TPO-Ab, Tg-Ab and t-uptake were significantly higher in girls $(\mathrm{n}=459)$ compared to boys $(\mathrm{n}=545)$. We conclude, that the strong dependence on age and sex for all thyroid parameters requires the use of validated reference intervals for subgroups as an obligatory tool for assessing thyroid function in children and adolescents. In summary, our results may contribute to an improved efficacy in the diagnostics of thyroid diseases in paediatrics.

\section{P01-743 Ovaries and Estrogens \\ Possible role of anti-Müllerian-hormone (AMH) in the diagnosis of ovarian hyperandrogenism in paediatric age}

Mariarosaria Lang-Muritano'; Francesca Navratil2; Renate Huerlimann²; Ishilde Forster ${ }^{3}$; Anna Lauber-Biason ${ }^{1}$; Eugen Schoenle ${ }^{4}$

'University Children's Hospital, Endocrinology and Diabetology,

Zurich, Switzerland; 'University Children's Hospital, Gynaecology,

Zurich, Switzerland; 'University Children's Hospital, Radiology, Zurich,

Switzerland; "University Children's Hospital, Endocrinology and

Diabetology, Zurich, Switzerland

A systematic recording of adolescent female patients presenting with a polycystic ovary syndrome (PCO)-like clinical picture was hold in our children's hospital in the last 3 years. After exclusion of non classical congenital

\section{P01-744 Ovaries and Estrogens \\ Clinical and laboratory features of polycystic ovarian syndrome in adolescents \\ Tolga Ozgen; Murat Aydin; Ayla Guven \\ Ondokuz Mayis University, Pediatrics, Samsun, Turkey}

Polycystic ovarian syndrome (PCOS) is the common cause of endocrinopathy in women of reproductive age. Pathogenesis of disease in lean PCOS patients is controversial. The aim of this study is to investigate clinic and laboratory features of obese and lean Turkish adolescents with PCOS. Body mass index (BMI) and age matched thirty adolescent with PCOS (15 obese and 15 lean) and 20 control subjects ( 10 obese and 10 lean) were enrolled to the study. Oral glucose tolerance tests were performed both of PCOS and control groups. Serum insulin, glucose, lipids, total and free testosterone, $17 \mathrm{OH}$ progesterone, dehydroepiandrosterone sulphate, follicle stimulating hormone, luteinizing hormone, estradiol, thyroid hormones, insulin like growth factor 1 and insulin like growth factor binding protein 3 were studied. Insulin resistance was determined by sum of insulin levels of $>300 \mu \mathrm{IU} / \mathrm{ml}$, during OGTT. Hypertriglyceridemia ( $>100 \mathrm{mg} / \mathrm{dl})$ and low HDL $(<50 \mathrm{mg} / \mathrm{dl})$ levels was accepted dyslipidemia. Girls with a systolic (SBP)and/or diastolic blood pressure that is higher than the 95 th percentile of normal for their age were classified as hypertensive Free testosterone, $17 \mathrm{OH}$ progesterone, DHEA-S and HOMA-IR and insulin responses to OGTT were higher in PCOS group than controls. Cardiovascular disease indicators (high insulin resistance, dyslipidemia and hypertension) were higher in obese PCOS group than controls. Insulin resistance were $\% 93,3$ and $\% 46,6$ in obese and nonobese PCOS respectively.

\begin{tabular}{|c|c|c|c|c|c|}
\hline & PCOS & & CONTROLS & & \\
\hline & Obese & Lean & Obese & Lean & $\mathrm{p}$ \\
\hline Age* & $14,90 \pm 0,90$ & $15,45 \pm 1,26$ & $14,98 \pm 1,55$ & $15,37 \pm 0,96$ & 0,381 \\
\hline BMÝ $(\mathrm{kg} / \mathrm{m} 2)^{\star}$ & $\star 32,67 \pm 4,91$ & $20,39 \pm 2,16$ & $31,63 \pm 4,75$ & $20,41 \pm 1,54$ & 0,001 \\
\hline $\begin{array}{l}\text { \% ideal body } \\
\text { weight* }\end{array}$ & $158,50 \pm 23,71$ & $97,00 \pm 10,01$ & $161,89 \pm 25,63$ & $100,29 \pm 9,96$ & 0,001 \\
\hline $\begin{array}{l}\text { SBP } \\
(\mathrm{mmHg})^{*}\end{array}$ & $127,50 \pm 17,25$ & $113,75 \pm 9,16$ & $125,56 \pm 16,67$ & $110,71 \pm 9,32$ & 0,001 \\
\hline $\begin{array}{l}\text { DBP } \\
(\mathrm{mmHg})^{*}\end{array}$ & $78,33 \pm 11,14$ & $70,00 \pm 7,55$ & $80,55 \pm 8,81$ & $71,42 \pm 6,90$ & 0,005 \\
\hline $\begin{array}{l}\text { Ferriman- } \\
\text { Gallwey } \\
\text { scores* }^{*}\end{array}$ & $13,58 \pm 9,71$ & $11,50 \pm 7,84$ & $1,89 \pm 2,85$ & $0,00 \pm 0,00$ & 0,001 \\
\hline $\begin{array}{l}\text { Acanthosis } \\
\text { nigricans }\end{array}$ & $\% 73,33$ & $\% 6,66$ & $\% 30,00$ & $\% 0,00$ & 0,001 \\
\hline $\begin{array}{l}\text { Irregular } \\
\text { menses }\end{array}$ & $\% 86,66$ & $\% 86,66$ & $\% 0,00$ & $\% 0,00$ & 0,001 \\
\hline $\mathrm{LH} / \mathrm{FSH}$ ratio* & 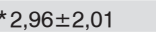 & $3,11 \pm 0,92$ & $0,87 \pm 0,44$ & $1,15 \pm 0,79$ & 0,001 \\
\hline $\begin{array}{l}\text { T. } \\
\text { testosterone } \\
(\mathrm{ng} / \mathrm{ml})^{\star}\end{array}$ & $0,91 \pm 0,45$ & $0,88 \pm 0,79$ & $0,68 \pm 0,46$ & $0,54 \pm 0,15$ & 0,686 \\
\hline $\begin{array}{l}\text { S. } \\
\text { testosterone } \\
(\mathrm{pg} / \mathrm{ml})^{\star}\end{array}$ & $4,24 \pm 2,21$ & $1,84 \pm 0,85$ & $1,34 \pm 0,61$ & $1,56 \pm 0,53$ & 0,002 \\
\hline
\end{tabular}


DHEA-S
(ig/dl)*

$183,03 \pm 104,71233,44 \pm 65,77 \quad 115,71 \pm 24,68 \quad 91,92 \pm 91,28 \quad 0,069$

$17 \mathrm{OH}$

\begin{tabular}{llllll}
$\begin{array}{l}\text { progesterone } 3,26 \pm 1,89 \\
\text { (ng/ml)* }\end{array}$ & $2,91 \pm 1,37$ & $1,71 \pm 1,22$ & $1,83 \pm 0,28$ & 0,104 \\
TT4 (ig/dl)* & $8,40 \pm 1,58$ & $8,47 \pm 0,73$ & $9,69 \pm 1,15$ & $8,40 \pm 1,42$ & 0,017 \\
TSH (ill/ml)* $2,53 \pm 1,84$ & $1,61 \pm 0,94$ & $2,53 \pm 0,67$ & $2,09 \pm 1,29$ & 0,325 \\
HDL(mg/dl)* & $44,88 \pm 11,94$ & $52,01 \pm 13,19$ & $35,61 \pm 10,88$ & $43,92 \pm 8,84$ & 0,015 \\
\hline LDL(mg/dl)* & $97,96 \pm 40,02$ & $80,34 \pm 17,09$ & $75,58 \pm 38,88$ & $60,37 \pm 15,84$ & 0,050
\end{tabular}

LDL(mg/dl)* $\quad 97,96 \pm 40,02 \quad 80,34 \pm 17,09 \quad 75,58 \pm 38,88 \quad 60,37 \pm 15,84 \quad 0,050$

Total

cholesterol $\quad 165,66 \pm 31,03 \quad 150,44 \pm 13,11 \quad 129,66 \pm 43,68 \quad 121,25 \pm 26,96 \quad 0,058$

$(\mathrm{mg} / \mathrm{dl})^{*}$

\begin{tabular}{|c|c|c|c|}
\hline iglyceride & $115,50 \pm 64,28$ & $86,22 \pm 45,81$ & $91,83 \pm 22,83$ \\
\hline
\end{tabular}

volume $(\mathrm{ml})^{*} 12,85 \pm 2,62 \quad 11,15 \pm 5,13 \quad 4,76 \pm 0,79 \quad 3,95 \pm 0,90 \quad 0,001$

$\begin{array}{llll}\text { Left ovarian } \\ \text { volume }(\mathrm{ml}) *\end{array} 11,20 \pm 1,69 \quad 8,16 \pm 2,82 \quad 5,01 \pm 1,03 \quad 5,27 \pm 0,67 \quad 0,001$

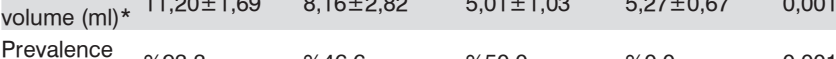

\begin{tabular}{|c|c|c|c|}
\hline Prevalence & $\% 93,3$ & $\% 46,6$ & $\% 50,0$ \\
\hline
\end{tabular}

Sum of insulin $670,38 \pm 317,34300,82 \pm 77 \quad 406,48 \pm 294,64209,84 \pm 66,96 \quad 0,001$

\begin{tabular}{|c|c|c|c|}
\hline & $3,44 \pm 1,53$ & $8,03 \pm 3,36$ & $6,30 \pm 3,51$ \\
\hline
\end{tabular}

$\begin{array}{llllll}\text { FGIR* }^{*} & 3,44 \pm 1,53 & 8,03 \pm 3,36 & 6,30 \pm 3,51 & 10,70 \pm 5,82 & 0,001 \\ \text { HOMA-IR* }^{*} 5,97 \pm 3,09 & 2,25 \pm 0,78 & 3,51 \pm 3,03 & 1,94 \pm 0,80 & 0,001\end{array}$

IGF1* (ng/ml) 291,00 $\pm 87,06 \quad 272,92 \pm 74,29 \quad 327,11 \pm 133,87334,80 \pm 85,64 \quad 0,364$

$\begin{array}{llllll}\text { IGFBP3* } & 5,39 \pm 0,63 & 4,78 \pm 0,78 & 4,44 \pm 0,92 & 5,39 \pm 1,11 & 0,031\end{array}$

Parameters of insulin resistance were correlated with waist to hip ratio, BMI, systolic blood pressure and free testosterone positively and with HDL negatively.

Conclusion: Adolescents with PCOS have high prevalence of insulin resistance. Hyperandrogenemia, metabolic indices and risk factors for cardiovascular disease are worse in obese patients compared to nonobese patients with PCOS.

\section{P01-745 Ovaries and Estrogens \\ Cellular immunity status in patients with polycystic ovary syndrome}

Nazeli Sargsyan'; Karine Tokhunts²; Rufina Mirimanova ${ }^{3}$;

Spartak Gambarov4; Gohar Abrahamyan ${ }^{5}$

YYerevan State Medical University, Perinatology, Obstetrics and

Gynecology, Armenia; ${ }^{2}$ Medical center "Prometeus", Ostetrics and

Gynecology, Yerevan, Armenia; ${ }^{3}$ Scientific Institute of Surgery,

Surgerical Reproductology, Yerevan, Armenia; ${ }^{4}$ Yerevan State Medical

University, Allergology and Immunology, Yerevan, Armenia; ${ }^{5}$ Yerevan

State Medical University, Perinatology,Obstetrics and Gynecology,

Yerevan, Armenia

Polycystic ovary syndrome ( PCOS ) is one of the most common endocrine disorders, although its etiology remains unknown.

By performing immunology tests in 15 affected and 10 healthy girls, Tlymphocytes populations were determined: the content of T-lymphocytes $(\mathrm{CD} 3+)$, inductors-helpers $(\mathrm{CD} 4+)$ and suppressors/catatonic cells (CD8) in population of T-lymphocytes, their ratio $(\mathrm{CD} 4 / \mathrm{CD} 8)$, and the phagocyte activity of monocytes. The results showed that T-lymphocytes were decreased in patients with PCOS, as compared with the control group.

Decrease of the absolute quantity of lymphocytes was more pronounced in patients with amenorrhea and long duration of the disease $(378 \pm 120 \mathrm{~mm} 3, \mathrm{P}$ $<0,05)$. The count of T-lymphocytes was decreased in all patients.

The study of T-cells sub-population showed the changes in the content of subfractions of T-cells in patients with PCOS. The content of T-suppressors (CD8) was increased up to $10,4 \pm 1,8 \%(\mathrm{P}<0,05)$, the content of T-helpers $(\mathrm{CD} 4+)$ was decreased up to $49,6 \pm 3,0(\mathrm{P}<0,05)$, and respectively, their ratio index was decreased $(0,2 \pm 0,04, \mathrm{P}<0,05)$. Marked systemic impairments of immune processes were identified in PCOS, which were presented by changes in the content of immune-competent cells: increase of T-suppressors count, decrease of activated T-lymphocytes and natural killer cells count in peripheral blood. The data acquired will serve as basis for elaboration of methods of immunecorrection in patients with PCOS.

\section{P01-746 Ovaries and Estrogens \\ Biochemical and hormonal evaluation in adolescent girls with polycystic ovary syndrome}

Aurora Rossodivita'; Clelia Cipolla'; Paola Villa²; Eleonora D'Alessio'; Gemma Chiaradia ${ }^{3}$; Giuseppe La Torre ${ }^{3}$

${ }^{1}$ Paediatric Clinic, Paediatric Department, Rome, Italy; ${ }^{2}$ Gynecologic Clinic, Gynecologic Department, Rome, Italy; ${ }^{3}$ Institute of Hygiene, Rome, Italy

Background: Polycystic ovary syndrome (PCOS) is a syndrome of ovarian disfunction that is frequently associated with hyperinsulinism and insulin resistance.

Objective: To assess hormonal, metabolic and ultrasound features in adolescent and adult girls with PCOS and to determine whether differences are present

Population and methods: We studied 38 adolescents (aged 12 to 18 yrs) and 40 adult girls (aged 19 to $36 \mathrm{yrs}$ ) with clinical, hormonal and ultrasound signs of PCOS. We assayed serum levels of gonadotropin, androgen and estradiol (E2) during the early follicular phase of the menstrual cycle (days 2 to 5). The free androgen index (FAI) was estimated for total testosterone (TT) and SHBG. All subjects underwent an oral glucose tolerance test and an insulin area under the curve (AUC) (cut off $7000 \mu \mathrm{UI} / \mathrm{ml}$ or more $\mathrm{x} 120 \mathrm{~min}$ ), the fasting glucose to insulin ratio (GIR), quantitative insulin sensitivity check index (QUICKY), and homeostatic model assessment (HOMA) have been chosen as measures of insulin resistance. In all patients we evaluated ovarian volume by use of pelvic ultrasound.

Results: Adolescents with PCOS showed significantly lower levels of $\mathrm{TT}(\mathrm{p}<0.03)$, androstenedione $(\mathrm{p}<0.004), \mathrm{E} 2 \quad(\mathrm{p}<0.04)$ and LH/FSH ratio $(p<0.02)$ when compared to adult girls. The two groups, however, didn't differ in the SHBG and the FAI value. Our results suggest that both groups were hyperinsulinemic $(36.8 \%$ and $42.5 \%$ respectively) and have an increased incidence of impaired glucose tolerance (IGT) (5.3\% and $12.5 \%$ respectively). None of the adolescent group had diabetes mellitus (DM type 2), whereas 5\% of adults showed overt DM. Nonetheless, there wasn't a statistical difference in indexes of insulin resistance between adolescents and adults with PCOS.

The latter showed significantly higher ovarian volume when compared with the former $(p<0,001)$.

Conclusions: Adolescents with PCOS were neither more hyperinsulinemic nor hyperandrogenic than adults.Further hormonal and metabolic studies will confirm our results.

\section{P01-747 Ovaries and Estrogens \\ Ovarian and androgen receptor function in prepubertal girls with hypertrichosis}

Isabel Hernandez; Andrea Castro; German Iñiguez; Cecilia Lardone; Alejandra Avila; Claudio Villaroel; Ethel Codner; Fernando Cassorla

University of Chile, Idimi, Santiago, Chile

Hypertrichosis is a relatively common clinical condition in prepubertal girls, which may cause significant parental anxiety, but does not appear to be associated with hyperandrogenism. We performed a comprehensive ovarian function and androgen receptor study in 44 prepubertal girls with hypertrichosis and 29 prepubertal control girls between the ages of 2 and 8 years. The patients and control girls underwent a careful physical examination to determine their hypertrichosis score according to Gryngarten (Horm Res $54: 20,2000)$. They subsequently underwent a Leuprolide acetate test with 500 ug administered sc, with determination of basal $\mathrm{LH}, \mathrm{FSH}, 17 \mathrm{OH}$ progesterone, androstenedione, testosterone, estradiol and SHBG, followed by measurement of LH and FSH 3 hours post Leuprolide, and of $17 \mathrm{OH}$ progesterone, androstenedione, testosterone and estradiol 24 hours post Leuprolide. In addition, we performed an abdominal ultrasound for determination of ovarian morphology, and we determined the number of androgen receptor CAG repeats in DNA obtained from peripheral leukocytes.

As expected, the hypertrichosis score was far greater in the cases compared to controls ( $16.3 \pm 3.6$ vs $3.3 \pm 2.1$ ). Serum gonadotropins and sex steroids were similar in both groups, but SHBG was significantly lower in the cases $(71.1 \pm 2.9 \mathrm{vs} 81.9 \pm 3.0 \mathrm{nmol} / \mathrm{L}, \mathrm{p}<0.02)$. In addition, the number of ovarian follicles was greater in the cases $(4.8 \pm 2.4$ vs $3.7 \pm 1.3)$, and the proportion of shorter androgen receptor CAG repeats $(<14)$ was higher in the cases $(18 \%$ vs $10 \%)$, but these differences did not reach statistical significance. 
We conclude that some prepubertal girls with hypertrichosis have lower SHBG concentrations compared to controls, which may be associated with a lower number of androgen receptor CAG repeats. These metabolic features may facilitate the development of hypertrichosis in some of these patients.

\section{P01-748 Ovaries and Estrogens \\ Differential effect of testosterone infusions on luteinizing hormone profile in eumenorrheic and polycystic ovary syndrome (PCOS) adolescents \\ Gabriela Ropelato'; Cecilia Garcia Rudaz'; Maria Escobar'; Viviana Bengolea ${ }^{2}$; Johannes Veldhuis ${ }^{3}$; Marta Barontini ${ }^{1}$ \\ ${ }^{1}$ Hospital de Niños Dr. Ricardo Gutierrez, Division de Endocrinologia, Buenos Aires, Argentina; ${ }^{2} \mathrm{Hospital}$ Fernandez, Departamento de Pediatria, Buenos Aires, Argentina; ${ }^{3}$ Mayo Clinic, Division of Endocrinology, Rochester, United States}

To evaluate the androgen negative feed back in the control of LH secretion in eumenorrheic and PCOS adolescents, pulsatile LH release was determined without (baseline: B) and under constant testosterone (T) infusions: $0.75(\mathrm{~T}$ $0.75)$ and 2.5 (T2.5) mg/12 h iv to 8 control adolescents (C) and 7 PCOS of similar chronological and gynecological age and normal BMI. C girls and 3 oligomenorrheic PCOS were studied at early follicular phase of 3 consecutive menstrual cycles. 4/7 PCOS in amenorrhea were studied monthly in three consecutive months. 20-min blood sampling for LH (IFMA) and T (RIA) measurements was drawn during nocturnal $12 \mathrm{~h}$ at B, T 0.75 and $\mathrm{T}$ 2.5. LH characteristics were analyzed by Cluster program. At B, T levels were significantly higher in PCOS than C ( $71 \pm 11$ vs $40 \pm 7 \mathrm{ng} / \mathrm{dl}, \mathrm{p}<0.01)$ but similar T serum levels were found in both groups under infusion.

Analysis of LH secretory pulses in $\mathrm{C}$ adolescents on $\mathrm{T} 0.75$ compared with B studies showed mean LH ( $4.5 \pm 1.0$ vs $3.4 \pm 0.4 \mathrm{mIU} / \mathrm{mL})$, pulse height $(6.6 \pm 1.6$ vs $4.9 \pm 0.4 \mathrm{mIU} / \mathrm{mL})$ and nadir levels $(2.9 \pm 0.8$ vs $2.3 \pm 0.3 \mathrm{mIU} /$ $\mathrm{mL})$, all significantly higher $(\mathrm{p}<0.05)$. In $\mathrm{C}$ girls $\mathrm{T} 2.5$ infusion produced a

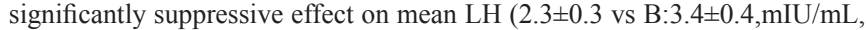
$\mathrm{p}<0.01)$, LH frequency $(0.25 \pm 0.08$ vs $\mathrm{B}: 0.38 \pm 0.03$ pulses $/ \mathrm{h}, \mathrm{p}<0.05)$ and $\mathrm{LH}$ nadir (1.3 \pm 0.3 vs B: $2.3 \pm 0.3 \mathrm{mIU} / \mathrm{mL}, \mathrm{p}<0.01)$. PCOS did not show significant changes on LH secretory characteristics under both $\mathrm{T}$ infusions.

Conclusion: Compared to normal adolescents, PCOS have substantially different responses to acute effects of $\mathrm{T}$ suggesting that an abnormal androgen negative feedback could be involved in this syndrome

\section{P01-749 Ovaries and Estrogens \\ Gonadoblastoma in the youngest sibling in a family of three sisters with pure $X Y$ gonadal dysgenesis}

M Eunice ${ }^{1}$; B Kulshreshtha ${ }^{1}$; Audran Francoise ${ }^{2}$; Pascal Phillibert'; A Kriplani ${ }^{3} ;$ K Kucheria ${ }^{4}$ Rima Dada ${ }^{4}$; AK Karak ${ }^{5}$; Gupta S Dutta ${ }^{5}$;

Mc Sharma ; Charles Sultan ${ }^{2}$; AC Ammini ${ }^{1}$

${ }^{1}$ All India Institute of Medical Sciences, Endocrinology and

Metabolism, Delhi, India; ${ }^{2}$ Hopital Lapeyronie, du Developpement et de la Reproduction, Montpellier, France; ${ }^{3} \mathrm{All}$ India Institute of Medical Sciences, Obstetrics \& Gynaecology, Delhi, India; ${ }^{4}$ All India Institute of Medical Sciences, Anatomy, Delhi, India; ${ }^{5}$ All India Institute of Medical Sciences, Pathology, Delhi, India

The occurrence of gonadoblastoma is known in patients with XY gonadal dysgenesis, although rare. Little is known however of the predisposition to tumor formation in these patients. Various factors including a genetic predisposition, role of candidate genes including TSPY, transcription factors involved in testicular differentiation and histological appearance of the surrounding gonadal tissue have been given, none has been conclusively prove. A familial form of gonadal dysgenesis is a good model to study the effects of genetic factors involved in tumor formation. We describe three XY females of one family with gonadal dysgenesis, the youngest sibling was diagnosed to have gonadoblastoma.

In a family of 5 siblings born of a non-consanguineous marriage, three sisters (age 13,15 \& 17 years) presented with complaints of primary amenorrhoea. They had a normal female phenotype and were prepubertal. The younger two brothers were apparently normal The clinical and hormonal profile of the three sisters is given in Table-1. The elder two siblings have undergone laparoscopic removal of the gonads and estrogen supplements have been initiated. The histopathology of gonads in the elder sibling (1) revealed ovarian stroma along with rete testes like elements. Bilateral the gonads of the younger sibling (2) showed a small portion of ovarian stroma. No focus of gonadoblastoma were identified in these two elder siblings. Histopathology of the youngest sibling (3) revealed presence of bilateral gonadoblastoma. Direct sequencing analysis of SRY and SF-1 genes found to be normal for all the three affected siblings. The youngest sibling showed a Ala387Thr polymorphism in the WT1 gene. WT1 gene analysis has not been performed for the elder two siblings.

\begin{tabular}{llllllll} 
S.no & $\begin{array}{l}\text { Age } \\
\text { (yrs) }\end{array}$ & $\begin{array}{l}\text { Ht. } \\
\text { LS) }\end{array}$ & $\begin{array}{l}\text { Sexual } \\
\text { maturation }\end{array}$ & $\begin{array}{l}\text { LH } \\
(\mathrm{U} / \mathrm{L})\end{array}$ & $\begin{array}{l}\mathrm{FSH} \\
(\mathrm{U} / \mathrm{L})\end{array}$ & Karyotype & $\begin{array}{l}\text { USG } \\
\text { pelvis }\end{array}$ \\
\hline 1 & 17 & $155(79 / 86)$ & A1B1 P1 & 33.3 & 80.7 & $46, \mathrm{XY}$ & $\begin{array}{l}\text { Infantile } \\
\text { uterus }\end{array}$ \\
\hline 2 & 15 & $156(75 / 81)$ & A1B1P1 & 32 & 42 & $46, \mathrm{XY}$ & $\begin{array}{l}\text { Infantile } \\
\text { uterus }\end{array}$ \\
3 & 13 & $153(73 / 80$ & A1B2P1 & 24 & 37 & $46, \mathrm{XY}$ & $\begin{array}{l}\text { Infantile } \\
\text { uterus }\end{array}$
\end{tabular}

The occurrence of gonadoblastoma in the youngest sibling in a family of three affected sisters is surprising. Possibly, the WT1 polymorphism is playing a role in the formation of gonadoblastoma in dysgenetic gonads.

\section{PO1-750 Ovaries and Estrogens \\ Ovarian hyperstimulation syndrome in preterm infants - case presentation and literature review \\ Jerzy Starzyk'; Malgorzata Wojcik'; Joanna Wojtys ${ }^{1}$; Zofia Mitkowska²; Jacek J. Pietrzyk ${ }^{3}$ \\ Collegium Medicum Jagiellonian University, Dep. of Pediatric and Adolescent Endocrinology, Krakow, Poland; ${ }^{2}$ Collegium Medicum Jagiellonian University, Dep. of Pediatrics, Krakow, Poland; ${ }^{3}$ Collegium Medicum Jagiellonian University, Dep. of Pediatrics, Krakow, Poland}

Approximately $8 \%$ of girls are preterm-born, presenting with high levels of gonadotrophins and estradiol (E2), while $40-80 \%$ have ovarian cysts, yet the ovarian hyperstimulation syndrome (OHS) has been described in eight premature newborns only.

A female neonate born after 28 weeks of gestation, pregnancy 1 , by a cesarean section, birth weight $1100 \mathrm{~g}$, length $38 \mathrm{~cm}$, Apgar score 4 - 1', 7- 5'. At 36 weeks of postconception age (WPCA), she developed hypogastric and vulvar swelling, with the E2 level of $22 \mathrm{pg} / \mathrm{ml}$; at 41 WPCA - breast budding (Tanner II), fluor pubertalis and enlargement of the labia minora. GnRH-dependent puberty was recognized due to the high E2 value and both baseline and postGnRH stimulation LH and FSH levels. Up to 42 WPCA, the LH and FSH values normalized, while E2 was increasing ( $\max 352 \mathrm{pg} / \mathrm{ml})$ and remained so up to 50 WPCA, what suggested cyst autonomization. During that period, US revealed multiple or single cysts involving one or both ovaries (15-22 $\mathrm{mm})$. Patient's linear growth and bone age was not accelerated. Between 35 and 39 WPCA, the previously described eight preterms developed: vulvar, hypogastric and upper legs swelling, ovarian cysts, elevated gonadotrophins and E2 (30-1500 pg/ml), without signs of puberty. In all discussed cases 6 untreated, 3 underwent medroxyprogesterone and/or surgical treatment the swelling resolved at 50 WPCA. Pathognomic signs for OHS are vulvar, hypogastric and leg swelling developing in preterm newborns around 37+-3 WPCA. High E2 values and ovarian cysts may only confirm the diagnosis. We suggest that OHS is diagnosed only infrequently, when the disease is fully symptomatic and swelling is profound. The cause of OHS symptoms in preterms is concomitant with overstimulation of both ovarian FSH and LH receptors. The E2 level does not seem to be a causative factor directly associated with swelling. 
P02-751 Turner Syndrome

Late start of grow th hormone treatment (GH) in Ullrich-Turner syndrome (UTS): beneficial or redundant?

loana Inta; Daniela Kiepe; Carolin Kneppo; Jana Mittnacht;

Markus Bettendorf

University Heidelberg, Paediatric Endocrinology, Heidelberg,

Germany

Objective: GH treatment improves growth and final height in UTS when initiated early e.g. as soon as the height falls below the third percentile. However, some girls present much later to the endocrinologist when the effectiveness of GH remains obscure. Therefore, we retrospectively screened all girls with UTS treated with GH in our department and identified 8 patients with a bone age (GP) $>11$ years at the onset of GH therapy and $>14$ years at the latest visit. The patients received $\mathrm{GH}(0.045-0.05 \mathrm{mg} / \mathrm{kg} / \mathrm{day} \mathrm{sc})$ either alone $(n=3)$ or in combination with Oxandrolone $(1.25 \mathrm{mg} / \mathrm{day}, \mathrm{n}=5)$ for $2.76 \pm 0.07$ years. Results are given as mean \pm SD. Statistical analysis was performed by nonparametric tests.

Results:

\begin{tabular}{|c|c|c|c|c|}
\hline & $\begin{array}{l}\text { Chronological } \\
\text { age (years) }\end{array}$ & $\begin{array}{l}\text { Bone age } \\
\text { (GP) }\end{array}$ & $\begin{array}{l}\text { Height SDS } \\
\text { (Brandt and } \\
\text { Reinken) }\end{array}$ & $\begin{array}{l}\text { Difference } \\
\text { Height SDS/ } \\
\text { Terget Height } \\
\text { SDS }\end{array}$ \\
\hline At GH start & $13.61 \pm 0.09$ & $11.94 \pm 0.17$ & $-3.25 \pm 0.08$ & $-2.96 \pm 0.15$ \\
\hline $\begin{array}{l}\text { Prospective } \\
\text { final height } \\
(\mathrm{BP})\end{array}$ & & & $-3.19 \pm 0.13 \bullet$ & $-2.89 \pm 0.17$ \\
\hline $\begin{array}{l}\text { Predicted } \\
\text { adult height } \\
\text { (Ranke) }\end{array}$ & & & $-1.63 \pm 0.08$ & $-1.34 \pm 0.16$ \\
\hline $\begin{array}{l}\text { At puberty } \\
\text { onset }\end{array}$ & $14.66 \pm 0.10$ & $12.81 \pm 0.14$ & $-2.84 \pm 0.11$ & $-2.55 \pm 0.20$ \\
\hline Latest visit & $17.48 \pm 0.18$ & $15.69 \pm 0.11$ & $-1.71 \pm 0.13$ & $-1.41 \pm 0.19$ \\
\hline
\end{tabular}

Total height gain $(\Delta \mathrm{HT})$ was $7.2 \pm 0.59 \mathrm{~cm}$ (SDS $1.48 \pm 0.12)$. Height at the latest visit was significantly higher than the prospective final height (BP, * $\mathrm{p}<0.003$ ), but was similar to the predicted adult height (Ranke). Height gain occurred partially before start of puberty ( $\triangle$ SDS $0.41 \pm 0.09$ ) and thereafter during spontaneous $(n=3)$ or induced puberty $(n=5, \Delta \operatorname{SDS} 1.14 \pm 0.13$; n.s.). Conclusions: These data show that a significant improvement of adult height can be even achieved in UTS patients by starting GH treatment late (bone age $>11$ years). Furthermore, the prediction model of Ranke serves as a reliable tool for the successful selection of UTS patients for late onset GH therapy. Finally, a significant improvement of height still occurs after spontaneous or induced onset of puberty under $\mathrm{GH}$ treatment.

\section{P02-752 Turner Syndrome}

\section{Characteristics of the young adult Turner seen} in consultation of transition

Catherine Pienkowsky'; Françoise Lamiche Lorenzini²;

Marcella Menendes'; Florence Lesourd2; Mutriel Clouet Delannoy²;

Maithé Tauber ${ }^{1}$

${ }^{1}$ Children Hospital, Endocrinology, Toulouse, France; ${ }^{2}$ Paule de Viguier

Hospital, Endocrinology, Toulouse, Francee

Turner syndrome (TS) is a chronic disorder that evolves at the adulthood and requires a pluri-disciplinary care. At completion of growth we organized these jointly consultations with 2 endocrinologists (paediatrician and adult) and 1 gynaecologist involved assisted reproduction technology (ART). The doctors specialists in ORL, cardiology or hepatology are contacted individually. The objective is to discuss important issues of TS with these young women : 1 / by commenting on their karyotype, 2 / by explaining the paediatric check up, $3 /$ by giving them a notebook which is used as guide for their future management, 4/ by explaining and programming the follow-up, in link with their general practitioner. 5 / by informing on the ART and of the oocyte donation for those who come in couple. Results: 21 patients were seen including 6 couples.

The average age was $20.4 \pm 2.8$ yrs (range 18-32 yrs). The karyotype was $\mathrm{XO}(\mathrm{n}=11)$, mosaic $(\mathrm{n}=8$ of which the presence of $\mathrm{Y}$ with gonadectomy in 2 cases), Iso $X(n=2)$. The mean height was $153 \pm 4 \mathrm{~cm}$ (extreme 146-164 $\mathrm{cm}$ ), the mean weight is of $57 \pm 12.8 \mathrm{~kg}$ (extreme $45-123 \mathrm{~kg}$ ), the mean body index was of $24.2 \pm 5.2 \mathrm{~kg} / \mathrm{m} 2$. Six patients presented with obesity of whom 2 had a complicated morbid obesity and type 2 diabetes. Hypercholesterolemia was noted in 5 cases and hypertriglyceridemia in 4 cases. Among them 10 had hypothyroidism, 6 disturbances of hepatic enzymes (one treated by Desoxycholic acid). Seven patients presented a congenital cardiopathy including 1 aortic dilation treated by beta blockers and 1 patient an aortic insufficiency which contra-indicated pregnancy. Deafness was detected in 6 patients (perception $n=3$, transmission $n=3$ ). They all had routine estroprogestative treatment, by pill in 5 cases. Considering the description of the various features, this follow-up of transition and adult is essential and must be developed in order to prevent complication and optimize quality of live.

\section{P02-753 Turner Syndrome \\ Target-height adjusted results of growth hormone treatment in Ullrich-Turner syndrome Katja Ziegenhorn'; Petra Beye ${ }^{1}$; Simone Poetzsch'; Klaus Mohnike ${ }^{1}$ ${ }^{1}$ Otto-von-Guericke University, Dept. of Paediatrics, Magdeburg, Germany; ${ }^{2}$ Congenital Malformation Monitoring Centre, Saxony- Anhalt, Germany}

In Ullrich-Turner syndrome (UTS) diminished growth rate results in a mean adult height of 136 to $147 \mathrm{~cm}$. Growth hormone (GH) is an approved indication in these girls. Here we report on 42 UTS patients, 33 were treated with GH until growth velocity was $<2 \mathrm{~cm} /$ year. Adult height of 9 patients with Turner syndrome not GH treated was included as control. Mean age at first visit was $10.32 \pm 2.64$ years in the treated group. Target height $(\mathrm{TH})$ was calculated in all patients. Growth hormone dose was 0.86 to $1.1 \mathrm{mg} / \mathrm{m} 2 * \mathrm{~d}$, mean duration of treatment was $6.0 \pm 2.5$ (range: 2,9- 9.6) years. Mean height of the treated group increased to $150.02 \pm 4.72$ compared to a TH of $161.1 \pm 4 \mathrm{~cm}(-0.19$ SDS). At this time patients were $16.09 \pm 1.41$ years old. Nine out of 33 patients were measured again at age 19.1 to 22.0 years with a height of $150.61 \pm 6.2 \mathrm{~cm}$ (SDS $-2.76 \pm 1.0$ ). There was no difference in this group between height at the end of therapy $150.34 \pm 6.1 \mathrm{~cm}(-2.60 \pm 0.9$ SDS $)$ and the adult height.

The untreated group reached a mean adult height of $151.1 \pm 6.13 \mathrm{~cm}$ which is $17.23 \pm 6.0 \mathrm{~cm}$ below target height. This is equivalent to reports of 16 to $20 \mathrm{~cm}$ difference between average height of UTS and reference population.

We conclude, (1) the difference between adult height and target height in the treated group equals to $10.44 \pm 5$.6. (2) In untreated Turner syndrome adult height was $17.2 \mathrm{~cm}$ below target height.

\section{P02-754 Turner Syndrome \\ Hypergonadrotopic hypogonadism and short stature in a girl with isochromosome Xp Sarina Kant'; Hetty Van der Kamp²; Danny Haring ${ }^{3}$; \\ Claudia Ruivenkamp ${ }^{4}$ \\ 1Leiden University Medical Center, CHCG, Dept of Clinical Genetics, \\ Leiden, Netherlands; '2Leiden University Medical Center, Dept of Pediatrics, Leiden, Netherlands; '3iaconessenhuis, Dept of Pediatrics, Leiden, Netherlands; ${ }^{4}$ Leiden University Medical Center, CHCG, \\ Cytogenetics Division, Leiden, Netherlands}

An isochromosome is a mirror-image chromosome with two identical arms on either side of the centromere. Iso X chromosomes have been described as a variant of Turner syndrome. In fact, isochromosomes for the long arm of the $\mathrm{X}$ chromosome $(\mathrm{i}(\mathrm{Xq}))$ are the most common structural abnormality in Turner syndrome patients. However, isochromosomes for the short arm of the $\mathrm{X}$ chromosome (i(Xp))are rare.

We describe a girl of Moroccan descent, with a pseudo-isodicentric Xchromosome with the breakpoint in Xq21.1. She was referred to the pediatrician because of short stature. At the age of 13 years she had a height of $141.6 \mathrm{~cm}$ (-3.1 SDS), weight of $42.3 \mathrm{~kg}(+1.5 \mathrm{SDS})$, head circumference of $52.7 \mathrm{~cm}$ (-1.3 SDS), and an $\mathrm{H} / \mathrm{SH}$ ratio of 0.519 (-0.2 SDS). Pubertal stages were M1, P2, A1. She didn't have clear signs of Turner syndrome. Her fat distribution showed abundant fat on the abdomen. She suffered from mild angioedema, with recurrent edema of the face, especially of the lips. Her FSH was 78 $\mathrm{U} / \mathrm{L}$ and $\mathrm{LH}$ was $20 \mathrm{U} / \mathrm{L}$. No cardiac or kidney abnormalities were found. Isochromosomes can arise by several mechanisms, and in the majority of $\mathrm{i}(\mathrm{Xq})$ it is suggested to arise by breakage and reunion of susceptible regions of the short arm. This theory was also postulated for $\mathrm{i}(\mathrm{Xp})$, and indeed monocentric 
$\mathrm{i}(\mathrm{Xp})$ with no long arm material does not exist. An $\mathrm{i}(\mathrm{Xp})$ is probably only viable if the XIST locus on Xq13 is retained in one or both partly deleted long arms. Our patient does have the Xq breakpoint distal to Xq13.

Although she had three copies of the SHOX gene, she did have short stature. This may be aggravated by prepubertal growth retardation. Treatment with estrogens is started.

\section{P02-755 Turner Syndrome \\ Monozygotic twins with Turner syndrome (TS) may respond differently to GH treatment and puberty induction \\ Franciska Verlinde'; Inge François ${ }^{2}$; Margaretha Craen $^{3}$; \\ Jean De Schepper'; Guy Massa \\ 'Belgian Study Group for Pediatric Endocrinology, Pediatric \\ Endocrinology, Brussels, Belgium; '2University of Leuven, Pediatric \\ Endocrinology, Leuven, Belgium; ' ${ }^{3}$ University of Ghent, Pediatric \\ Endocrinology, Ghent, Belgium; ${ }^{4}$ University of Brussels, Pediatric \\ Endocrinology, Brussels, Belgium}

Monozygotic twins with TS have rarely been reported. These twins are not necessarily phenotypically or genetically identical, and many forms of discordance have been described. The congruence or difference in response to growth hormone $(\mathrm{GH})$ and estrogen treatment in monozygotic TS twins has so far not been described. We here report on 3 monozygotic TS twins (karyotype 45,X) treated with GH and ethinyloestradiol (EE2) to induce puberty. Twin $1(1 \mathrm{M}, 1 \mathrm{~J})$ was diagnosed at birth due to dysmorphic features and oedema of feet. Blood group typing showed $99.9 \%$ probability of being monozygotic. Twin $2(2 \mathrm{~A}, 2 \mathrm{C})$ were diagnosed at the age of $10.5 \mathrm{yrs}$ because of short stature and dysmorphic features. Monozygosity was confirmed by DNA analysis. Twin 3 was diagnosed at birth $(3 \mathrm{~T}, 3 \mathrm{~S})$ because of oedema. They were only karyotyped. Results on growth and pubertal development are shown in the Table 1

\begin{tabular}{|c|c|c|c|c|c|c|}
\hline & $1 \mathrm{M}$ & $1 \mathrm{~J}$ & $2 \mathrm{~A}$ & $2 \mathrm{C}$ & $3 \mathrm{~T}$ & $3 S$ \\
\hline Birthweight SDS & 1.0 & 0.8 & -2.4 & -1.6 & -0.8 & -1.6 \\
\hline $\begin{array}{l}\text { Age at start GH } \\
\text { (Y) }\end{array}$ & 3.2 & 3.2 & 10.6 & 10.6 & 8.2 & 8.2 \\
\hline $\begin{array}{l}\text { Height SDS at } \\
\text { start GH }\end{array}$ & -2.9 & -2.9 & -2.7 & -2.7 & -0.8 & -1.2 \\
\hline $\begin{array}{l}\text { Age at start EE2 } \\
\text { (Y) }\end{array}$ & 13.3 & 13.3 & 12.7 & 12.7 & 12.8 & 12.8 \\
\hline $\begin{array}{l}\text { Height SDS at } \\
\text { start EE2 }\end{array}$ & -1.2 & -1.7 & -2.0 & -2.3 & -0.5 & -0.8 \\
\hline $\begin{array}{l}\text { prepubertal } \\
\text { height gain (SDS) }\end{array}$ & +1.7 & +1.2 & +0.7 & +0.4 & +0.3 & +0.4 \\
\hline Age at M2 $(\mathrm{Y})$ & 13.7 & 13.7 & 13.5 & 14.6 & 13.1 & 13.1 \\
\hline $\begin{array}{l}\text { Time EE2 - M2 } \\
\text { (Y) }\end{array}$ & 0.4 & 0.4 & 0.8 & 1.9 & 0.3 & 0.3 \\
\hline Final Height (cm) & 155.0 & 152.2 & 157.7 & 152.5 & 162.5 & 158.6 \\
\hline $\begin{array}{l}\text { Final Height } \\
\text { (SDS) }\end{array}$ & -1.2 & -1.7 & -0.8 & -1.6 & +0.1 & -0.6 \\
\hline $\begin{array}{l}\text { Pubertal height } \\
\text { gain (SDS) }\end{array}$ & 0.0 & 0.0 & +1.3 & +0.7 & +0.6 & +0.2 \\
\hline
\end{tabular}

Twin's height at start of GH treatment was similar in twin 1 and 2, whereas in twin 3 there was 0.4 SDS difference. Prepubertal growth during GH treatment was similar in twin 2 and 3, whereas in twin 1 there was a 0.5 SDS difference. Pubertal growth was similar in twin 1, but in twin 2 and 3 there was a difference of 0.6 and 0.4 SDS, respectively. The timing of breast development was different in twin 2 . We conclude that monozygote TS twins may respond differently to GH and EE2 treatment, which can be considered as another form of genetic discordance.

\section{P02-756 Turner Syndrome \\ Impact of patient characteristics and clinical factors on decision to initiate grow th hormone treatment in Turner syndrome}

Karine Khatchadourian"; Nathalie Alos²; Céline Huot²; Guy Van Vliet², Cheri Deal $^{2}$

UUniversité de Montréal, Faculté de Médecine, Montréal,

Canada; ${ }^{2}$ Centre Hospitalier Universitaire Ste-Justine, Pediatrics

(Endocrinology), Montréal, Canada

Our objective was to evaluate factors contributing to the decision to initiate treatment with growth hormone $(\mathrm{GH})$ in patients with Turner syndrome (TS). This retrospective chart review included patients with TS seen by the Endocrinology Service between 1984 and $2006(n=78)$. Ethnicity, karyotype, parent's education and work status, pubertal development, clinical severity score, age at diagnosis, ages when $\mathrm{GH}$ was proposed and initiated, mid-parental height (sex-adjusted), bone age, and height SDS scores were recorded.

Forty-six patients received, or are receiving GH, whereas 32 were not (current ages: $\mathrm{GH}$ Tx $=10.1 \pm 2.8 \mathrm{y}$; no GH Tx $=14.4 \pm 6.5 \mathrm{y}$; $\mathrm{p}=0.00062)$; six of the untreated girls were $<6 \mathrm{y}$ and although discussed, starting $\mathrm{GH}$ had not yet been proposed. No differences were found between treated and untreated patients with regards to ethnicity, karyotype, education and employment status, presence of spontaneous pubertal development and clinical severity score. $\mathrm{GH}$ was proposed to 59 of 72 patients $>6$ y (82\%), and of these, $46(78 \%)$ accepted treatment. Reasons for not proposing $\mathrm{GH}$ included late diagnosis (2), loss to follow-up or transfer to other hospital (5) and good growth (3). Age at diagnosis of TS differed significantly between GH-treated $(n=46)$ and untreated $(n=26)$ girls $(6.8 \pm 4.7$ y versus $4.3 \pm 5.1 \mathrm{y} ; \mathrm{p}=0.04)$, as did the TS-specific height SDS $(0.08 \pm 0.81$ versus $0.66 \pm 0.87 ; \mathrm{p}=0.01)$. For those patients on $\mathrm{GH}$, mean age at which it was suggested to begin treatment was $9.2 \pm 2.9 \mathrm{y}$; a trend towards early treatment was observed in patients seen after 2002. Reasons for refusal of treatment included parent's preoccupation with other medical issues, mental health problems, fear of injections and unknown side effects.

In conclusion, $\mathrm{GH}$ treatment was not acceptable to all patients, even when discussed early and repeatedly. Refusal to treat was not related to reimbursement issues since treatment with $\mathrm{rhGH}$ is covered fully by our public health insurance plan, but more often involved parental concerns, as well as age at diagnosis and height SDS.

\section{P02-757 Turner Syndrome \\ Ef fects of oxandrolone therapy on fundamental voice frequency in girls with Turner syndrome aged 12 years or older}

Leonie Menke'; Theo C.J. Sas ${ }^{2}$; Sophie H.L. van Koningsbrugge ${ }^{3}$; Maria de Ridder'; Gladys R.J. Zandwijken ${ }^{1}$; Philippe H. DeJonckere ${ }^{4}$; Sabine M.P.F. de Muinck Keizer-Schrama; ${ }^{5}$ Barto J. Otten ${ }^{6}$; Jan M. Wit 'Dutch Growth Foundation, , Rotterdam, Netherlands; ${ }^{2} J u l i a n a$ Children's Hospital, The Hague / Leiden University Medical Center, Leiden, Netherlands; ${ }^{3}$ Leiden University Medical Center, Department of Pediatrics, Leiden, Netherlands; ${ }^{4}$ University Medical Center Utrecht, Department of Phoniatrics, Utrecht, Netherlands; ${ }^{5}$ Erasmus Medical Center, Department of Pediatric Endocrinology, Rotterdam, Netherlands; ${ }^{6}$ Radboud University Medical Centre, Department of Pediatric Endocrinology, Nijmegen, Netherlands

Lowering of the fundamental voice frequency (FVF) is a valuable indicator of possible masculinizing effects of the anabolic steroid oxandrolone (Ox).

The aim of this study was to assess differences in FVF change between girls with Turner syndrome (TS) aged $\geq 12$, receiving $\mathrm{Ox}$ at dosages of $0.06,0.03$ $\mathrm{mg} / \mathrm{kg} /$ day or placebo, in combination with growth hormone $(\mathrm{GH}, 1.33 \mathrm{mg} /$ $\mathrm{m} 2 /$ day) and low-dose oestrogens (17- $\beta$-oestradiol $5 \mathrm{ug} / \mathrm{kg} /$ day during first 2 years, subsequently followed by $10 \mathrm{ug} / \mathrm{kg} / \mathrm{day})$.

Before start, after 6 and 12 months, and yearly up to 6 months after discontinuation of therapy, a reversed count from 10 to 0 (in duplo) was taped by a DAT recorder and transferred to a computer for calculation of FVF. FVF SDS was calculated using reference values for FVF by age in normal girls. For calculating baseline FVF SDS, height age was also used. From 138 recordings in 33 girls, 86 recordings in 20 girls were of satisfactory quality. At start, FVF SDS was high for age $(+1.0 \mathrm{SD}, \mathrm{P}=0.005)$, but normal for height age $(+0.1 \mathrm{SD}, \mathrm{P}=0.6)$. Repeated measurements analysis, performed 
since recordings were unequally distributed among both girls and time, showed no significant lowering in FVF SDS during treatment (-0.1 SD per year, $\mathrm{P}=0.3)$. No significant differences in $\mathrm{FVF}$ change were observed between the different treatment groups. After therapy, mean FVF was +0.4 SD $(\mathrm{P}=0.4)$, while 2 patients from both Ox groups displayed a FVF $<-2$ SDS.

We conclude that untreated patients with TS have relatively high-pitched voices, concordant with their short stature. No statistically significant effect of Ox was found, although an effect on FVF could not be excluded in 2 patients, who ended up with low voices.

\section{P02-758 Turner Syndrome \\ Final height in a double blind placebo controlled trial on the effect of oxandrolone combined with growth hormone and low-dose oestrogens in girls with Turner syndrome aged 12 years or older}

Leonie A. Menke'; Theo C.J. Sas ${ }^{2}$; Maria de Ridder ${ }^{1}$;

Gladys R.J. Zandwijken"; Sabine M.P.F. de Muinck Keizer-Schrama ${ }^{3}$, Jan M. Wit'; Barto J. Otten ${ }^{5}$

${ }^{1}$ Dutch Growth Foundation, Rotterdam, Netherlands; ${ }^{2} J u l i a n a$ Children's Hospital, The Hague / Leiden University Medical Center, Leiden, Netherlands; ${ }^{3}$ Erasmus Medical Center, Department of Pediatric Endocrinology, Rotterdam, Netherlands; ' $L$ Leiden University Medical Center, Department of Pediatrics, Leiden, Netherlands; ${ }^{5}$ Radboud University Medical Centre, Department of Pediatric Endocrinology, Nijmegen, Netherlands

Girls with Turner syndrome (TS) are currently treated with growth hormone $(\mathrm{GH})$ and oestrogens to improve height and induce puberty, respectively. In recent decades, the additional growth promoting effect of the anabolic steroid oxandrolone $(\mathrm{Ox})$ has been claimed in a few studies. However, virilizing side effects have been encountered in girls using $\mathrm{Ox} \geq 0.1 \mathrm{mg} / \mathrm{kg} / \mathrm{day}$. The aim of present study was to assess the efficacy and safety of Ox at dosages of $0.06,0.03 \mathrm{mg} / \mathrm{kg} /$ day or placebo in combination with $\mathrm{GH}$ (Humatrope 1.33 $\mathrm{mg} / \mathrm{m} 2 /$ day) and low-dose oestrogens (17- $\beta$-oestradiol $5 \mathrm{ug} / \mathrm{kg} /$ day during the first 2 years, subsequently followed by $10 \mathrm{ug} / \mathrm{kg} /$ day) in TS patients aged $\geq 12$ years. Thirty-four girls with a mean $\pm \mathrm{SD}$ age of $13.5 \pm 1.2$ were assigned to one of the treatment regimens, to which only the statistician has been un-blinded. Height SDS calculations were based on the Dutch-Scandinavian references. Treatment effect (final height (FH-) gain) was estimated by the difference between FH and modified projected adult height (MPAH). Mean FH-gain was significantly different from zero for all treatment groups $(\mathrm{P} \leq 0.006)$. Compared to the placebo group, it was $2.7 \mathrm{~cm}$ greater in the $\mathrm{Ox} 0.03$ group $(\mathrm{P}=0.07)$. For patients receiving $\mathrm{Ox} 0.06$, mean $\mathrm{FH}$-gain was not different from placebo, but $\mathrm{FH}$ was reached after a significantly shorter period of $\mathrm{GH}$ therapy $(-8.0$ months, $\mathrm{P}=0.015)$. No serious adverse events were reported. Eight patients, of whom 2 discontinued Ox, complained of hirsutism.

\begin{tabular}{llll|} 
& Placebo $(\mathrm{n}=12)$ & $\begin{array}{l}\text { Ox } 0.03 \mathrm{mg} / \mathrm{kg} / \\
\text { day }(\mathrm{n}=12)\end{array}$ & $\begin{array}{l}\text { Ox } 0.06 \mathrm{mg} / \mathrm{kg} / \\
\text { day }(\mathrm{n}=10)\end{array}$ \\
\hline $\begin{array}{l}\text { Height SDS (for Turner) } \\
\text { at start }\end{array}$ & $+0.8 \pm 1.1$ & $+0.9 \pm 0.9$ & $+1.1 \pm 0.8$ \\
$\begin{array}{l}\text { Duration of GH } \\
\text { treatment (months) }\end{array}$ & $43.4 \pm 9.9$ & $40.9 \pm 8.2$ & $35.4 \pm 7.1$ \\
\hline Final height (cm) & $155.5 \pm 5.9$ & $159.1 \pm 5.3$ & $157.1 \pm 6.4$ \\
\hline Final height gain $(\mathrm{cm})$ & $5.8 \pm 2.6$ & $8.5 \pm 3.0$ & $5.3 \pm 4.8$ \\
\hline
\end{tabular}

Although not statistically significant, patients receiving Ox 0.03 tended to show a larger FH-gain in a somewhat shorter duration of therapy, while patients receiving $\mathrm{Ox} 0.06$ reached $\mathrm{FH}$ in significantly less months of $\mathrm{GH}$ therapy. Though possibly at the expense of some side-effects, these results suggest a positive effect of Ox on growth in the treatment of TS.

\section{P02-759 Turner Syndrome \\ The effects of growth hormone treatment on bone mineral density in Turner Syndrome}

Zehra Aycan ${ }^{1}$; Ergun Cetinkaya1; Sadi Vidinlisan"; Firdevs Bas²;

Feyza Darendeliler'; Aysun Bideci ${ }^{3}$; Fatma Demirel/4; Sukran Darcan ${ }^{5}$;

Atilla Buyukgebiz ${ }^{6}$; Metin Yildiz ${ }^{7}$; Merih Berberoglü; Ilknur Arslanoglü;

Ruveyde Bundak ${ }^{2}$

'SB Ankara Dýskapý Children's Hospital, Pediatric Endocrinology, Ankara, Turkey; ${ }^{2}$ Istanbul University, Pediatric Endocrinology, Istanbul, Turkey; ${ }^{3}$ Gazi University, Pediatric Endocrinology, Gazi, Turkey;

${ }^{4}$ Karaelmas University, Pediatric Endocrinology, Zonguldak, Turkey;

${ }^{5}$ Ege University, Pediatric Endocrinology, Izmir, Turkey; ${ }^{6}$ Dokuz Eylul

University, Pediatric Endocrinology, Izmir, Turkey; 'SB Goztepe

Children's Hospital, Pediatric Endocrinology, Istanbul, Turkey;

${ }^{8}$ Ankara University, Pediatric Endocrinology, Ankara, Turkey

Turner Syndrome (TS) patients are treated with growth hormone $(\mathrm{GH})$ to increase adult height. Although it is well established that GH promotes longitudinal bone growth, its effects on bone density are less clear. Our objective was to determine how GH treatment affects trabecular bone mineral density (BMD) in girls with TS in a prospective multi center study at prepubertal ages. Twenty-two children with TS in the prepubertal period with a mean age of $9.8 \pm 2.5$ years $(3.6-12.8)$ were included in the study. All girls with TS underwent measurement of areal BMD using dual energy X-ray absorptiometry to obtain pre-treatment anteroposterior lumbar spine values at L1 - L4. All patients received GH (genotropin) subcutaneously for a year at a dose of $0.05 \mathrm{mg} / \mathrm{kg} /$ day. The anteroposterior lumbar spine BMD and BMC were measured again using the same technique after approximately one year of treatment. BMD Z scores were calculated using our country standards. The Wilcoxon test was used to determine treatment efficacy and $p$ value $<0.05$ was considered to be significant. The height SDS of our cases showed a significant increase while there was no significant change in the weight SDS and BMI SDS values. Pre-treatment lumbar spine values for (L1-L4 ) BMD was 0.532 $\pm 0.09 \mathrm{gr} / \mathrm{cm} 2, \mathrm{BMC} ; 15.8 \pm 3.0 \mathrm{gr}$ and BMD Z score $-1.1 \pm 1.3 \mathrm{SD}$ while these values after the treatment were $0.571 \pm 0.10 \mathrm{gr} / \mathrm{cm} 2,18.4 \pm 4.0 \mathrm{gr}$ and $1.2 \pm 1.3 \mathrm{SD}$ respectively. Though the lumbar spine BMD and BMC values of our cases increased the BMD Z scores were not affected after approximately a year of GH treatment. Growth hormone seemed to have no positive influence on bone density while having a marked effect on longitudinal growth. Short term GH therapy in prepubertal Turner Syndrome patients didn't have any significant effect on trabecular bone.

\section{P02-760 Turner Syndrome \\ Patient with 45 XO karyotype and normal pubertal uterus size}

Oksana Lazareva'; Radhika Purushothaman'; Svetlana Ten ${ }^{2}$

'Infants and Children's Hospital at Maimonides, Department of

Pediatrics, Brooklyn, New York, United States; 'Infants and Children's

Hospital at Maimonides, Department of Pediatric Endocrinology,

Brooklyn, New York, United States

Introduction: Fertility has been reported in $45, \mathrm{X}$ women, but all cases had been attributed to an undetected 46,XX cell line. Later aneploidy lead to early apoptosis of primordial follicles and premature ovarian failure in almost all cases.

Case Presentation: C.P. girl presented at 12 yrs for evaluation of short stature. She was found to have karyotype $45 \mathrm{XO}$

Her height was $141 \mathrm{~cm}(-2.97 \mathrm{SDS})$. High arched palate and mild ptosis were noticed. There was no history of lyphoedema and autoimmune thyroiditis.

Renal sonogram and cardiac echocardiogram were normal. On ultrasound normal size ovaries and uterus were identified: uterus $6.7 \times 2.2 \mathrm{~cm}$, right ovary $1.1 \mathrm{X} 1.4 \mathrm{~cm}$ and left $1.1 \mathrm{X} 1.2 \mathrm{~cm}$. FISH of the peripheral blood sample with X and Y chromosome probes revealed that 199 (99.5\%) interphase nuclei showed only 1 copy of $\mathrm{X}$ chromosome, where as 1 nucleus showed 2 copies of the $\mathrm{X}$ chromosome $(0.05 \%)$. At 14 yrs she developed primary ovarian failure with elevated FSH and LH and low Antimullerian Hormone (AMH) $(<0.1)$ and Inhibin B $(<7)$.

Discussion: Failure of sexual maturation, cardiac and renal malformation, lymphoedema are the typical features of the girls with 45XO karyotype. This case presents a rare normal phenotype without lyphoedema, cardiac, renal, developmental or immune problems in a girl with only $0.05 \%$ of cells carrying 2 copies of X chromosome. She produced enough estradiol 
to develop pubertal uterus size, but later ovarian failure occurred anyway. During young adolescent years it was unclear will she develop ovarian failure and when. However at 14 yrs her inhibin B and AMH were undetectable indicating complete ovarian failure. Searching for $46, \mathrm{XX}$ cells in a girl with a 45,X karyotype may be necessary in a view of new treatment option such as cyopreservayion of ovarian tissue. In cases of detected 46,XX cell line we need to consider cryopreservation of ovarian tissue early before complete primordial follicles apoptosis developed.

\section{P02-761 Turner Syndrome \\ Analysis of $Y$ specific sequences in patients with 45,X karyotype \\ C. Nur Semerci'; Lale Satiroglu-Tufan'; Serap Turan²; \\ Abdullah Bereket2; Beyhan Tuysuz ${ }^{3}$; Elif Yilmaz ; Hulya Kayserili"; \\ Birsen Karaman ${ }^{4}$; Serap Semiz ${ }^{5}$; Fusun Duzcan ${ }^{1}$; Huseyin Bagci ${ }^{1}$ \\ ${ }^{1}$ Pamukkale University, Medical Biology, Center for Genetic Diagnosis, \\ Denizli, Turkey; ${ }^{2}$ Marmara University, Pediatric Endocrinology, Istanbul, \\ Turkey; ${ }^{3}$ stanbul University, Cerrahpasa Medical Faculty, Medical \\ Genetics, Istanbul, Turkey; ' Istanbul University, Istanbul Medical \\ Faculty, Medical Genetics, Istanbul, Turkey; ${ }^{5}$ Pamukkale University, \\ Pediatric Endocrinology, Denizli, Turkey}

Determination of $\mathrm{Y}$ chromosome derivatives in patients with 45,X karyotype is important for the management of these patients due to increased risk of gonadoblastoma. Frequency of the cryptic Y chromosome in patient with 45 ,X karyotype varies from \%0-61 depending on the molecular methods used, study group and selection of the $\mathrm{Y}$ chromosome specific primers. The aim of our study is to analyze cryptic $\mathrm{Y}$ chromosome derivatives using $\mathrm{Y}$ specific sequences in 40 Turkish patients with pure 45 ,X karyotype. Four nulliparous healthy females and 4 healthy males were included as a control group. Fourteen different $Y$ specific sequences along the $Y$ chromosome were selected for the detection of cryptic $\mathrm{Y}$ chromosome material for PCR analysis. The present study demonstrated that 2 patients with $45, \mathrm{X}$ karyotype (5\%) have $\mathrm{Y}$ specific sequences except SRY by PCR analysis. One of them had displayed enhanced virilisation whereas other had no virilisation. In conclusion we found that $5 \%$ of patients with $45, \mathrm{X}$ karyotype have $\mathrm{Y}$ chromosome sequences in the absence of any marker chromosome. Our data also support that the patients with 45,X karyotype should be analyzed for the presence of Y chromosome derivatives by more sensitive methods to predict the future risk of developing gonadoblastoma.

\section{P02-762 Turner Syndrome \\ Adiponectin and lipid profile in Turner syndrome}

Beata Wikiera; Ewa Barg; Anna Noczynska

Medical University, Department of Endocrinology for Children and Adol, Wroclaw, Poland

Women with Turner syndrome (TS) more frequently develop cardiovascular disease. Abnormal lipid metabolism is a well known risk factor for ischemic heart disease. Adipocyte-derived hormone, adiponectin is a useful tool in evaluation fat tissue metabolism.

The aim of the study was to evaluate the relationship between adiponectin, lipids, insulin and IGF1 in patients with TS.

The study group consisted of 94 girls with TS without clinical signs of thyroid dysfunction or diabetes mellitus. The mean age was $13.87 \pm 6.04$ (2 - 25) years. X chromosome monosomy was found in 59\%, mosaicism in $30.12 \%$, structural aberration in the rest of the patients. $41.5 \%$ of them received GH treatment, $34 \%$ finished treatment prior to the study, and $24.5 \%$ didn't start it yet. Height, weight, BMI, BMISDS, adiponectin, cholesterol, TG, HDL, LDL, Lp(a), insulin, HBA1c, IGF1, IGFBP3 were determined. Thyroid hormones values were within normal ranges in all the patients. Mean concentration of adiponectin was $14.7 \pm 7.4 \mathrm{mg} / \mathrm{l}(1.2-32.7)$. Adiponectin correlated inversely with BMISDS $(r=-0.34)$ and HBA1c $(r=-0.39)$. Several correlations were found between: insulin and BMISDS $(r=0.43)$, insulin and TG $(r=0.51)$, insulin and IGF1 $(r=0.63)$, insulin and IGFBP3 $(r=0.57)$. We compared the group of GH treated TS patients with girls who finished GH therapy or didn't start it yet. Their mean age was respectively: $12.7 \pm 3.4$, $19.8 \pm 2.7$ and $8.9 \pm 6.3$, mean BMI was: $20.0 \pm 3.2,21.0 \pm 4.6$ and 17.2 \pm 3.0 . GH treated patients had higher level of adiponectin (15.7 vs 13.6 and $14.0 \mathrm{mg} / \mathrm{l})$. The difference however was not statistically important.

Conclusion: GH therapy seems to augment adiponectin concentration and thus can be protective for ischemic heart disease. This effect appears to be sustained by estrogen administration in later life.

\section{P02-763 Turner Syndrome \\ The effects of the $X$-chromosome loss on the brain cognitive function in Turner syndrome Ummuhan Isoglu-Alkac'; Hulya Gunoz ${ }^{2}$; Sacit Karamursel'; \\ Firdevs Bas \\ ${ }^{1}$ Istanbul University Istanbul Faculty of Medicine, Department of Physiology, Istanbul, Turkey; ${ }^{2}$ Istanbul University Istanbul Faculty of Medicine, Department of Pediatrics, Pediatric Endocrinology, Istanbul, Turkey}

Turner Syndrome (TS) is a genetic disorder causing from the loss of the entire or a part of the $\mathrm{X}$ - chromosome that it consists of many genetic knowledge. The lose of X-chromosome in girls with TS differs from healthy girls with the genetic properties of the intrauterine and postnatal development and also with reduced estrogen girls. It may be important to determine of brain electrical activity in girls with TS that describes deficiency of sexual identity.The aim of the present study was to define specifically the effect of the lack of Xchromosome on cognitive development of the brain. Eleven children with TS (females, aged 14,3 $\pm 1.8 \mathrm{yrs}$ ) and 22 healthy volunteers participated in this study (11 males and 11 females). Electroencephalographic (EEG) activity was recorded from 32 sites by Neuroscan 4.1. Since, P300 component of the ERPs can be used to identify cognitive functions of the brain by using "auditory oddball" paradigm (AERPs), the recording session was consisted of two experimental paradigms

I.Auditory Oddball (P300) Paradigm (AERPs)

II.Combined Auditory Oddball (P300) Paradigm and Visual Evoked Potentials (AERPs+VEPs).In AERPs paradigm, P300 responses were smaller in amplitude in TS than in female and also male controls. P300 responses latencies were longer in TS than in female controls but also shorter than in male controls. In AERPs paradigm, those differences were not significant. The same differences were more obvious both for P300 amplitude and latency in AERPs+VEPs paradigm than in AERPs paradigm and also were statistically significant (see Table). Differences in cognitive P300 responses in TS compared both to female and male controls may reflect the effects of the X-chromosome lossing. The present study is the pioneer research on the relationship between TS and the brain electrical activity using both AERPs and AERPs+VEPs paradigms.

$\begin{array}{lllll}\begin{array}{l}\text { P300 Frontal } \\ \text { electrode(Fz) }\end{array} & \text { AERPs +VEPs } & \text { AERPs+VEPs } & \text { AERPs } & \text { AERPs } \\ & \text { Amplitude } \mu \mathrm{V} & \text { Latency msec } & \text { Amplitude } \mu \mathrm{V} & \text { Latency msec } \\ \begin{array}{l}\text { TS_-Female } \\ \text { Control }\end{array} & 6.7-13.3+\dagger & 379-353+\dagger & 5.5-7.8 & 355-348 \\ \begin{array}{l}\text { TS-Male } \\ \text { Control }\end{array} & 6.7-9.3+\dagger & 379-390 \dagger & 5.5-6.1 & 355-360\end{array}$

$\uparrow \mathrm{p}<0.05, \uparrow \uparrow \mathrm{p}<0.01$

\section{P02-764 Turner Syndrome}

\section{Adult care of young women with Turner syndrome in real life: how far are we from international recommendations?}

M. Devernay-Lefort ${ }^{1}$; E. Ecosse ${ }^{2}$; J. Coste ${ }^{2}$;

$J$-C. Carel on behalf of the STaTur investigators ${ }^{1}$

'Hôpital Robert Debré, Department of Pediatric Endocrinology, Inserm U690, Paris, France; ${ }^{2}$ Hôpital Cochin, Department of Biostatistic, Paris, France

Background: Patients with Turner syndrome have multi-system impairments resulting in reduced life expectancy. Recently published guidelines emphasize the need for lifelong specific surveillance.

Objective: The aim of this study was to compare medical practice in France as of 2001, with recently published international guidelines (J Clin Endocrinol 
Metab, 2007; 92: 10-25).

Population: Participants were a national population-based cohort of 566

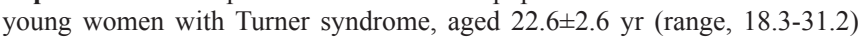
who responded to a questionnaire on current medical follow-up (STaTur cohort).

Results: The majority of patients were followed exclusively by general practitioners or gynecologists, whereas a multidisciplinary follow-up is recommended. During the previous 4 years, 28\% had hearing evaluation and echocardiography, contrasting with the recommendations of hearing assessments every $1-5$ years and heart imaging every $5-10$ years. Only $64 \%$ of patients reported blood pressure being measured during the previous 4 years while blood pressure measurement is recommended annually. During the previous 4 years, the following laboratory tests were reported by the patients : blood glucose: $55 \%$, lipid profiles: $70 \%$, liver enzymes: $20 \%$, thyroid hormones tests: $45 \%$, whereas these tests are recommended yearly.

Conclusion: Current follow-up for women with Turner syndrome in France is inadequate, compared to international consensus guidelines. Multidisciplinary adult care centers should be established, in collaboration with pediatric endocrinologists, to improve the transition to adult care. However, further research is needed to demonstrate the impact of the new guidelines in reducing long term morbidity and mortality in Turner syndrome.

\section{P02-765 Turner Syndrome \\ Turner syndrome and DM type 1 combination in a 17 years old girl (a case report) \\ Tatiana Shiryaeva'; Irina Aleksandrova²; Valentina Peterkova ${ }^{2}$ ${ }^{1}$ Endocrinology Research Center, Moscow, Institute of Pediatric Endocrinology, Moscow, Russian Federation; ${ }^{2}$ Endocrinology Research Center, Institute of Pediatric Endocrinology, Moscow, Russian Federation}

Turner's syndrome (TS) is a chromosomal disorder, caused by complete or partial X monosomy, occurring in approximately $1 / 2000$ living female births. There are many data which confirm increased frequency of impaired glucose tolerance, insulin resistance and diabetes mellitus (DM) type 2 in TS. Knowledge about DM type 1 (T1DM) in this syndrome is very limited.

The aims of the study was to present a clinical case of coexistence of TS and T1DM. Patient EH, 17 years old, characteristic fenotype, karyotype 45X0/ 46XY. Since a birth had low growth rates, but TS recognised only in the age of 11 years. DM manifested in the age of 9-years from classical symptoms thirst, polyuria, weight reduction. Fasting glycemia was $13 \mathrm{mmol} / \mathrm{l}, \mathrm{HbA} 1 \mathrm{c}$ was $13,8 \%$. Insulinotherapy was started in intensive regime.

Further current of DM was labile. In our department she was admitted for the first time in the age of 17,3 years. At the examination : Height $127.5(-5.78$ SDS), weight $30,3 \mathrm{~kg}$ ( BMI=18,95). TS stigmata were as follows: low hairline, low set ears, short neck, high arched palate, cubitus valgus, hyperconvex uplifted nails. Tanner 2 (on replacement estrogen therapy during 6 months) Bone Age was 12,5 yr. The daily insulin requirement was 1,2 IU/kg, HbAlc level $13 \%$. Glycemia daily changed from 4 up to $21 \mathrm{mmol} / 1$. C-peptide- 0 pg/ml. HLA-typing ( DR1 04, 07; DQA1 0301, 0201; DQB1 0302, 0201) has revealed the combination of high risk alleles for development of T1DM. It was found microalbuminuria frrom 39 up 130mg /daily. On ophthalmoscopy the singes of nonproliferative retinopathy and the complicated cataract were revealed. Taking into account heavy current of T1DM, progressing of vascular complications, and also unsatisfactory self-checking, we were not solved on growth hormone replacement therapy.

Conclusion: We have described a unique case of TS and T1DM association. T1DM was genetically verificated, characterized heavy current and progressive development of complications.

\section{P02-766 Turner Syndrome \\ Morphologic study of capillaries with nailfold capillaroscopy in Turner syndrome considering dyslipidemia and HOMA IR}

Simone Cristina Coelho; Gabriela Vizzoni; Felipe Oliveira;

Tereza Cristina Abi-Chain; Andressa Doelinger Ramos;

Janaina Polo Faria; Paulo Collett-Solberg;

Therezinha de Jesus Fernandes; Marília Martins Guimarães

Universidade Federal do Rio de Janeiro, Endocrinology, Rio de

Janeiro, Brazil

Turner syndrome patients (TS) have an increased prevalence of impaired glucose homeostasis and dyslipidemia. Endothelium abnormalities are present in groups with increased risk for insulin resistance or dyslipidemia.

We compared the morphology of nailfold capillaries, using videocapillaroscopy, in TS patients and healthy controls, considering dyslipidemia and HOMA IR as main variables.

Videocapillaroscopy was performed in 33 TS and 35 healthy girls, all under the age of 20 , to study the following patterns: loops distribution and length, papilla, avascular fields, edema, form, tortuosity, flow, hemorrhagic extravasion, and microectasy. We analyzed the use of medications, serum lipids, insulin and glucose. The significance level accepted was $\mathrm{p}<0.05$. The mean age of patients and controls was similar $(p=0.85) 13.4 \pm 3.8$ and $13.2 \pm 3.8$. Thirteen patients of each group had dislipidemia. The mean HOMA IR was higher $(\mathrm{p}=0.0005)$ in controls than in patients $(1.9 \pm 0.89$ and $1.3 \pm 0.69$, respectively). Abnormal capillaroscopy was found in $22(32.4 \%)$ patients and $2(9.1 \%)$ controls $(\mathrm{p}<0.0001)$. Edema occurred in $13(39.4 \%)$ TS and 3 $(8.6 \%)$ controls $(\mathrm{p}=0.002)$. The papillas were ratified in $6(18.2 \%)$ patients and $1(2.9 \%)$ control $(\mathrm{p}=0.04)$ and enlarged papilla in $3(9.1 \%)$ TS and 1 $(2.9 \%)$ control $(\mathrm{p}=0.28)$. No control had flow abnormalities while in TS the flow was granulous in $3(9.1 \%)(p=0.10)$; slow in $5(15.2 \%)(p=0.02)$ and fast in $6(18.2 \%)(p=0.01)$. Macrocapillaries were present in $3(6 \%) \mathrm{TS}(\mathrm{p}=0.10)$. Branched capillaries were observed in $3(9.1 \%)$ TS $(p=0.10)$ and $1(2 \%)$ control. Tortuosity was present in $5(15.2 \%)$ TS and no control. Hemorrhagic extravasations occurred in $1(2 \%)$ TS $(p=0.48)$.

Twenty six patients were using sex hormone replacement or GH and 14 $(53.8 \%)$ had abnormal capillaroscopy, of those $10(71.4 \%)$ were in use of GH. In the Turner Syndrome there are more alterations in capillaroscopy than in healthy people independently of dyslipidemia or HOMA IR values. 